\title{
AN INTRODUCTION TO FINANCIAL MATHEMATICS
}

$>\quad$ INTRODUCTION: SOME GENERAL IREAS

$>$ FINANCIALARRANGEMENTS

$>$ ANNUITIES

$>$ LOANS

$>$ BONDS

BIBHOGRAPHY

Slides prepared by:

Maite Mármol Jiménez

Department of Mathematics for Economics, Finance and Actuarial Sciences

Universitat de Barcelona 


\section{INTRODUCTION Some general ideas}

$\checkmark$ Financial transaction:

$\checkmark$ Definition

$\checkmark$ Elements:

$\checkmark$ Personal elements

$\checkmark$ Material element

$\checkmark$ Formal element

$\checkmark$ Classification of financial transactions

$\checkmark$ Equilibrium in a financial transaction:

$\checkmark$ Financial capital

$\checkmark$ Equilibrium between two financial capitals

$\checkmark$ Accumulation function

$\checkmark$ Price in a common financial transaction 


\section{FINANCIAL TRANSACTION}

In this first class we are going to analyze what a financial transaction is. This is the main concept that we need in order to understand this subject.

So, first today we are going to study the definition of financial transaction:

\section{Financial transaction:}

A financial transaction is an agreement between two parties to exchange cash/liquidity/money at different moments in time.

To analyze financial transactions, it is necessary to understand the concept of interest.

\section{Interest:}

Interest is the amount charged to a borrower for the use of the lender's money over a period of time. To the borrower, it is the cost of renting money; to the lender, the income from lending it.

Remember that a:

- borrower is an individual, organization or company that is using funds on credit;

- lender is an entity that advances cash to a borrower for a period and for a fixed or variable rate of interest. 
For example, if you have borrowed $€ 1500$ and you have promised to pay back $€ 1600$ after one year, then the lender is making a profit of $€ 100$, which is the fee for borrowing the money.

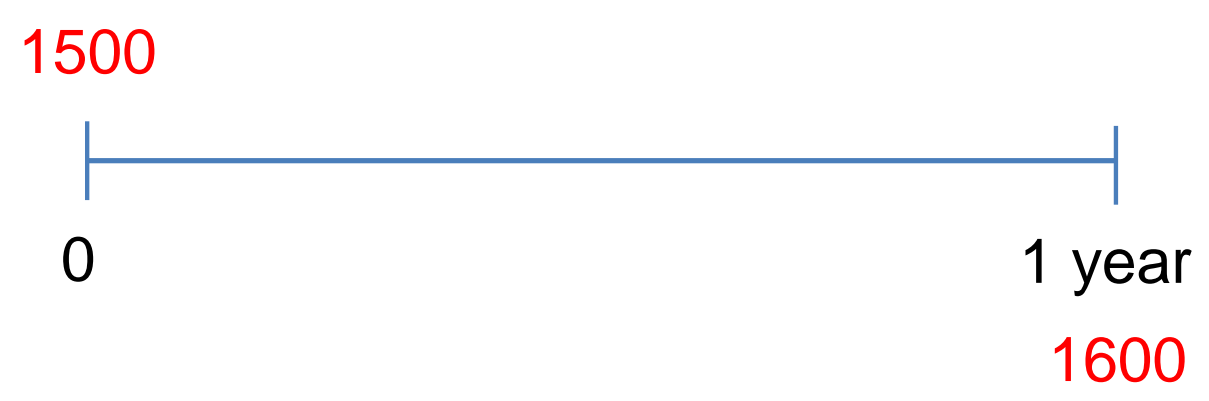

We denote the initial amount as $C=1500$, and the final amount as $C^{\prime}=1600$. In this example, the amount of interest earned during one year is

$$
\begin{gathered}
I T=C^{\prime}-C \\
I T=1600-1500=100
\end{gathered}
$$


Obviously, when someone cedes money (lender), they do this with the expectation of a financial gain, i.e. with the expectation to recover their money plus interest. If an initial amount $C$ grows to an amount $C^{\prime}$, the difference, $C^{\prime}-C$, is the interest.
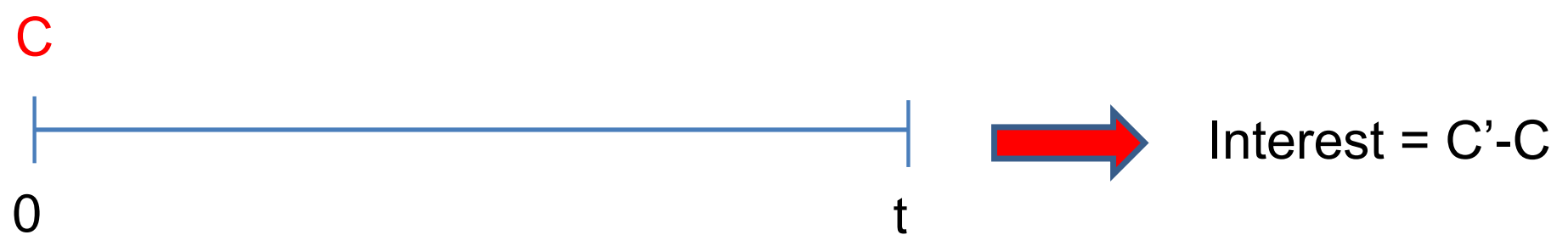

$C^{\prime}$

So, the interest is the rent paid by the borrower to the lender for the use of $\mathrm{C}$.

\section{But, what is the justification for charging interest?} Why does the lender charge interest?

The answer is the time preference theory!!

\section{Time preference theory}

People prefer to have money now rather than the same amount of money at some later date:

- If you have the money now, you have a choice as to whether you use it now or save it for the future.

- If you lend it, you no longer have the option of immediately using your money. Interest compensates the lender for this loss of choice. 


\section{Elements of financial transactions}

\section{- Personal elements:}

- Active party: this is the party that finances the operation, so this is the party that lends the money. This party is called the lender.

- Passive party: this is the party that receives the money. This party is called the borrower.

\section{Example 1:}

If you borrow money from a bank, you will be charged interest: in this case you are the passive party and the bank is the active party.

$>$ If you lend money to a bank by opening a saving account, you will receive interest: in this case you are the active party and the bank is the passive party.

- Formal element: The deals/terms between the two parties to reach an agreement. For example:

$\checkmark$ When is the interest paid?

$\checkmark$ How do you calculate the interest?

$\checkmark$ The way the initial amount is repaid. 
- Material element: The amount of money exchanged, i.e. the amount agreed upon. In the previous slides we referred to these amounts as $\mathrm{C}$ and $\mathrm{C}^{\prime}$.

So, we know that in a financial transaction, the two parties to the agreement exchange liquidity:

$\square$ the sum of money that the active party (lender) cedes is called "payout" (C);

$\square$ and the monetary compensation that the passive party (borrower) pays back is called "repayment" (C').

\section{Obviously the payouts and the repayments must be equivalent.}

\section{Example 2:}

Today, 15-02-2015, two people agree to sign a contract. In the deal, person A lends $€ 1000$ to person B today. Person B will cancel the debt by paying $€ 200$ on 03/07/2015 and $€ 1500$ on $30 / 01 / 2016$.

- The payout is $€ 1000$ on $15 / 02 / 2015$

- The repayment consists of two amounts: $€ 200$ on $03 / 07 / 2015$ and $€ 1500$ on $30 / 01 / 2016$ 
Following that easy example, we can analyze two concepts.

- Temporal graph / Time diagram: In order to understand and simplify financial transactions, we will always represent the payouts and repayments in graphic form. For example, if we want to represent example 2:

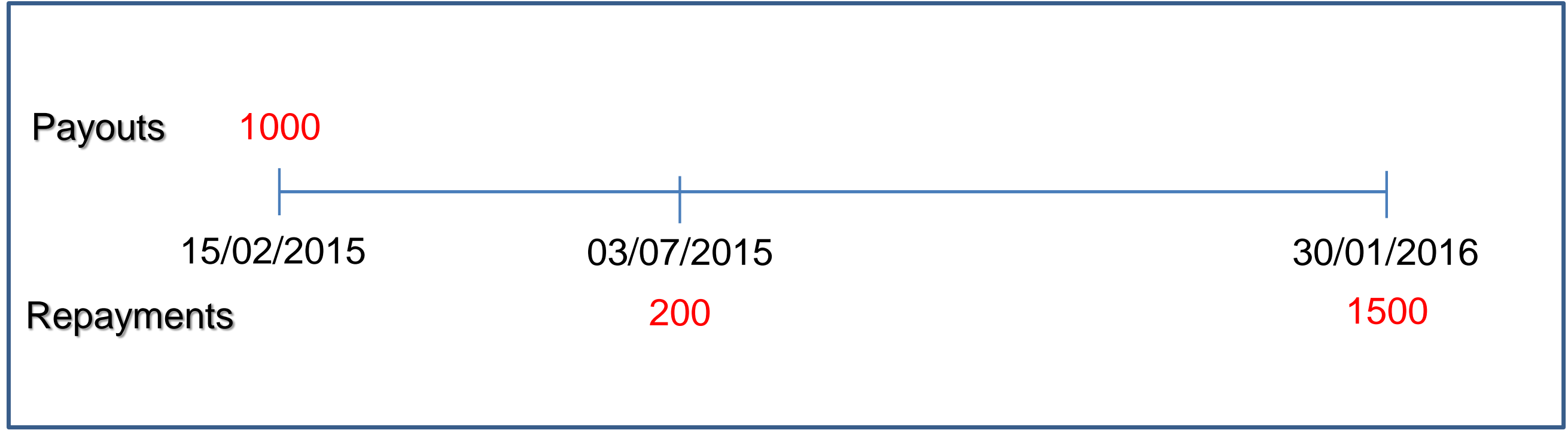

A time diagram is a one-dimensional diagram where the only variable is time. In this graph we have the payouts above the time axis and the repayments below it.

A time diagram is not a formal part of the solution, but may be very helpful in visualizing the solution 


\section{Classification of financial transactions}

Depending on the number of payments and repayments that the active and passive parties agree to, we refer to the financial transaction as:

- a common operation: The payout is only one amount, and the repayment is only one amount, too. So, one party lends another party a lump sum of money. Then, interest is expected in addition to the return of the initial amount;

1000

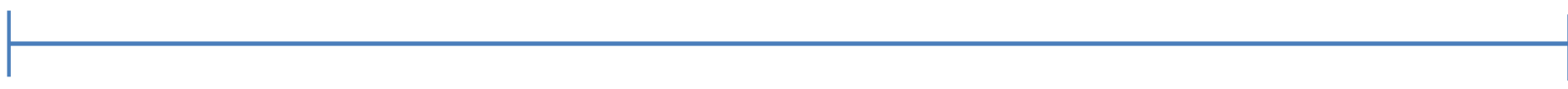

$10 / 01 / 2015$

$10 / 01 / 2016$

1500

- a complex operation: all other financial transactions, as represented in the following time diagram, for example

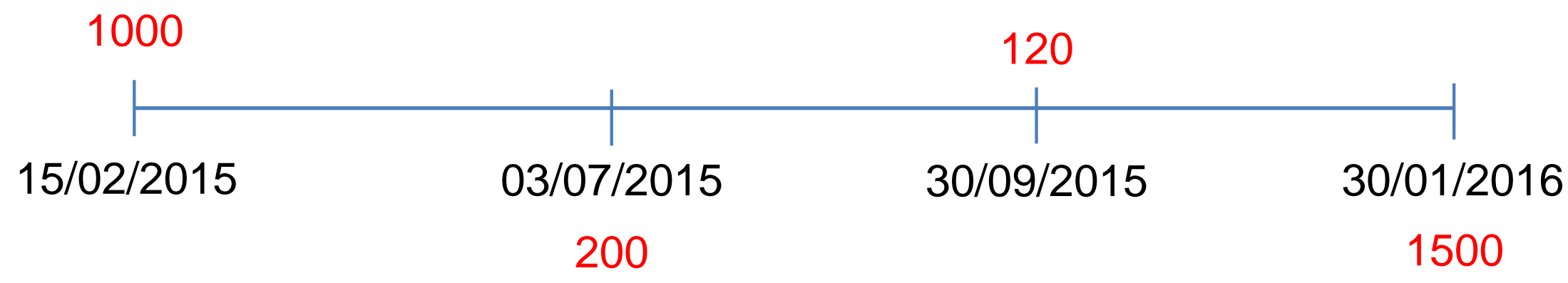




\section{Equilibrium in a financial transaction}

\section{Financial capital}

In previous slides, we defined a financial transaction as an agreement between two parties to exchange cash/liquidity at different times.

Obviously, it is not the same to have a sum of money today as to have it in two months. I think that everyone prefers to enjoy money as soon as possible! (Time preference theory.)

So, because it is not the same to have $€ 100$ today as it is to have it in a week, when you refer to an amount of money, it is necessary to include when the money is available.

So, we need a new way to represent a sum of money; we need to include the moment at which the money is available!

\section{Financial capital}

We define financial capital as

$$
(C, T) \text { where } C, T \in R^{+}
$$

C the sum of money and $\mathbf{T}$ the time when the money is available.

For us, T will always be measured in years! 


\section{Example 3:}

- $€ 100$ today is indicated as $(100,0)$

- $€ 100$ in one year is indicated as $(100,1)$

- $€ 100$ in fifteen months is indicated as $(100,15 / 12)$

\section{Example 4:}

Imagine the following financial transaction,

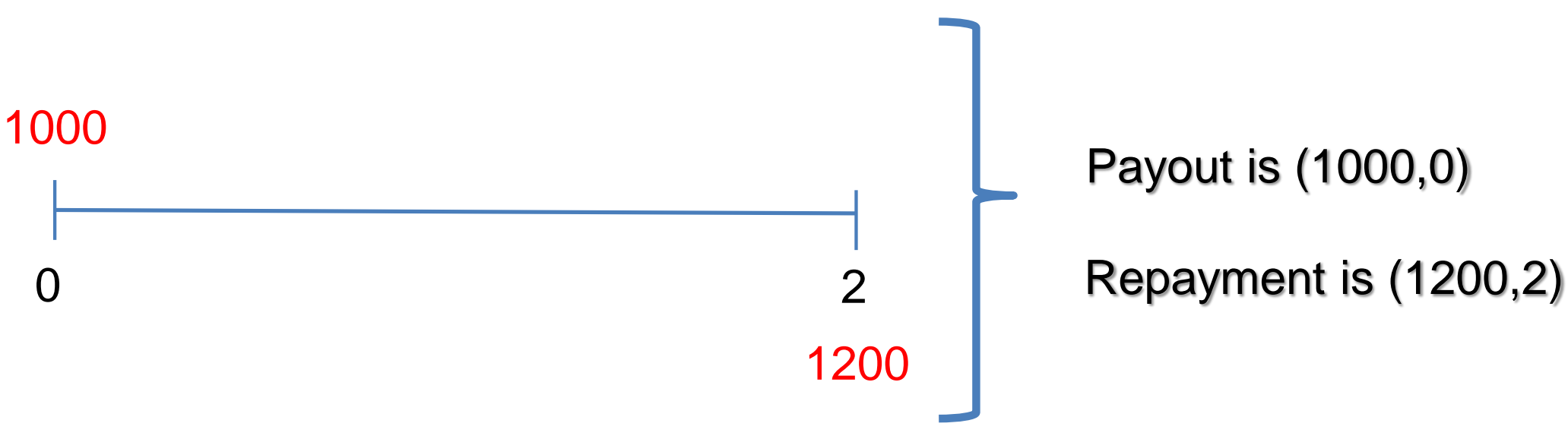

The active party cedes $€ 1000$ today to the passive party in exchange for receiving $€ 1200$ in two years. The two subjects reach an agreement. So, the payout and the repayment are equivalent financial capitals. This is indicated as:

$$
(1000,0) \sim(1200,2)
$$


Let $(C, T)$ be the payout, and let $\left(C^{\prime}, T^{\prime}\right)$ be the repayment in a financial transaction. As we have just seen, the following form indicates that two financial capitals are equivalents:

$$
(C, T) \sim\left(C^{\prime}, T^{\prime}\right)
$$

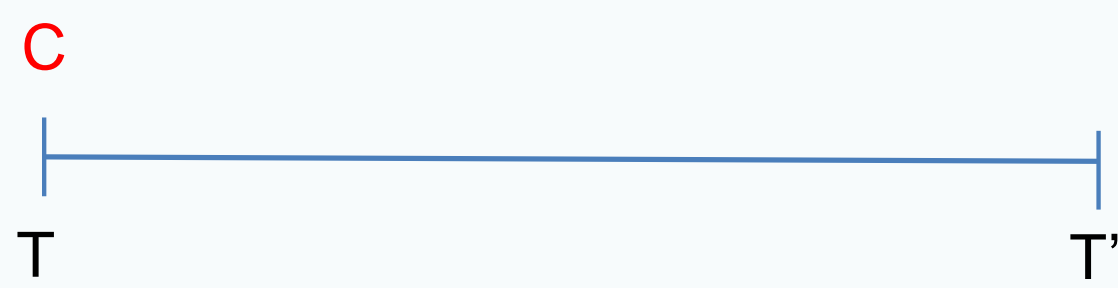

C'

\section{ACCUMULATION FUNCTION}

If two financial capitals are equivalent,

$$
(C, T) \sim\left(C^{\prime}, T^{\prime}\right)
$$

we can define a new function $f\left(T, T^{\prime}\right)$ as the quotient of $C^{\prime}$ divided by $C$,

$$
f\left(T, T^{\prime}\right)=\frac{C^{\prime}}{C} \Rightarrow C^{\prime}=C \cdot f\left(T, T^{\prime}\right)
$$

where $f\left(T, T^{\prime}\right)$ is called the accumulation function. 


\section{Example 5:}

Imagine the following financial transaction: $(100,4) \sim(300,6)$

100

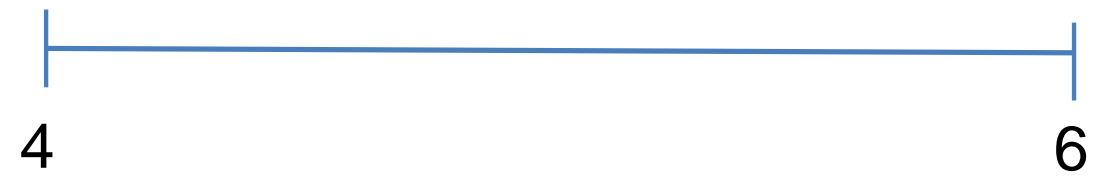

In this case, the accumulation function, $f\left(T, T^{\prime}\right)$, is:

$$
f\left(T, T^{\prime}\right)=\frac{C^{\prime}}{C} \quad \Longrightarrow \quad f(4,6)=\frac{300}{100}=3
$$

The accumulation function depends on the deals between the two parties to the financial transaction. In example 5 , there are some deals that determine that $€ 100$ at time 4 is equivalent to $€ 300$ at time 6 ,

$$
(100,4) \sim(300,6)
$$

Obviously, if the deals were different, the accumulation function would be different. According to other deals (for example, for a different interest rate), the equivalence could, for example, be:

$$
(100,4) \sim(310,6)
$$

and then the accumulation function would be:

$$
f(4,6)=\frac{310}{100}=3^{\prime} 1
$$




\section{But, what does the accumulation function mean?}

An accumulation function allows us to obtain an equivalent amount of money at a different time.

$$
\text { Or, }
$$

The accumulation function represents the way in which money grows as time goes by.

That is to say, the accumulation function indicates how the initial capital, $\mathrm{C}$, grows, and it depends on the deals between the two parties to the financial transaction. The idea is that one euro invested at time $T$ grows to $f\left(T, T^{\prime}\right)$ in time $T^{\prime}$.

So, the accumulation function represents the accumulated value of an initial amount of $€ 1$ invested at time $T$.

We expect $f\left(T, T^{\prime}\right)$ to represent the way in which money accumulates as time goes by. 


\section{Example 6:}

Suppose that the accumulation function is:

$$
f\left(T, T^{\prime}\right)=1+0.03\left(T^{\prime}-T\right)
$$

and you lend $€ 1000$ to a friend at $T=2$. Find the amount your friend would be required to pay if they make their repayment at $T^{\prime}=5$.

\section{0}

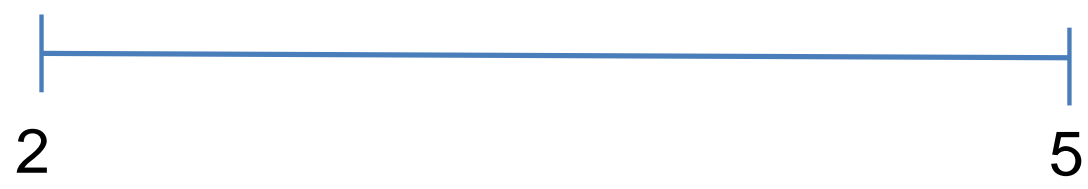

Solution:

$$
\begin{aligned}
& f\left(T, T^{\prime}\right)=\frac{C^{\prime}}{C} \Rightarrow C^{\prime}=C \cdot f\left(T, T^{\prime}\right) \\
& C^{\prime}=1000 \cdot\left(1+0.03\left(T^{\prime}-T\right)\right) \\
& C^{\prime}=1000 \cdot(1+0.03(5-2))=1090
\end{aligned}
$$

So,

$$
(1000,2) \sim(1090,5)
$$




\section{Example 7:}

Suppose that the accumulation function is:

$$
f\left(T, T^{\prime}\right)=1+0.03\left(T^{\prime}+T\right)
$$

and you lend $€ 1000$ to a friend at $T=2$. Find the amount your friend would be required to pay if they make their repayment at $T^{\prime}=5$.

Solution:

1000

$$
f\left(T, T^{\prime}\right)=\frac{C^{\prime}}{C} \Rightarrow C^{\prime}=C \cdot f\left(T, T^{\prime}\right)
$$

So,

$$
(1000,2) \sim(1210,5)
$$


Let $t=T^{\prime}-T$, be the length of the financial transaction

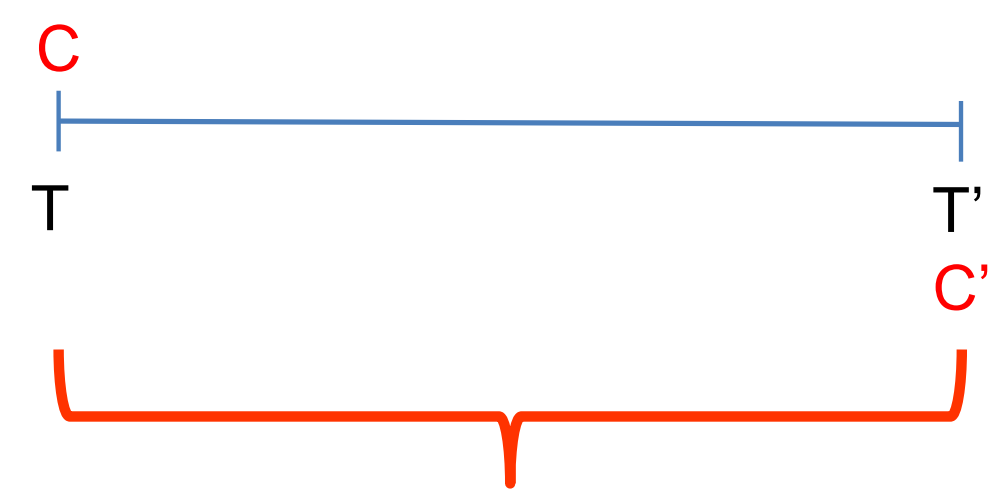

$$
t=T^{\prime}-T
$$

For instance, in example $7, \mathrm{t}=\mathrm{T}^{\prime}-\mathrm{T}=5-2=3$.

\section{Property of the accumulation function}

If $f\left(T+h, T^{\prime}+h\right)=f\left(T, T^{\prime}\right)$ then the accumulation function is stationary; i.e., it is possible to represent $f\left(T, T^{\prime}\right)$ as $f(t)$

The idea is that the moment, $\mathrm{T}$, at which the financial transaction begins is not important, and neither is the moment of the end of the financial transaction, T'. The accumulation function only depends on the length of the financial transaction, $t$. 


\section{Example 8: Stationary accumulation function}

Remember Example 6: the accumulation function is $f\left(T, T^{\prime}\right)=1+0.03\left(T^{\prime}-T\right)$, and the financial transaction is

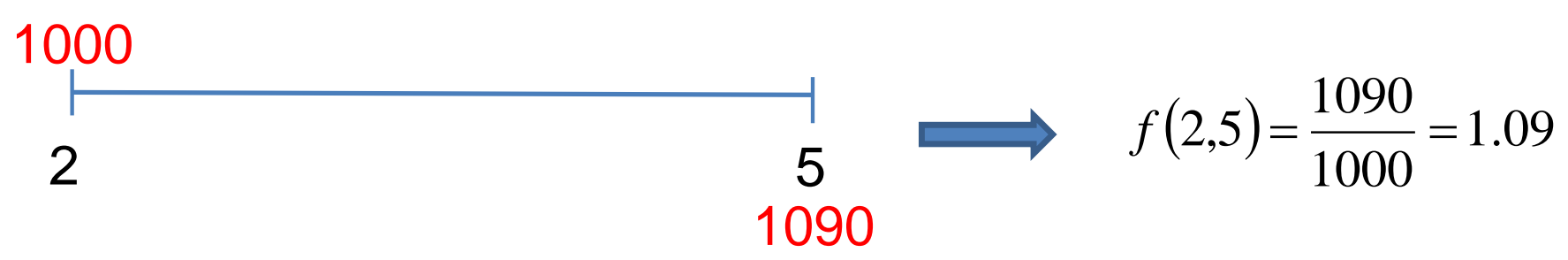

Now suppose that you lend $€ 1000$ to your friend at $T=6$. Find the amount your friend would be required to pay if they make their repayment at $T^{\prime}=9$.

$$
\begin{aligned}
& 6\left(T, T^{\prime}\right)=\frac{C^{\prime}}{C} \Rightarrow C^{\prime}=C \cdot f\left(T, T^{\prime}\right) \\
& C^{\prime}=1000 \cdot\left(1+0.03\left(T^{\prime}-T\right)\right) \\
& C^{\prime}=1000 \cdot(1+0.03(9-6))=1090
\end{aligned}
$$$$
f(6,9)=\frac{1090}{1000}=1.09
$$

This result is the same as the previous case.

You can observe that in the two cases $t=T^{\prime}-T$ is the same. The length of the transaction is $t=3$ !

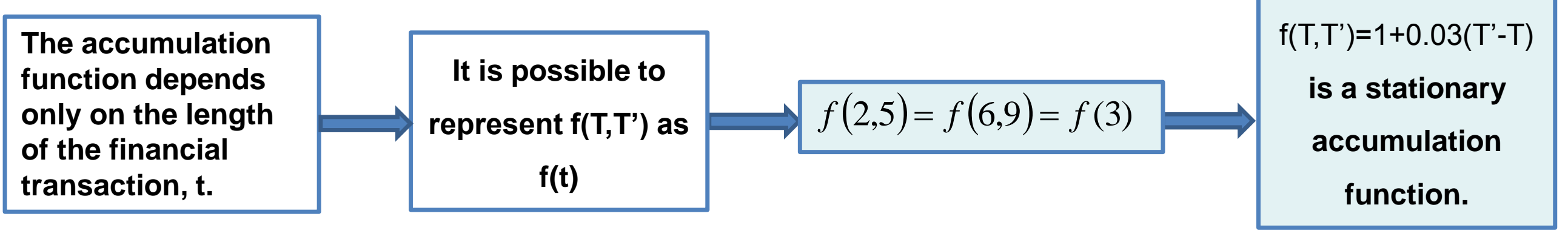




\section{Example 9: Non-stationary accumulation function}

Remember Example 7: the accumulation function is $f\left(T, T^{\prime}\right)=1+0.03\left(T^{\prime}+T\right)$, and the financial transaction is

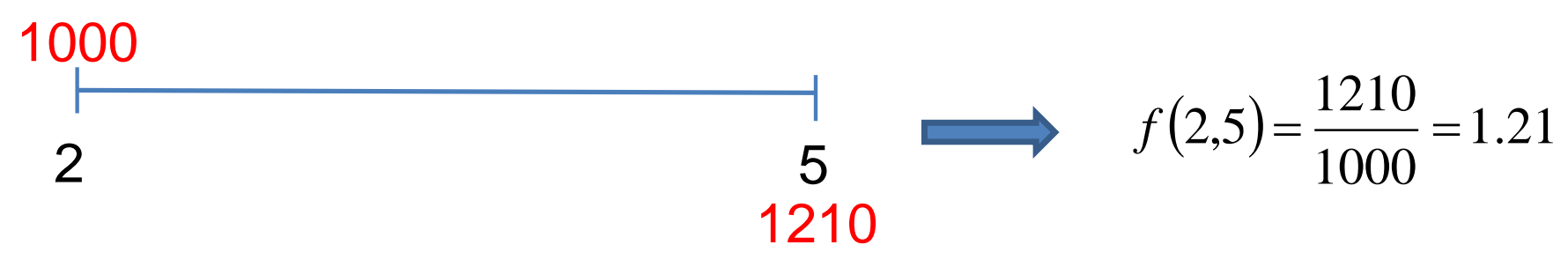

Now suppose that you lend $€ 1000$ to your friend at $T=6$. Find the amount your friend would be required to pay if they make their repayment at $T^{\prime}=9$.

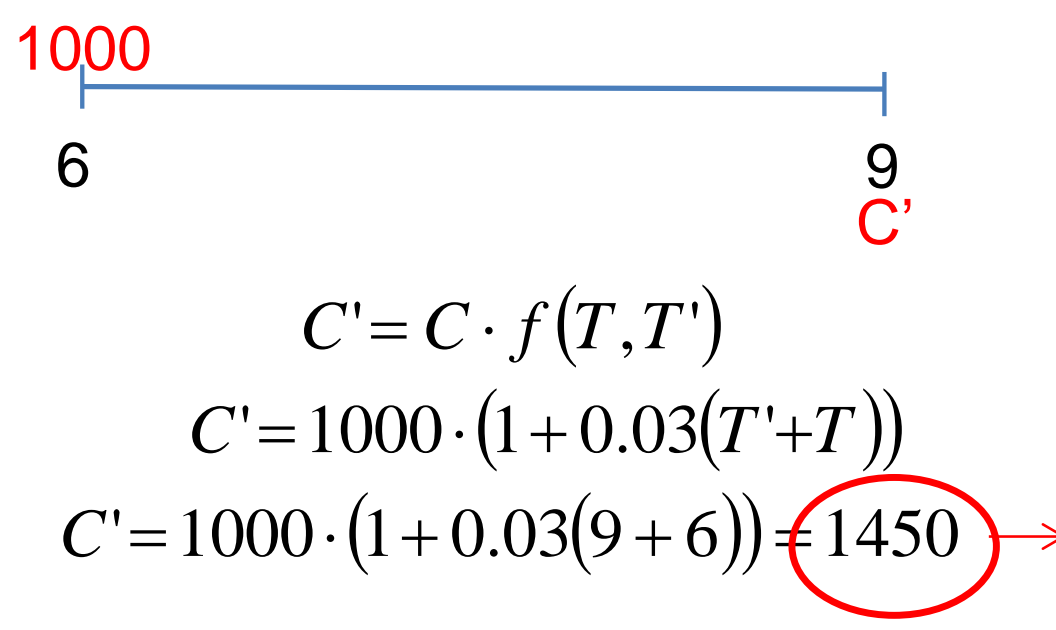

$$
f(6,9)=\frac{1450}{1000}=1.45
$$

This result is not the same as in the previous case.

You can observe that in the two cases the length of the transaction is $t=3$, but the accumulation function is not the same in the two cases.

$$
\begin{array}{|l|}
f(2,5) \neq f(6,9) \Rightarrow \begin{array}{c|}
\mathrm{f}\left(\mathrm{T}_{\mathrm{T}} \mathrm{T}^{\prime}\right)=1+0.03\left(\mathrm{~T}^{\prime}+\mathrm{T}\right) \\
\text { is a non-stationary } \\
\text { accumulation function. }
\end{array} \\
\hline
\end{array}
$$




\section{Price in a common financial transaction}

Imagine a common financial transaction, that is to say:

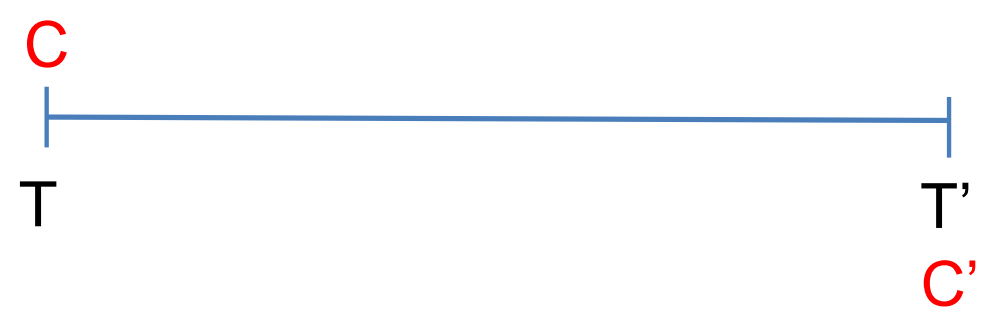

Total price: this gives us the amount of interest earned between time T and T'. It is calculated as the difference between the amount of value at the end of the period and the amount of value at the beginning of the period; that is to say, the difference between C' and C.

$$
I T=\Delta C=C^{\prime}-C
$$

But this definition is not very helpful in practical situations, since we are generally interested in comparing different financial transactions to find the most profitable one. And, obviously, it is very important to take into account the length of the transaction or the relationship with the initial amount, C; which are not included in the definition of total price! It only takes into account $\mathrm{C}$ and $\mathrm{C}^{\prime}$. 
For example, imagine the following two financial transactions:
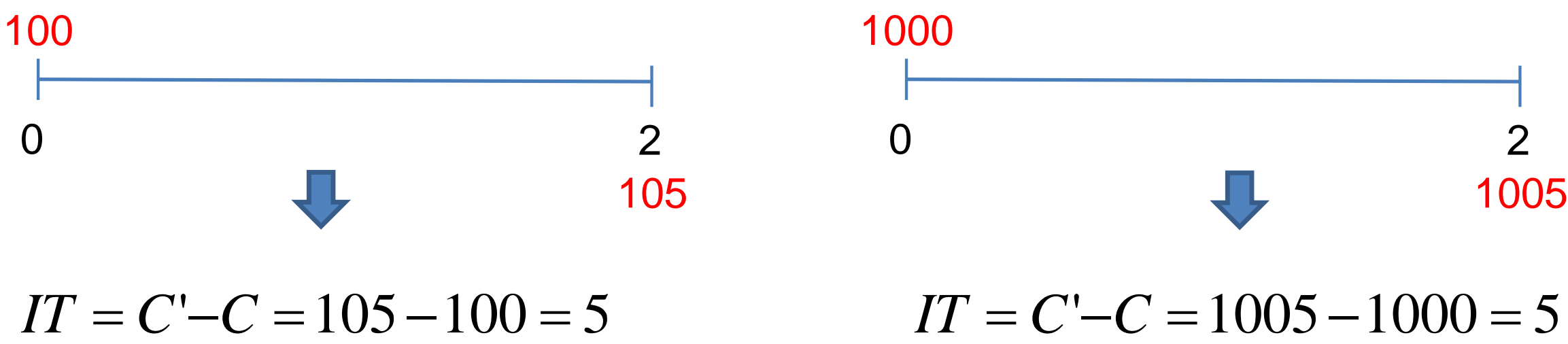

The total interest is the same in the two situations, but....

Which financial transaction would you prefer?

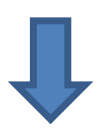

In the first case you earn $€ 5$ with an initial amount of $€ 100$.

In the second situation you earn $€ 5$ with an initial investment of $€ 1000$.

I prefer the first situation! 
Unit price: this represents the interest rate earned by one unit of $C$.

$$
I\left(T, T^{\prime}\right)=\frac{\Delta C}{C}=\frac{C^{\prime}-C}{C} \Rightarrow \quad \begin{gathered}
\begin{array}{c}
\text { Effective interest } \\
\text { rate }
\end{array} \\
\hline
\end{gathered}
$$

The effective rate of interest is the amount of money that one unit invested at the beginning of a period will earn during the period, with interest being paid at the end of the period.

In the previous example,
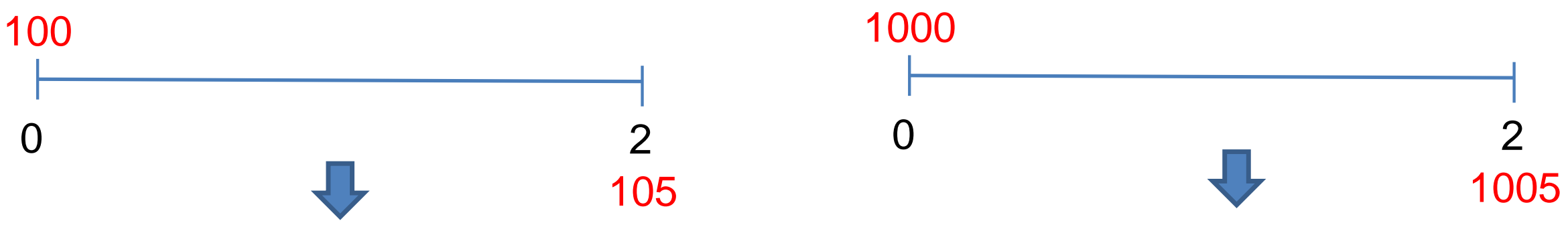

$I\left(T, T^{\prime}\right)=\frac{C^{\prime}-C}{C}=\frac{105-100}{100}=0.05 \quad I\left(T, T^{\prime}\right)=\frac{C^{\prime}-C}{C}=\frac{1005-1000}{1000}=0.005$ 
Now, let's compare two different situations:

CASE 1
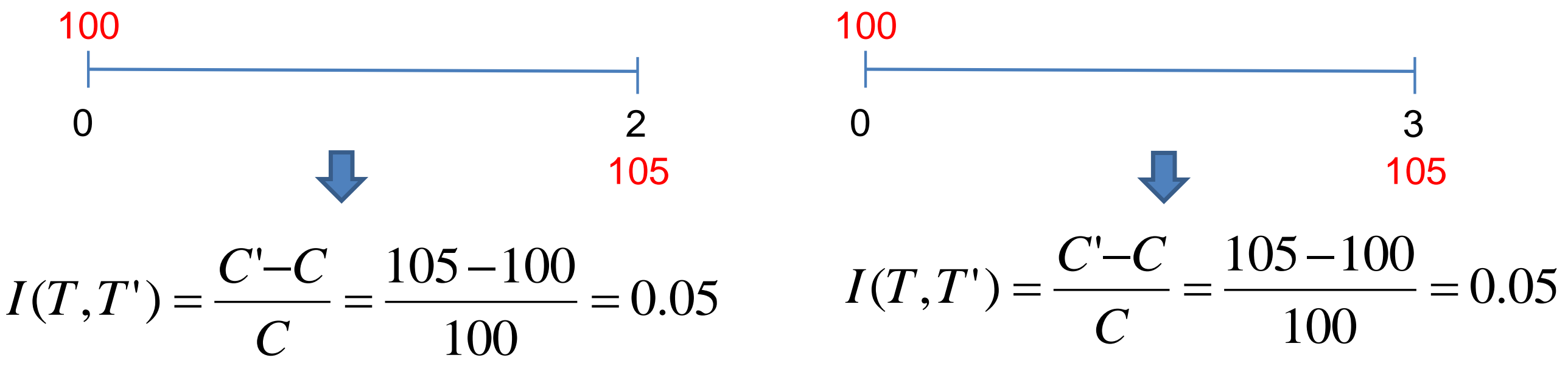

The effective interest rate is the same in the two cases; but obviously, the first case is better: you earn $€ 5$ in 2 years, whereas in the second case you need three years to earn $€ 5$.

Unit and medium price: this represents the interest rate earned by one unit of $C$ in one unit of time.

$$
i\left(T, T^{\prime}\right)=\frac{I\left(T, T^{\prime}\right)}{T^{\prime}-T}=\frac{C^{\prime}-C}{C\left(T^{\prime}-T\right)} \Rightarrow \begin{gathered}
\begin{array}{c}
\text { Nominal interest } \\
\text { rate }
\end{array} \\
\text { rate }
\end{gathered}
$$

It is the amount of interest earned in one period divided by the initial amount, $\mathrm{C}$. 
In the previous example:

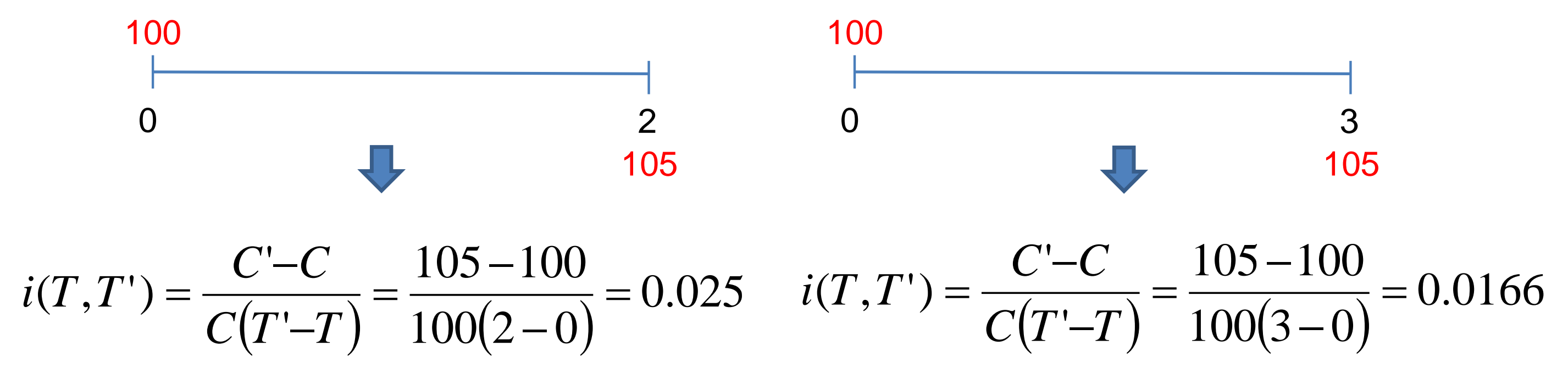

The effective interest rate is the same in the two cases, but the nominal interest rate is higher in the first case! 


\section{Example 10: Prices of financial transactions}

Find the total price IT, I(T, $\left.\mathrm{T}^{\prime}\right)$ and $\mathrm{i}\left(\mathrm{T}, \mathrm{T}^{\prime}\right)$ in the following common financial transaction:

Solution:

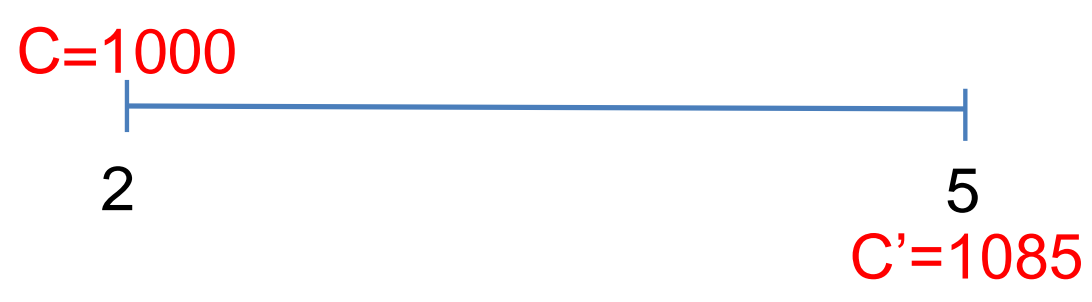

- Total price:

$$
I T=\Delta C=C^{\prime}-C=1085-1000=85
$$

- Unit price:

$$
I\left(T, T^{\prime}\right)=\frac{\Delta C}{C}=\frac{C^{\prime}-C}{C}=\frac{1085-1000}{1000}=0.085
$$

- Unit and medium price:

$$
i\left(T, T^{\prime}\right)=\frac{I\left(T, T^{\prime}\right)}{T^{\prime}-T}=\frac{C^{\prime}-C}{C\left(T^{\prime}-T\right)}=\frac{1085-1000}{1000(5-2)}=0.0283333
$$




\section{Example 11: Prices of financial transactions}

Peter deposits $€ 2500$ in an account at SA Bank today. He will recover $€ 2750$ in two years. Find:

$\square$ Total price

$\square$ Effective interest rate

$\square$ Nominal interest rate 


\section{Financial arrangement or financial regime}

$\checkmark$ Financial arrangement: definition

$\checkmark$ Simple interest

$\checkmark$ Price in the simple interest agreement

$\checkmark$ Techniques for counting days in a period

$\checkmark$ Compound interest at a constant rate

$\checkmark$ Price in compound interest

$\checkmark$ Effective rates and nominal rates

$\checkmark$ Discount functions (present value)

$\checkmark$ Equivalent effective rates

$\checkmark$ Compound interest with varying interest rates

$\checkmark$ An equivalent annual effective yield

$\checkmark$ Simple discount

$\checkmark$ Price in the simple discount agreement

$\checkmark$ Analogous simple interest rate and simple discount rate 


\section{Financial regime: definition}

In the world of day-to-day financial transactions, you do not hear anyone talk of accumulation functions. However, financial transactions are usually made according to the same deals between parties, and many of these agreements are easily translated into the language of accumulation functions.

\section{Financial regime}

A financial regime is the formal expression of the deals between parties that regulate financial transactions.

In the following sections we will analyze four financial regimes:

$\square$ Simple interest

Compound interest at a constant rate

$\square$ Compound interest with varying interest rates

$\square$ Simple discount 


\section{Simple interest}

$>$ The total interest (IT) depends on the initial amount $(\mathrm{C})$ and on the length of the transaction $\left(\mathrm{t}=\mathrm{T}^{\prime}-\mathrm{T}\right)$. The interest is directly proportional to both these factors, with the rate being what determines this relationship, i $>0$. Therefore, the total price/interest is:

$$
I T=i \cdot \underset{\downarrow}{\text { Interest rate }} \underset{\text { Initial amount }}{\stackrel{\uparrow}{\downarrow}\left(T^{\prime}-T\right)=i \cdot C \cdot t} \begin{gathered}
\text { Length of the transaction } \\
\text { (always measured in years) }
\end{gathered}
$$

$>$ The interest is paid at the end of the financial transaction, at T', with the repayment of the principal of the transaction $(\mathrm{C})$

$$
\begin{aligned}
& \mathrm{C} \\
& \mathrm{T}
\end{aligned}
$$

C
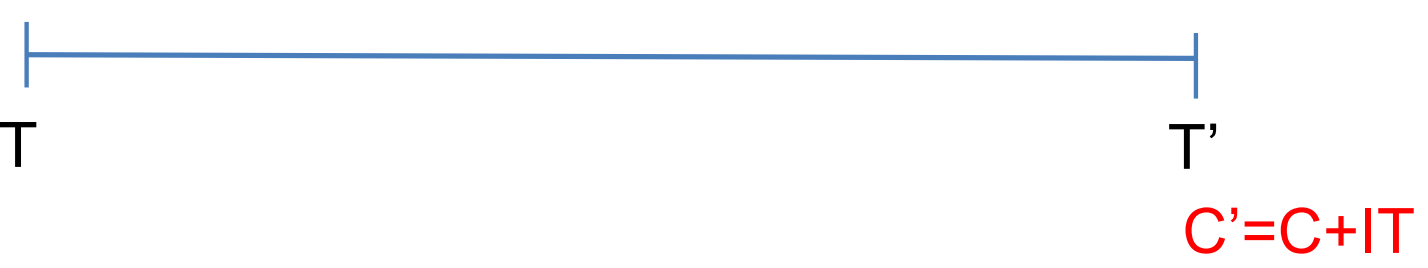

$$
C^{\prime}=C+I T=C+i \cdot C \cdot t=C(1+i t)
$$




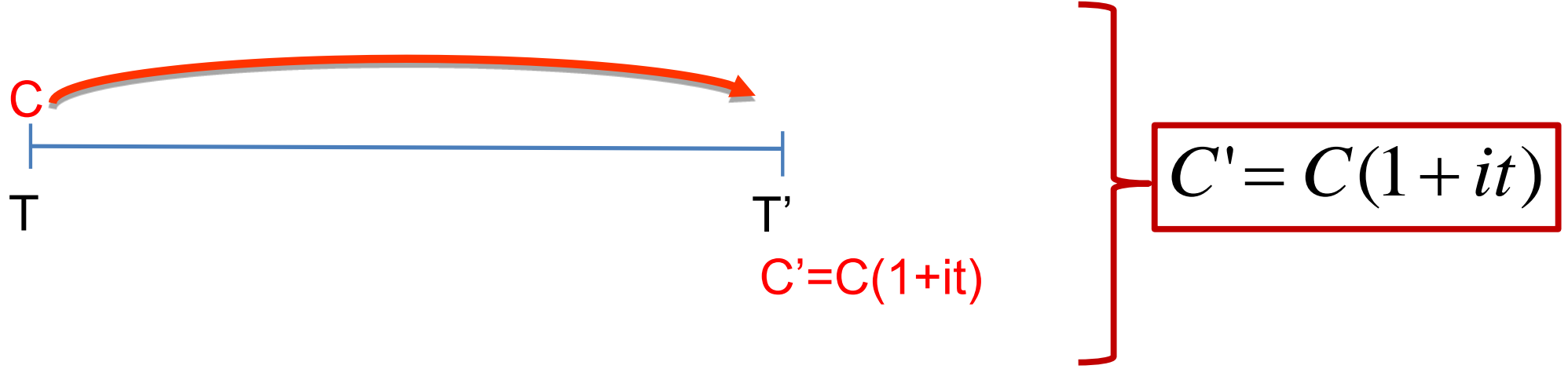

Remember that the accumulation function $f\left(T, T^{\prime}\right)$ is $\Rightarrow f\left(T, T^{\prime}\right)=\frac{C^{\prime}}{C} \Rightarrow C^{\prime}=C \cdot f\left(T, T^{\prime}\right)$ So, the simple interest accumulation function is

$$
f\left(T, T^{\prime}\right)=\frac{C^{\prime}}{C}=\frac{C(1+i t)}{C}=(1+i t)
$$

Obviously $f\left(T, T^{\prime}\right)=f(t)$. It is an stationary accumulation function. That is to say, it only depends on $t$, not on T or T'.

The accumulation function is a linear function

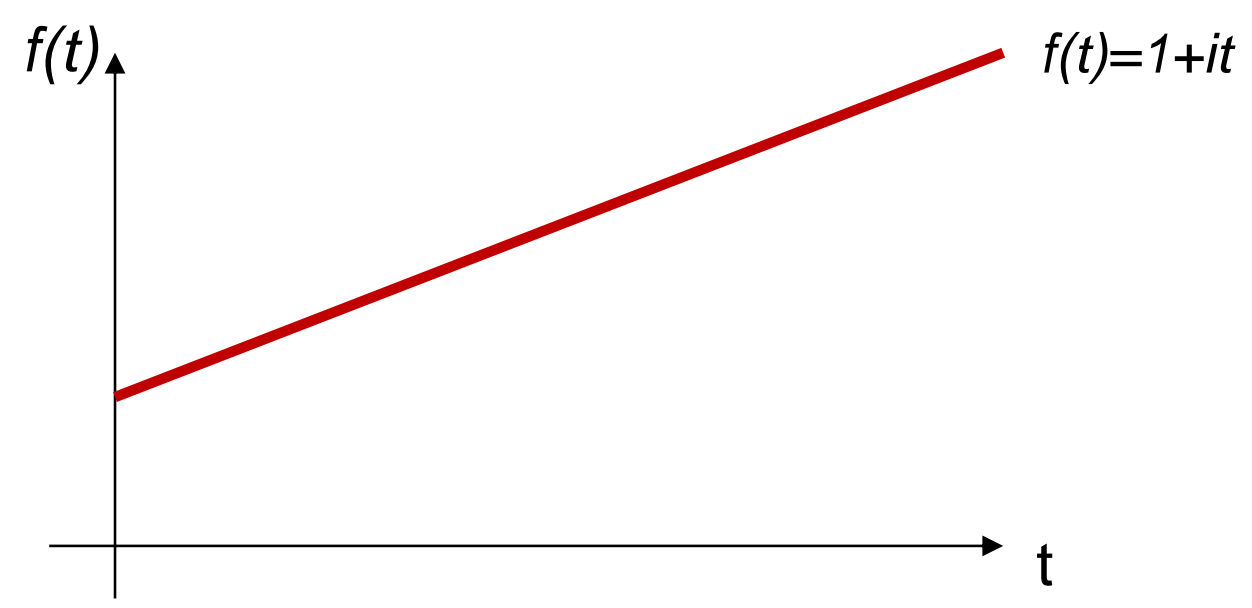




\section{Example 1: Simple Interest}

You invest $€ 100$ at time 0 , at an annual simple interest rate of $10 \%$. Find the accumulated value after six months.

100

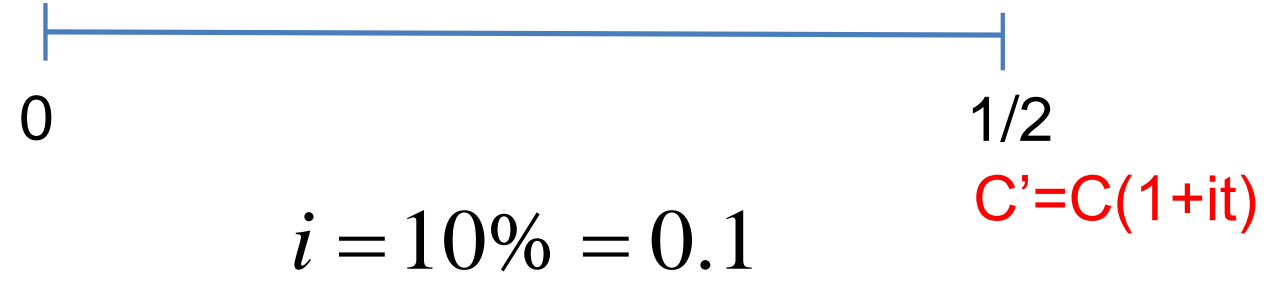

$C^{\prime}=C(1+i t)=$

$$
=100\left(1+0.1 \cdot \frac{1}{2}\right)=105
$$

\section{Example 2: Simple Interest}

Maria borrows €2000 from Marc at 3\% annual simple interest and agrees to repay the loan in two years. What is the amount that Maria is required to repay to Marc?

\section{Example 3: Simple Interest}

Peter lends Mary $€ 1800$. Mary promises that in return, she will pay Peter $€ 2025$ after four years. What annual rate of simple interest does this correspond to?

\section{Example 4: Simple Interest}

How many years will it take for $€ 500$ to increase to $€ 800$ at $6 \%$ annual simple interest? 


\section{Example 5: Simple Interest}

At what annual rate of simple interest will $€ 500$ increase to $€ 615$ in two and a half years?

\section{Example 6: Simple Interest}

What initial amount will earn interest of $€ 100$ in 7 years at an annual simple interest of $6 \%$ ?

\section{Example 7: Simple Interest}

At time 0 , you invest some money in an account earning $5.75 \%$ annual simple interest. How many years will it take to double your money?

\section{Example 8: Simple Interest}

The total amount of a loan to which interest has been added is $€ 20,000$. The term of the loan was four and a half years. If the money accumulated annual simple interest at a rate of $6 \%$, how much was the original loan?

\section{Example 9: Simple Interest}

At a particular rate of simple interest, $€ 1200$ invested at time $t=0$ will increase to $€ 1320$ over $T$ years. Find the accumulated value of $€ 500$ invested at the same rate of simple interest and again at $\mathrm{t}=0$, but this time for $2 \mathrm{~T}$ years. 


\section{Price in the simple interest agreement}

$$
C^{\prime}=C(1+i t)
$$

- Total price: this is calculated as the difference between $C^{\prime}$ and $C$ :

$$
I T=\Delta C=C(1+i t)-C=C \cdot i \cdot t
$$

- Unit price: this represents the interest rate earned by one unit of $C$ :

$$
I\left(T, T^{\prime}\right)=\frac{\Delta C}{C}=\frac{C^{\prime}-C}{C}=\frac{C(1+i t)-C}{C}=\frac{C \cdot i \cdot t}{C}=i \cdot t
$$

- Unit and medium price: this represents the interest rate earned by one unit of $C$ in one unit of time:

$$
i\left(T, T^{\prime}\right)=\frac{I\left(T, T^{\prime}\right)}{t}=\frac{C^{\prime}-C}{C\left(T^{\prime}-T\right)}=\frac{C \cdot i \cdot t}{C \cdot t}=i \Rightarrow \begin{gathered}
\text { Nominal interest } \\
\text { rate }
\end{gathered}
$$




\section{Example 10: Price in simple interest}

You invest $€ 325$ at an annual simple interest of $5 \%$. Find the accumulated value after one and a half years. Calculate the total interest, the unit price and the unit and medium price.

$$
\begin{gathered}
C^{\prime}=C(1+i t)= \\
\begin{array}{c}
1+1 / 2 \\
C^{\prime}=C(1+\mathrm{it})
\end{array} \quad=325(1+0.05 \cdot 1.5)=349.37 \\
I T=\Delta C=C^{\prime}-C=349.37-325=24.37 \\
I\left(T, T^{\prime}\right)=\frac{C^{\prime}-C}{C}=\frac{24.37}{325}=0.075 \\
i\left(T, T^{\prime}\right)=\frac{C^{\prime}-C}{C\left(T^{\prime}-T\right)}=\frac{24.37}{325 \cdot 1.5}=0.05
\end{gathered}
$$

\section{Example 11: Price in simple interest}

Mary deposits $€ 1550$ at an annual simple interest of $5 \%$. Find the accumulated value after two and a quarter years. Calculate the total interest, the unit price and the unit and medium price. 
Remark: Simple interest is in general inconvenient for banks to use. It is used over short periods. In order to understand this idea, let's resolve the next exercise

Example 12: John deposits $€ 100$ into a savings account that pays $6 \%$ simple interest for 2 years. Peter now deposits $€ 100$ with the same bank at the same interest rate. At the end of the year, he withdraws his balance and closes his account. Then, he reinvests all the money in a new savings account that offers the same rate. Who has accumulated the greater value at the end of two years?

- John

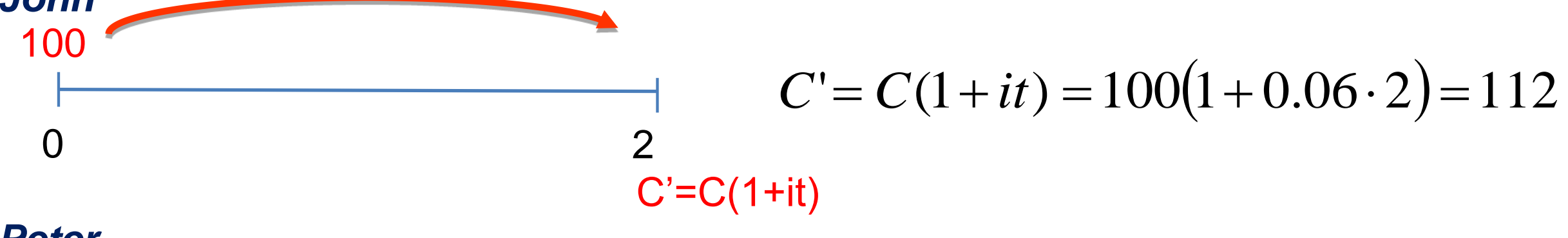

- Peter

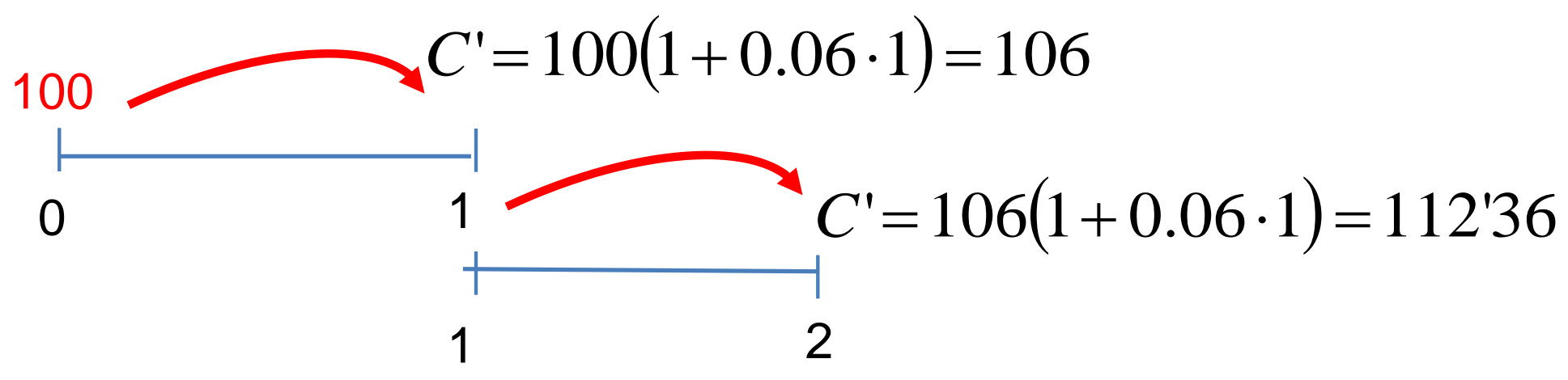

At the end of each period, depositors will withdraw the interest earned and the original deposit and immediately redeposit the sum into a new account as a larger deposit. This leads to higher interest being earned over the next investment year. 


\section{Techniques for counting the number of days in a period}

In the simple interest problems solved thus far, the length of the financial transactions has been a number of years; but what happens if the time is given in days? Obviously we need to convert the days into years, because $t$ is always measured in years.

That is to say, in this section we will answer questions such as:

- How many years are 25 days equal to?

- How many days are there between January $1^{\text {st }}$ and October $2^{\text {nd }}$ ?

Now, we are going to discuss three techniques for counting the number of days in a period, that is, between two dates. The methods are:

$>$ The actual/actual method (exact simple interest)

$>$ The $30 / 360$ method (ordinary simple interest)

$>$ The actual/360 method (Banker's rule)

$$
\text { time in years }(t)=\frac{\text { days between two dates }}{\text { days in a year }}
$$




\section{The actual/actual method (exact simple interest)}

$>$ We use the exact number of days in the period (for this method, it is important to know the number of days in each month).

$>$ When counting days between two dates, the last date is included but the first is not.

$>$ We use 365 days for a non-leap year and 366 for a leap year.

Example 13: Suppose that $€ 2500$ is deposited on March 8th and withdrawn on October $3^{\text {rd }}$ of the same year, and that the annual interest rate is $5 \%$. Find the amount of interest earned, computed using the actual/actual method. Assume a non-leap year (365 days).

Solution: From March $3^{\text {rd }}$ (not incl.) to October $3^{\text {rd }}$ (incl.) there are:

So,

$$
\text { time in years }=\frac{209}{365}=0.572602
$$

$$
C^{\prime}=C(1+i t)=2500(1+0.05 \cdot 0.572602)=€ 2571.58
$$

\begin{tabular}{|cc|}
\hline Month & Days \\
\hline March (31) & 23 \\
\hline April (30) & 30 \\
\hline May (31) & 31 \\
\hline June (30) & 30 \\
\hline July (31) & 31 \\
\hline August (31) & 31 \\
\hline September (30) & 30 \\
\hline October (31) & 3 \\
\hline TOTAL & $\mathbf{2 0 9}$ \\
\hline
\end{tabular}




\section{The 30/360 method (ordinary simple interest)}

$>$ The premise is that all months have 30 days, and all years have $12 \times 30=360$ days.

$>$ Like the actual/actual method, the end date is counted but the starting date is not.

Example 14: Jack borrows $€ 1000$ from the bank on January $28^{\text {th }} 1996$ at a rate of $15 \%$ simple interest. How much does he owe on March $5^{\text {th }} 1996$ ? Use the $30 / 360$ method.

Solution: From January $28^{\text {th }}$ (not included) to March $5^{\text {th }}$ (included) there are 37 days

\begin{tabular}{|ll|}
\hline Month & Days \\
\hline January & 2 \\
\hline February & 30 \\
\hline March & 5 \\
\hline TOTAL & $\mathbf{3 7}$ \\
\hline
\end{tabular}

So,

$$
\begin{gathered}
\text { time in years }=\frac{37}{360}=0.102777 \\
C^{\prime}=C(1+\text { it })=1000(1+0.15 \cdot 0.102777)=€ 1015.42
\end{gathered}
$$




\section{The actual/360 method (Banker's rule)}

$>$ This method uses the exact number of days for the period, that is to say, the number of days between the two dates is found in the same way as for the actual/actual method.

$>$ The calendar year has 360 days.

$>$ We also count the last day, but not the first day.

Example 15: Jack borrows $€ 1000$ from the bank on January $1^{\text {st }} 1996$ at a rate of $15 \%$ simple interest. How much does he owe on January $17^{\text {th }} 1996$ ? Use the Banker's rule.

Solution: From January $1^{\text {st }}$ (not included) to January $17^{\text {th }}$ (included) there are 16 days

\begin{tabular}{|ll|}
\hline Month & Days \\
\hline January & 16 \\
\hline TOTAL & $\mathbf{1 6}$ \\
\hline
\end{tabular}

So,

$$
\begin{gathered}
\text { time in years }=\frac{16}{360}=0.04444 \\
C^{\prime}=C(1+i t)=1000(1+0.15 \cdot 0.04444)=€ 1006.67
\end{gathered}
$$


Example 16: Find the amount of interest that $€ 2000$ deposited on June $17^{\text {th }}$ will earn, if the money is withdrawn on September $10^{\text {th }}$ of the same year and if the annual simple rate of interest is $8 \%$, using the:

a) actual/actual method (exact simple interest);

b) 30/360 method (ordinary simple interest);

c) actual/360 method (Banker's rule).

Consider a non-leap year

Example 17: Find the amount of interest that $€ 3500$ deposited on September $17^{\text {th }} 2014$ will earn, if the money is withdrawn on January $20^{\text {th }} 2015$, if the annual simple rate of interest is $8 \%$, using the:

a) actual/actual method (exact simple interest);

b) $30 / 360$ method (ordinary simple interest);

c) actual/360 method (Banker's rule).

The methods discussed above do not only apply to simple interest rate problems but also to compound interest rate problems. Compound interest rates will be introduced in the next section. In later sections, we will assume always the actual/actual method. 


\section{Compound Interest at a constant rate}

Simple interest means that the interest earned is not invested to earn additional interest. In contrast, for compound interest, the interest earned at the end of one period is automatically invested in the next period to earn additional interest.

So, in simple interest,

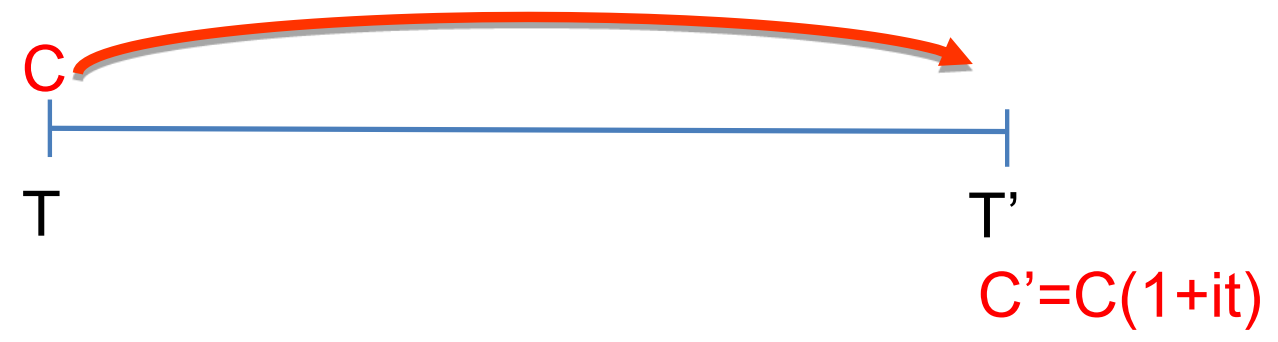

For compound interest, we divide the financial transaction into periods of $p$

C

T

T
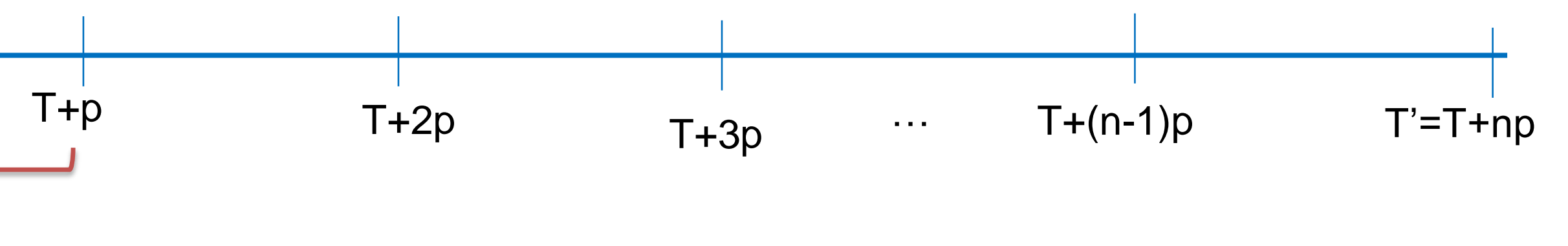

$p$

$$
t=T^{\prime}-T
$$

$n$ : number of periods, $p$, in $t=T^{\prime}-T$ 
Let's find the accumulation function for compound interest.
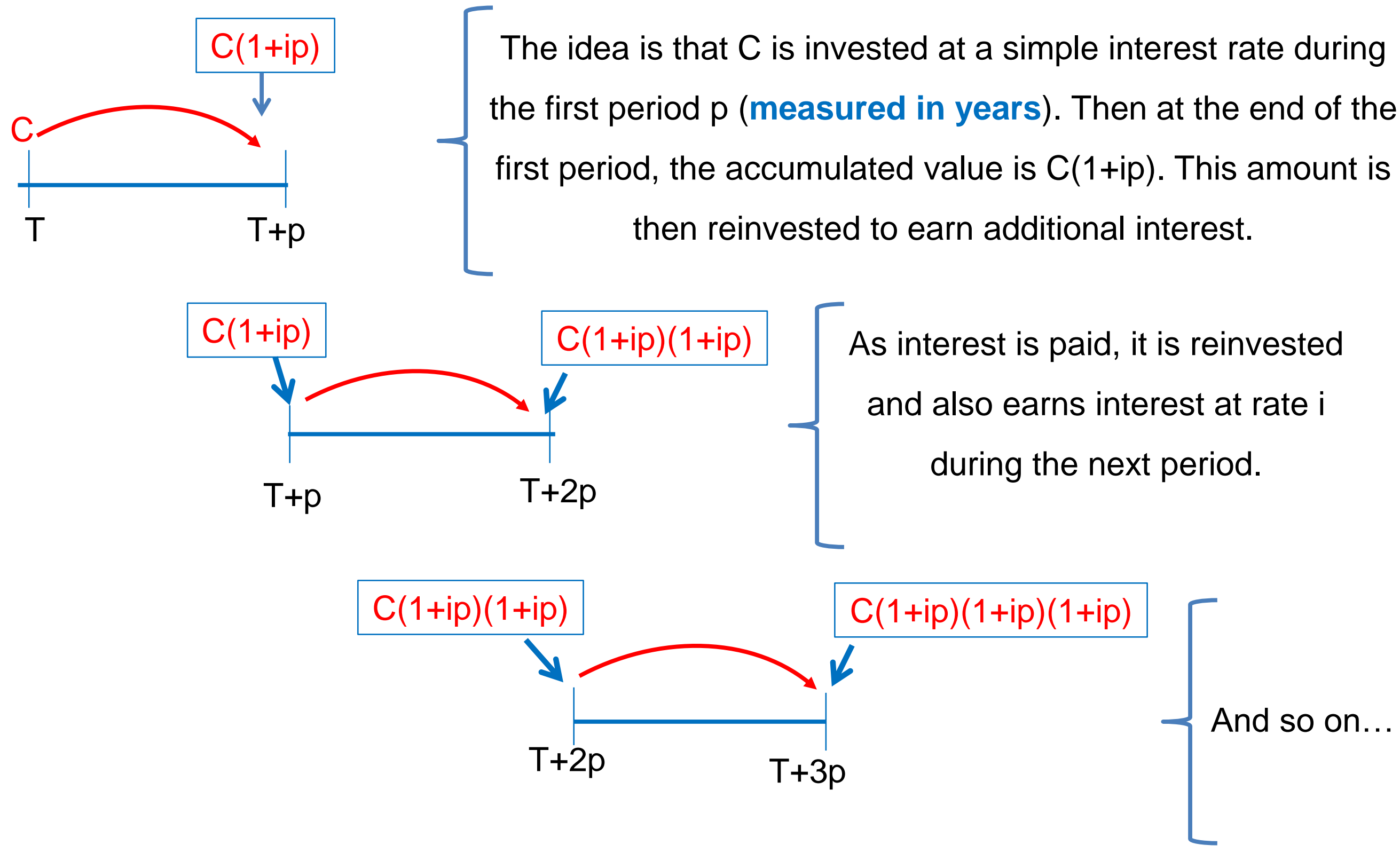
So, we find that the accumulated value after $\mathrm{n}$ periods is given by an exponential function:

$$
C^{\prime}=C(1+i p)^{n} \text {. }
$$

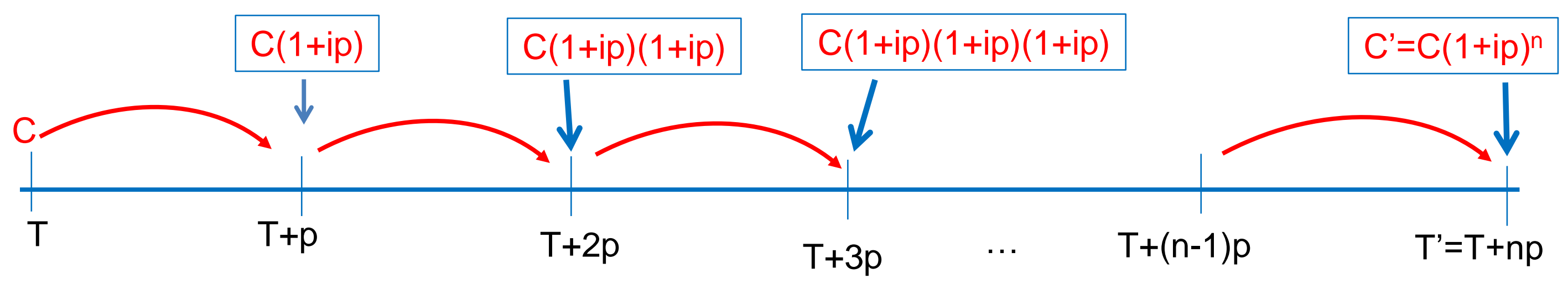

\begin{tabular}{|c|c|}
\hline Time & Accumulated amount \\
\hline$T$ & $C$ \\
\hline$T+p$ & $C(1+i p)$ \\
\hline$T+2 p$ & $C(1+i p)(1+i p)=C(1+i p)^{2}$ \\
\hline$T+3 p$ & $C(1+i p)(1+i p)(1+i p)=C(1+i p)^{3}$ \\
\hline$\ldots$ & $\ldots$ \\
\hline$T+(n-1) p$ & $C(1+i p)^{n-1}$ \\
\hline$T^{\prime}=T+n p$ & $C^{\prime}=C(1+i p)^{n}$ \\
\hline
\end{tabular}




\section{Summarizing the previous ideas,}

$>$ The length of the financial transaction $\left(t=T^{\prime}-T\right)$ is divided in $n$ "capitalization periods":

$$
T^{\prime}-T=n p \Rightarrow T^{\prime}=T+n p
$$

$$
n=\frac{T^{\prime}-T}{p}
$$

As interest is paid, it is reinvested and also earns interest at rate i during the next period.

$>$ The total price is paid at the end of the financial transaction. 
So, for compound interest

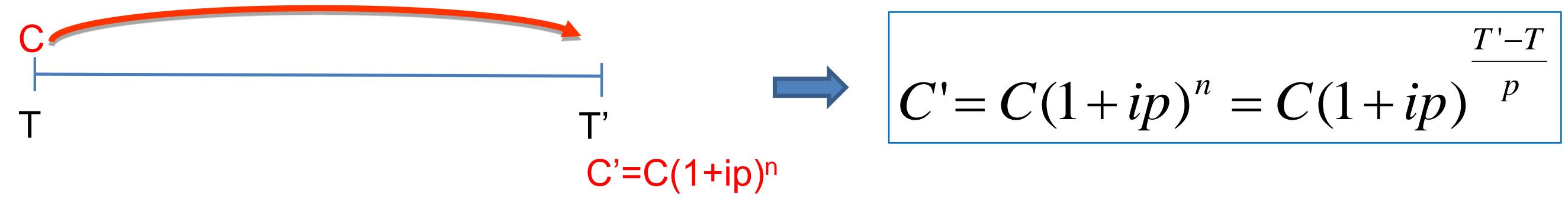

Remember that the accumulation function $f\left(T, T^{\prime}\right)$ is:

$$
f\left(T, T^{\prime}\right)=\frac{C^{\prime}}{C} \Rightarrow C^{\prime}=C \cdot f\left(T, T^{\prime}\right)
$$

So, in compound interest, the accumulation function is:

$$
f\left(T, T^{\prime}\right)=\frac{C^{\prime}}{C}=\frac{C(1+i p)^{\frac{T^{\prime}-T}{p}}}{C}=(1+i p)^{\frac{T^{\prime}-T}{p}}=(1+i p)^{n}
$$

Obviously $f\left(T, T^{\prime}\right)=f(t)$. It is an stationary accumulation function. 
Graph of the accumulation function $f\left(T, T^{\prime}\right)=f(t)=(1+i p)^{n}$,

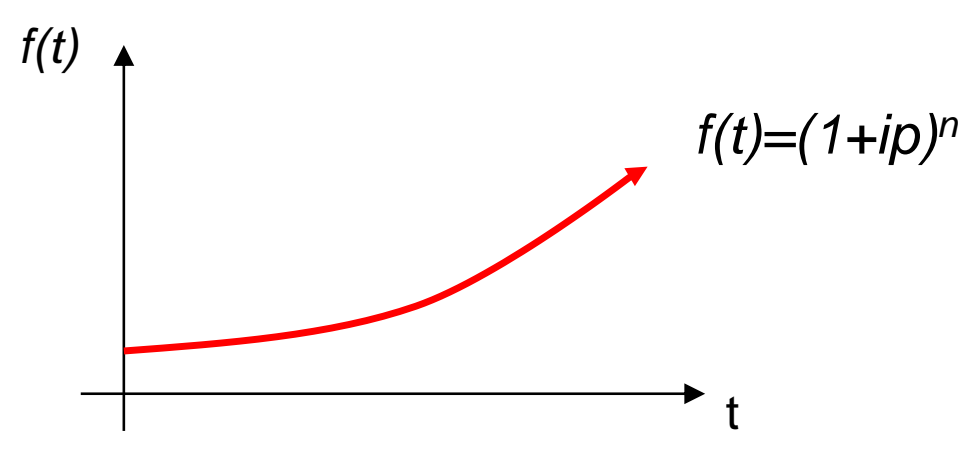

Now, we can compare simple interest and compound interest:

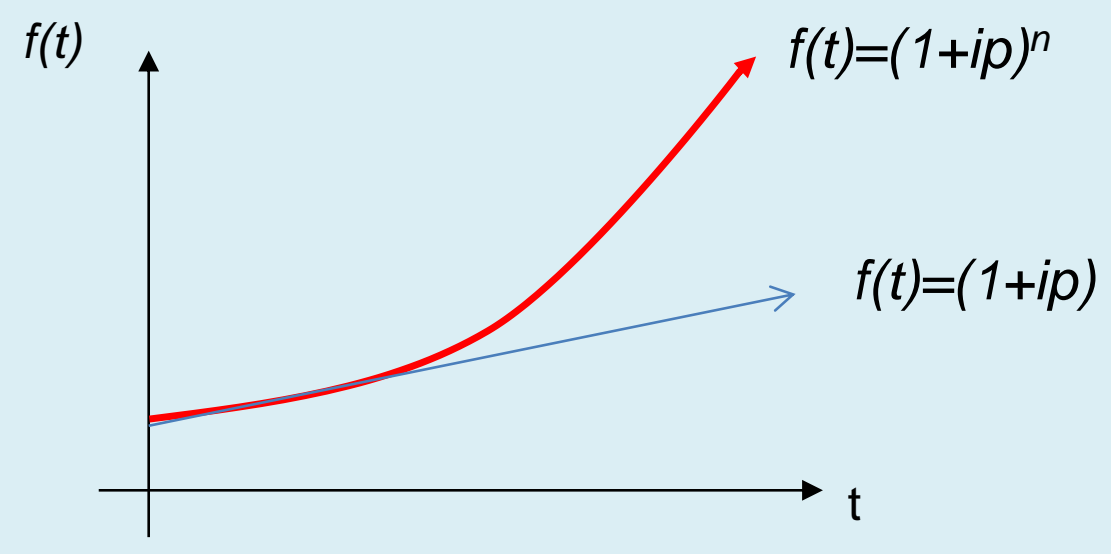

$\checkmark$ If you go far enough to the right (large $t$ ), the compound interest accumulation function lies above the simple interest accumulation function.

$\checkmark$ The simple interest function is larger than the compound interest function until time $t=p$, at which point the compound interest function begins to dominate. 


\section{Price in compound interest with a period $p$}

$$
C^{\prime}=C(1+i p)^{n}
$$

- Total price: this is calculated as the difference between $C$ and C':

$$
I T=\Delta C=C(1+i p)-C=C \cdot i \cdot p
$$

- Unit price: this represents the interest rate earned by one unit of $\mathrm{C}$ :

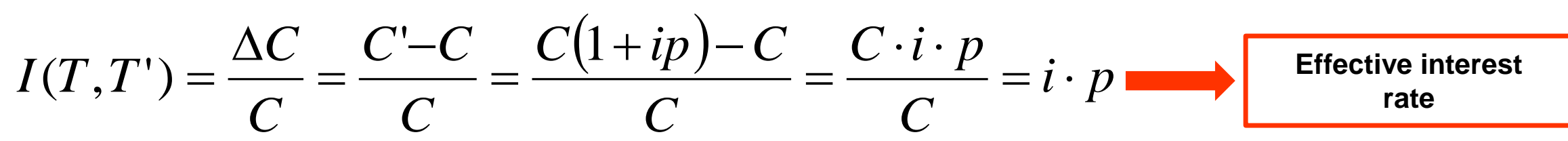

- Unit and medium price: this represents the interest rate earned by one unit of $\mathrm{C}$ over one unit of time:

$$
i\left(T, T^{\prime}\right)=\frac{I\left(T, T^{\prime}\right)}{T^{\prime}-T}=\frac{C^{\prime}-C}{C\left(T^{\prime}-T\right)}=\frac{C \cdot i \cdot p}{C \cdot p}=i \Rightarrow \begin{gathered}
\begin{array}{c}
\text { Nominal interest } \\
\text { rate }
\end{array} \\
.
\end{gathered}
$$


Let's rewrite the previous expressions.

- Total price: $I T=C \cdot i \cdot p$

- Unit price or effective interest rate

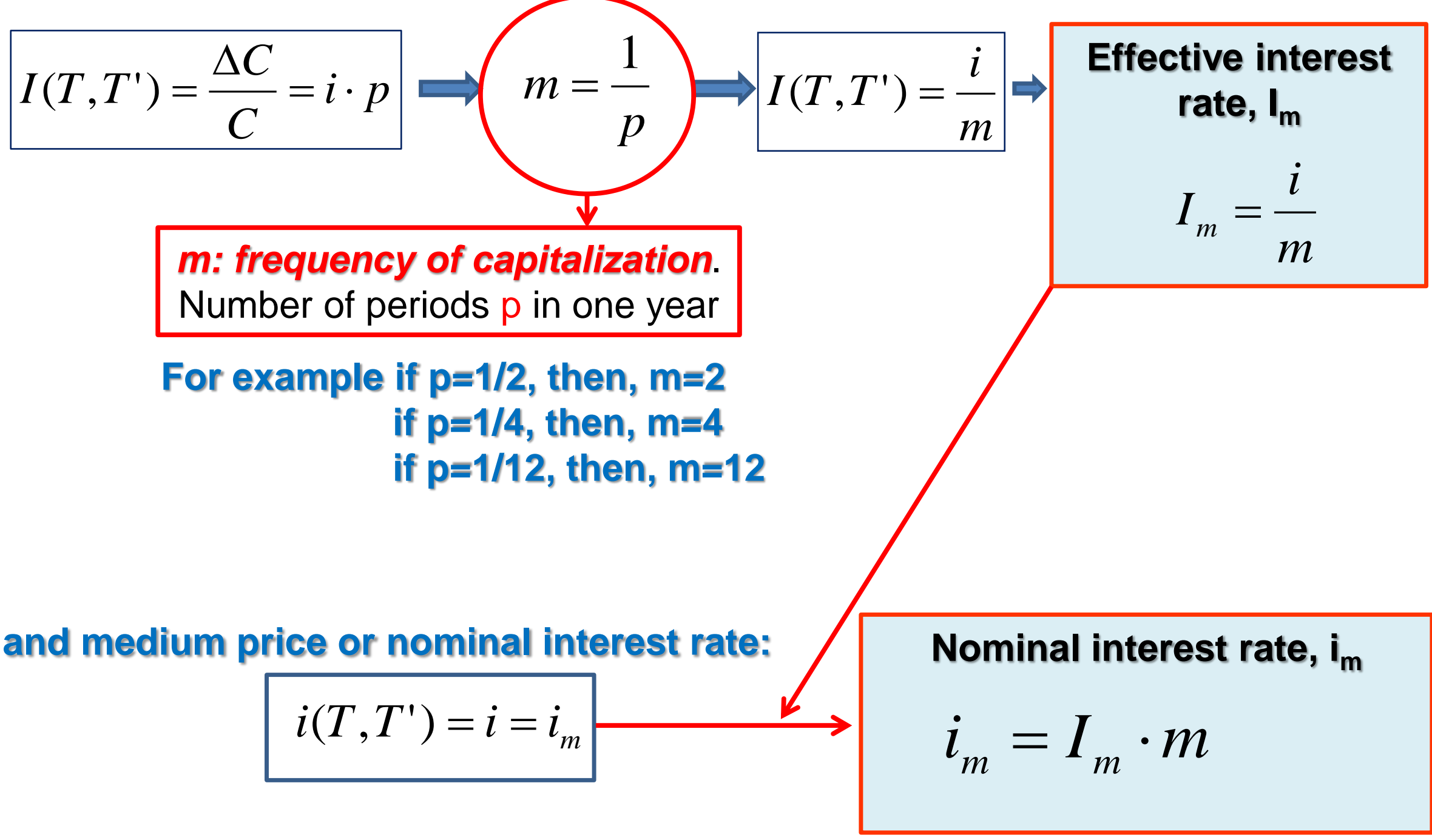

- Unit and medium price or nominal interest rate:

$$
\begin{aligned}
& i\left(T, T^{\prime}\right)=i=i_{r} \\
& i_{m}=I_{m} \cdot m
\end{aligned}
$$


Remember that $\mathbf{n}$ indicates the number of capitalization periods, $p$, over the full length of the financial transaction

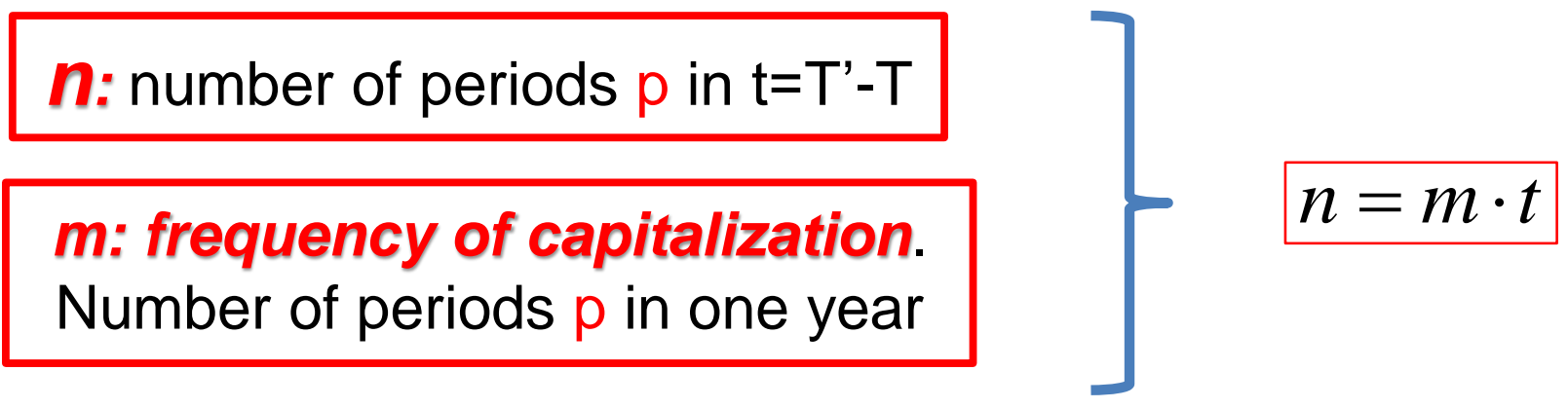

For example, if $p=1 / 2, T=0$ and $T^{\prime}=2.5$ :

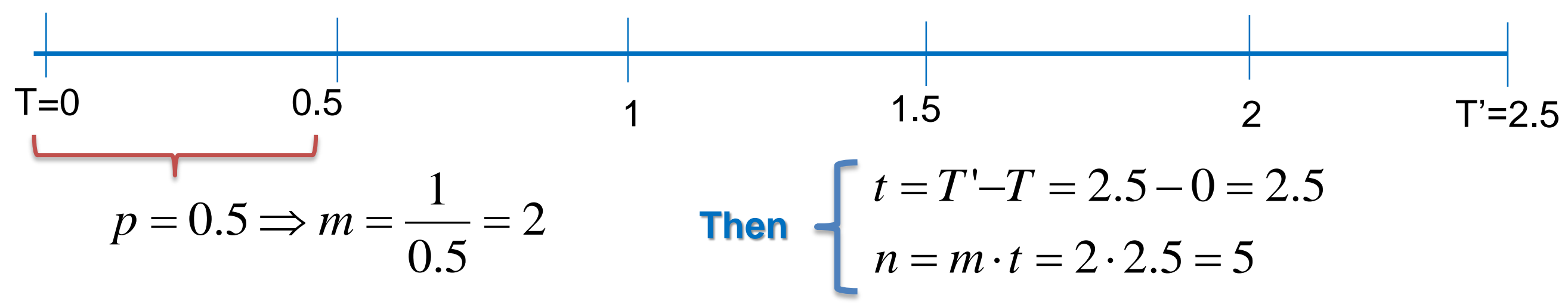

Example 18: Calculate $\mathrm{m}$ and $\mathrm{n}$ for the following situations:

- If $\mathrm{p}=1 / 2, T=0$ and $\mathrm{T}^{\prime}=4$

- If $p=1 / 4, T=0$ and $T^{\prime}=2$

- If $p=1 / 3, T=2$ and $T^{\prime}=5$

- If $p=1 / 6, T=1$ and $T^{\prime}=3$ 
Summarizing the previous results, we now know that for compound interest:

$m=\frac{1}{p}$

Nominal interest rate, $\mathbf{i}_{m}$

$$
i_{m}=I_{m} \cdot m
$$

Effective interest rate, $I_{m}$

$$
I_{m}=\frac{i_{m}}{m}
$$

So,

$$
\begin{gathered}
C^{\prime}=C\left(1+i_{m} p\right)^{n}=\left\{p=\frac{1}{m}\right\}=C\left(1+\frac{i_{m}}{m}\right)^{n}= \\
=\left\{I_{m}=\frac{i_{m}}{m}\right\}=C\left(1+I_{m}\right)^{n} \\
C^{\prime}=C\left(1+I_{m}\right)^{n}
\end{gathered}
$$

So, for the compound interest, the accumulation function is:

$$
f\left(T, T^{\prime}\right)=\frac{C^{\prime}}{C}=\frac{C\left(1+I_{m}\right)^{n}}{C}=\left(1+I_{m}\right)^{n}
$$


Example 19: Fernando deposits $€ 12,000$ in an account with compound interest an annual effective interest rate of $2 \%$. He makes no further deposits or withdrawals until he closes the account six and half years after he opened it. How much money does Fernando receive when he closes the account?

$\mathrm{C}=12,000$

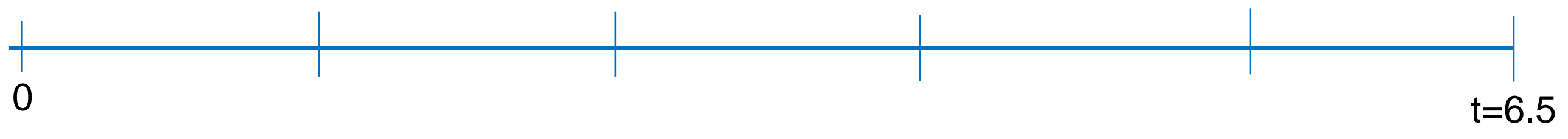

$$
\begin{aligned}
& I_{1}=0.02 \\
& C^{\prime}=C\left(1+I_{m}\right)^{n}= \\
& =12000\left(1+I_{1}\right)^{6.5}=12000(1+0.02)^{6.5}=13648^{\prime} 42 €
\end{aligned}
$$




\section{Example 20:}

Alice invests $€ 2200$. Her investment grows according to compound interest at an annual effective interest rate of $4 \%$ for $T$ years, at which time it has accumulated to $€ 4000$. Find $T$.

\section{Example 21:}

On his fifth birthday Elliot received an inheritance from his aunt. The inheritance has grown to $€ 32,168$ by the time he is 18 . If the money has been growing by compound interest at an annual effective interest rate of $6.2 \%$, find the amount of the inheritance.

\section{Example 22:}

Horatio invests money in an account that earns compound interest at an unknown annual effective interest rate. His money doubles in nine years. Find $\mathrm{I}_{1}$.

\section{Example 23:}

How much interest is earned in the fourth year by $€ 1000$ invested under compound interest at an annual effective interest rate of $5 \%$ ? 


\section{Effective rates and nominal rates}

In previous slides I introduced the nominal interest rate, $i_{m}$, and the effective interest rate, $I_{m}$.
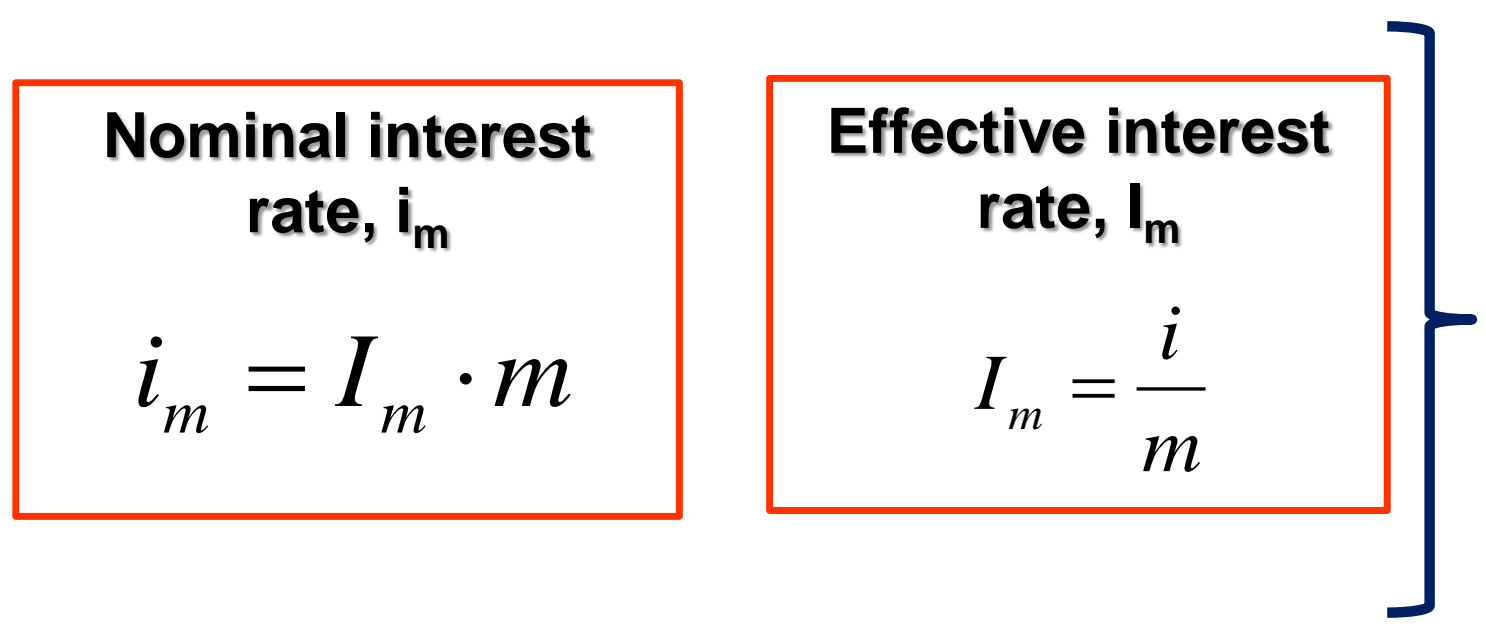

We obtained a relationship between the nominal interest rate and

effective interest rate that depends on $\boldsymbol{m}$ ( frequency of capitalization).

We refer to $i_{m}$ as a nominal (annual) interest rate compounded or payable $\mathrm{m}$ times per year.

We refer to $i_{1}=I_{1}$ as the "annual percentage yield".

Example 24: The National Bank advertises a savings account paying $4 \%$ nominal interest compounded quarterly. What is the quarterly effective interest rate?

$$
\begin{gathered}
i_{4}=0.06 \Rightarrow I_{4}=? \\
I_{m}=\frac{i_{m}}{m} \\
I_{4}=\frac{i_{4}}{4}=\frac{0.06}{4}=0.015
\end{gathered}
$$


So, in the exercises, the interest can be expressed as an effective rate or as a nominal rate. Obviously, it is necessary to indicate the capitalization frequency $\mathrm{m}$.

\section{Effective interest rate:}

Annual effective rate $\rightarrow I_{1}$

Monthly effective rate $\rightarrow I_{12}$

Quarterly effective rate $\rightarrow I_{4}$

\section{Nominal interest rate:}

Nominal interest rate compounded/payable annually $\rightarrow i_{1}$

Nominal interest rate compounded/payable monthly $\rightarrow i_{12}$

Nominal interest rate compounded/payable quarterly $\rightarrow i_{4}$

In the formula, we use the effective interest rate

$\Rightarrow C^{\prime}=C\left(1+I_{m}\right)^{n}$

So, remember that

$$
I_{m}=\frac{i_{m}}{m}
$$




\section{Example 25:}

Pam deposits $€ 17,500$ in an account with compound interest. She makes no further deposits or withdrawals until she closes the account six and a half years after she opened it. How much money does Pam receive when she closes the account if:

- The account is governed by a monthly effective interest rate of $1 \%$ ?

- The account is governed by a quarterly (every three months) effective interest rate of $2 \%$ ?

- The account is governed by a biannual effective interest rate of $1 \%$ ?

- The account is governed by an annual effective interest rate of $1 \%$ ?

- The account is governed by a triannual/four-monthly effective interest rate of $1 \%$ ?

\section{Example 26:}

Find the accumulated value of $€ 3000$ to be paid at the end of 8 years with a $5 \%$ nominal interest rate compounded:

- Annually.

- Quarterly.

- Monthly. 


\section{Discount functions / the time value of money}

An amount invested now (C) will grow to $C^{\prime}$ in t years. For compound interest, we know that:

$$
C^{\prime}=C\left(1+I_{m}\right)^{n}
$$

Observe that if we find $\mathrm{C}$ :

$$
C=C^{\prime} \cdot \frac{1}{\left(1+I_{m}\right)^{n}}
$$

So $C$ is the amount of money you must invest at time 0 to have $C^{\prime}$ after $n$ periods.

This leads us to define the discount function as:

$$
v=\frac{1}{\left(1+I_{m}\right)^{n}}=\left(1+I_{m}\right)^{-n}
$$

where the value $v$ is the amount you must invest at time 0 to have $€ 1$ after $n$ periods. 


\section{Example 27:}

Imagine that the growth of money over the next three years is governed by compound interest at an annual effective interest rate of $5 \%$. How much money should you invest now in order to have a balance of 23,000 three years from now?

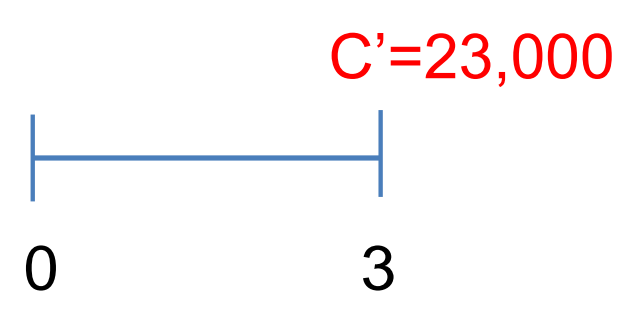

$$
C=\frac{23,000}{(1+0.05)^{3}}=23,000 \cdot(1+0.05)^{-3}=19,868.26
$$

In this example, the discount function is:

$$
v=\frac{1}{(1+0.05)^{3}}=(1+0.05)^{-3}
$$


Now, we can generalize the definition of the discount function.

In the previous definition we assumed compound interest, i.e., we assumed that:

$$
f\left(T, T^{\prime}\right)=\left(1+I_{m}\right)^{n}
$$

Now, we can assume a general accumulation function: $\mathrm{f}\left(\mathrm{T}, \mathrm{T}^{\prime}\right)$.

So, the discount function is now:

$$
v=\frac{1}{f\left(T, T^{\prime}\right)} \stackrel{\text { For simple interest }}{\longrightarrow} v=\frac{1}{(1+i t)}
$$

\section{Example 28:}

Imagine that the growth of money over the next three years is governed by simple interest at $5 \%$. How much money should you invest now in order to have a balance of 23,000 three years from now?

$$
\begin{array}{ccc}
C^{\prime}=23,000 & C^{\prime}=C(1+i t) \Rightarrow C=\frac{C^{\prime}}{(1+i t)}=C^{\prime}(1+i t)^{-1} \\
0 & 3 & C=23,000 \cdot(1+0.05 \cdot 3)^{-1}=20,000 \\
& & v=\frac{1}{(1+i \cdot t)}=\frac{1}{(1+0.05 \cdot 3)}
\end{array}
$$


We next introduce present value.

\section{Present value}

The present value is the current worth of a future sum of money given a specified accumulation function.

\section{Example 29:}

What is the present value of $€ 2000$ to be paid in four years assuming money grows by compound interest at an annual effective interest rate of $6 \%$ ? What if money grows by compound interest at a nominal interest rate payable monthly of $3 \%$ ?

2000

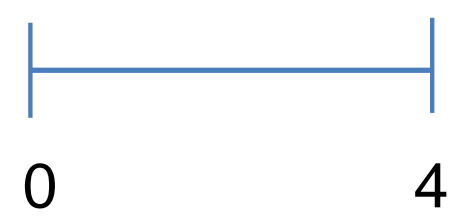

$$
\begin{gathered}
I_{1}=0.06 \\
P V=2000 \cdot(1+0.06)^{-4}=€ 1584.19
\end{gathered}
$$$$
i_{12}=0.03 \Rightarrow I_{12}=\frac{i_{12}}{12}=\frac{0.03}{12}=0.0025
$$$$
P V=2000 \cdot(1+0.0025)^{-48}=€ 1774.10
$$ 


\section{Example 30:}

Brian and Jennifer each take out a loan of value $\mathrm{X}$. Jennifer will repay her loan by making one payment of $€ 800$ at the end of year 10. Brian will repay his loan by making one payment of $€ 1120$ at the end of year 8 . The nominal interest rate payable quarterly is $3 \%$. Calculate the principal of the loan in both cases.

\section{Example 31:}

What deposit made today will provide for a payment of $€ 1000$ in 1 year and $€ 2000$ in 3 years, if the effective rate of interest is $7.5 \%$ ?

\section{Example 32:}

It is known that an investment of $€ 500$ will increase to $€ 4000$ at the end of 30 years under compound interest. Find the sum of the present value of three payments of $€ 10,000$ at the end of 20,40 and 60 years. 


\section{Equivalent effective rates}

Suppose a financial transaction in compound interest payable $m$ times per year, with an $\mathrm{m}$ effective interest rate

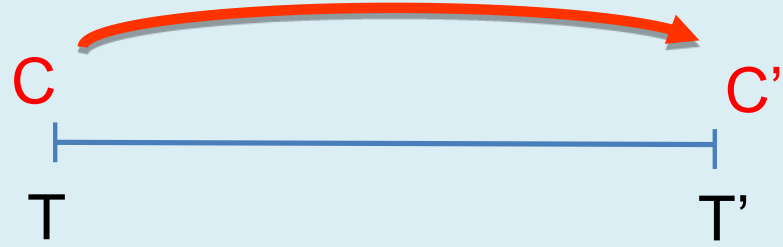

where $n$ is the number of periods $p$ in $t=T^{\prime}-T$, and $n=m . t$. Now, we know that:

$$
C^{\prime}=C\left(1+I_{m}\right)^{n}=C\left(1+I_{m}\right)^{m \cdot t}
$$

For example, suppose $\mathrm{C}=€ 100, \mathrm{t}=3$ and $\mathrm{m}=4$; then $p=1 / 4$ and so $n \equiv 12$. The quarterly effective interest rate is $I_{4}=0.02$

So:

$$
\begin{aligned}
C^{\prime} & =100\left(1+I_{4}\right)^{12}= \\
& =100(1+0.02)^{12}=€ 126.82
\end{aligned}
$$

Suppose a financial transaction in compound interest payable $\mathrm{m}^{\prime}$ times per year, with an m'effective interest rate

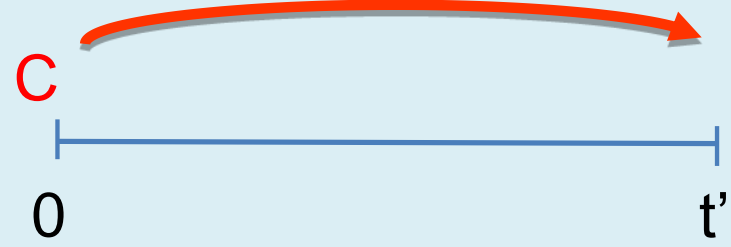

where $n^{\prime}$ is the number of periods $p^{\prime}$ in $t=T^{\prime}-T$, and $n^{\prime}=m^{\prime}$.t. Now, we know that:

$$
C^{\prime}=C\left(1+I_{m^{\prime}}\right)^{n^{\prime}}=C\left(1+I_{m^{\prime}}\right)^{m^{\prime} \cdot t}
$$

For example, suppose $\mathrm{C}=€ 100, \mathrm{t}=3$ and $m^{\prime}=12$; then $p=1 / 12$ and so $n^{\prime}=36$. The monthly effective interest rate is $I_{12}=0.006622$ So:

$$
\begin{aligned}
C^{\prime} & =100\left(1+I_{12}\right)^{36}= \\
& =100(1+0.006622)^{36}=€ 126.82
\end{aligned}
$$

As you can see, $I_{4}=0.02$ and $I_{12}=0.006622$ give the same accumulated value.

So, these two effective interest rates are equivalent.

$$
I_{4} \sim I_{12}
$$


If we generalize,

$$
\begin{array}{ll}
C^{\prime}=C\left(1+I_{m}\right)^{m \cdot t} & C^{\prime}=C\left(1+I_{m^{\prime}}\right)^{m^{\prime} \cdot t} \\
\frac{C^{\prime}}{C}=\left(1+I_{m}\right)^{m \cdot t} & \frac{C^{\prime}}{C}=\left(1+I_{m^{\prime}}\right)^{m^{\prime} \cdot t}
\end{array}
$$

To obtain equivalent interest rates, C'/C must be equal. So,

$$
\begin{gathered}
\left(1+I_{m}\right)^{m \cdot t}=\left(1+I_{m^{\prime}}\right)^{m^{\prime} \cdot t} \\
\left(1+I_{m}\right)=\left(1+I_{m^{\prime}}\right)^{\frac{m^{\prime} \cdot t}{m \cdot t}} \\
\left(1+I_{m}\right)=\left(1+I_{m^{\prime}}\right)^{\frac{m^{\prime}}{m}} \\
I_{m}=\left(1+I_{m^{\prime}}\right)^{\frac{m^{\prime}}{m}}-1
\end{gathered}
$$

This is the formula to obtain equivalent effective interest rates

$$
I_{m}=I_{m^{\prime}}
$$

In our example, $I_{4}=0.02$ If we want to obtain the equivalent monthly effective interest rate:

$$
\begin{aligned}
& I_{12}=\left(1+I_{4}\right)^{\frac{4}{12}}-1 \\
& I_{12}=(1+0.02)^{\frac{4}{12}}-1=0.006622
\end{aligned}
$$


Example 33: The National Bank advertises a savings account paying $4 \%$ nominal interest compounded quarterly. What is the annual effective yield (APY) for this account?

$$
\begin{gathered}
i_{4}=0.06 \Rightarrow I_{1}=? \\
I_{m}=\frac{i_{m}}{m} \\
I_{4}=\frac{i_{4}}{4}=\frac{0.06}{4}=0.015
\end{gathered}
$$

And to obtain APY, we use:

$$
I_{m}=\left(1+I_{m^{\prime}}\right)^{\frac{m^{\prime}}{m}}-1
$$

$$
I_{1}=\left(1+I_{4}\right)^{\frac{4}{1}}-1=(1+0.015)^{4}-1=0.061363
$$

Example 34: The National Bank advertises a savings account paying $2 \%$ annual effective yield. What is the nominal interest rate compounded monthly for this account?

Example 35: Given a nominal interest rate of $12 \%$ compounded monthly, find the equivalent effective annual interest rate. 


\section{Example 36}

Joe invests money in a fund. The effective interest rate per two-year period is $14 \%$. Find the nominal interest rate convertible biennially and the annual effective interest rate governing the fund ${ }^{*}$.

$$
\begin{aligned}
& I_{\frac{1}{2}}=0.14 \Rightarrow\left\{\begin{array}{l}
i_{1}=? \\
\frac{2}{2} \\
I_{1}=?
\end{array}\right. \\
& I_{\frac{1}{2}}=\frac{i_{\frac{1}{2}}}{\frac{1}{2}} \Rightarrow i_{\frac{1}{2}}=\frac{1}{2} \cdot 0.14=0.07 \\
& I_{1}=\left(1+I_{\frac{1}{2}}\right)^{\frac{1}{2}}-1=(1+0.14)^{\frac{1}{2}}-1=0.0677 \approx 6.77 \%
\end{aligned}
$$

*Biennially means once every two years. Semiannually means twice a year

\section{Example 37:}

a) Find the annual effective interest rate which is equivalent to a nominal interest rate of $8 \%$ compounded quarterly.

b) Find the nominal interest rate compounded semiannually which is equivalent to an annual effective rate of $8 \%$.

c) Find the interest rate compounded quarterly which is equivalent to an interest rate of $8 \%$ payable semiannually. 


\section{Problems: compound interest}

\section{Example 38:}

You invest $€ 10,000$ at time 0 into each of two accounts. Account $A$ earns interest at an annual simple interest rate of $8 \%$. Account $B$ earns interest at an effective annual compound interest rate of $6 \%$. What is the difference in the amount of interest earned during the $5^{\text {th }}$ year in these two accounts?

\section{Example 39:}

On January $1^{\text {st }} 2009$, you invest $€ 500$ in an account earning an $8 \%$ monthly effective interest rate. On January $1^{\text {st }} 2011$, you deposit an additional $€ 1000$ into the account. What is the accumulated value of your account on January $1^{\text {st }} 2014$ ?

\section{Example 40:}

Today Mary deposits $€ 1750$ into an account that earns compound interest at the monthly effective interest rate of $2 \%$. In six months' time, Mary will deposit an additional $€ 1000$; and in a year, she will deposit $€ 200$. Find the accumulated value of the account in two and a half years.

\section{Example 41:}

In the previous example, if Mary withdraws $€ 300$ in eight months, find the accumulated value of the account in two and a half years.

\section{Example 42:}

On January $1^{\text {st }} 2010$, you invest $€ 3500$ in an account earning $6 \%$ annual effective interest. On January $1^{\text {st }} 2011$, you deposit an additional $€ 500$ into the account; and on January $1^{\text {st }} 2012$, you withdraw $€ 460$. What is the accumulated value of your account on January 1 st 2013 ? 


\section{Varying interest rates}

In this type of agreement, the interest rate is not the same during the financial transaction. That is to say, we consider situations involving varying interest.

For example...

\section{Example 43:}

Bob invests $€ 1000$ in an account that earns compound interest paid at different interest rates. During the first two years, the annual effective rate of compound interest rate is $3 \%$. The following two years, it is 3.5\%; and the last year it is $4 \%$. How much money does Bob receive when he closes the account?

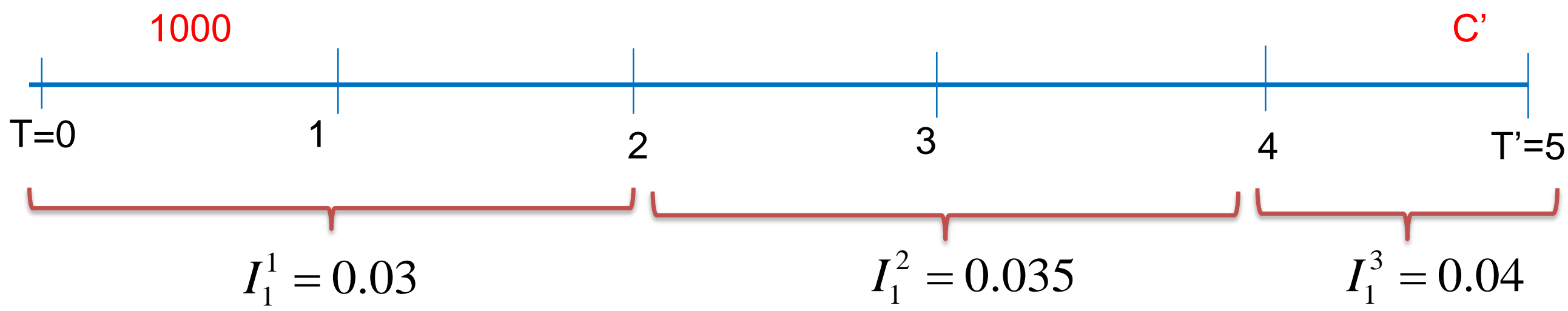


To solve this kind of problems it is necessary to use a different accumulation function for each period with a different rate of interest.

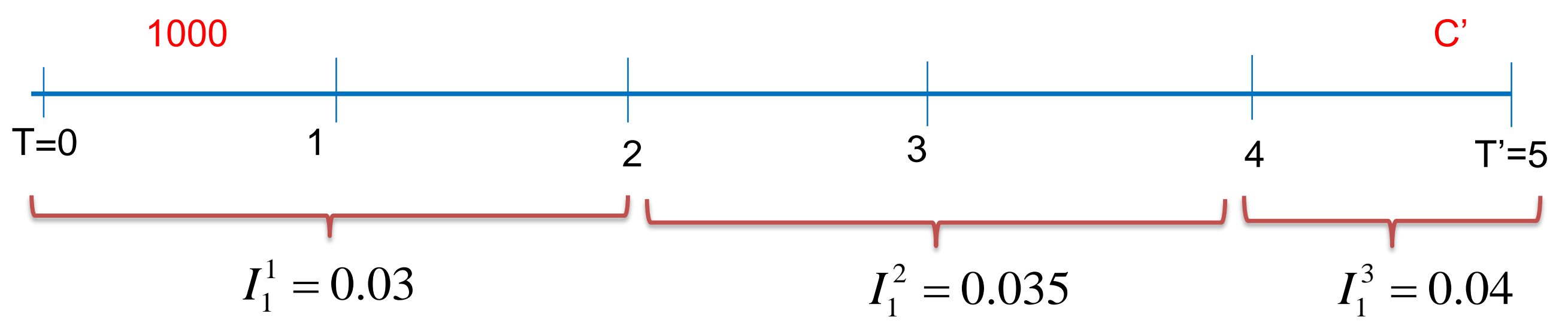
$(1+0.03)^{2}$
$(1+0.035)^{2}$
$(1+0.04)^{1}$

$C^{\prime}=1000(1+0.03)^{2}(1+0.035)^{2}(1+0.04)^{1}=€ 1181.92$ 


\section{Example 44:}

Arisha deposits $€ 8000$ in a savings account at the Victory Bank. For the first three years, the annual effective rate of compound interest paid is 5\%. For the next two years it is 5.5\%; and for the following four years it is $6 \%$. If Arisha closes her account after nine years, what will her balance be?

\section{Example 45:}

Sean deposits $€ 826$ in a savings account that earns interest at varying interest rates. For the first three years, the annual effective interest rate is $3 \%$. For the next two years, the monthly effective interest rate is $4 \%$; and for the following five years, the quarterly effective interest rate is $5 \%$. What is Sean's balance at the end of ten years?

\section{Example 46:}

Bob opens an account governed by compound interest with $€ 3500$. He deposits $€ 750$ three and a half years after opening it. For the next half a year, the monthly effective interest is $2 \%$; while for the rest of the time, the nominal interest compounded semiannually is $1.5 \%$. Find the accumulated value after five years.

\section{Example 47:}

An account is governed by compound interest. The annual effective interest for the first two years is $4 \%$. For the next three years the quarterly effective interest rate is $2 \%$; and for the last year the monthly effective interest rate is $1 \%$. Find the accumulated value at the end of six years if the initial amount is $€ 4600$ and two years later a deposit of $€ 3000$ is made. 


\section{An equivalent annual effective yield, $I_{1}^{*}$}

It is possible to find a fixed annual effective interest rate that is equivalent to several interest rates. A common issue involving varying interest is that of finding a stable rate equivalent to the rate that varies. We focus our attention on finding an annual effective interest rate.

Example 48: Suppose that in an account governed by compound interest, the monthly effective rate for the first year is 3\%; and for the second year, the annual effective rate is $5 \%$. Find the accumulated value if the initial amount is $€ 100$.

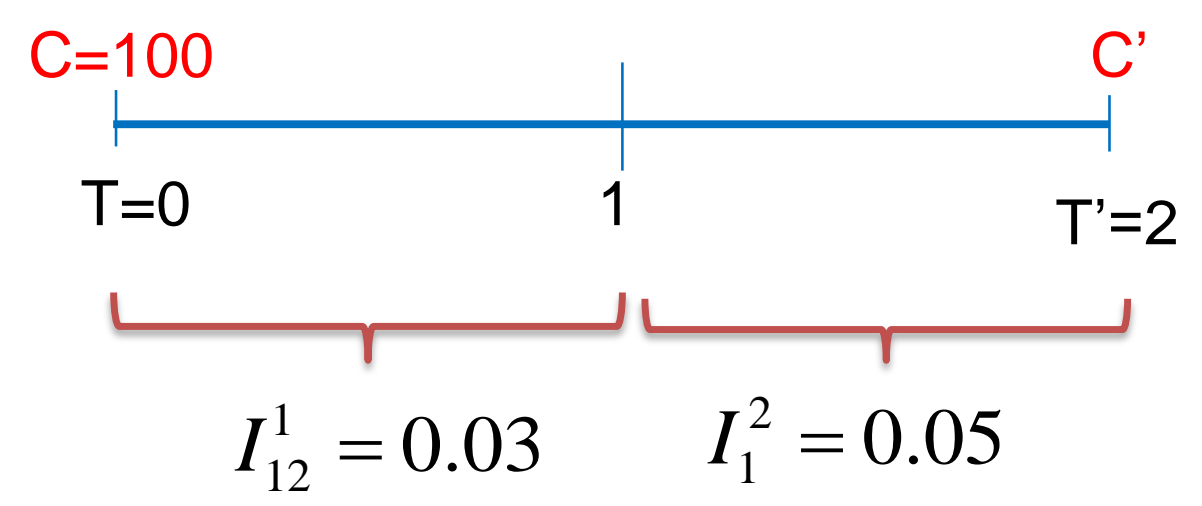

$$
C^{\prime}=100(1+0.03)^{12}(1+0.05)^{1}=149.7
$$


Now, we know $(100,0)-(149.7,2)$ under the varying interest rate.

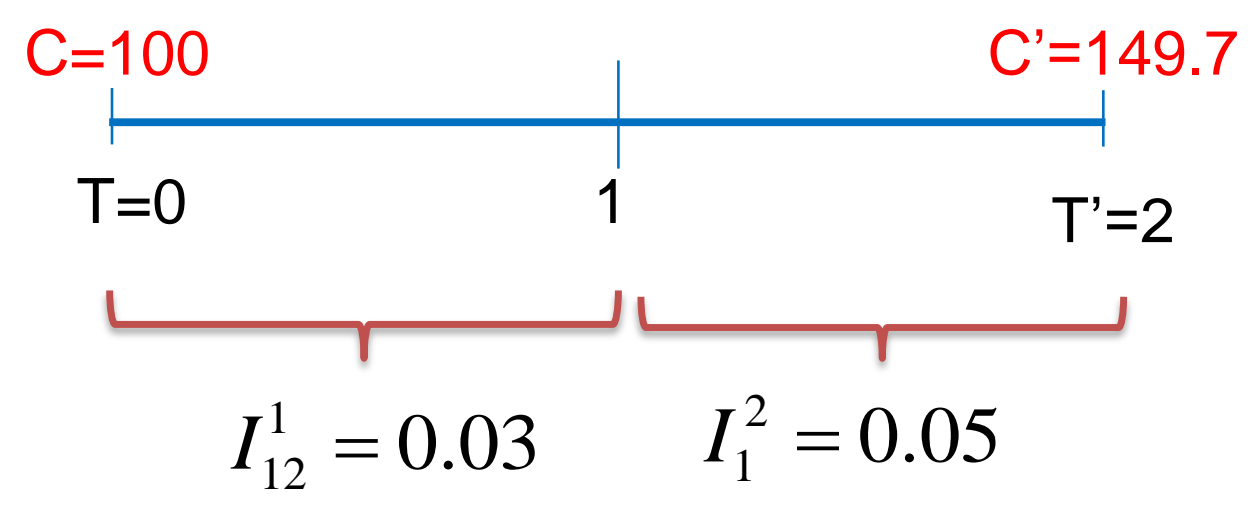

The question is: what is the financially equivalent fixed annual effective rate?

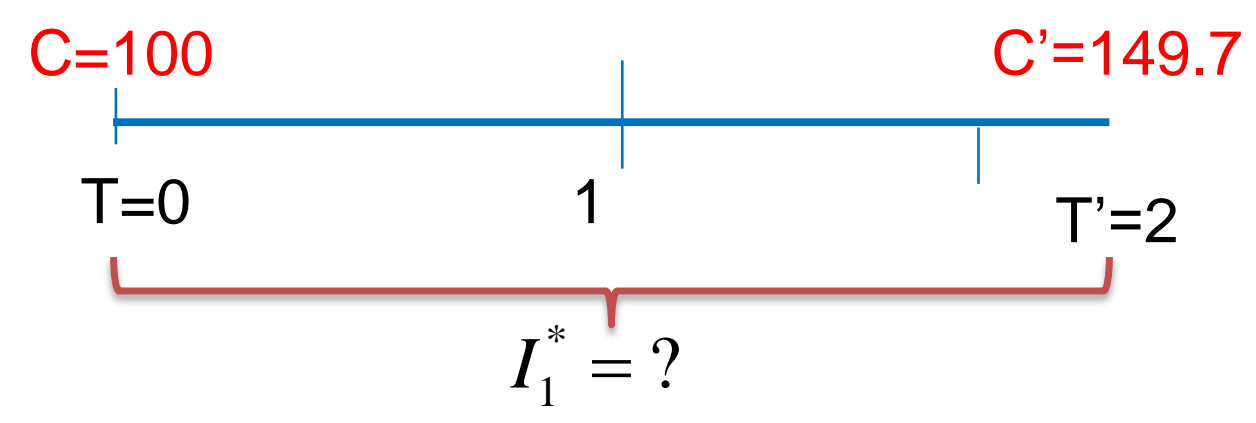

$$
\begin{gathered}
149.7=100\left(1+I_{1}\right)^{2} \\
\frac{149.7}{100}=\left(1+I_{1}\right)^{2} \\
I_{1}=\left(\frac{149.7}{100}\right)^{\frac{1}{2}}-1=0.22351 \approx 22.35 \% \rightarrow \begin{array}{c}
I_{1}^{*}=22.35 \% \\
\text { This is the equivalent } \\
\text { annual effective yield }
\end{array}
\end{gathered}
$$


Example 49: For a fourteen-year investment, what stable annual effective rate of interest gives the same accumulation as an annual effective rate of interest of $5 \%$ for eight years followed by a monthly effective interest rate of interest $0.6 \%$ for six years?

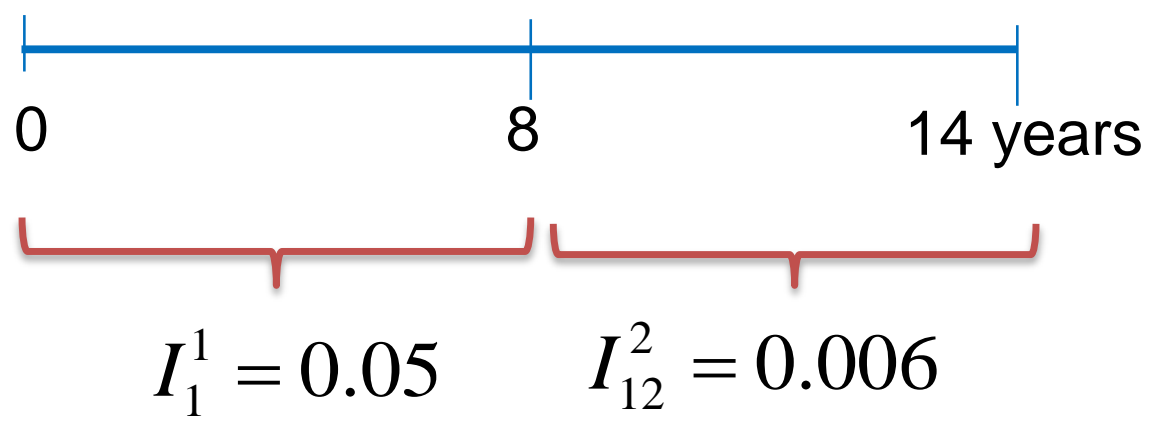

$$
\begin{gathered}
(1+0.05)^{8}(1+0.006)^{72}=\left(1+I_{1}^{*}\right)^{14} \\
2.272840=\left(1+I_{1}^{*}\right)^{14} \\
I_{1}^{*}=2.272840^{\frac{1}{14}}-1=0.06039
\end{gathered}
$$

Example 50: Find the effective interest rate over a three-year period which is equivalent to an effective rate of $8 \%$ the first year, $7 \%$ the second year, and $6 \%$ the third year. 


\section{Interest in advance}

Up to now, the rate of interest has been defined as a measure of the interest paid at the end of the period.

In this section, we introduce the rate of discount (d) which is a measure of interest, where the interest is paid at the beginning of the period.

Here, when $\mathbf{C}$ is borrowed at a discount rate of $\mathbf{d}$, the borrower will have to pay $\mathbf{C} . \mathbf{d}$ in order to receive $\mathbf{C}$. So, the borrower does not have use of $\mathbf{C}$ at the beginning of the period, they only have the use of $\mathbf{C}-\mathbf{C d}$.

Thus, the lender is getting the interest in advance from the borrower.

Example 51: Bob borrows $€ 1000$ at a discount rate of $7 \%$. How much money does he actually have the use of?

Solution: In order to get the $€ 1000$, he must first pay $C \cdot d$ :

$$
€ 1000 \cdot 0.07=€ 70
$$

So Bob has the use of $\quad(C-C \cdot d)$

$$
€ 1000-€ 1000 \cdot 0.07=€ 930
$$




\section{Simple discount}

$>$ The total price depends on the final amount and on the length of the transaction. The price is directly proportional to both these factors, and the rate is what determines this relationship, the discount rate $d>0$.

So, the total price is

$$
D T=\Delta C=C^{\prime}-C=C^{\prime} \cdot d \cdot\left(T^{\prime}-T\right)=C^{\prime} \cdot d \cdot t
$$

$>$ The price is paid at the beginning of the financial transaction, at $\mathrm{T}$,

$$
\begin{gathered}
C=C^{\prime}-D T=C^{\prime}-d \cdot C^{\prime} \cdot t=C^{\prime}(1-d t) \\
C=C^{\prime}(1-d t)
\end{gathered}
$$

That is to say, under the discount model, payment for the use of the money is deducted at the beginning of the period. 
Then:

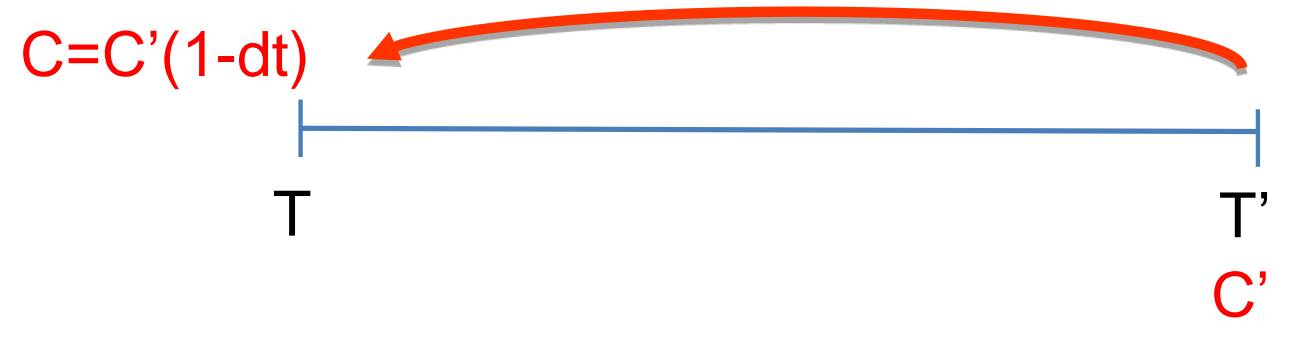

Remember that the accumulation function $f\left(T, T^{\prime}\right)$ is:

$$
f\left(T, T^{\prime}\right)=\frac{C^{\prime}}{C} \Rightarrow C^{\prime}=C \cdot f\left(T, T^{\prime}\right)
$$

So, for a simple discount:

$$
f\left(T, T^{\prime}\right)=\frac{C^{\prime}}{C^{\prime}(1-d t)}=\frac{1}{1-d t}
$$

So, the simple discount accumulation function at rate $d$ is:

$$
f\left(T, T^{\prime}\right)=\frac{1}{1-d t}
$$


Graph of the accumulation function $\quad f\left(T, T^{\prime}\right)=f(t)=\frac{1}{1-d t}$

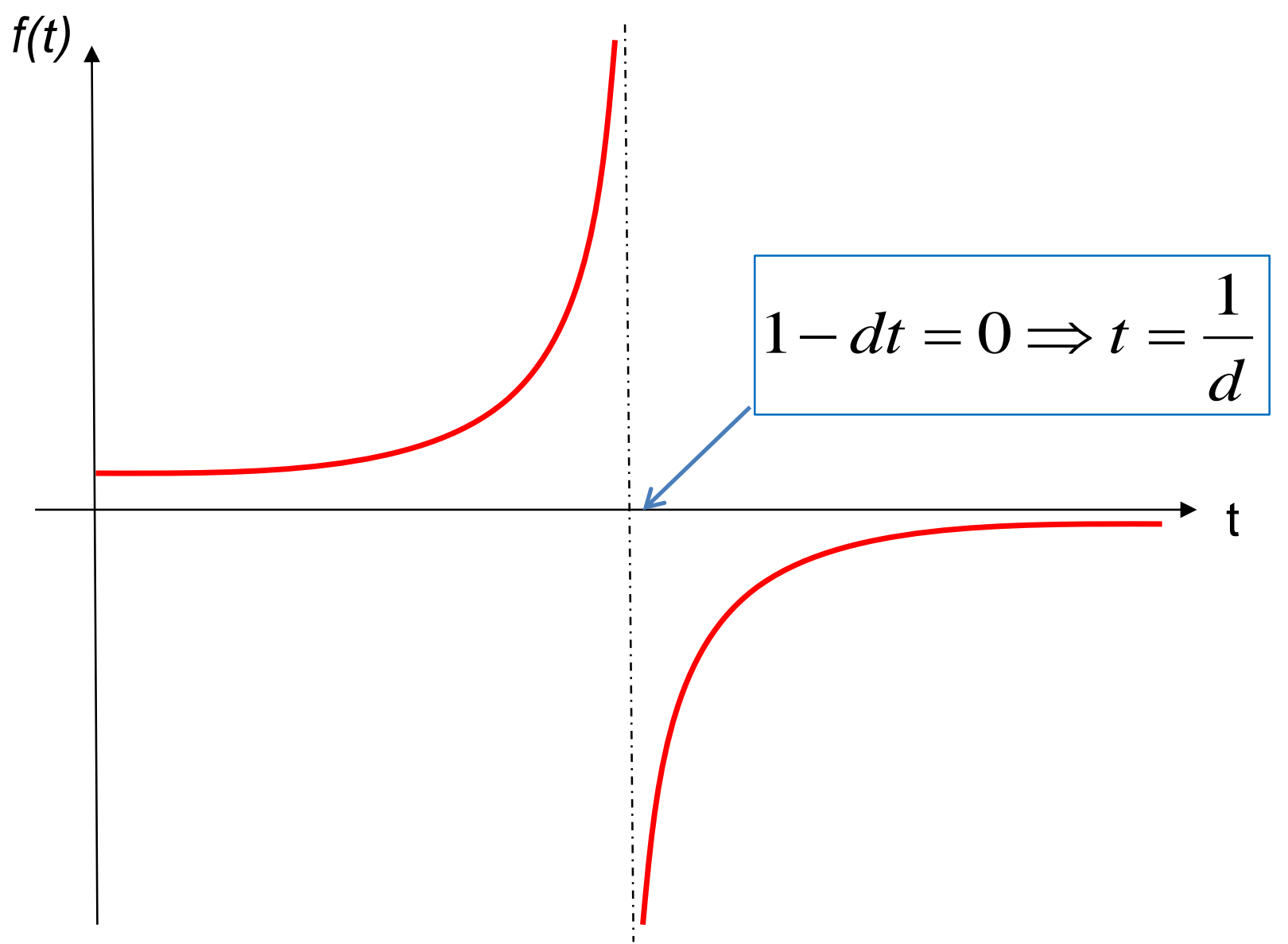

The accumulation function is an increasing function that is asymptotic at the line $t=\frac{1}{d}$

Therefore, it only makes sense to talk about simple discount if $t<\frac{1}{d}$ 


\section{Definition: trade bills}

These give the owner the right to receive, on a fixed date (due date) and in the short term, an amount of money (face value).

Bills can be sold at a discounted rate compared to their face value. For instance, you could pay $€ 990$ for a bill with a face value of $€ 1000$. Then, when the bill matures, you will receive $€ 1000$. The difference between the price you pay $(€ 990)$ and the face value $(€ 1000)$ is the interest.

That is to say, if you have a trade bill and you need cash, you can go to the bank to "sell" it. The bank deducts interest according to the time remaining till the due date, and you receive a cash amount. In this financial transaction the agreement is based on a simple discount.

\section{d: discount rate}

C: Cash amount

(€990)

$$
C=C^{\prime}(1-d t)
$$

(€1000) 
Example 52: You have a trade bill with a face value of $€ 1000$. You need cash, and you go to the bank to trade it. The bank offers you a simple discount agreement at an annual discount rate of $5 \%$. How much money will you receive from the bank today if the due date is in three months?

Cash amount

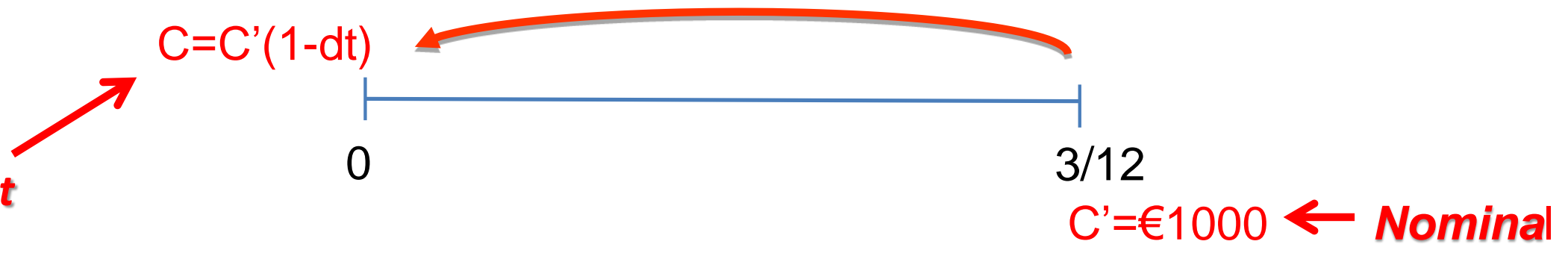

$$
C=C^{\prime}(1-d t)=€ 1000\left(1-0.05 \cdot \frac{3}{12}\right)=€ 987.5
$$

Example 53: Today, a trade bill with a face value of $€ 2560$ and due date in seven months is discounted. If the bank applies a simple discount agreement at $3 \%$, how much money do you receive?

Example 54: The cash obtained by the discount of a trade bill is $€ 1000$. Find the face value if the due date is in 5 months and the discount rate applied is $2 \%$.

Example 55: The cash obtained by the discount of a trade bill is $€ 725$. The face value is $€ 775$, and the due date is in 3 months. Find the discount rate, $d$. 


\section{Example 56: Discounting expenses}

A company has a bill portfolio with a face value of $€ 20,000$ with a due date in 8 months. The bank discounts the portfolio in a simple discount agreement at $3 \%$. The financial transaction involves expenses of $0.2 \%$ of the face value. How much money does the company receive?

\section{Solution:}

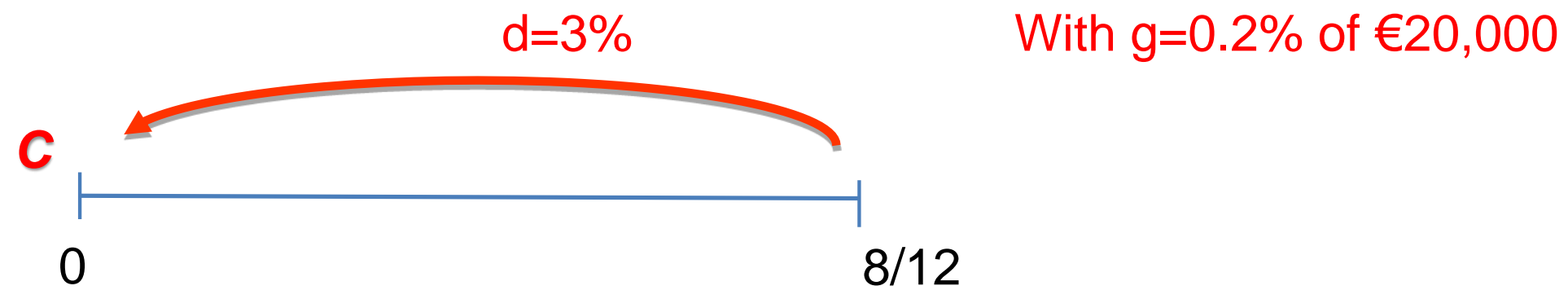

- Without expenses:

$$
C^{\prime}=20000
$$

$$
C=€ 20,000\left(1-0.03 \frac{8}{12}\right)=€ 1960
$$

- Discounting expenses:

$$
C=€ 20,000\left(1-0.03 \frac{8}{12}\right)-0.002 \cdot € 20,000=€ 1920
$$

Obviously, you receive a smaller amount because you have to pay the expenses. 
Example 57: Bob has a bill portfolio with a face value of $€ 2600$. Forty per cent of the portfolio matures in six months, and the rest in 9 months. The bank discounts the portfolio in a simple discount agreement at $1.5 \%$. The financial transaction involves expenses of $0.2 \%$ of the face value. How much money does Bob receive? 


\section{Price in the simple discount agreement}

$$
C=C^{\prime}(1-d t)
$$

- Total price: this is calculated as the difference between $C^{\prime}$ and $C$

$$
D T=\Delta C=C^{\prime}-C=C^{\prime}-C^{\prime}(1-d t)=C^{\prime} \cdot d \cdot t
$$

- Unit price: this represents the interest rate earned by one unit of C'.

$$
D\left(T, T^{\prime}\right)=\frac{\Delta C}{C^{\prime}}=\frac{C^{\prime}-C}{C^{\prime}}=\frac{C^{\prime} \cdot d \cdot t}{C^{\prime}}=d \cdot t
$$

- Unit and medium price: this represents the interest rate earned by one unit of $C^{\prime}$ in one unit of time

$$
d\left(T, T^{\prime}\right)=\frac{C^{\prime}-C}{C^{\prime}\left(T^{\prime}-T\right)}=\frac{C^{\prime} \cdot d \cdot t}{C^{\prime} \cdot t}=d
$$




\section{Example 58: Price in simple discount}

A trade bill with a face value of $€ 9000$ and due date in two months is discounted. If the bank applies a simple discount agreement at 3\%, how much money do you receive? Calculate the total price, the unit price, and the unit and medium price.

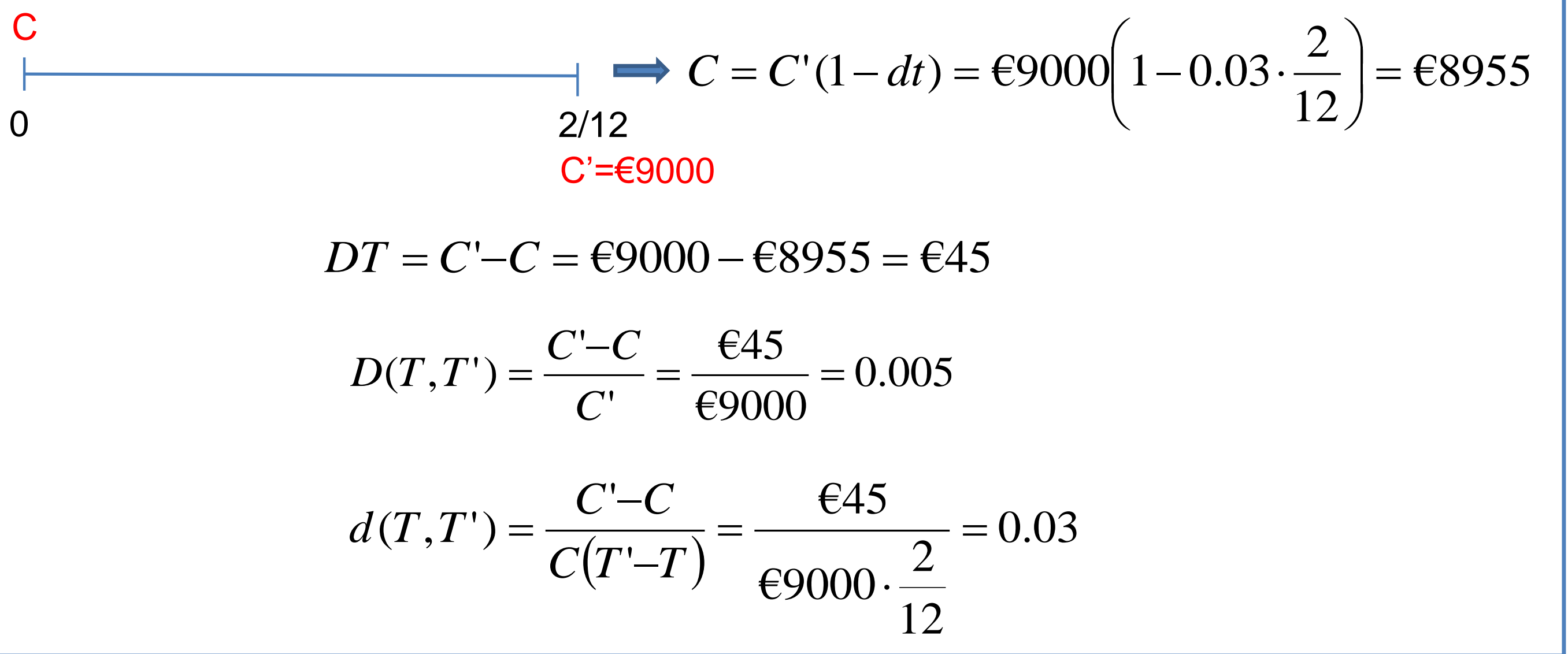

Example 59: The cash obtained by the discount of a trade bill is $€ 6350$. Find the face value if the due date is in 6 months and the discount rate applied is $2.5 \%$. Calculate the total price, the unit price, and the unit and medium price. 


\section{Analogous simple interest rate (i) and simple discount rate (d)}

Imagine a financial transaction applying simple interest at interest rate $i$,

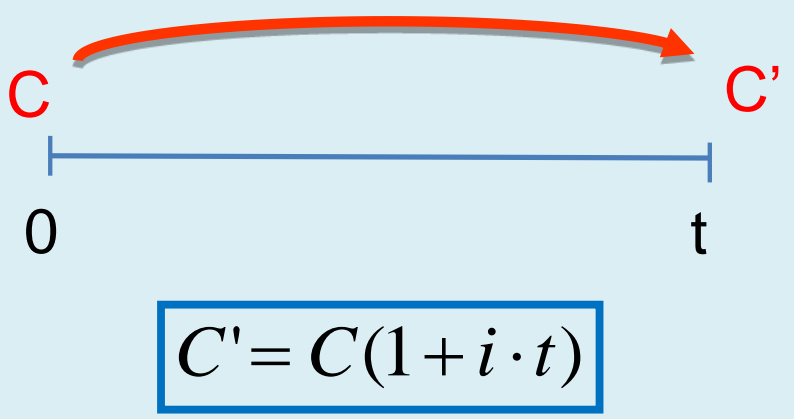

For example, suppose $\mathrm{C}=€ 100, \mathrm{t}=3$ and $\mathrm{i}=0,03$ .Then C' is:

$$
C^{\prime}=€ 100(1+0.03 \cdot 3)=€ 109
$$

Imagine a financial transaction applying simple discount at discount rate $d$,

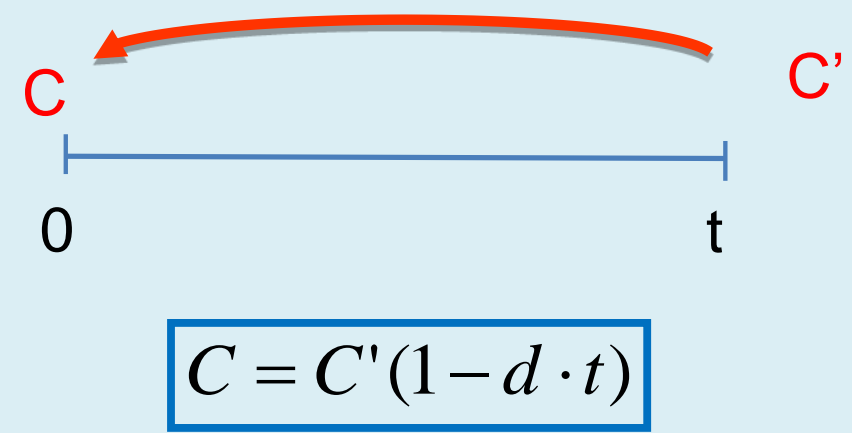

For example, suppose $C^{\prime}=€ 109, \quad t=3$ and $d=0.02752$. Then $C$ is:

$$
C=€ 109(1-0.02752 \cdot 3)=€ 100
$$

As you can observe, in the two financial transactions $(100,0)-(109,3)$, but one of them is in interest simple, and the other one is a discount simple agreement. So, the interest rate $i=0.03$ is equivalent to the discount rate $d=0.02752$ 
If we generalize,

\section{In simple interest}

$$
C^{\prime}=C(1+i \cdot t) \Rightarrow \frac{C^{\prime}}{C}=(1+i \cdot t)
$$

\section{In simple discount}

$$
C=C^{\prime}(1-d \cdot t) \Rightarrow \frac{C^{\prime}}{C}=\frac{1}{1-d t}
$$

If we wish to define an interest rate analogous to the discount rate, we equate $\mathrm{C}^{\prime} / \mathrm{C}$

$$
(1+i \cdot t)=\frac{1}{1-d \cdot t}
$$

Then, solving this last equation for $d$ and $i$ we find:

$$
\begin{gathered}
(1+i \cdot t)(1-d \cdot t)=1 \\
1-d \cdot t+i \cdot t-i \cdot d \cdot t^{2}=1 \\
-d \cdot t+i \cdot t-i \cdot d \cdot t^{2}=1 \\
t(i-d-i \cdot d \cdot t)=0
\end{gathered}
$$

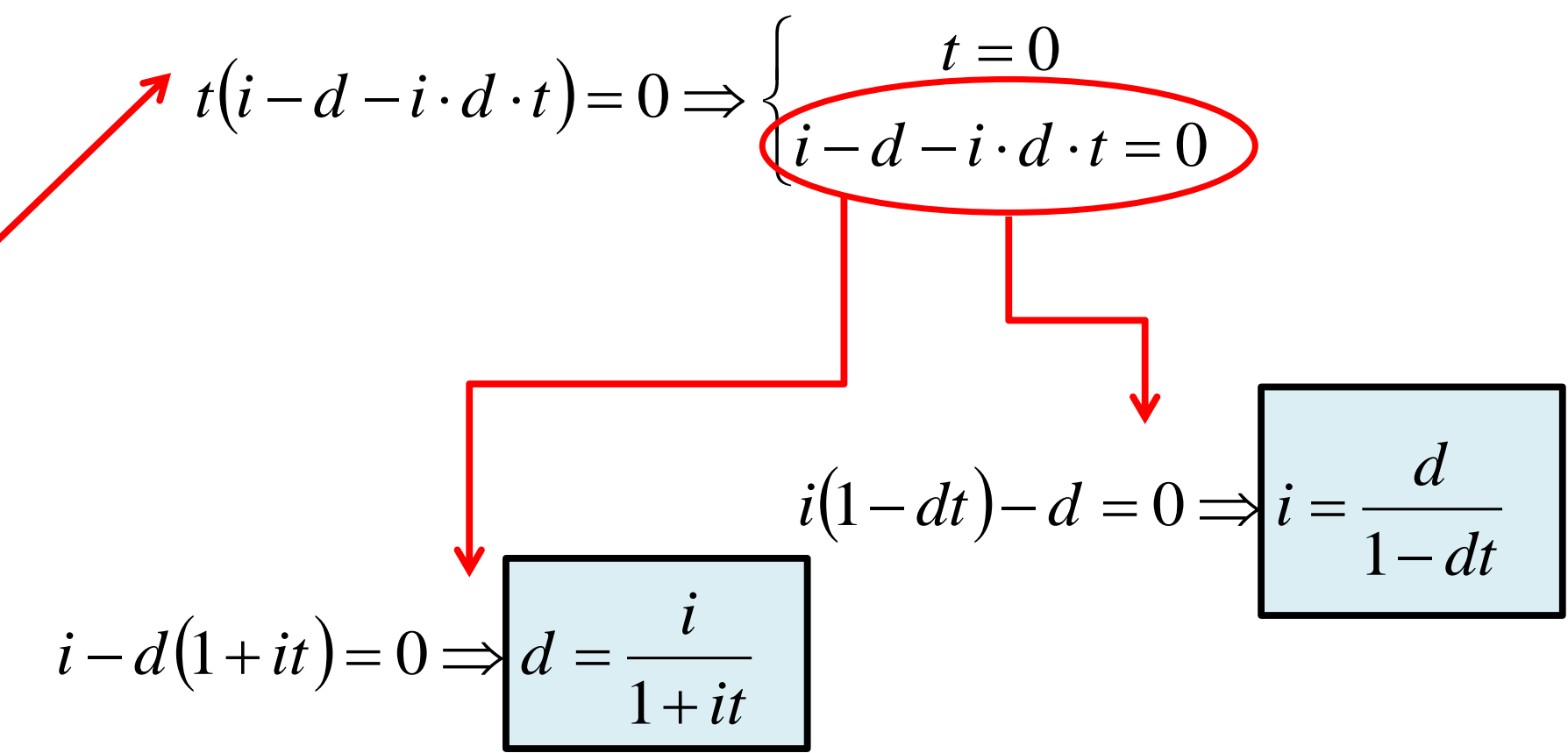


Example 60: Obtain the simple interest rate equivalent to a simple discount rate of $8 \%$ in a term of 92 days. Use ACT/365.

Example 61: Bob discounts a bill portfolio at a bank that will mature in nine months in a simple discount agreement at $6 \%$ and obtains $€ 754.45$. Calculate the profitability obtained by the bank if a simple interest agreement is considered. 


\section{ANNUITIES}

$\checkmark$ Present value of a set of capitals

$\checkmark$ Value of a set of capitals on a given date $V$

$\checkmark$ Annuities

$\checkmark$ Definition

$\checkmark$ Classification

$\checkmark$ Model annuity

$\checkmark$ Present value of the model annuity

$\checkmark$ Present value of a constant annuity

$\checkmark$ Accumulated value of the model annuity

$\checkmark$ Accumulated value of a constant annuity

$\checkmark$ Annuities-due

$\checkmark$ Present value of an annuity-due

$\checkmark$ Present value of a constant annuity-due

$\checkmark$ Accumulated value of an annuity-due

$\checkmark$ Accumulated value of a constant annuity-due

$\checkmark$ Deferred annuities and values on any date

$\checkmark$ Present value of the deferred annuity

$\checkmark$ Present value of a constant deferred annuity

$\checkmark$ Non-level annuities or varying annuities

$\checkmark$ Annuities with payments in geometric progression

$\checkmark$ Immediate annuity

$\checkmark$ Annuity-due

$\checkmark$ Annuities with payments in arithmetic progression

$\checkmark$ Immediate annuity

$\checkmark$ Annuity-due

$\checkmark$ Perpetuities

$\checkmark$ Annuity exercises 


\section{Present value of a set of capitals, $V_{0}$}

Suppose you have a set of financial capitals:

$$
\left(C_{1}, T_{1}\right),\left(C_{2}, T_{2}\right),\left(C_{3}, T_{3}\right), \ldots,\left(C_{n}, T_{n}\right)
$$

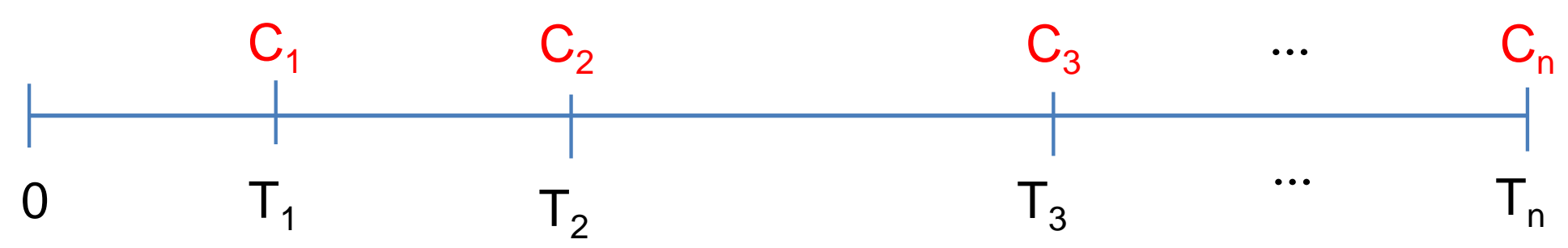

This can be expressed as:

$$
\left\{\left(C_{i}, T_{i}\right)\right\}_{i=1, \ldots, n}
$$

We assume an accumulation function $\mathrm{f}\left(\mathrm{T}, \mathrm{T}^{\prime}\right)$.

\section{Present value, $\mathbf{V}_{0}$}

The present value is the current worth of a set of future sums of money given a specific accumulation function (simple interest, compound interest, simple discount, etc.). 
Suppose we have the following set of capitals:

$$
\left(C_{1}, T_{1}\right),\left(C_{2}, T_{2}\right),\left(C_{3}, T_{3}\right)
$$

We can calculate the present value of each financial capital:

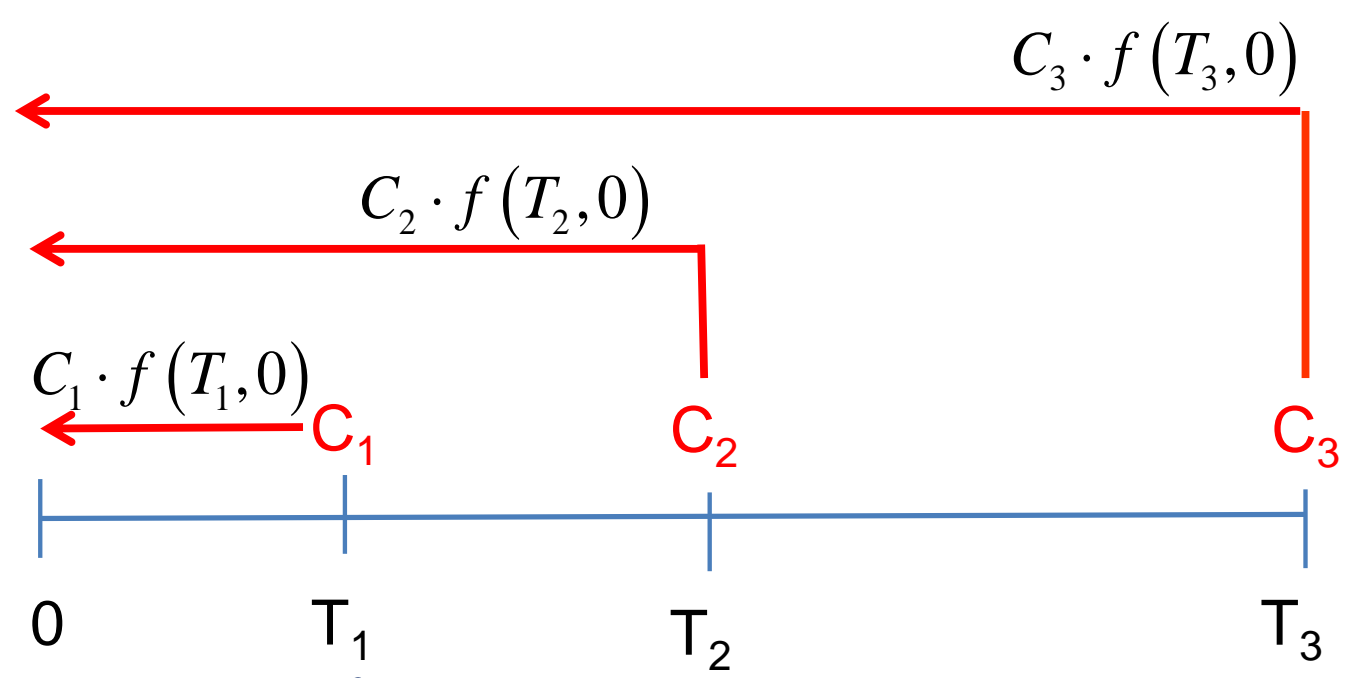

If we sum the discounted values of the three amounts, we obtain the present value of the set of capitals:

$$
V_{0}=C_{1} \cdot f\left(T_{1}, 0\right)+C_{2} \cdot f\left(T_{2}, 0\right)+C_{3} \cdot f\left(T_{3}, 0\right)
$$

Therefore:

$$
\left(V_{0}, 0\right) \sim\left\{\left(C_{1}, T_{1}\right),\left(C_{2}, T_{2}\right),\left(C_{3}, T_{3}\right),\right\}
$$

From now, we will assume compound interest, therefore

$$
f\left(T, T^{\prime}\right)=\left(1+I_{m}\right)^{\frac{T^{\prime}-T}{p}}=\left(1+I_{m}\right)^{n}
$$


Example 1: Find the present value of the following set of capitals:

$$
(100,1),(110,2),\left(120,3^{\prime} 5\right)
$$

We assume compound interest at an annually effective rate of $2 \%$. First, we calculate the present value of each financial capital:

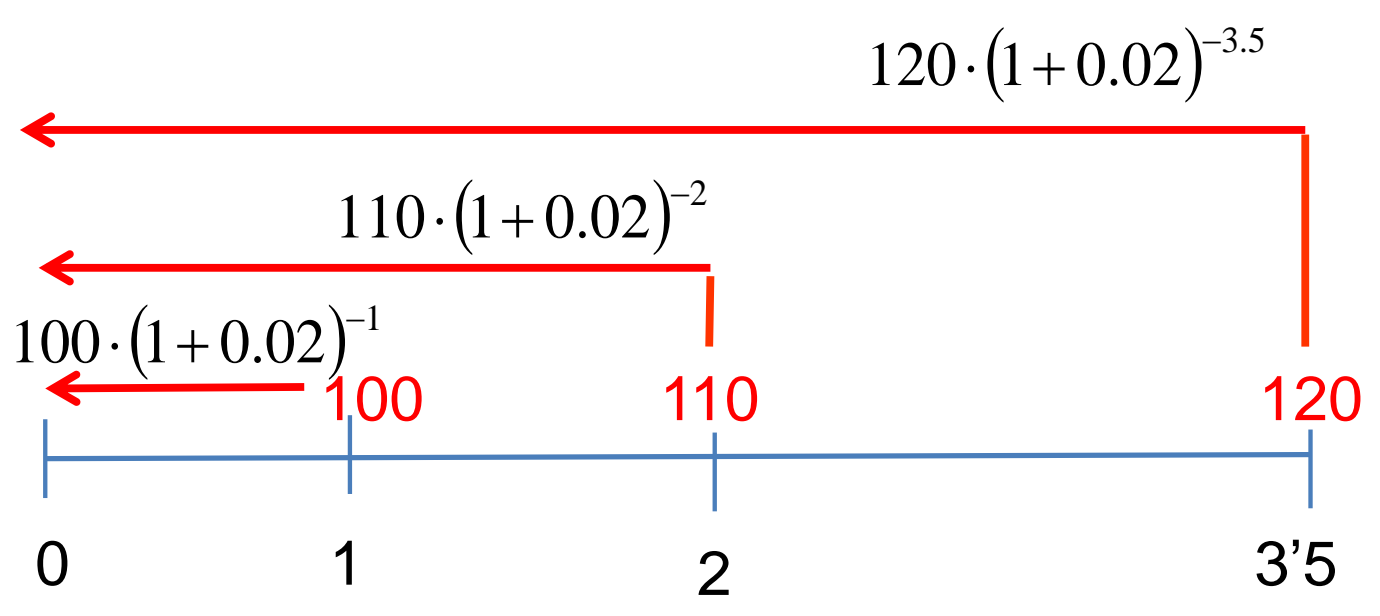

Then we sum the discounted values of the three financial capitals, to obtain the present value of the set of capitals:

$$
V_{0}=100 \cdot(1+0.02)^{-1}+110 \cdot(1+0.02)^{-2}+120 \cdot(1+0.02)^{-35}=315.73 €
$$

So:

$$
(315.73,0) \sim\{(100,1),(110,2),(120,3.5)\}
$$




\section{Example 2:}

Find the present value of the following set of capitals:

$$
(145,0.5),(110,0.75),(150,1.5) \text {, }
$$

if we assume compound interest at a monthly effective rate of $2 \%$. 


\section{Value of a set of capitals on a given date, $V_{T}$}

Suppose we have the following set of capitals:

$$
\left(C_{1}, T_{1}\right),\left(C_{2}, T_{2}\right),\left(C_{3}, T_{3}\right)
$$

If you want to compute the value of a set of capitals on a given date, which we denote as $V_{T}$

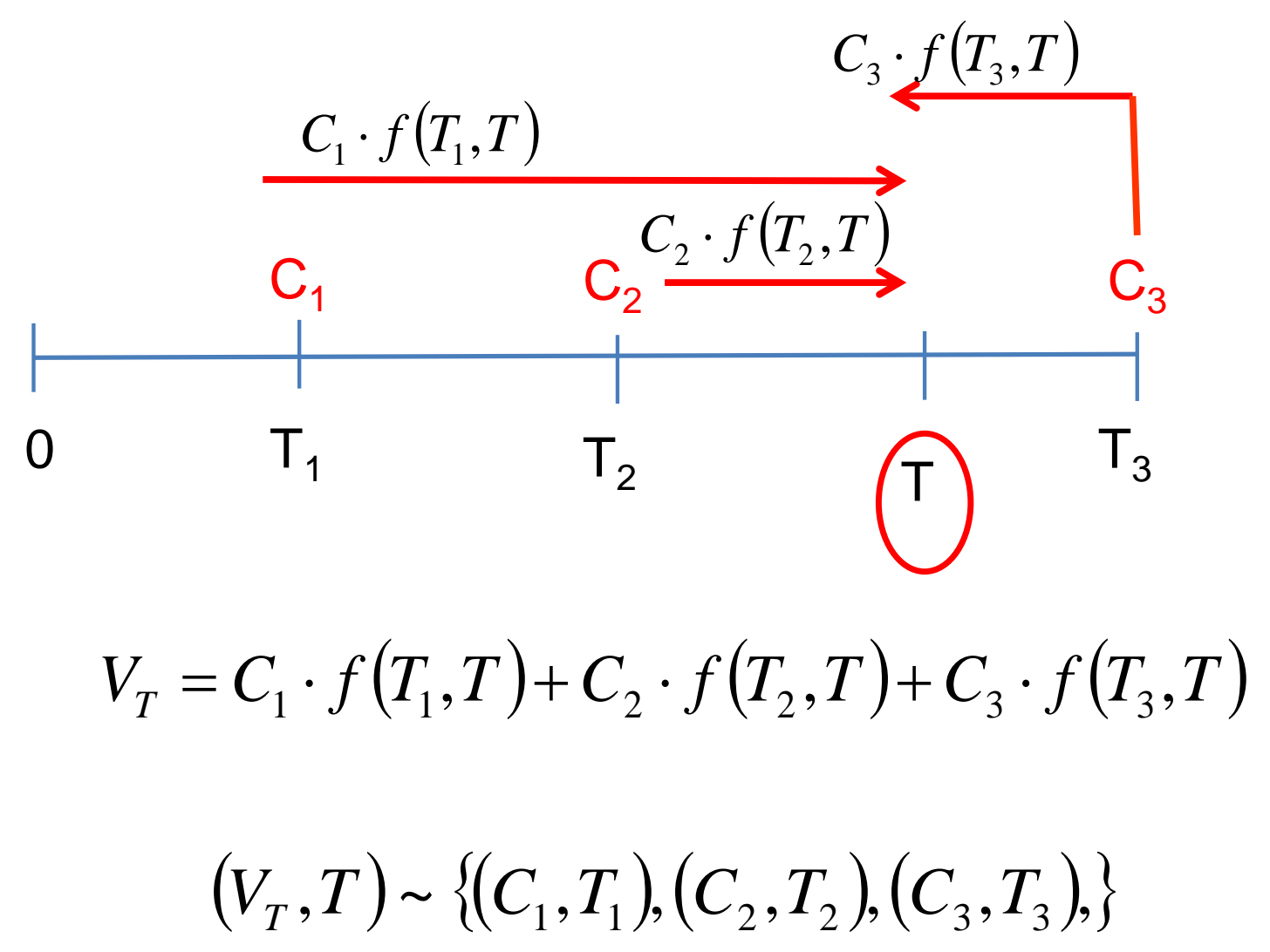


Example 3: Find the financial value at time $T=1$ of the following set of capitals:

$$
(145,0.5),(110,0.75),(150,1.5)
$$

if we assume compound interest at a monthly effective rate of $2 \%$.

$$
V_{0}=145 \cdot(1+0.02)^{6}+110 \cdot(1+0.02)^{3}+150 \cdot(1+0.02)^{-6}=€ 413.22
$$




\section{Example 4:}

Recall example 2:

$$
(325.82,0) \sim\{(145,0.5),(110,0.75),(150,1.5)\}
$$

And example 3:

$$
(413.22,1) \sim\{(145,0.5),(110,0.75),(150,1.5)\}
$$

Thus, we know that:

$$
(325.82,0) \sim(413.22,1)
$$

So, clearly:

$$
325.82 \cdot(1+0.02)^{12}=413.22
$$




\section{ANNUITIES}




\section{Definition}

A series of payments made at equal intervals of time is called an annuity.

The interval between annuity payments is called the payment period, often just called the period.

We refer to this period as $p$, and it is always measured in years.

$\checkmark$ The idea is that the sequence of payments are equally spaced.

$\checkmark$ The payment period, $p$, is expressed in years.

Common examples are house rents, mortgage payments on a home or installment payments on cars.

An example is receiving a salary $(€ 1000)$ at the end of each month for one year:

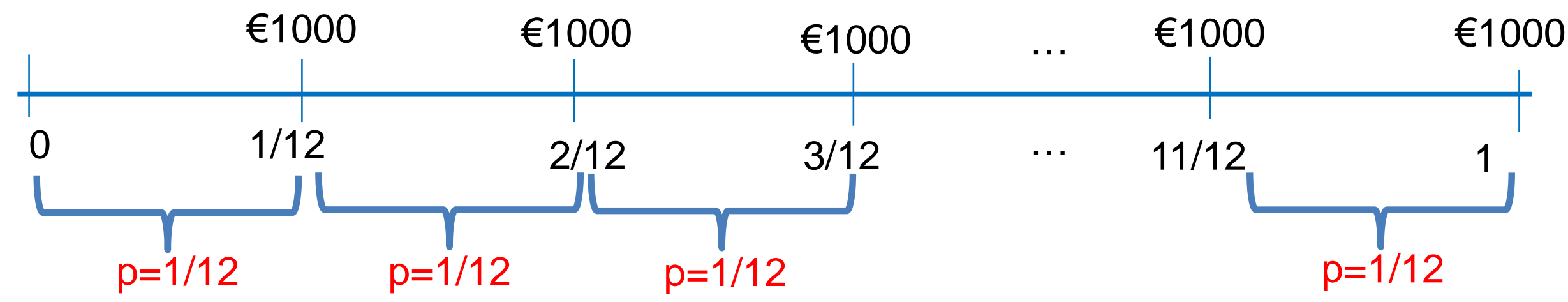

$p=1 / 12$, is the payment period

In this case, you receive 12 payments. The number of payments is denoted by $\mathbf{n}$; so, $n=12$. 
Or when you repay a loan by a series of quarterly payments over the next two years:

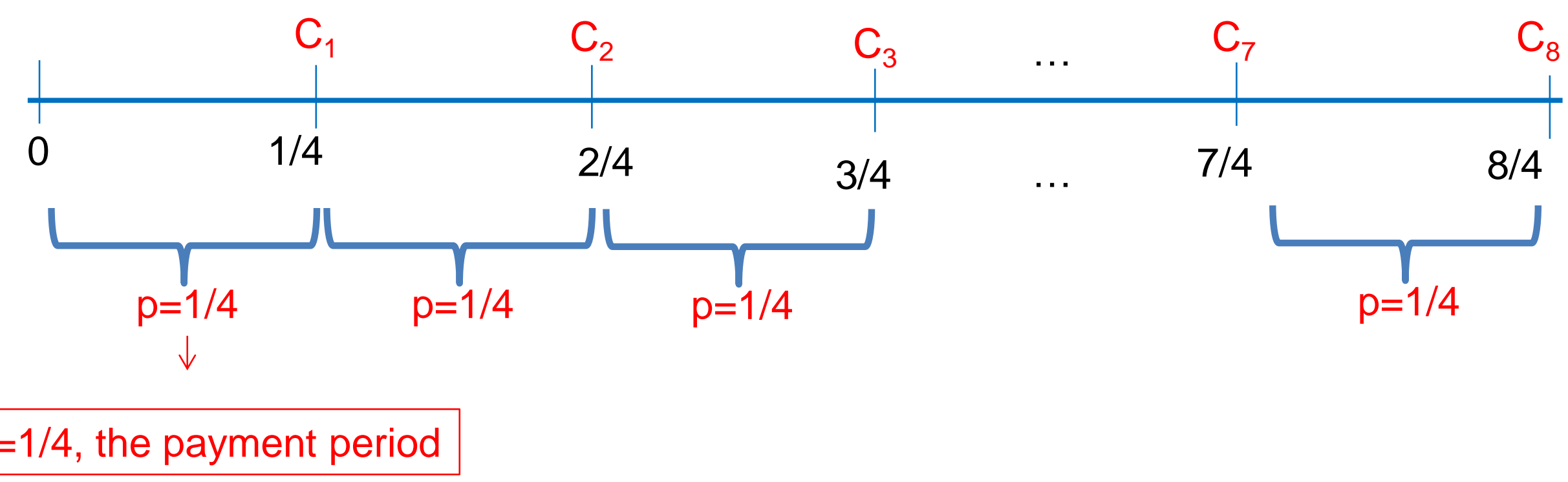

In this case, the bank receives 8 payments; so, $n=8$. 
Or when you pay the rent for your flat at the beginning of each month over two years:

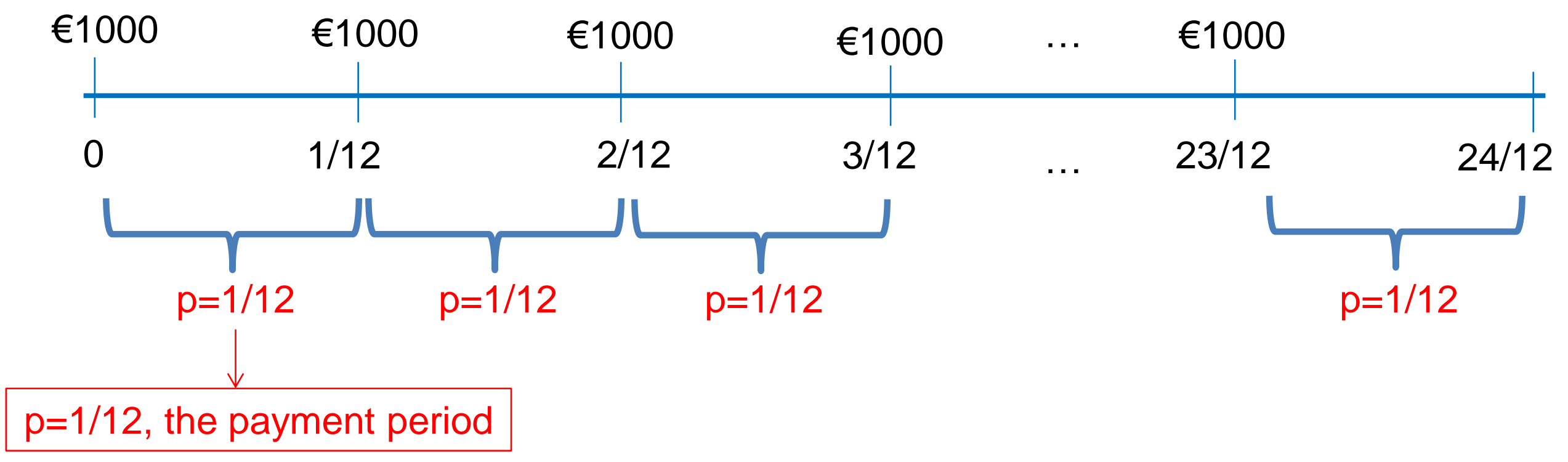

In this case, you pay 24 times;

so, $n=24$. 
If we generalize the previous examples, we denote an annuity as

$$
\left\{\left(C_{r}, T_{r}\right)\right\}_{r=1, \ldots, n}, \text { with } T_{r}-T_{r-1}=p
$$

where:

$\checkmark \mathbf{p}$ is the payment period (interval between payments);

$\checkmark \mathbf{n}$ is number of annuity payments.

Graphically,

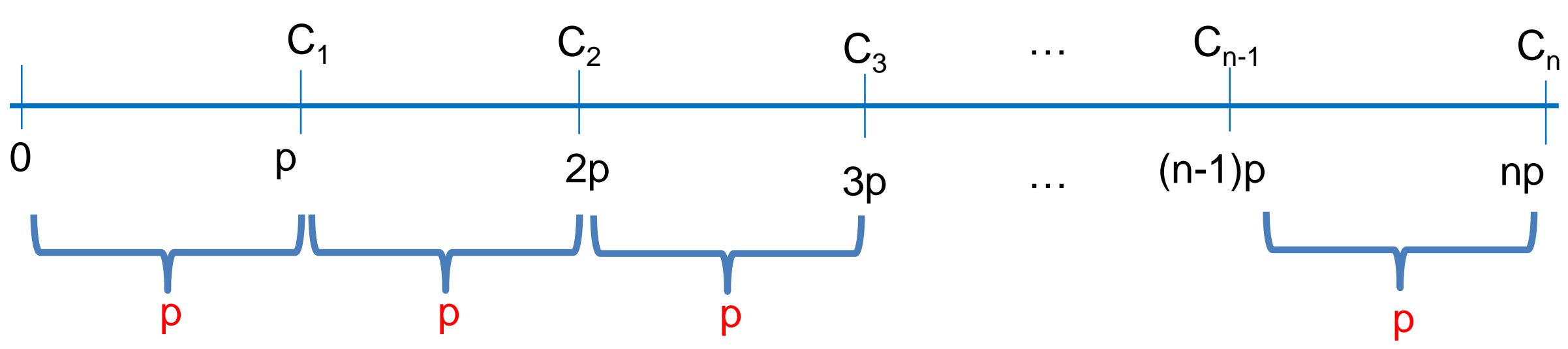


We know that $\mathbf{p}$ is measured in years. We can define a new variable, denoted by $\mathbf{m}$, given as:

$$
m=\frac{1}{p}
$$

So, $m$ indicates the number of payment periods in a year.

For example,

- If $p=1 / 2$, then $m=2 \Rightarrow$ Semi-annually annuity. That's to say, you pay twice in a year.

- If $p=1 / 4$, then $m=4 \Rightarrow$ Quarterly annuity. That's to say, you pay four times in a year.

- If $p=1 / 3$, then $m=3 \Rightarrow$ Four-monthly annuity. That's to say, you pay three times in a year.

- If $p=1 / 12$, then $m=12 \Rightarrow$ Monthly annuity. That's to say, you pay twelve times in a year. 


\section{Classification}

Depending on the number of payments, $\mathbf{n}$ :

$\checkmark$ Temporal annuity: if $\mathbf{n}$ is a finite number.

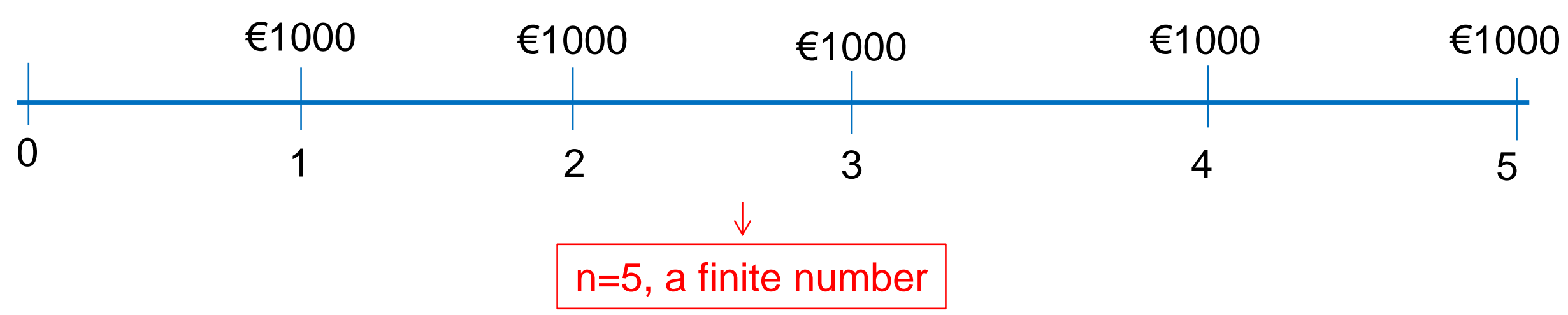

$\checkmark$ Perpetuity: this is an annuity with an infinite term. That's to say, a perpetuity has payments that last forever.

\begin{tabular}{cccccc}
$€ 1000$ & $€ 1000$ & $€ 1000$ & $€ 1000$ & $\cdots$ \\
\hline & 1 & 2 & 3 & 4 & $\cdots$
\end{tabular}


Depending on the structure of the terms of the annuity:

$\checkmark$ Constant annuity: if $C_{r}=C$, i.e., if all the terms are equal.

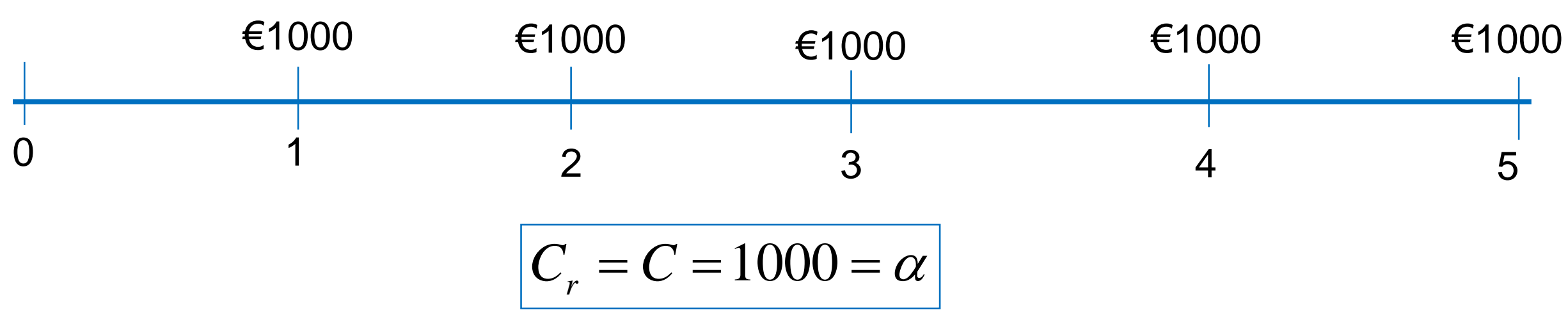

$\checkmark$ Non-level annuity: if the terms of the annuity are not equal.

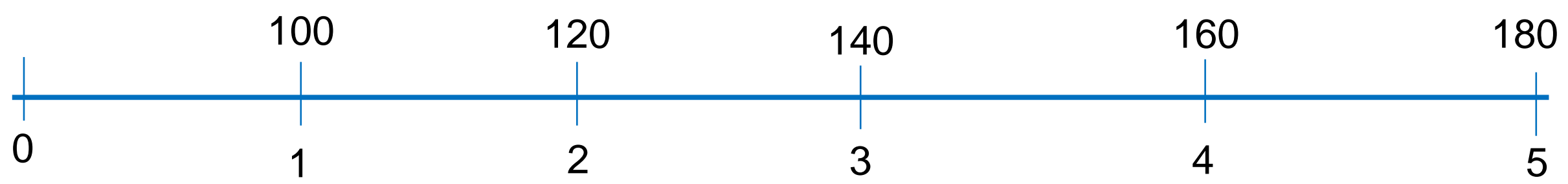

We will study:

$\checkmark$ annuities with payments forming a geometric sequence;

$\checkmark$ annuities with payments forming an arithmetic sequence. 
Depending on whether you pay at the beginning or end of each period,

$\checkmark$ Annuity-Immediate : if payments are made at the end of each period.

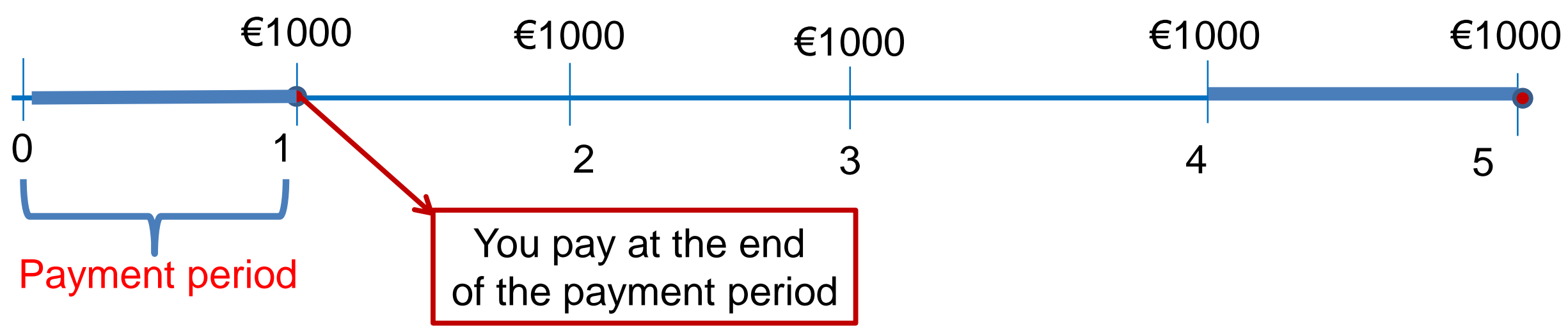

$\checkmark$ Annuity-due : if payments are made at the beginning of each period.

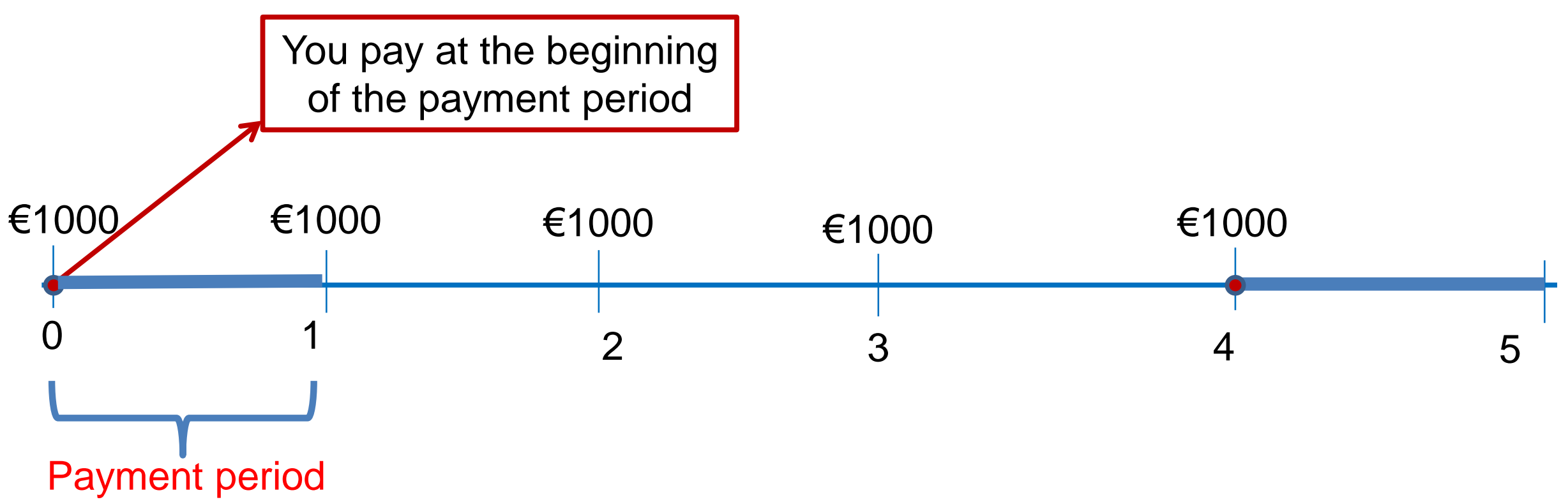




\section{Model annuity}

In order to calculate the value of an annuity (present value or accumulated value), first we need to analyze an annuity with some specific characteristics, known as a model annuity

\section{Model annuity}

- Annuity-Immediate (payments are made at the end of each period)

- Temporal annuity (if $\mathbf{n}$ is a finite number)

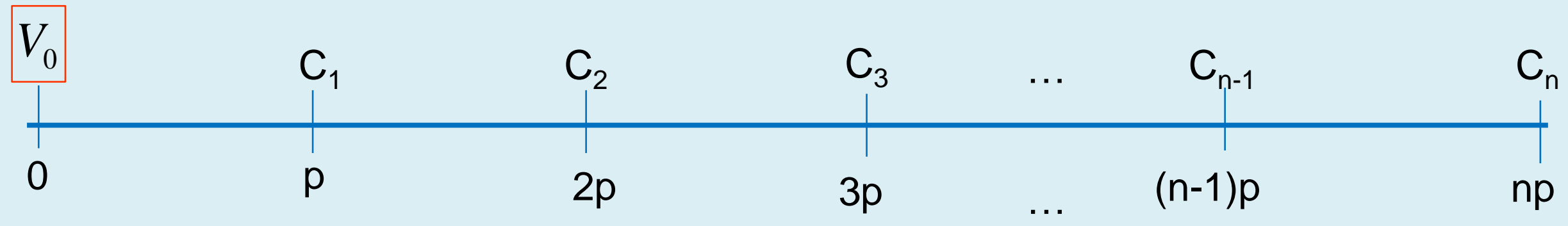

This annuity is known as a model annuity.

Now we calculate the present value of the model annuity that lasts $\boldsymbol{n}$ payment periods.

This value is the present value of the annuity, $V_{0}$;

it gives the value of the annuity one period before the first payment

From now on, we will assume compound interest; therefore $f\left(T, T^{\prime}\right)=\left(1+I_{m}\right)^{n}$ 


\section{Present value of the model annuity, $\mathrm{V}_{0}$}

The present value of an annuity is the sum of the present value of each of the $n$ payments.

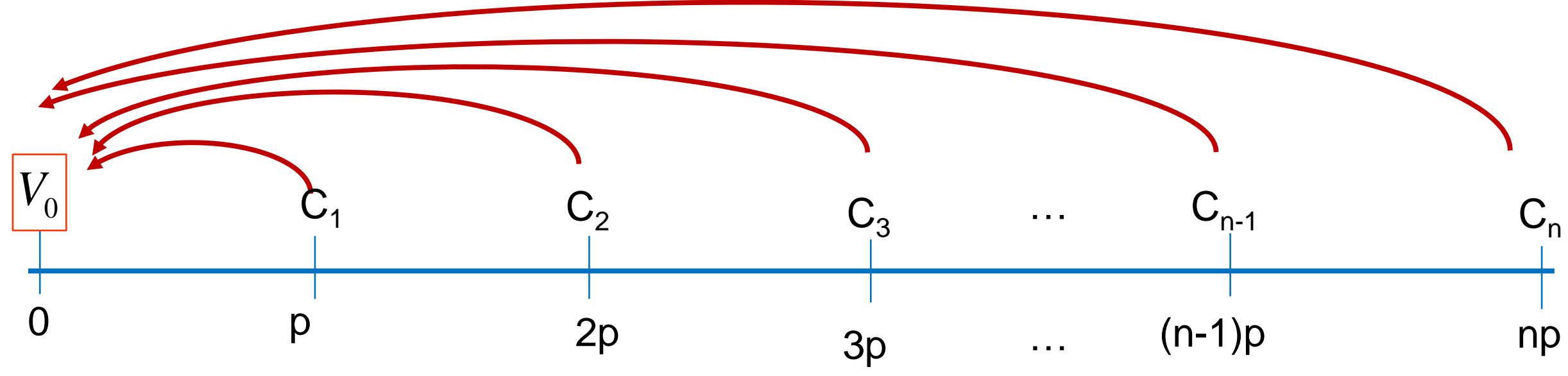

We know that:

$$
V_{0}=C_{1} \cdot\left(1+I_{m}\right)^{-1}+C_{2} \cdot\left(1+I_{m}\right)^{-2}+C_{3} \cdot\left(1+I_{m}\right)^{-3}+\ldots+C_{n} \cdot\left(1+I_{m}\right)^{-n}
$$

This can be rewritten as:

$$
V_{0}=\sum_{i=1}^{n} C_{i} \cdot\left(1+I_{m}\right)^{-i}
$$

So, we know that:

$$
\left(V_{0}, 0\right) \sim\left\{\left(C_{i}, T_{i}\right)\right\}_{i=1, \ldots, n}
$$




\section{Present value of a constant annuity, $C_{r}=C$}

Now we obtain the expression for the present value of a model annuity with level payments, that's to say if $\mathrm{C}_{\mathrm{r}}=\mathrm{C}$ (if all the terms are equal). So, substituting into previous expressions:

$$
\begin{gathered}
V_{0}=C \cdot\left(1+I_{m}\right)^{-1}+C \cdot\left(1+I_{m}\right)^{-2}+C \cdot\left(1+I_{m}\right)^{-3}+\ldots+C \cdot\left(1+I_{m}\right)^{-n} \\
V_{0}=\sum_{i=1}^{n} C \cdot\left(1+I_{m}\right)^{-i}=C \cdot \sum_{i=1}^{n}\left(1+I_{m}\right)^{-i}
\end{gathered}
$$

We recognize the summation on the right-hand side as a geometric progression that can be rewritten as:

$$
\sum_{i=1}^{n}\left(1+I_{m}\right)^{-i}=\frac{1-\left(1+I_{m}\right)^{-n}}{I_{m}}
$$

So, substituting:

$$
V_{0}=C \cdot \frac{1-\left(1+I_{m}\right)^{-n}}{I_{m}}
$$

We usually use the annuity symbol $a_{\bar{n} \mid I_{m}}$, defined as $a_{\bar{n} \mid I_{m}}=\frac{1-\left(1+I_{m}\right)^{-n}}{I_{m}}$ So, last expression can be rewritten as:

$$
V_{0}=C \cdot a_{\bar{n} \mid I_{m}}
$$


Example 5: Paul receives an allowance of $€ 450$ at the end of each month for two years. Find the value today (January $1^{\text {st }}$ ) using a monthly effective interest rate of $0.6 \%$.

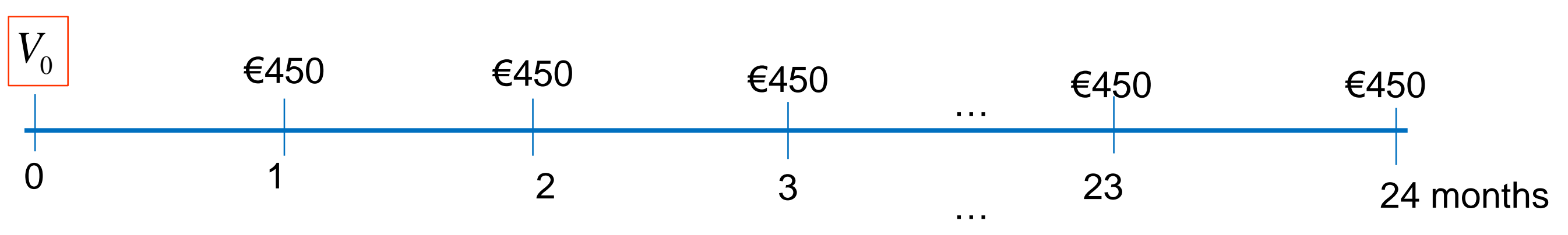

This is a model annuity with level payments, where $\mathrm{C}=450, \mathrm{~m}=12, \mathrm{n}=24$ and $\mathrm{I}_{12}=0.006$.

$$
\begin{gathered}
V_{0}=C \cdot \frac{1-\left(1+I_{m}\right)^{-n}}{I_{m}} \\
V_{0}=€ 450 \cdot \frac{1-(1+0.006)^{-24}}{0.006}=€ 10,030.46
\end{gathered}
$$

So,$$
(10030.46,0) \sim\left\{\left(450, \frac{1}{12} \cdot i\right)\right\}_{i=1, \ldots, 24}
$$ 
Example 6: Find the present value (one period before the first payment) of an annuity-immediate that lasts for five years and pays $€ 3000$ at the end of each month, using an annual effective rate of $3 \%$. Then repeat the problem using a nominal interest of $4 \%$ compounded monthly.

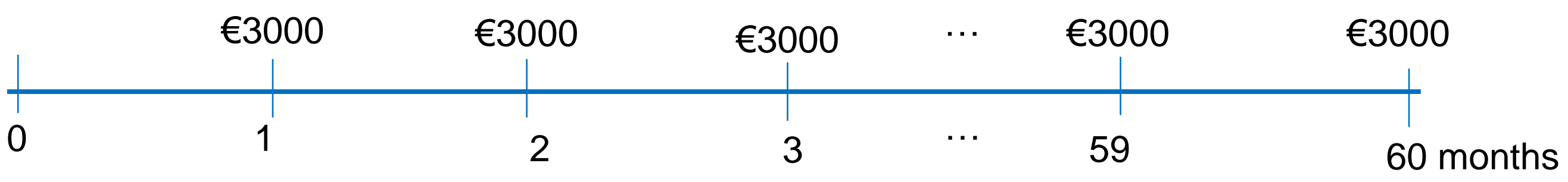

This is a constant model annuity with $C=3000, m=12$ and $n=60$.

a) $I_{1}=0.03$. We need to obtain $I_{12}$ because we have monthly payments!

$$
\begin{gathered}
I_{m}=\left(1+I_{m^{\prime}}\right)^{\frac{m^{\prime}}{m}}-1 \Rightarrow I_{12}=\left(1+I_{1}\right)^{\frac{1}{12}}-1 \\
I_{12}=(1+0.03)^{\frac{1}{12}}-1=0.00246626
\end{gathered}
$$$$
V_{0}=C \cdot \frac{1-\left(1+I_{12}\right)^{-60}}{I_{12}}=€ 3000 \cdot \frac{1-(1+0.00246626)^{-60}}{0.00246626}=€ 167,124.97
$$ 
b) $i_{12}=0.03$. We need to obtain $\mathrm{I}_{12}$ because we have monthly payments!

$$
I_{m}=\frac{i_{m}}{m} \Rightarrow I_{12}=\frac{i_{12}}{12}=\frac{0.03}{12}=0.0025
$$

Then,

$$
V_{0}=C \cdot \frac{1-\left(1+I_{12}\right)^{-60}}{I_{12}}=€ 3000 \cdot \frac{1-(1+0.0025)^{-60}}{0.0025}=€ 166,957.07
$$

Example 7: Bob receives payments of $€ 100$ at the end of each quarter for 3 years at a monthly effective rate of $1.5 \%$. Find the present value of his annuity.

Example 8: Pep receives payments of $€ C$ at the end of each year for 10 years at a quarterly effective rate of $2.5 \%$. The present value of his annuity is $€ 8500$. Find $\mathrm{C}$.

Example 9: If the present value of a monthly annuity that lasts for 5 years is $€ 1000$, with the constant payments being $€ 25.4$, find the interest rate. 
Example 10: Marc wants to buy a new car. His budget allows him to make monthly payments of $€ 500$, and he has saved $€ 1800$ for a down payment. He qualifies for a 36month car loan at a nominal interest rate of $4.8 \%$ compounded monthly. How much can he afford to spend on the car?

Example 11: Marc wants to borrow $€ 1350$ so he can pay his tuition. He qualifies for a two-year loan with a monthly effective interest rate of $2.5 \%$ and level payments. Find the amount of Marc's monthly payments under the terms of this loan.

Example 12: The price of a new car is $€ 10,000$. The purchaser is willing to finance the car at $18 \%$ compounded monthly and to make payments of $€ 250$ at the end of each month for 4 years. Find the necessary down payment.

Example 13 : A loan of $€ 10,000$ is being repaid by 10 semi-annual payments, with the first payment made half a year after the loan is taken out. The first 5 payments are $€ \mathrm{~K}$ each, and the final 5 are $€(K+200)$ each. What is $K$ if $I_{2}=0.06$ ? 


\section{Accumulated value of the model annuity, $V_{f}$}

Recall that the model annuity is:

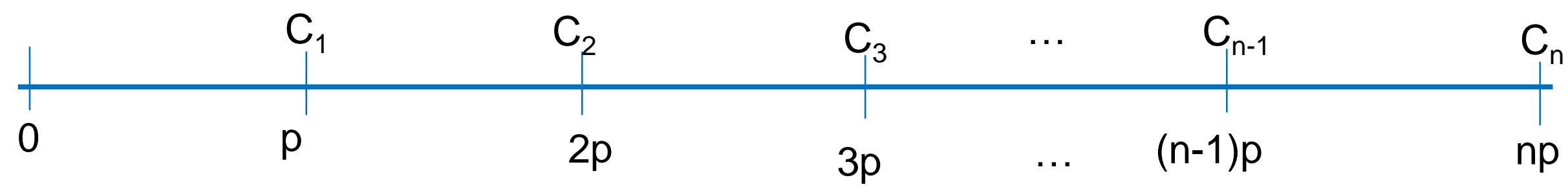

Now we will calculate the value of the model annuity lasting $n$ interest periods at the time of its final payment. That is, just after the last payment is made.

This value is the accumulated value of the annuity, $V_{f}$, which gives the value of the annuity at the time of the final payment.

\begin{tabular}{ccccccc}
$V_{0}$ & $\mathrm{C}_{1}$ & $\mathrm{C}_{2}$ & $\mathrm{C}_{3}$ & $\ldots$ & $\mathrm{C}_{\mathrm{n}-1}$ & $\mathrm{C}_{\mathrm{n}}$ \\
\hline 0 & $\mathrm{p}$ & $2 \mathrm{p}$ & $3 \mathrm{p}$ & $\cdots$ & $(\mathrm{n}-1) \mathrm{p}$ & $\mathrm{np}$
\end{tabular}




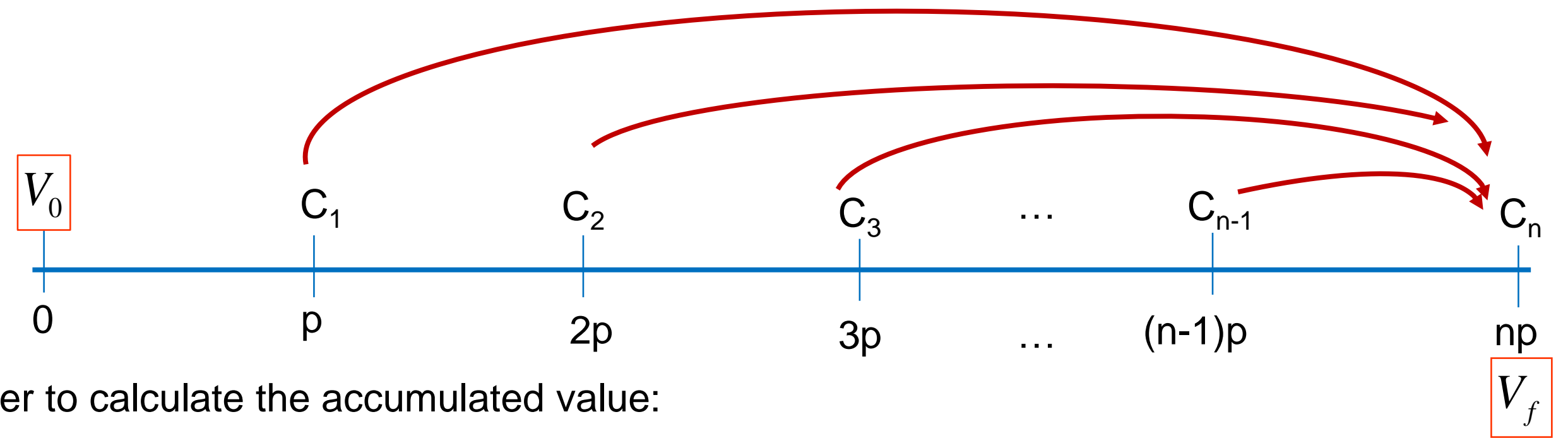

$$
V_{f}=C_{1} \cdot\left(1+I_{m}\right)^{n-1}+C_{2} \cdot\left(1+I_{m}\right)^{n-2}+C_{3} \cdot\left(1+I_{m}\right)^{n-3}+\ldots+C_{n}
$$

But it's easier to obtain the accumulated value from the present value:

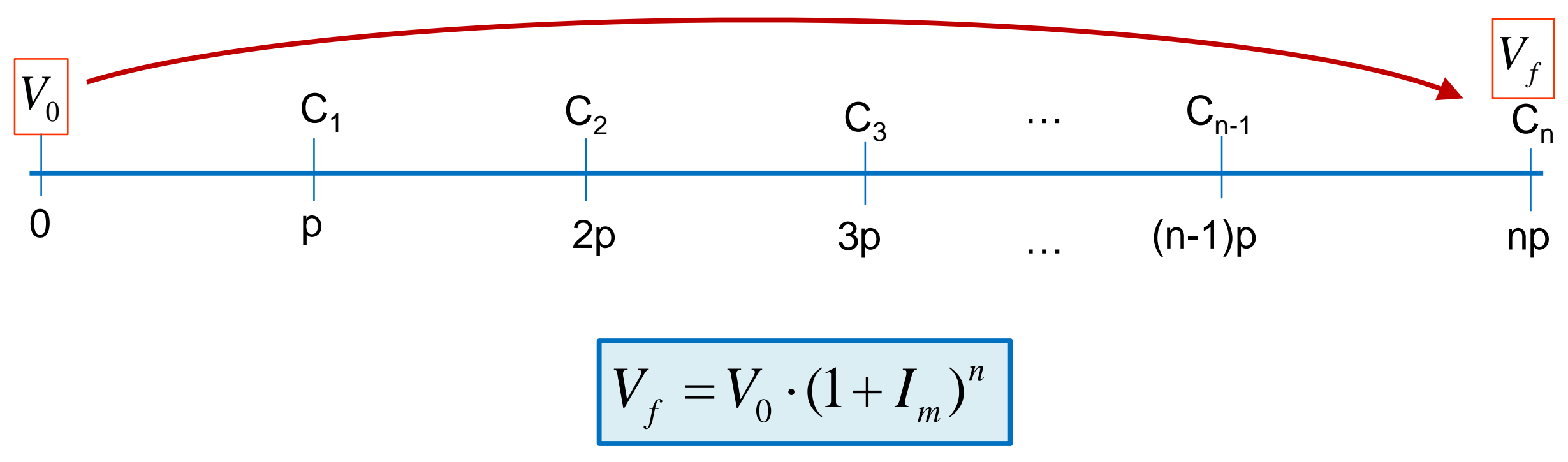




\section{Accumulated value of a constant annuity, $C_{r}=C$}

If $C_{r}=C$, that is to say, if all the terms are equal, the accumulated value is:

$$
\begin{aligned}
& V_{f}=V_{0} \cdot\left(1+I_{m}\right)^{n}=\left\{V_{0}=C \cdot \frac{1-\left(1+I_{m}\right)^{-n}}{I_{m}}\right\}= \\
& =C \cdot \frac{1-\left(1+I_{m}\right)^{-n}}{I_{m}} \cdot\left(1+I_{m}\right)^{n}=C \cdot \frac{\left(1+I_{m}\right)^{n}-1}{I_{m}}
\end{aligned}
$$

So:

$$
V_{f}=C \cdot \frac{\left(1+I_{m}\right)^{n}-1}{I_{m}}
$$

We usually use the annuity symbol

$$
S_{\vec{n} \mid I_{m}}=\frac{\left(1+I_{m}\right)^{n}-1}{I_{m}}
$$

Then the last expression can be rewritten as:

$$
V_{f}=C \cdot S_{\bar{n} I_{m}}
$$




\section{Example 14:}

Find the accumulated value (the value of the annuity at the time of the final payment) of the annuity defined in Example 5.

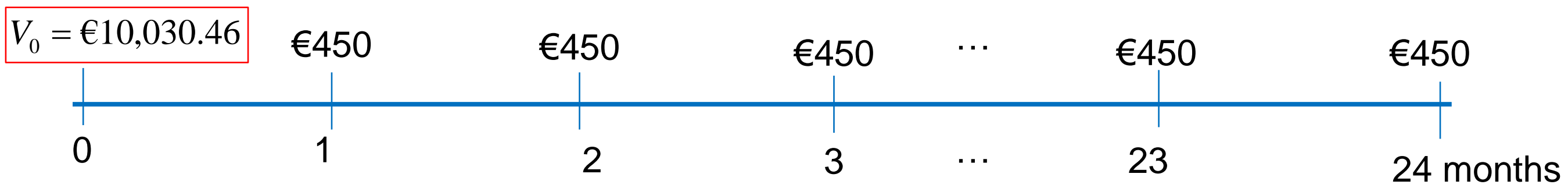

This is a constant model annuity with $\mathrm{C}=€ 450, \mathrm{~m}=12, \mathrm{n}=24$ and $\mathrm{I}_{12}=0,006$.

It is possible to obtain the accumulated value using the formula:

$$
V_{f}=C \cdot \frac{\left(1+I_{m}\right)^{n}-1}{I_{m}} \Rightarrow V_{f}=€ 450 \cdot \frac{\left(1+I_{12}\right)^{24}-1}{I_{12}}=€ 11,579.03
$$

Or from the present value:

$$
V_{f}=V_{0} \cdot\left(1+I_{m}\right)^{n} \Rightarrow V_{f}=€ 10,030.46 \cdot\left(1+I_{12}\right)^{24}=€ 11,579.03
$$


Example 15: Find the accumulated value (the value of the annuity at the time of the final payment) of the annuity defined in Example 6.

Example 16: The Browns wish to accumulate $€ 150,000$ at the time of their last deposit in a college fund by contributing an amount $C$ at the end of each year for eighteen years. What amount $\mathrm{C}$ is necessary to reach their goal, if the annual effective interest rate is $2 \%$ ?

College fund: is a tax-advantaged investment plan, issued and operated by a state or educational institution which helps families save for college.

Example 17: Peter wishes to accumulate $€ 12,500$ by depositing an amount $C$ at the end of each month for two years. What amount $\mathrm{C}$ is necessary to reach his goal, if the annual effective interest rate is $3 \%$ ?

Example 18: Stuart wishes to have $€ 14,000$ to buy a used car three years from now. He plans to accomplish this through an account with a nominal interest rate of $3 \%$ compounded monthly, by depositing $€ 300$ at the end of each month for three years. He has saved for a down payment of $€ 2500$. Will Stuart be able to buy the car? 


\section{Annuities-due}

An annuity lasting $\mathrm{n}$ interest periods with payments at the beginning of each payment period is called an annuity-due,

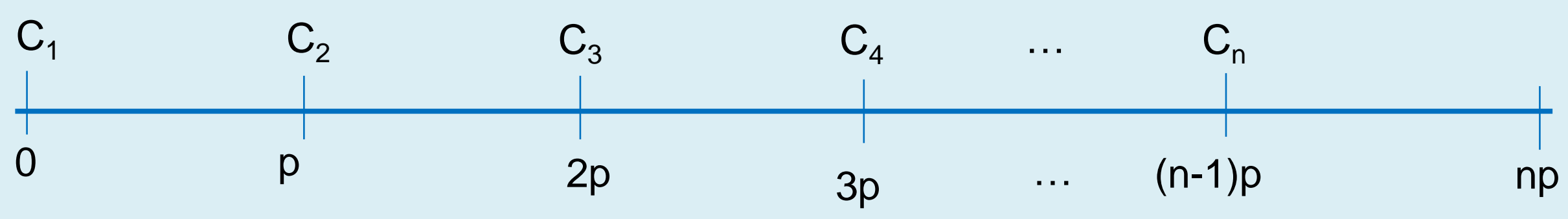

$\checkmark$ The present value of an annuity-due is represented as $\ddot{V}_{0}$. It is at the time of the first payment.

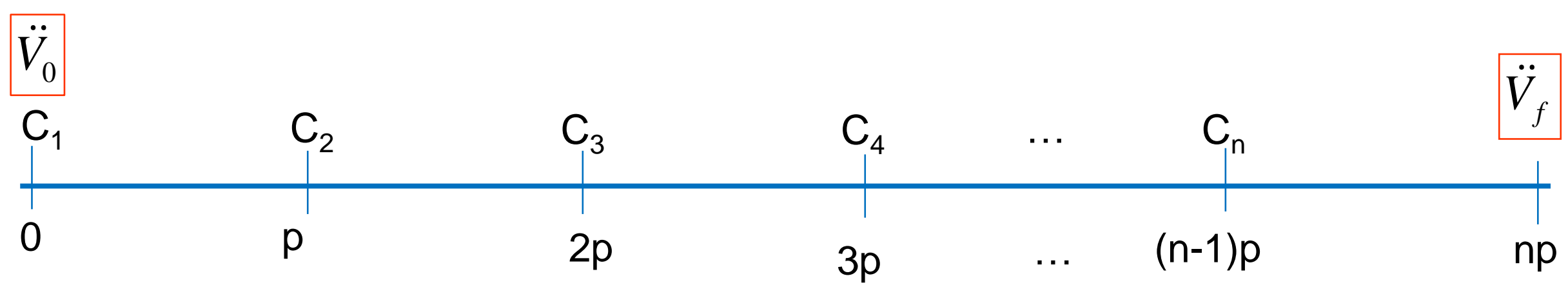

$\checkmark$ The accumulated value of an annuity-due is represented as: $\ddot{V}_{f}$. It gives the value of the annuity one period after the last payment, that is to say at the end of the n-th period. 


\section{Present value of the annuity-due}

The present value of an annuity is the sum of the present value of each of the $n$-payments

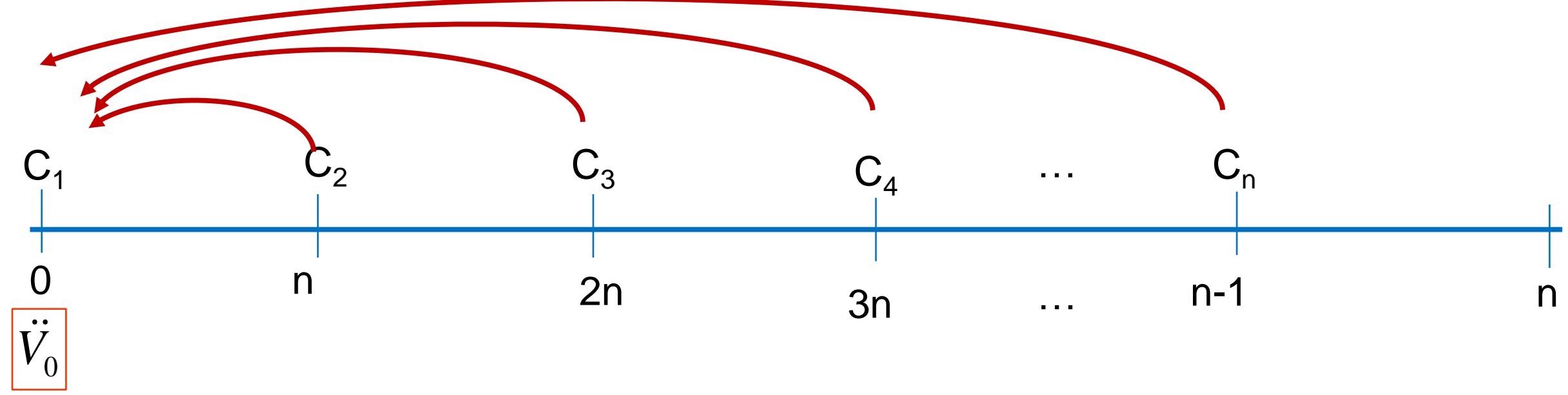

To calculate the present value:

$$
\ddot{V}_{0}=C_{1}+C_{2} \cdot\left(1+I_{m}\right)^{-1}+C_{3} \cdot\left(1+I_{m}\right)^{-2}+C_{4} \cdot\left(1+I_{m}\right)^{-3}+\ldots+C_{n} \cdot\left(1+I_{m}\right)^{-(n-1)}
$$

This can be rewritten as:

$$
\ddot{V}_{0}=\sum_{i=1}^{n} C_{i} \cdot\left(1+I_{m}\right)^{-(i-1)}
$$

So, we know that:

$$
\left(\ddot{V}_{0}, 0\right) \sim\left\{\left(C_{i}, T_{i}\right)\right\}_{i=1, \ldots, n} \quad, \text { where } T_{1}=0
$$


Now, we work with the expression for the present value obtained in the previous slide:

$$
\begin{aligned}
\ddot{V}_{0} & =\sum_{i=1}^{n} C_{i} \cdot\left(1+I_{m}\right)^{-(i-1)}=\sum_{i=1}^{n} C_{i} \cdot\left(1+I_{m}\right)^{-i} \cdot\left(1+I_{m}\right)^{1}= \\
& =\left(1+I_{m}\right) \sum_{i=1}^{n} C_{i} \cdot\left(1+I_{m}\right)^{-i}
\end{aligned}
$$

And if we recall that the present value of an immediate annuity is: $V_{0}=\sum_{i=1}^{n} C_{i} \cdot\left(1+I_{m}\right)^{-i}$

$$
\ddot{V}_{0}=V_{0} \cdot\left(1+I_{m}\right)
$$

The present value of an annuity-due, $\ddot{V}_{0}$, can be obtained from the present value of the immediate annuity, $V_{0}$. 


\section{Present value of a constant annuity, $C_{r}=C$}

If $\mathrm{C}_{\mathrm{r}}=\mathrm{C}$, that is to say, if all the terms are equal, knowing that for an immediate annuity the present value is:

$$
V_{0}=C \cdot \frac{1-\left(1+I_{m}\right)^{-n}}{I_{m}}=C \cdot a_{\left.\vec{n}\right|_{m}}
$$

We now know that the present value of an annuity-due can be obtained from the present value of an immediate annuity,

$$
\begin{gathered}
\ddot{V}_{0}=V_{0} \cdot\left(1+I_{m}\right) \\
\ddot{V}_{0}=V_{0} \cdot\left(1+I_{m}\right)=C \cdot \frac{1-\left(1+I_{m}\right)^{-n}}{I_{m}} \cdot\left(1+I_{m}\right)=C \cdot a_{\bar{n} \mid I_{m}} \cdot\left(1+I_{m}\right)
\end{gathered}
$$

where $\quad \ddot{a}_{\bar{n} \mid I_{m}}=\left.\left(1+I_{m}\right) \cdot a_{-}\right|_{I_{m}}$

So:

$$
\ddot{V}_{0}=C \cdot \ddot{a}_{\bar{n} \mid I_{m}}=C \cdot \frac{1-\left(1+I_{m}\right)^{-n}}{I_{m}} \cdot\left(1+I_{m}\right)
$$




\section{Example 19:}

Steve wants to save for his retirement by depositing $€ 1200$ at the beginning of each month for ten years. Find the present value if the annual effective interest rate is $5 \%$.

$$
\begin{aligned}
& \ddot{V}_{0} \\
& \begin{array}{ccccccc}
1200 & 1200 & 1200 & 1200 & \cdots & 1200 & \\
\hline 0 & 1 & 2 & 3 & \cdots & 119 & 120 \text { months }
\end{array} \\
& I_{1}=0.05 \quad I_{12}=\left(1+I_{1}\right)^{\frac{1}{12}}-1=(1+0.05)^{\frac{1}{12}}-1=0.004074 \\
& \ddot{V}_{0}=V_{0} \cdot\left(1+I_{m}\right)=C \cdot \frac{1-\left(1+I_{m}\right)^{-n}}{I_{m}} \cdot\left(1+I_{m}\right) \\
& \ddot{V}_{0}=C \cdot \ddot{a}_{\bar{n}_{\mid} I_{m}}=€ 1200 \cdot \frac{1-\left(1+I_{12}\right)^{-120}}{I_{12}} \cdot\left(1+I_{12}\right)=€ 114,182.79
\end{aligned}
$$




\section{Example 20:}

April received an inheritance from her grandmother in the form of an annuity. The annuity pays $€ 3000$ on January $1^{\text {st }}$ from 1966 through 1984 . Find the value of this annuity on January $1^{\text {st }} 1966$ using an annual effective interest rate of $5 \%$.

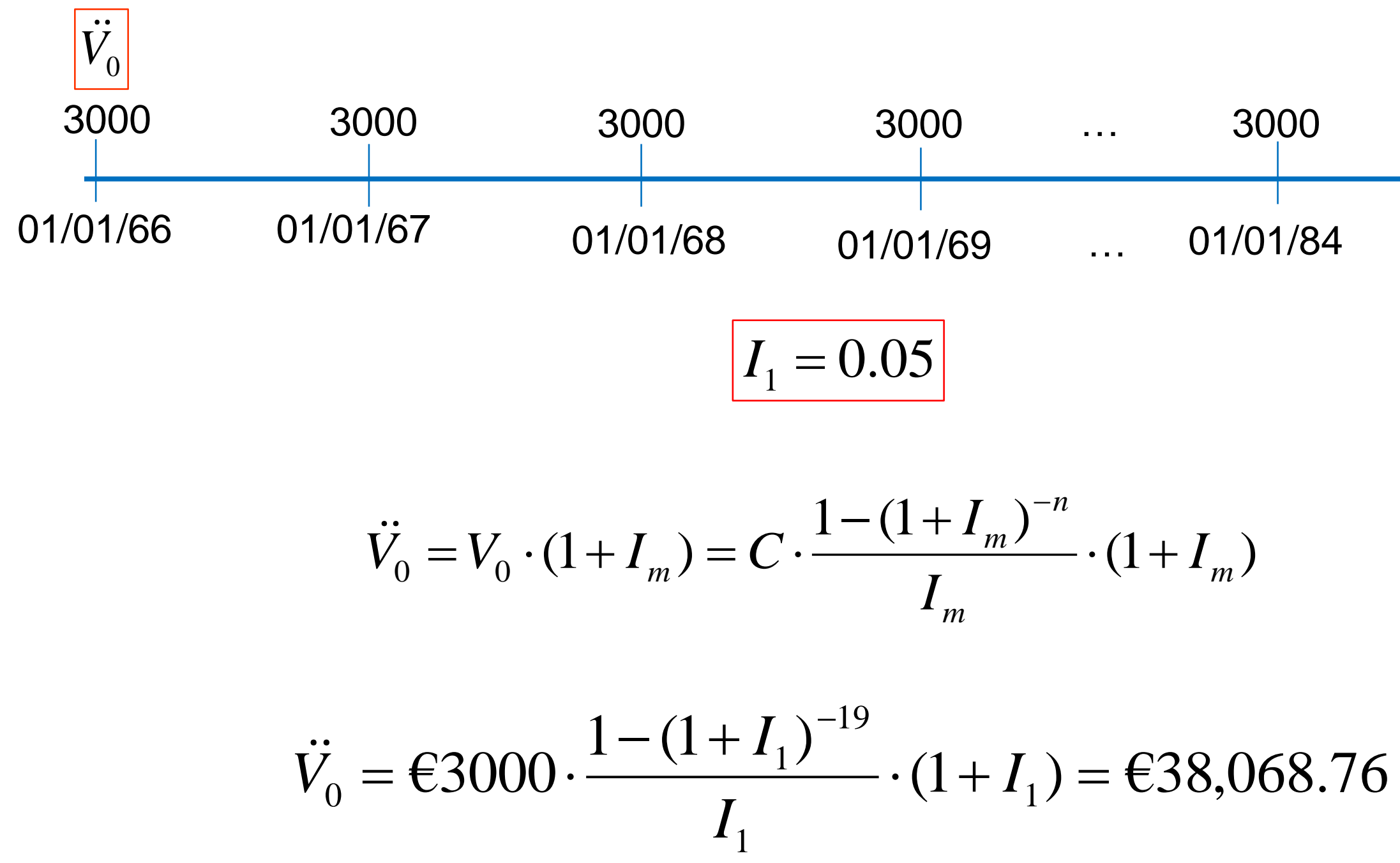




\section{Accumulated value of the annuity-due}

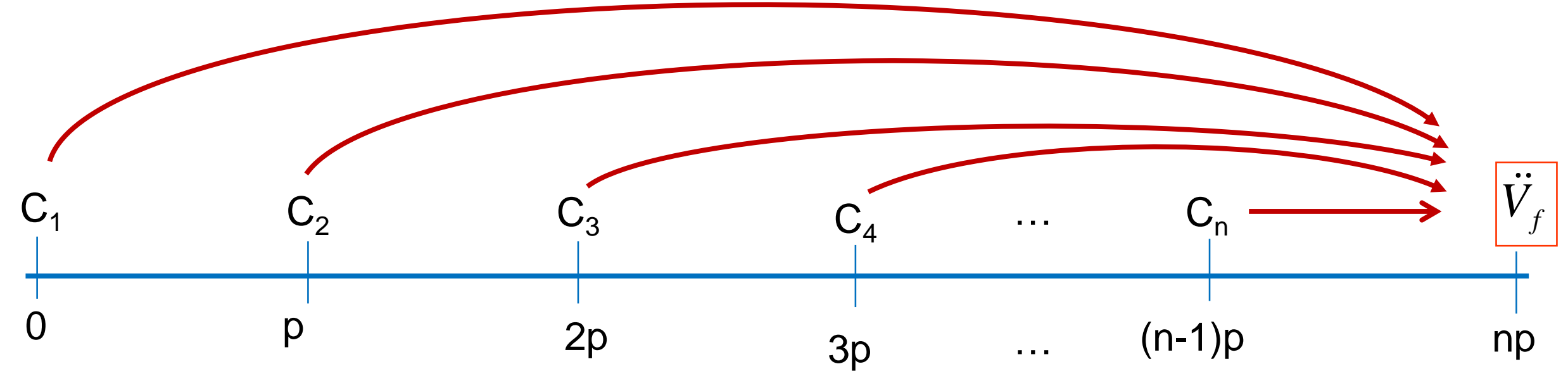

In order to calculate the accumulated value;

$$
\ddot{V}_{f}=C_{1} \cdot\left(1+I_{m}\right)^{n}+C_{2} \cdot\left(1+I_{m}\right)^{n-1}+C_{3} \cdot\left(1+I_{m}\right)^{n-2}+\ldots+C_{n} \cdot\left(1+I_{m}\right)
$$

But it's easier to obtain the accumulated value from the present value:

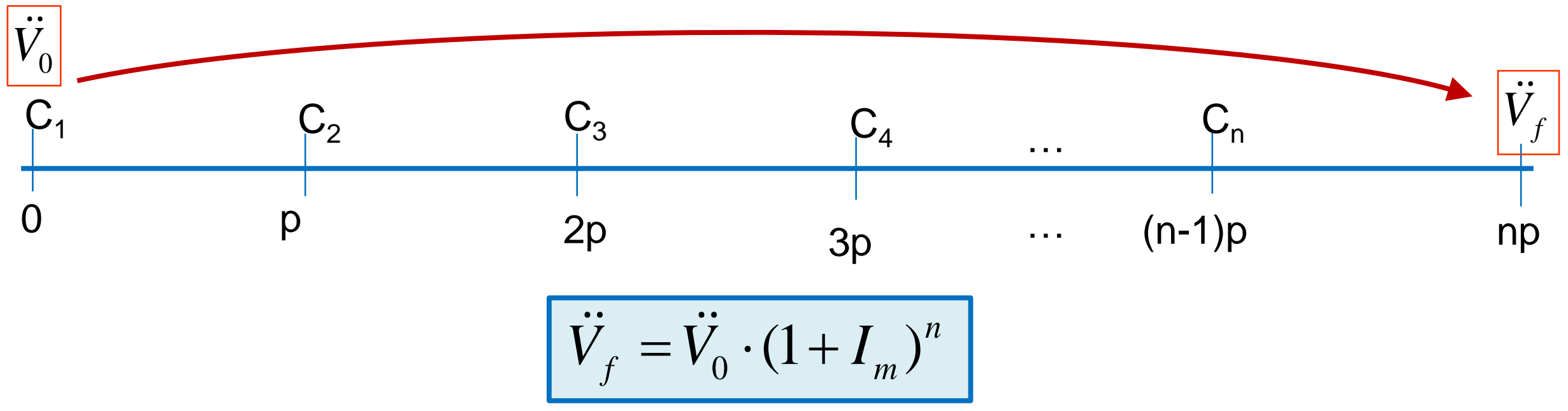




\section{Accumulated value of a constant annuity, $C_{r}=C$}

If $\mathrm{C}_{r}=\mathrm{C}$, that is to say, if all the terms are equal, knowing that the present value of an annuity-due is:

$$
\ddot{V}_{0}=C \cdot \frac{1-\left(1+I_{m}\right)^{-n}}{I_{m}} \cdot\left(1+I_{m}\right)
$$

And

$$
\ddot{V}_{f}=\ddot{V}_{0} \cdot\left(1+I_{m}\right)^{n}
$$

We obtain:

$$
\ddot{V}_{f}=C \cdot \frac{1-\left(1+I_{m}\right)^{-n}}{I_{m}} \cdot\left(1+I_{m}\right) \cdot\left(1+I_{m}\right)^{n}=C \cdot \frac{\left(1+I_{m}\right)^{n+1}-\left(1+I_{m}\right)}{I_{m}}
$$


Example 21: In 1998, Omar had a dividend payment of $€ 100$ directly deposited into his savings account on the first day of each month. Find the accumulated value of these payments at the end of the year if his savings account had a nominal interest rate of $5 \%$ payable monthly.

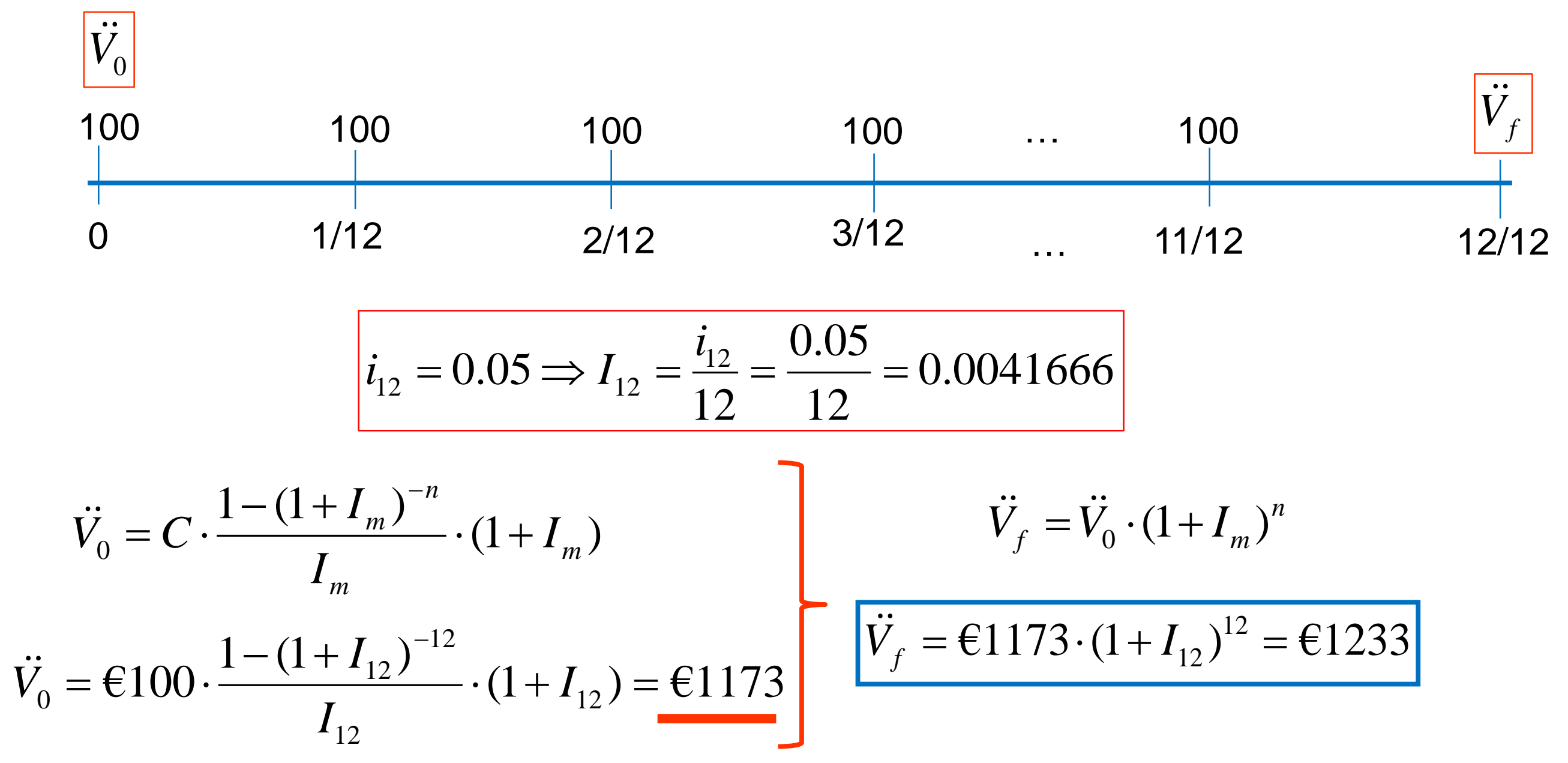

Example 22: In examples 19 and 20, find the accumulated value. 
Example 23: Megan wants to buy a car in 4 years for $€ 18,000$. For four years, at the beginning of each month she deposits $€ C$ into an account that earns $6 \%$ compounded monthly. Calculate C.

Example 24: A worker aged 40 wishes to accumulate a fund for retirement by depositing $€ 1000$ at the beginning of each year for 25 years. The effective interest rate is $8 \%$. Find the accumulated value at the moment the worker is 65 years.

Example 25: Starting at age 65, the worker plans to make 15 annual withdrawals at the end of each year. Find the amount of each withdrawal assuming that they are all equal, starting at the age of 65 .

Example 26: An investor wishes to accumulate $€ 8000$ at the end of 10 years in a fund which earns $4 \%$ effective interest. To accomplish this, the investor considers two options:

- make deposits at the end of each year; or

- make deposits at the beginning of each year. How large should each deposit be under these two options? 


\section{Deferred annuities and values on any date}

\section{Deferred annuities}

In previous sections we have analyzed the present value of annuities at the time of the first payment (annuity-due) or one period before the first payment (immediate annuity).

Now we are going to consider the present value of an annuity supposing that the first payment is at time $d+1$, where $d$ is measured in payment periods. This present value is denoted by: $V_{0}^{d}$.

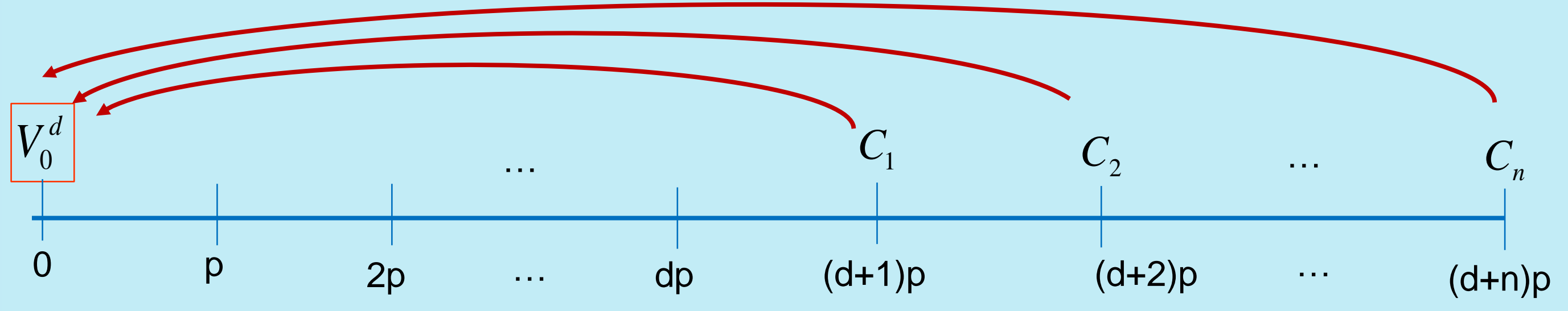

This is called a deferred annuity. In this annuity there is a wait of more than one payment period for a payment.

Note that you can consider an immediate annuity as an annuity-due deferred for one period. 


\section{Present value of the deferred annuity}

To obtain the present value of a deferred annuity we can consider it as an immediate annuity (Situation A) or as an annuity-due (Situation B).

Situation A: we can consider the annuity as an immediate annuity.

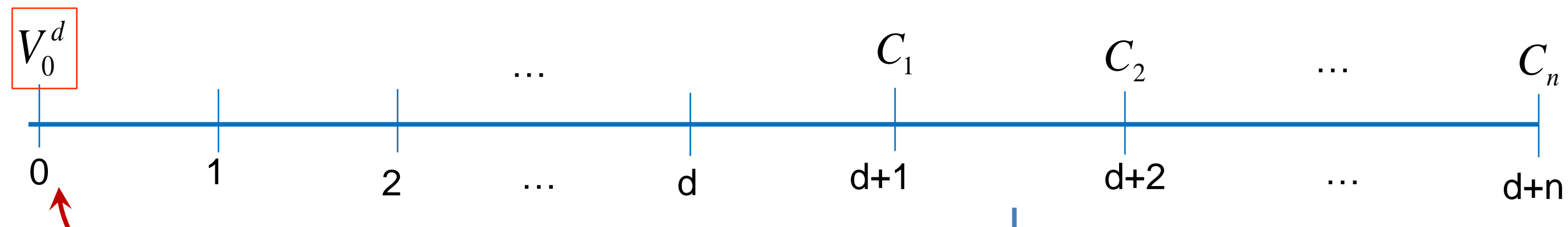

From the deferred annuity, we can obtain an auxiliary annuity.

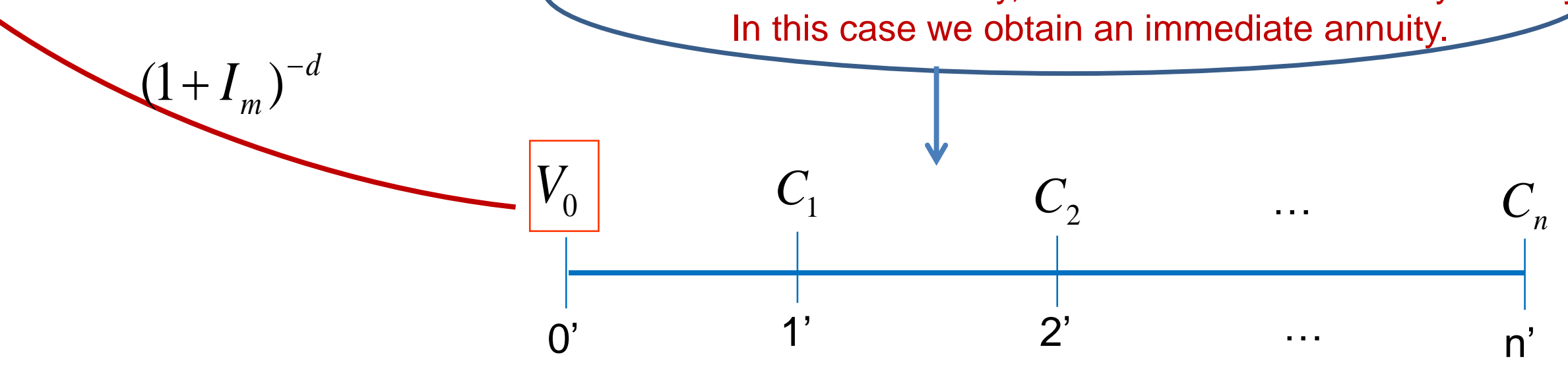

So, the present value of a deferred annuity is the present value at time $d$, discounted for $d$ periods:

$$
V_{0}^{d}=V_{0}\left(1+I_{m}\right)^{-d}
$$




\section{Present value of a constant annuity, $C_{r}=C$}

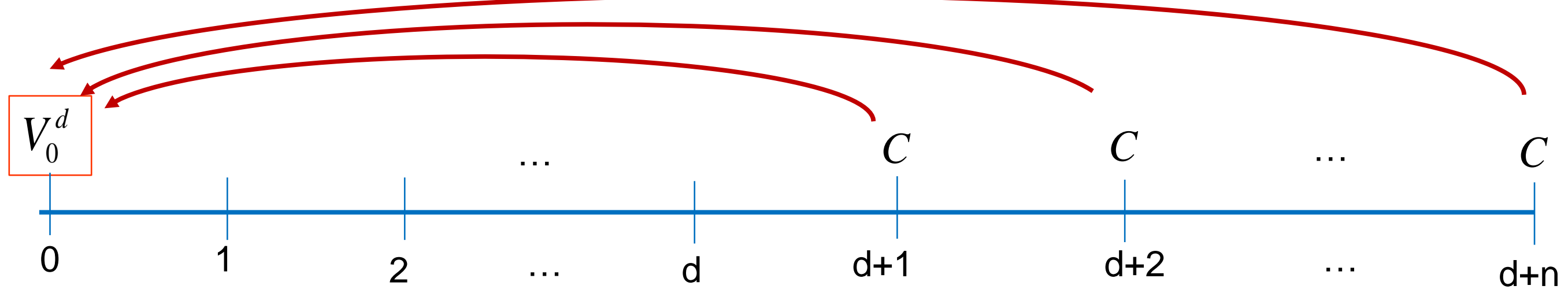

If $\mathrm{C}_{\mathrm{r}}=\mathrm{C}$, that is to say, if all the terms are equal, knowing that for an immediate annuity the present value is:

$$
V_{0}=C \cdot \frac{1-\left(1+I_{m}\right)^{-n}}{I_{m}}
$$

and knowing that the present value of a deferred annuity can be obtained from the present value of an immediate annuity:

$$
V_{0}^{d}=V_{0}\left(1+I_{m}\right)^{-d}
$$

we obtain,

$$
V_{0}^{d}=C \cdot \frac{1-\left(1+I_{m}\right)^{-n}}{I_{m}}\left(1+I_{m}\right)^{-d}
$$


Example 27: Exactly three years from now, the first of four $€ 200$ annual payments will be made, with an effective $8 \%$ rate of interest. Find the present value of the annuity.

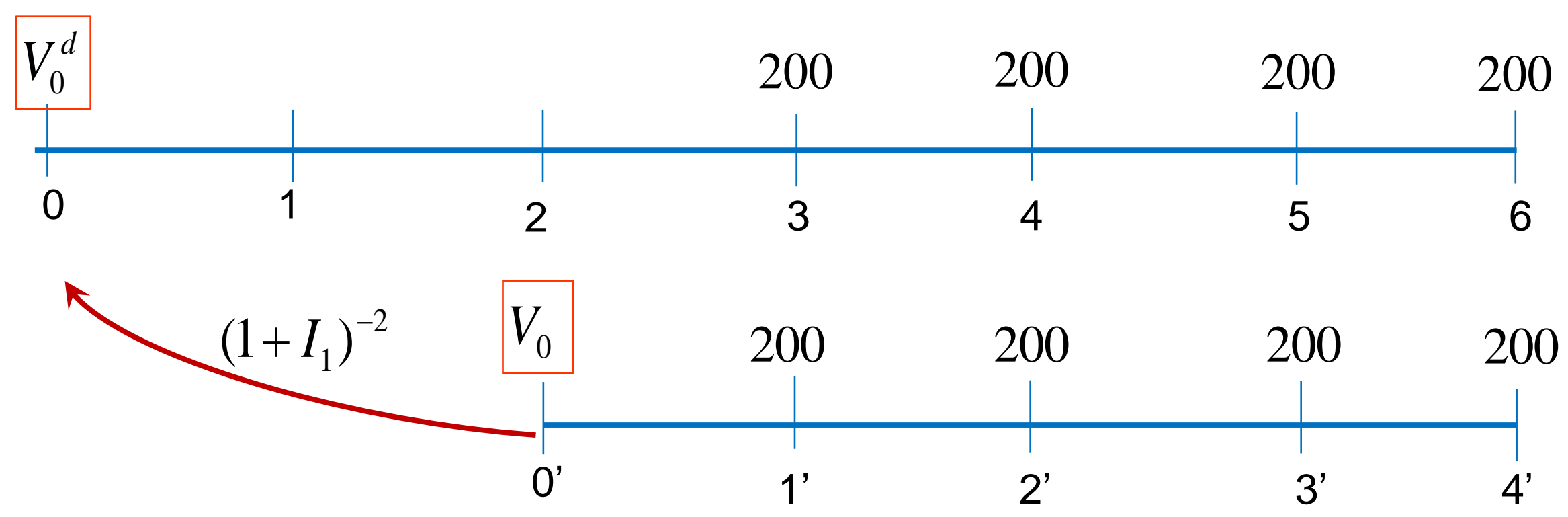

$$
V_{0}=C \cdot \frac{1-\left(1+I_{m}\right)^{-n}}{I_{m}}=€ 200 \cdot \frac{1-\left(1+I_{1}\right)^{-4}}{I_{1}}=€ 662.42
$$

$$
\begin{gathered}
V_{0}^{d}=V_{0}\left(1+I_{m}\right)^{-d} \\
V_{0}^{d}=€ 662.42 \cdot\left(1+I_{1}\right)^{-2}=€ 567.92
\end{gathered}
$$


Example 28: On his eighteenth birthday, Pau receives an annuity that is to pay $€ 5000$ on his twenty-fifth through thirty-ninth birthdays. Calculate the value of the annuity on his eighteen birthday using an annual effective interest rate of $5 \%$.

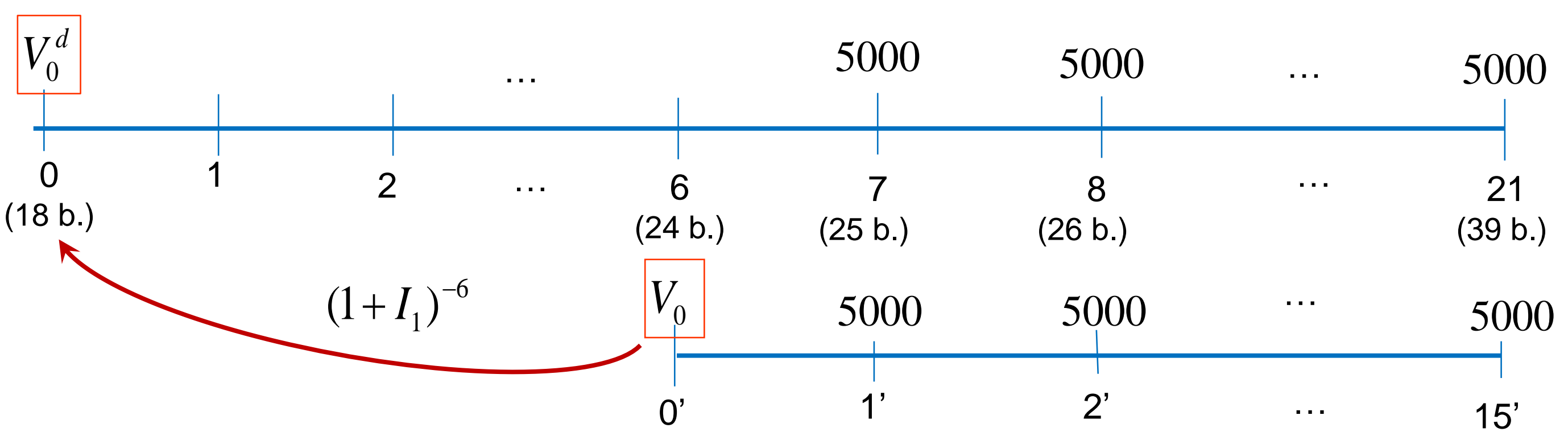

$$
V_{0}=C \cdot \frac{1-\left(1+I_{m}\right)^{-n}}{I_{m}}=€ 5000 \cdot \frac{1-\left(1+I_{1}\right)^{-15}}{I_{1}}=€ 51,898.29
$$

$$
\begin{gathered}
V_{0}^{d}=V_{0}\left(1+I_{m}\right)^{-d} \\
V_{0}^{d}=€ 51,898.29 \cdot\left(1+I_{1}\right)^{-6}=€ 38,727.30
\end{gathered}
$$




\section{Present value of a constant annuity, $C_{r}=C$}

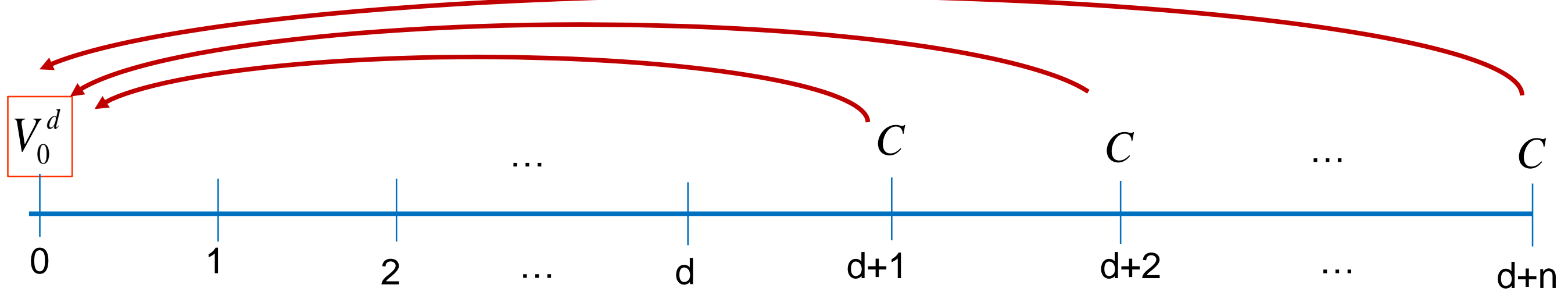

If $\mathrm{C}_{\mathrm{r}}=\mathrm{C}$, that is to say, if all the terms are equal, knowing that for an immediate annuity the present value is:

$$
\ddot{V}_{0}=C \cdot \frac{1-\left(1+I_{m}\right)^{-n}}{I_{m}}\left(1+I_{m}\right)
$$

and knowing that the present value of a deferred annuity can be obtained from the present value of an annuity-due:

$$
V_{0}^{d}=\ddot{V}_{0}\left(1+I_{m}\right)^{-(d+1)}
$$

we obtain;

$$
V_{0}^{d}=C \cdot \frac{1-\left(1+I_{m}\right)^{-n}}{I_{m}} \cdot\left(1+I_{m}\right) \cdot\left(1+I_{m}\right)^{-(d+1)}
$$


Example 29 (following example 27): Exactly three years from now the first of four $€ 200$ annual payments will be made, with an effective $8 \%$ interest rate. Find the present value of the annuity.

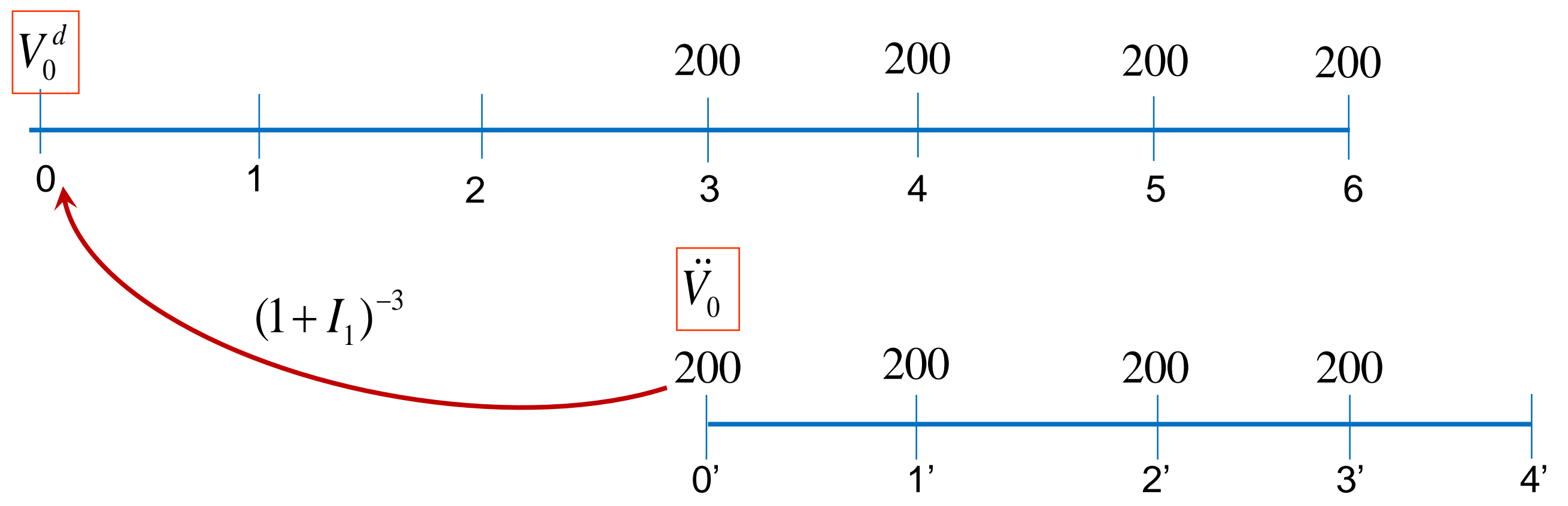

$$
\ddot{V}_{0}=C \cdot \frac{1-\left(1+I_{m}\right)^{-n}}{I_{m}}\left(1+I_{m}\right)=200 \cdot \frac{1-\left(1+I_{1}\right)^{-4}}{I_{1}}\left(1+I_{m}\right)=715^{\prime} 42 €
$$

$$
\begin{gathered}
V_{0}^{d}=\ddot{V}_{0}\left(1+I_{m}\right)^{-(d+1)} \\
V_{0}^{d}=€ 715.42 \cdot\left(1+I_{1}\right)^{-3}=€ 567.92
\end{gathered}
$$


Example 30 (following example 28): On his eighteenth birthday, Pau receives an annuity that is to pay $€ 5000$ on his twenty-fifth through thirty-ninth birthdays. Calculate the value of the annuity on his eighteenth birthday using an annual effective interest rate of $5 \%$.

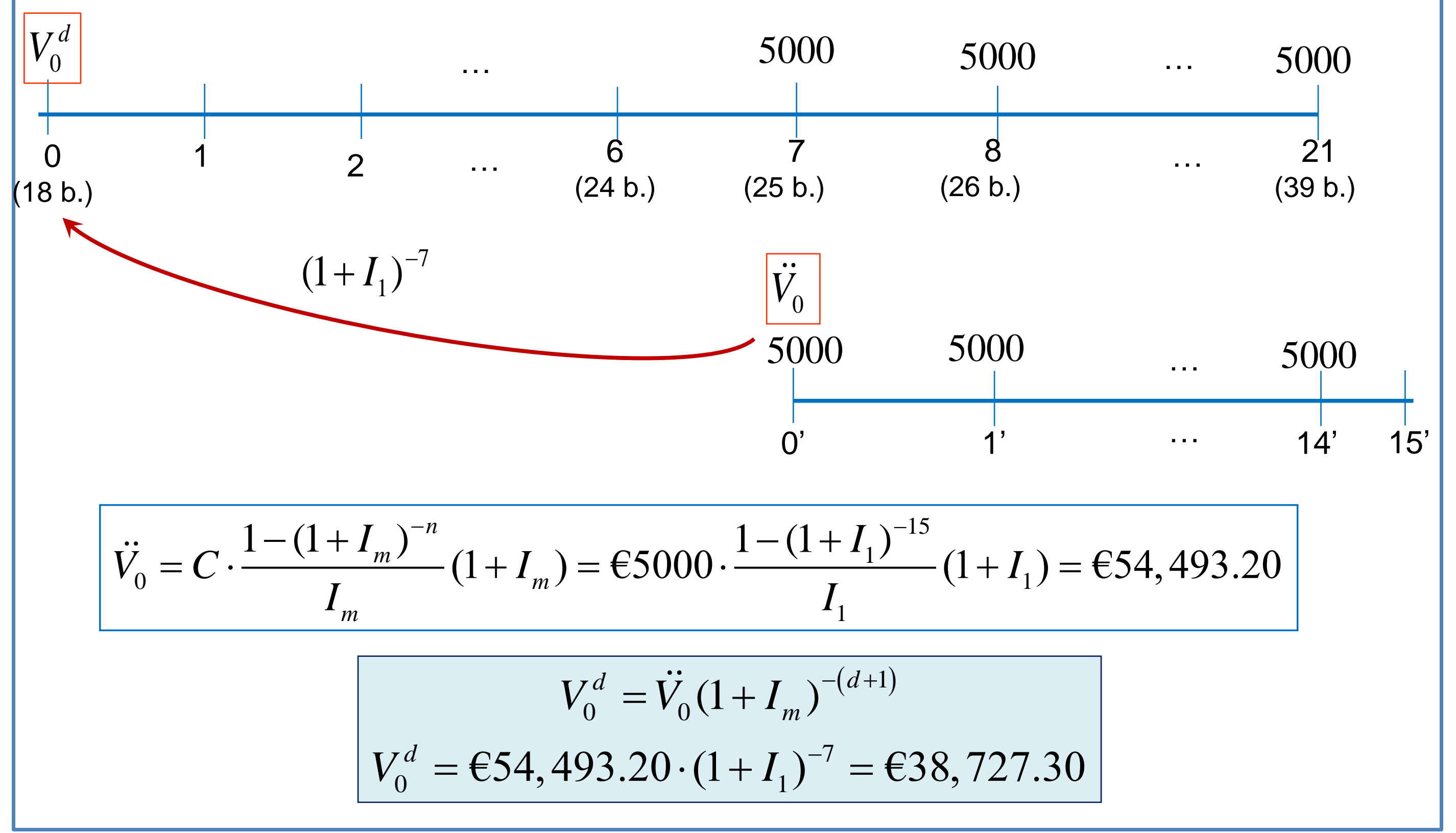




\section{Non-level annuities or varying annuities}

Recall that a non-level annuity means that the payments vary.

We will study:

$\checkmark$ annuities with payments forming a geometric sequence.

$$
C_{r}=C_{1} \cdot q^{r-1}, q>0 \quad \text { and } \quad r=1, \ldots n
$$

$\checkmark$ annuities with payments forming an arithmetic sequence.

$$
C_{r}=C_{1}+(r-1) \cdot h, \quad r=1, \ldots, n
$$




\section{Annuities with payments in geometric progression}

We now consider payments varying in a geometric progression.

In this case, the payments of the annuity are:

$$
C_{r}=C_{1} \cdot q^{r-1}, q>0 \quad \text { and } \quad r=1, \ldots, n
$$

If $q>1$, the terms of the annuity increase

For example, if the terms increase by $5 \%$ (each term is $5 \%$ greater than the preceding payment), then $\mathrm{q}=1.05$.

If $\mathrm{C}_{1}=100$ :

$$
\begin{gathered}
C_{1}=100 \\
C_{2}=C_{1}(1+0.05)=100 \cdot 1.05=105 \\
C_{3}=C_{1}(1+0.05)^{2}=100 \cdot 1.05^{2}=110.25 \\
C_{4}=C_{1}(1+0.05)^{3}=100 \cdot 1.05^{3}=150.76
\end{gathered}
$$

If $q<1$, the terms of the annuity decrease For example, if the terms decrease by $2 \%$ (each term is $2 \%$ less than the preceding payment), then $\mathrm{q}=0.98$.

If $\mathrm{C}_{1}=100$ :

$$
\begin{gathered}
C_{1}=100 \\
C_{2}=C_{1}(1-0.02)=100 \cdot 0.98=98 \\
C_{3}=C_{1}(1-0.02)^{2}=100 \cdot 0.98^{2}=96.04 \\
C_{4}=C_{1}(1-0.02)^{3}=100 \cdot 0.98^{3}=94.11
\end{gathered}
$$




\section{Immediate annuity for $C_{r}=C_{1} \cdot q^{r-1}$}

\section{Present value}

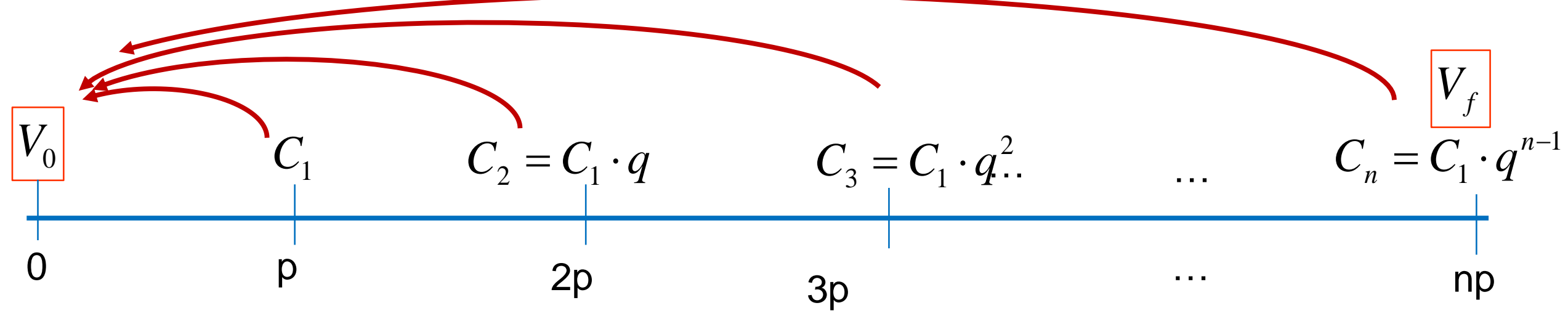

$$
V_{0}=C_{1} \cdot\left(1+I_{m}\right)^{-1}+C_{2} \cdot\left(1+I_{m}\right)^{-2}+C_{3} \cdot\left(1+I_{m}\right)^{-3}+\ldots+C_{n} \cdot\left(1+I_{m}\right)^{-n}=\sum_{i=1}^{n} C_{i} \cdot\left(1+I_{m}\right)^{-i}
$$

From the previous expression it is possible to obtain:

$$
V_{0}=\left\{\begin{array}{llc}
1+I_{m}=q & \Rightarrow & V_{0}=\frac{C_{1} \cdot n}{1+I_{m}} \\
1+I_{m} \neq q & \Rightarrow & V_{0}=C_{1} \frac{1-\left(1+I_{m}\right)^{-n} \cdot q^{n}}{1+I_{m}-q}
\end{array}\right.
$$

\section{Accumulated value}

$$
V_{f}=V_{0} \cdot\left(1+I_{m}\right)^{n}
$$


Example 31: On June 15th 1975 , Roy purchased an immediate annuity with annual payments for twenty-five years. The first payment was $€ 800$ and the payments increased by $3 \%$ each year. The purchase price was based on an annual effective interest rate of $7 \%$. Find that price.

$$
C_{r}=C_{1} \cdot q^{r-1} \Rightarrow C_{r}=800 \cdot 1.03^{r-1} \quad I_{1}=0.07
$$

$$
\begin{aligned}
& \text { Price }=V_{0} \quad 800 \quad 800 \cdot 1.03=824 \quad 800 \cdot 1.03^{2}=848.72 \quad \ldots \quad 800 \cdot 1.03^{24}=1626.23 \\
& \begin{array}{ll|l|l|ll} 
& & & & & \\
\hline 0 & 1 & 2 & 3 & \ldots & 25 \text { years }
\end{array} \\
& V_{0}=C_{1} \frac{1-\left(1+I_{m}\right)^{-n} \cdot q^{n}}{1+I_{m}-q}=\left\{\begin{array}{l}
I_{1}=0.07 \\
C_{1}=800 \\
q=1.03
\end{array}\right\}=800 \frac{1-\left(1+I_{1}\right)^{-25} \cdot 1.03^{25}}{1+I_{1}-1.03}=12,284.46 \\
& \underline{V_{f}}=V_{0} \cdot\left(1+I_{m}\right)^{n}=12,284.46 \cdot\left(1+I_{1}\right)^{25}=\underline{66,673.07}
\end{aligned}
$$




\section{Annuity-due for $C_{r}=C_{1} \cdot q^{r-1}$}

\section{Present value}

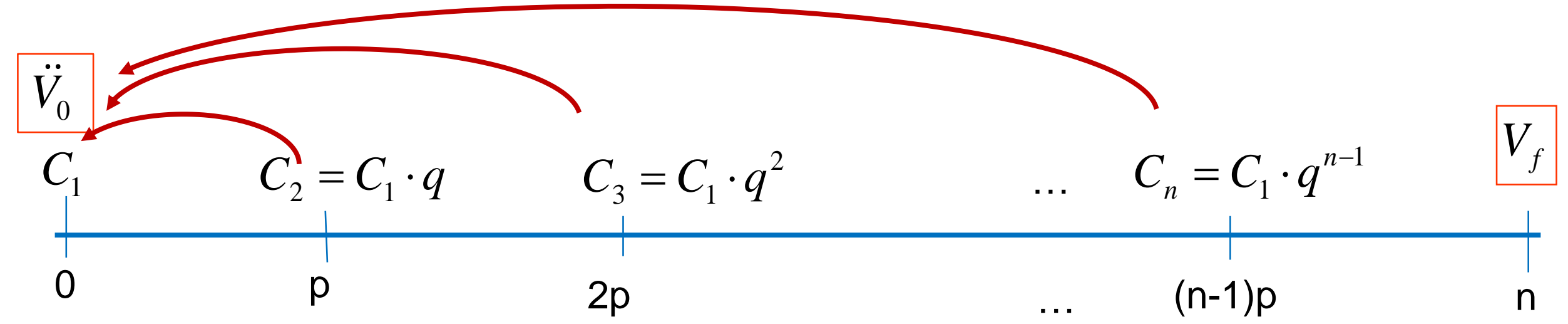

We know that the present value of an annuity-due, $\ddot{V}_{0}$, can be obtained from the present value of an immediate annuity: $V_{0} \Rightarrow \ddot{V}_{0}=\left(1+I_{m}\right) \cdot V_{0}$

So, we only have to multiply the previous expressions for $V_{0}$ by $\left(1+I_{m}\right)$

$$
\ddot{V}_{0}=\left\{\begin{array}{lcc}
1+I_{m}=q & \Rightarrow & \ddot{V}_{0}=\frac{C_{1} \cdot n}{1+I_{m}}\left(1+I_{m}\right) \\
1+I_{m} \neq q & \Rightarrow & \ddot{V}_{0}=C_{1} \frac{1-\left(1+I_{m}\right)^{-n} \cdot q^{n}}{1+I_{m}-q}\left(1+I_{m}\right)
\end{array}\right.
$$

\section{Accumulated value}

$$
V_{f}=\ddot{V}_{0} \cdot\left(1+I_{m}\right)^{n}
$$


Example 32: On January $1^{\text {st }} 2002$, Andrea inherits an annuity-due with monthly payments for the next ten years. The first payment is $€ 2000$ and after that the payments increase by $2 \%$. Find the value of this annuity on January $1^{\text {st }} 2002$, and at the end of the last period (accumulated value) if the annual effective rate of interest is $3 \%$.

$$
\begin{aligned}
& C_{r}=C_{1} \cdot q^{r-1} \Rightarrow C_{r}=2000 \cdot 1.02^{r-1} \\
& I_{1}=0.03 \Rightarrow I_{12}=\left(1+I_{1}\right)^{\frac{1}{12}}-1=0.002466 \\
& \ddot{V}_{0} \\
& 2000
\end{aligned}
$$

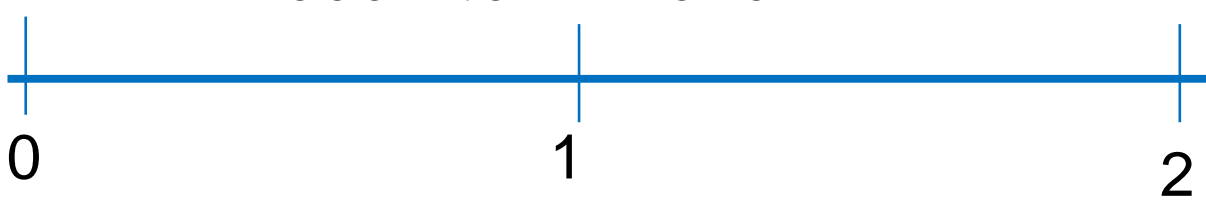

$$
\begin{aligned}
& \begin{aligned}
\underline{\ddot{V}_{0}} & =C_{1} \frac{1-\left(1+I_{m}\right)^{-n} \cdot q^{n}}{1+I_{m}-q}\left(1+I_{m}\right)=\left\{\begin{array}{c}
I_{12}=0.002466 \\
C_{1}=€ 2000 \\
q=1.02
\end{array}\right\}= \\
& =€ 2000 \frac{1-\left(1+I_{12}\right)^{-120} \cdot 1.02^{120}}{1+I_{12}-1.02}\left(1+I_{12}\right)=€ 801,624.15
\end{aligned} \\
& \underline{V_{f}}=\ddot{V}_{0} \cdot\left(1+I_{m}\right)^{n}=€ 801,624.15 \cdot\left(1+I_{12}\right)^{120}=€ 1,077,281.03
\end{aligned}
$$


Example 33: The first of 40 payments of an annual annuity occurs in exactly one year and is equal to $€ 300$. The payments increase so that each payment is $3 \%$ greater than the preceding payment.

a) Find the present value of this annuity with an annual effective rate of interest of $8 \%$.

b) Find the present value of this annuity if the first payment is made in exactly 5 years.

Example 34: A monthly two-year immediate annuity pays $€ 200$ at the end of the first month. The payments grow at a monthly rate of $2.5 \%$.

a) What is the present value of this set of payments at an annual effective rate of interest of $4 \%$ ?

b) Find the accumulated value in two years.

Example 35: A small business pays you a quarterly profit at the beginning of each quarter for 10 years. The payments decrease by $2 \%$. The first payment is $€ 1500$. The annual effective interest rate is $5 \%$.

a) What is the present value of this annuity?

b) And the accumulated value in 10 years? 


\section{Annuities with payments in arithmetic progression}

Let us assume that payments vary following an arithmetic progression. In this case, the payments of the annuity are:

$$
C_{r}=C_{1}+(r-1) \cdot h, \quad r=1, \ldots, n
$$

The first payment is $\mathrm{C}_{1}$ and the payments increase by the constant amount $\mathrm{h}$ each payment period

\section{If $h>0$, the terms of the annuity increase}

For example, if the payments increase by $€ 50$ each payment period, then $\mathrm{h}=50$.

If $\mathrm{C}_{1}=1000$ :

$$
\begin{gathered}
C_{1}=1000 \\
C_{2}=C_{1}+(2-1) \cdot 50=1050 \\
C_{3}=C_{1}+(3-1) \cdot 50=1100 \\
C_{4}=C_{1}+(4-1) \cdot 50=1150
\end{gathered}
$$

If $h<0$, the terms of the annuity decrease For example, if the terms decrease by $€ 20$ each payment period, then $\mathrm{h}=-20$.

If $\mathrm{C}_{1}=1000$ :

$$
\begin{gathered}
C_{1}=1000 \\
C_{2}=C_{1}+(2-1) \cdot(-20)=980 \\
C_{3}=C_{1}+(3-1) \cdot(-20)=960 \\
C_{4}=C_{1}+(4-1) \cdot(-20)=940
\end{gathered}
$$




\section{Immediate annuity for $C_{r}=C_{1}+(r-1) \cdot h$}

\section{Present value}

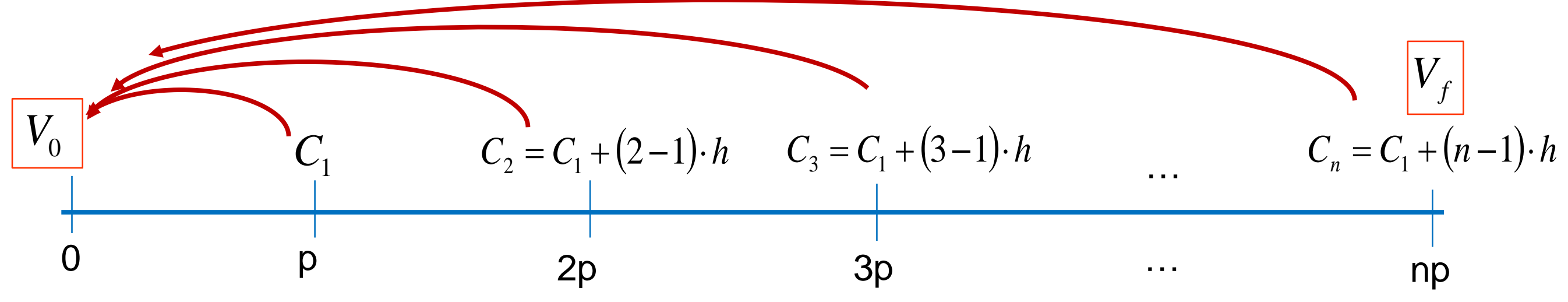

$$
V_{0}=C_{1} \cdot\left(1+I_{m}\right)^{-1}+C_{2} \cdot\left(1+I_{m}\right)^{-2}+C_{3} \cdot\left(1+I_{m}\right)^{-3}+\ldots+C_{n} \cdot\left(1+I_{m}\right)^{-n}=\sum_{i=1}^{n} C_{i} \cdot\left(1+I_{m}\right)^{-i}
$$

The previous expression can be rewritten as:

$$
\begin{aligned}
V_{0} & =\left(C_{1}+n \cdot h+\frac{h}{I_{m}}\right) a_{\bar{n} \mid I_{m}}-\frac{n \cdot h}{I_{m}}= \\
& =\left(C_{1}+n \cdot h+\frac{h}{I_{m}}\right) \frac{1-\left(1+I_{m}\right)^{-n}}{I_{m}}-\frac{n \cdot h}{I_{m}}
\end{aligned}
$$

\section{Accumulated value}

$$
V_{f}=V_{0} \cdot\left(1+I_{m}\right)^{n}
$$


Example 36: Susan receives an annuity for her eighteenth birthday. The annuity pays $€ 2000$ on her nineteenth birthday and then has an annual payment on each of her birthdays through her thirty-fifth birthday. Each year the payments increase by $€ 500$. Find the value of the annuity on Susan's eighteenth birthday, assuming the annual effective rate of interest is $4.2 \%$. Calculate the accumulated value on Susan's thirty-fifth birthday.

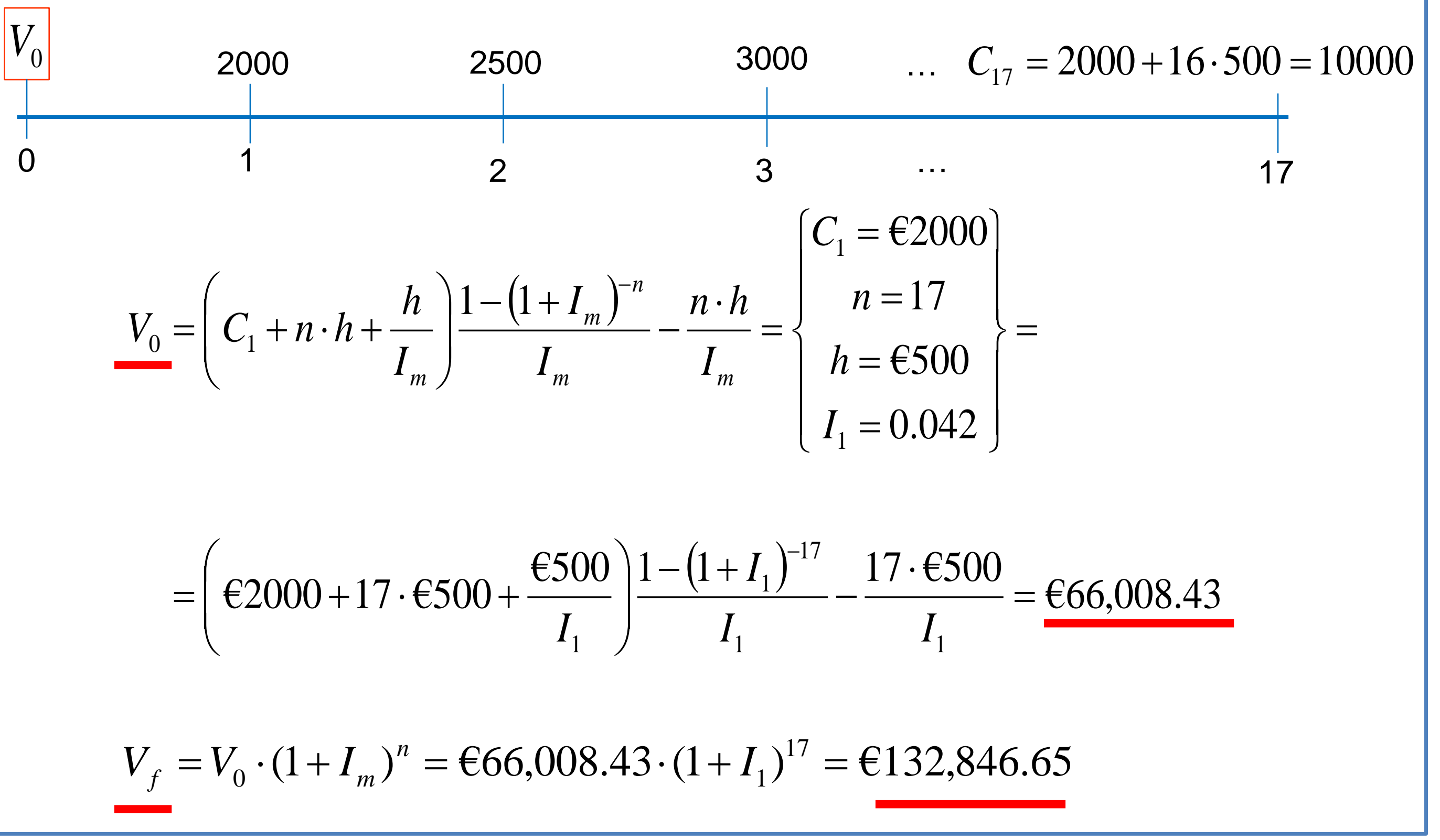




\section{Annuity-due for $C_{r}=C_{1}+(r-1) \cdot h$}

\section{Present value}

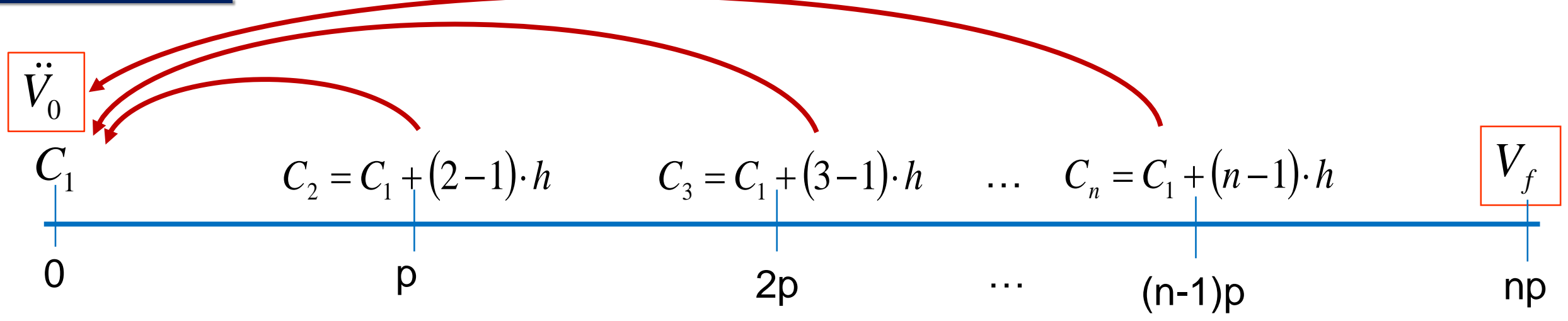

We know that the present value of an annuity-due, $\ddot{V}_{0}$, can be obtained from the present value of an immediate annuity: $V_{0} \Rightarrow \ddot{V}_{0}=\left(1+I_{m}\right) \cdot V_{0}$

So, we only have to multiply the previous expressions for $V_{0}$ by $(1+\operatorname{lm})$

$$
\ddot{V}_{0}=\left(\left(C_{1}+n \cdot h+\frac{h}{I_{m}}\right) \cdot a_{\bar{n} \mid I_{m}}-\frac{n \cdot h}{I_{m}}\right) \cdot\left(1+I_{m}\right)
$$

\section{Accumulated value}

$$
V_{f}=\ddot{V}_{0} \cdot\left(1+I_{m}\right)^{n}
$$


Example 37: Bob receives $€ 400$ at the beginning of the first year, $€ 350$ at the beginning of the second year, $€ 300$ at the beginning of the third year and so on until a final payment of $€ 50$. Using an annual effective interest rate of $3.5 \%$, calculate the present value.

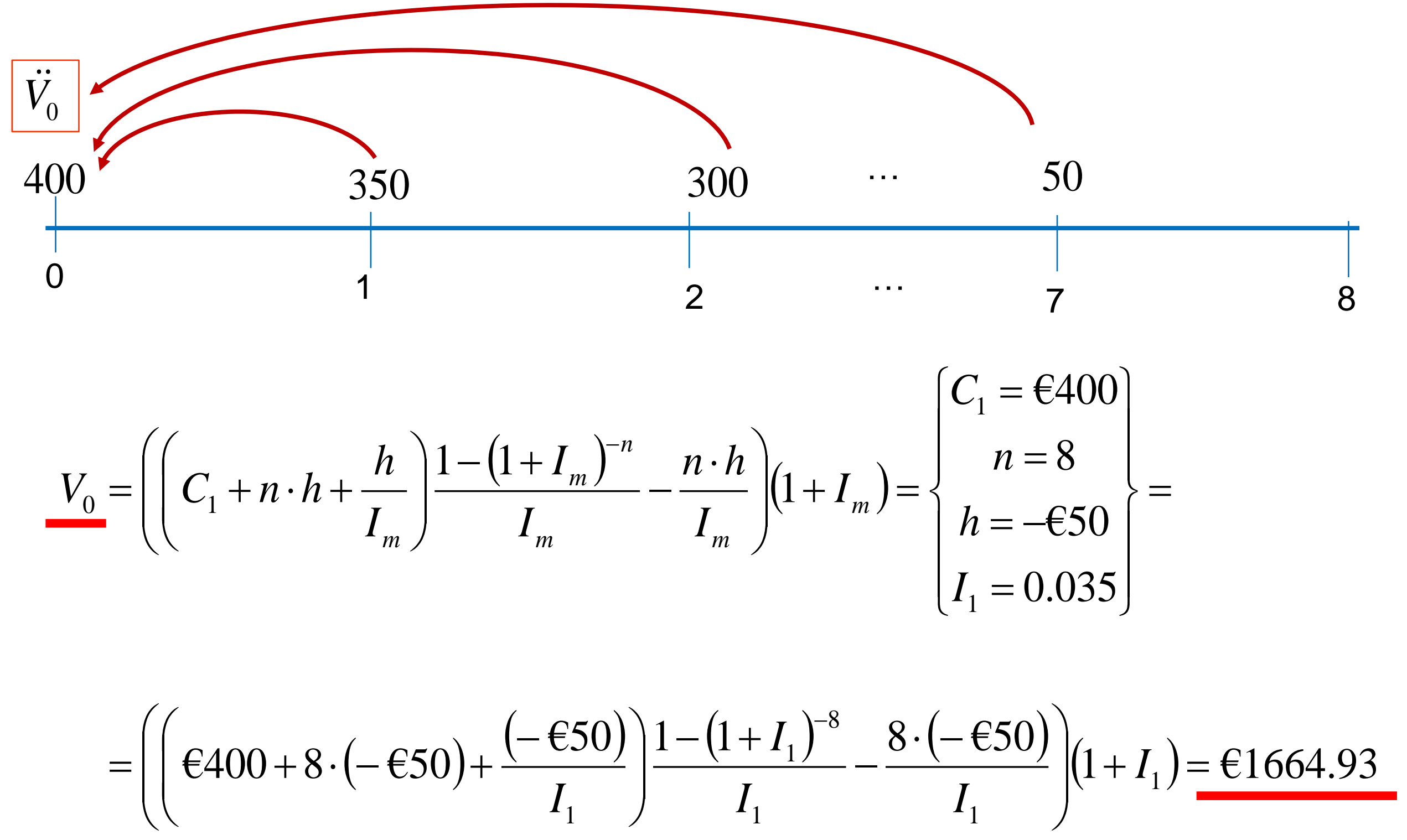


Example 38: Alfonso has an annuity that will pay $€ 4000$ on October 30th 2010 and has monthly payments through October 30th 2024. The payments increase by $€ 80$ each month. The effective monthly interest rate is $0.5 \%$.

- Find the value of the annuity on September 30th 2010.

- Find the present value of the annuity on August 30th 2010.

- Find the accumulated value on October 30th 2014.

- Find the accumulated value on October 30th 2024.

Example 39: The following payments are to be received: $€ 500$ at the end of the first year, $€ 520$ at the end of the second year, $€ 540$ at the end of the third year, and so on, until a final payment of $€ 800$. Using an annual effective interest rate of $2 \%$, find the present value of these payments at time 0 and the accumulated value of the payments at the time of the last one. 


\section{Perpetuities}

A perpetuity is an annuity with an infinite term. That is to say, a perpetuity has payments that last forever.

In order to obtain the formula for the present value of an annuity with infinite payments, which is called $V_{0}^{\infty}$, we apply:

$$
V_{0}^{\infty}=\lim _{n \rightarrow \infty} V_{0}
$$

So,

constant annuity $\Rightarrow V_{0}^{\infty}=\frac{C}{I_{m}}$

annuity with payments in geometric progression $\Rightarrow V_{0}^{\infty}=\left\{q<1+I_{m}\right\}=C_{1} \frac{1}{1+I_{m}-q}$

annuity with payments in arithmetic progression $\Rightarrow V_{0}^{\infty}=\left(C_{1}+\frac{h}{I_{m}}\right) \cdot \frac{1}{I_{m}}$ 
The previous formulas are used when the first payment occurs one period from now (perpetuityimmediate).

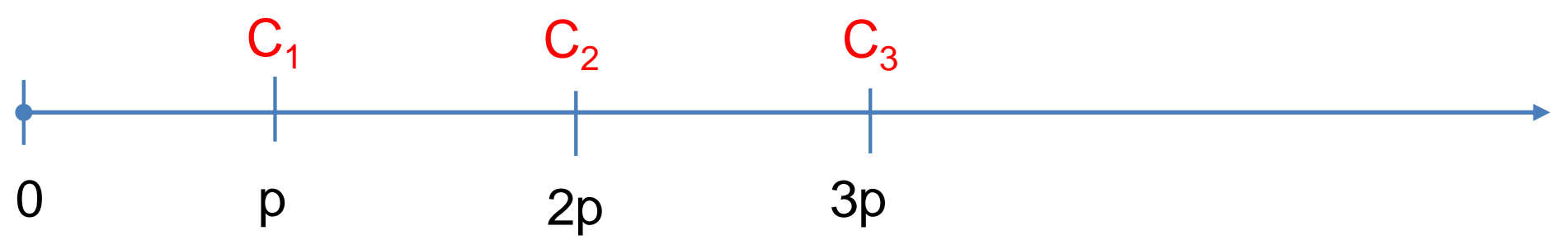

If the first payment occurs immediately, that is to say, at the beginning of each period (perpetuitydue), then:

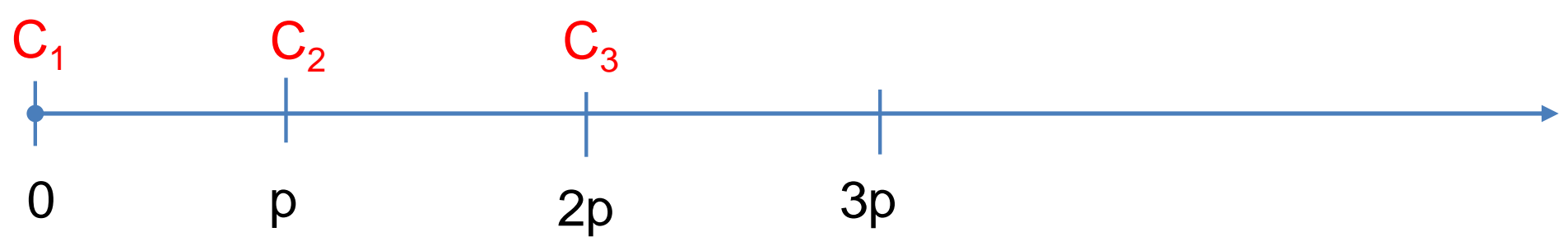

$$
\ddot{V}_{0}^{\infty}=\left(1+I_{m}\right) \cdot V_{0}^{\infty}
$$


Example 40: Gustave has saved $€ 20,000$. On January $1^{\text {st }}$ he purchased a perpetuity with constant end-of-month payments. The perpetuity price is based on an annual effective interest rate of $5 \%$. What are the monthly payments for Gustave's perpetuity?

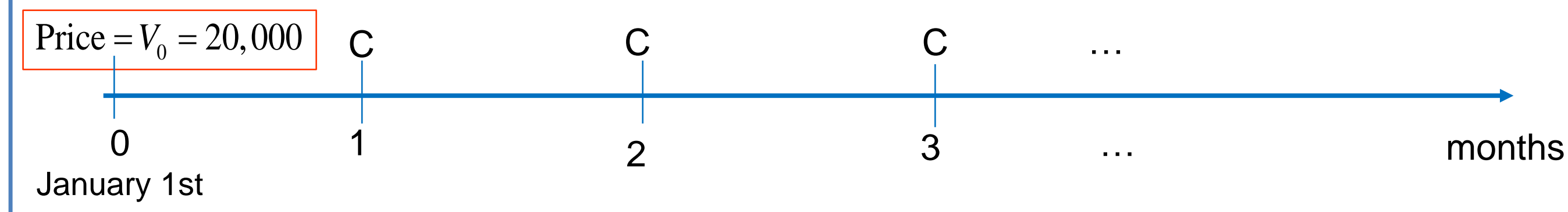

$$
\begin{gathered}
I_{12}=\left(1+I_{1}\right)^{\frac{1}{12}}-1=\left\{I_{1}=0.05\right\}=(1.05)^{\frac{1}{12}}-1=0.0040741 \\
V_{0}^{\infty}=\frac{C}{I_{m}}
\end{gathered}
$$

$$
€ 20,000=\frac{C}{I_{12}} \Rightarrow C=€ 20,000 \cdot I_{12}=€ 81.48
$$


Example 41: A company issues stock that indefinitely pays a dividend at the end of each year of $€ 10$. The annual effective interest rate is $6 \%$. What is the value of the stock at the beginning of the year?

Example 42: What would you be willing to pay for an infinite stream of annual $€ 37$ payments beginning now if the monthly effective interest rate is $1.5 \%$ ?

Example 43: Fifty euros is paid at the end of each year forever, starting six years from now. Assume that the annual effective rate of interest is $10 \%$. Find the present value of the investment. - Find the present value if each payment is $€ 1$ greater than the preceding figure.

Example 44: Raquel wishes to endow her university with a professorship. She wants to know what amount she must contribute to leave an annual salary of $€ 20,000$ at the end of the first year, with payments increasing by $3 \%$ each year forever. Find the initial contribution if the quarterly effective interest rate is $1 \%$. 


\section{Annuity exercises}

Example 45: Gala received a gift of a thirty-year immediate annuity on the day she was born. The annuity pays $€ 1000$ on her first ten birthdays, $€ 2000$ on her next ten birthdays, and $€ 3000$ on the following ten birthdays. If the nominal rate of interest is $5 \%$ compounded quarterly, find the value of the annuity on the day she was born.

Example 46: Pau wishes to contribute $€ 100$ at the end of each month to his savings account until the account has a balance of $€ 3204.22$, at which time he will buy a piano. Pau's saving account has an annual interest rate of $5.4 \%$ compounded monthly. How many months will it take Pau to accumulate the money he needs?

Example 47: In 2013, Marc has a dividend payment of $€ 1250$ deposited directly into his savings account on the first day of every two months. Find the accumulated value of these payments at the end of the year if his savings account has a nominal interest rate of $4 \%$ payable monthly.

Example 48: Sara wishes to purchase a house. She has saved up $€ 13,200$ for a down payment. Based on her earnings, she qualifies for a thirty-year mortgage with level monthly payments of $€ 820$ with a nominal interest rate of $5.85 \%$ convertible monthly. Her payments are due at the end of each month. How expensive is that flat? 


\begin{abstract}
Example 49: Fran purchases a perpetuity-immediate. The perpetuity pays $€ 1000$ at the end of each of the first eleven years and then has payments that increase by $€ 180$ each year. So, the payment at time 11 is $€ 1000$, and the payment at time 12 is $€ 1180$. The purchase price was determined using a 5\% annual effective interest rate. Find Fran's purchase price.
\end{abstract}

Example 50: Paola receives a fifty-year annuity-due that has payments that start at $€ 2000$ and increase by $3 \%$ per year through the twenty-fourth payment, then stay level at $€ 4000$. Find the accumulated value of this annuity at the end of fifty years if the annual effective interest rate remains at $4.2 \%$ throughout the time of the annuity.

Example 51: Pau wins a prize. He has a choice of receiving a payment of $€ 160,000$ immediately or of receiving a deferred perpetuity with $€ 1000$ annual payments, the first payment occurring in exactly four years. Which has a greater present value if the calculation is based on an annual effective interest rate of $5 \%$ ?

Example 52: Marc is given a fifteen-year annuity with end-of-month payments. The first payment Marc receives, precisely one year from the date he is given the annuity, is of $€ 100$, and the subsequent payments decrease by $4 \%$ monthly. Calculate the present value and the accumulated value using an annual effective interest rate of $3 \%$. 
Example 53: Consider an immediate annuity with annual payments for twenty years. The payments are level throughout the first 10 years, the amount being $€ 1000$. The next payment is $€ 100$ greater than the preceding one, and so on. Find the present value of this annuity if the annual effective interest rate is $3 \%$.

Example 54: Erik receives an eight-year immediate annuity with monthly payments. The first payment is $€ 300$ and payments increase by $€ 6$ each month. The payments are deposited in an account earning interest at a nominal interest rate of $6 \%$ compounded monthly. What is the balance in the account at the end of the eighth year? 


\section{LOANS}

$\checkmark$ Definition: a loan of amount C

$\checkmark$ Classification

$\checkmark$ Loans repaid by a single repayment ( $\left.C^{\prime}\right)$ at the end of the loan

$\checkmark$ "Non-amortizing loan" or "interest only loan"

$\checkmark$ Amortizing loans (level payments)

$\checkmark$ Amortizing loan with a waiting period, $d$ 


\section{Definition: A loan of amount C}

This is an arrangement by which a lender gives money (C: called principal of the loan) to a borrower, and must be repaid with interest at some point in the future.

Some loans are repaid by a single payment or a few payments, whose amounts and times are agreed upon at the time of the loan.

\section{Classification}

- Loans repaid by a single repayment $\left(C^{\prime}\right)$ at the end of the financial transaction, which includes the principal and the interest.

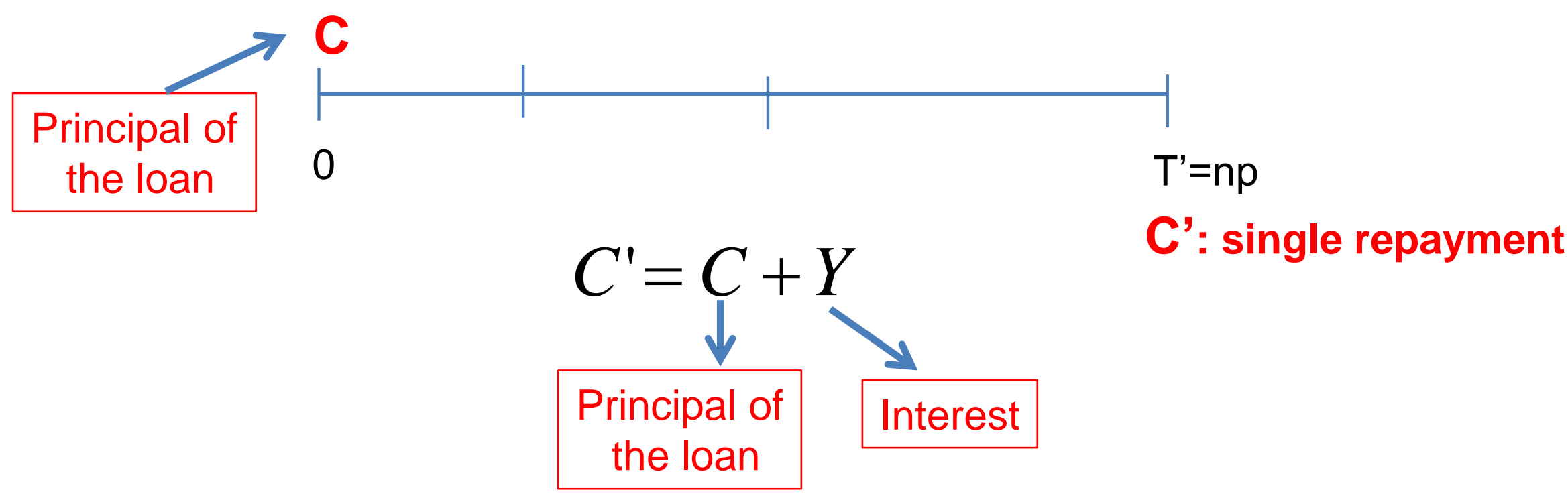


- "Non-amortizing loan" or "interest only loan": one possible way to structure the repayment of a loan is for the borrower to pay the interest on the loan periodically $(\mathrm{Y})$ but to make no partial repayments of the loan principal.

That is to say, loans repaid by payments of interest at the end of each period $(\mathrm{Y})$, and the principal is then paid as a lump sum at the end of the loan (C).

C: principal

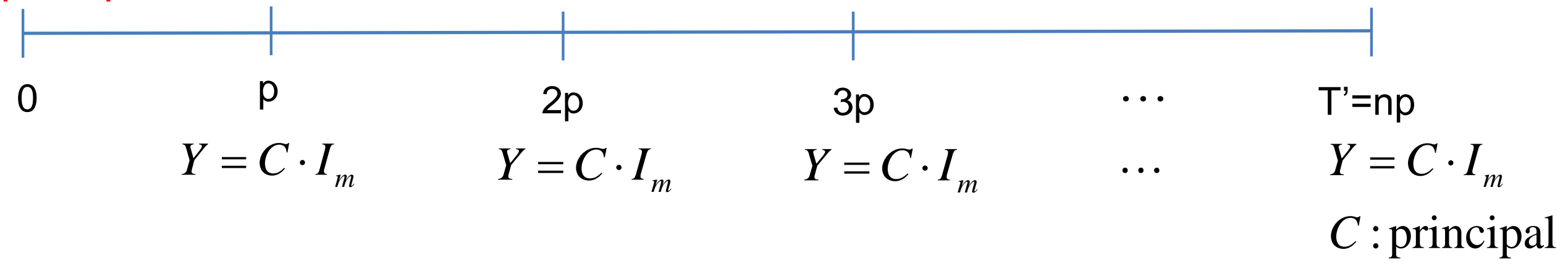

You pay $Y$ (interest) at the end of each period, and at the end of the loan, you repay $C$ (the principal or amount of the loan). 
"Amortizing loan": this is a loan where the principal of the loan is paid back over the life of the loan (that is, amortized) according to an amortization schedule.

We will study loans repaid with level repayments $(\alpha)$ at the end of each period.

These repayments $(\alpha)$ include:

- partial repayment of the principal of the loan $\left(A_{r}\right)$; and

- payments of interest $\left(\mathrm{Y}_{\mathrm{r}}\right)$.

C: principal

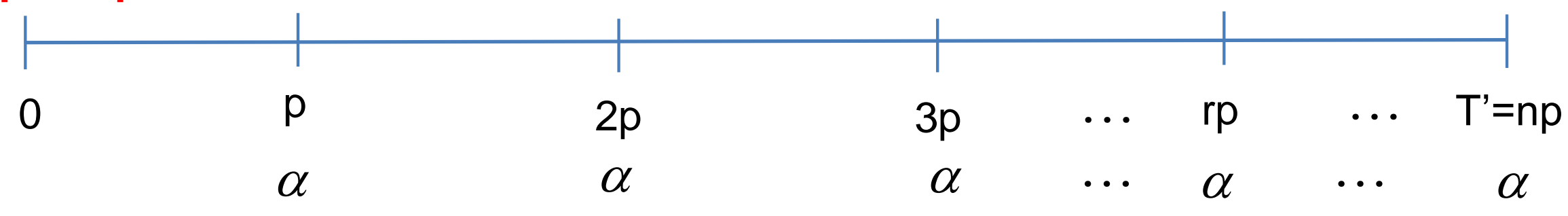

where $\alpha$ is the level repayment at the end of each period $\alpha=Y_{r}+A_{v}, r=1, \ldots, n$

Payment of interest

$$
Y_{r}, r=1, \ldots, n
$$

Partial repayment of the principal

$$
\begin{gathered}
A_{r}, r=1, \ldots, n \\
C=\sum_{i=1}^{n} A_{i}
\end{gathered}
$$




\section{Loans repaid by a single repayment $\left(C^{\prime}\right)$ at the end of the loan}

C: principal
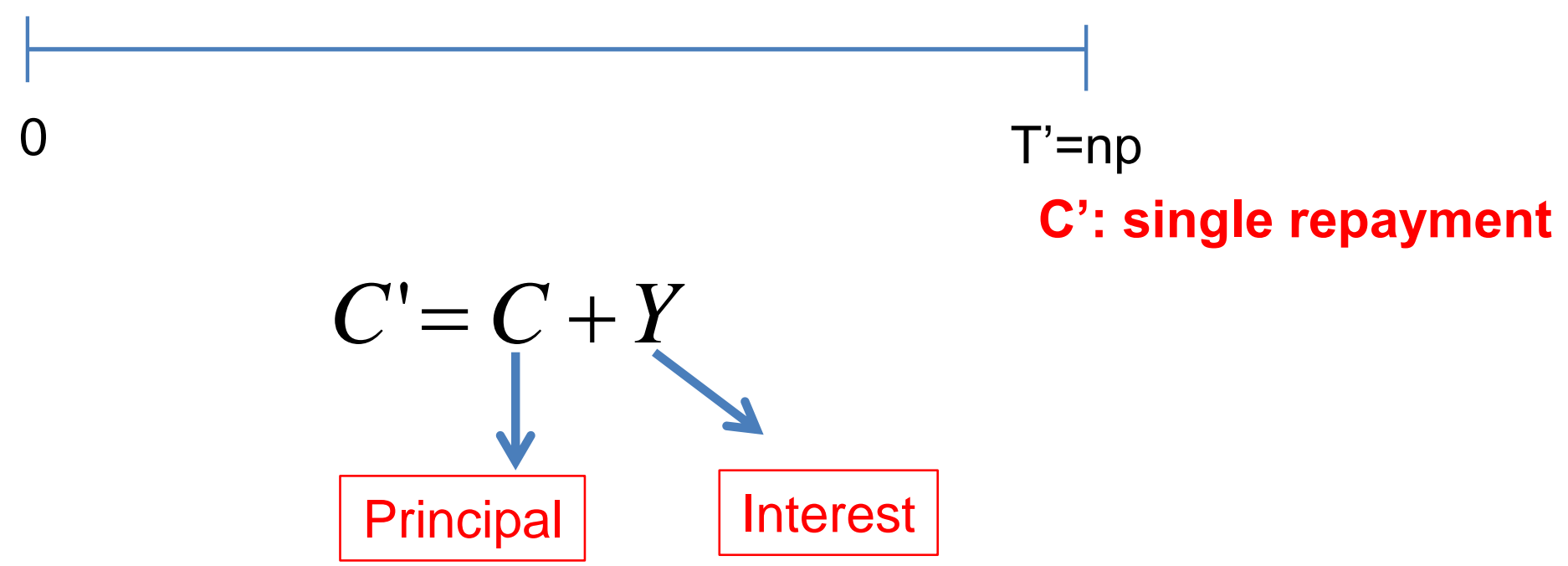

Initial equilibrium equation:

$$
(C, 0) \sim\left(C^{\prime}, T^{\prime}\right)
$$

Assuming compound interest:

$$
C^{\prime}=C\left(1+I_{m}\right)^{n}
$$


Example 1: A loan with a principal of $€ 2600$ is being repaid by a single amount in two years. If the nominal rate of interest compounded semi-annually is $8 \%$, find the amount, $\mathrm{C}$, to be repaid.

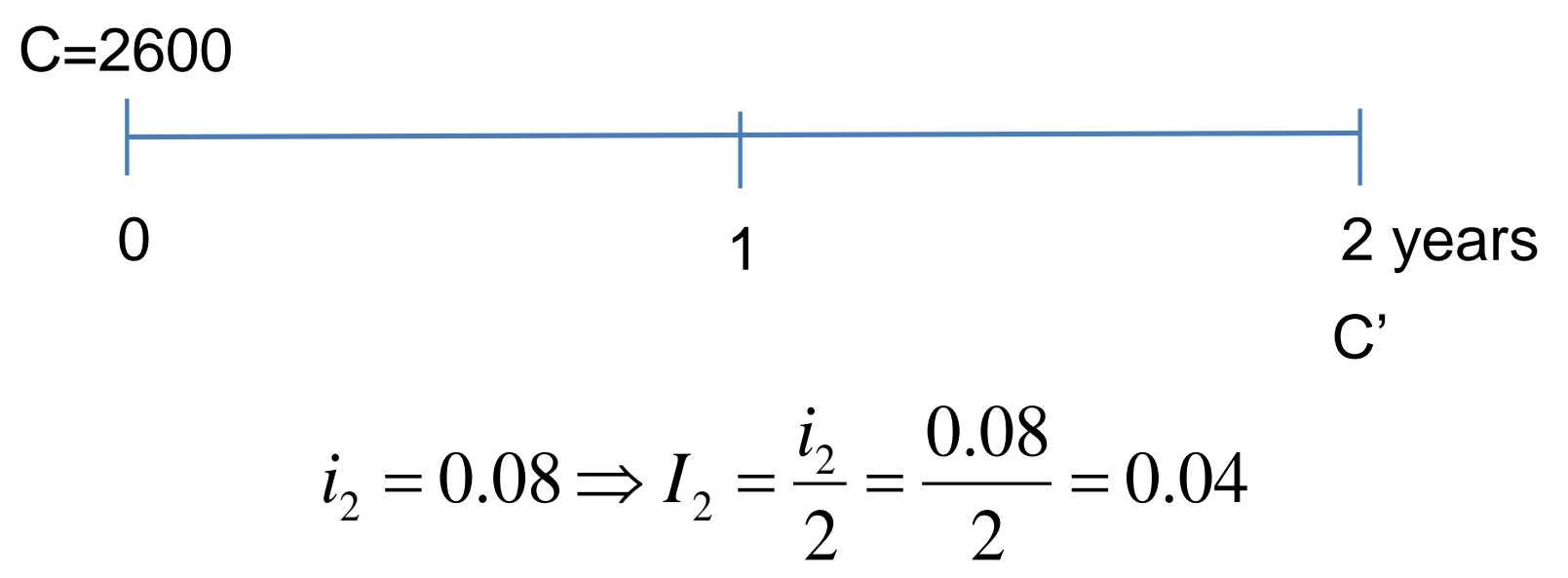

So, $C^{\prime}=C\left(1+I_{m}\right)^{n}$

$$
C^{\prime}=€ 2600\left(1+I_{2}\right)^{4}=€ 2600(1+0.04)^{4}=€ 3041.63
$$

Example 2: Peter borrows $€ \mathrm{C}$ from the National Bank at an annually effective interest rate of $3 \%$. If the loan is repaid with a single amount of $€ 3950$ exactly in one and a half years, find the principal of the loan. 


\section{"Non-amortized capital of a loan" or "Outstanding Principal"}

The non-amortized capital of a loan at time $\tau p$ is the part of the principal left to pay at time $\tau p .(0 \leq \tau \leq n)$ That is to say, the portion of the principal that has yet to be repaid.

At the beginning of the loan, $\mathbf{T}=\mathbf{0}$, you have to repay all the principal

$$
C P_{0}=C
$$

C: principal

of the

0

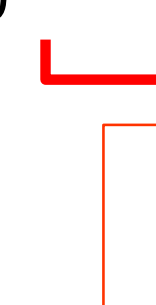

At any intermediate date between the beginning of the loan and the date of the final payment, you still have to repay all the principal

$$
C P_{\tau}=C
$$

At the end of the loan,

$T^{\prime}=n p$, just after the

payment, the principal is repaid.

$$
C P_{n}=0
$$

$$
C P_{\tau}=\left\{\begin{array}{cc}
C & \tau=0 \\
C & 0 \leq \tau<n \\
0 & \tau=n
\end{array} \Rightarrow \begin{array}{c}
\text { You do not pay back the } \\
\text { principal until the end of the loan }
\end{array}\right.
$$

Example 3: In example 1, find the non-amortized capital at time 0, at 18 months after the beginning of the loan, and at the end of the loan.

$$
C P_{\tau}=\left\{\begin{array}{cc}
2600 & t=0 \\
2600 & t=18 \text { months } \\
0 & t=2 \text { years }
\end{array}\right.
$$




\section{Amortized capital of the loan $\Rightarrow M_{\tau}$}

The amortized capital of the loan at time $\tau p$ is the part of the principal paid at time $\tau p$. That is to say, the portion of the principal that has been repaid.

Obviously:

$$
C=M_{\tau}+C P_{\tau}
$$

So:

$$
M_{\tau}=C-C P_{\tau}=\left\{\begin{array}{cc}
0 & \tau=0 \\
0 & 0 \leq \tau<n \\
C & \tau=n
\end{array}\right.
$$

Example 4: In example 1, find the amortized capital at time 0, at 18 months after the beginning of the loan and at the end of the loan.

$$
M_{\tau}=2600-C P_{\tau}=\left\{\begin{array}{cc}
0 & t=0 \\
0 & t=18 \text { months } \\
2600 & t=2 \text { years }
\end{array}\right.
$$




\section{Outstanding loan balance $\Rightarrow O L B_{\tau}$}

We now consider the important question of how to find the loan balance at an intermediate date between the beginning of the loan and the date of the final payment. That is to say, the loan balance is the amount that you have to pay to the bank in order to cancel the loan. It is not the same as the non-amortized capital because in the OLB you have to take into account the interest charged to the borrower.

We consider two approaches to compute the $O L B_{\tau}$ : the prospective method and the retrospective method. The two methods are equivalent.

Prospective method: this is based on "looking into the future". We calculate the value at time $\tau p$ of the remaining payments from time $\tau p$ until the end of the loan.

Retrospective method: this is based on "looking back", i.e., of examining how much one has repaid up until time $\tau p$. It is equal to the principal of the loan accumulated to that date, less the accumulated value at that date of all payments already made. 
Prospective method $\left(O L B_{\tau}^{\text {prop }}\right)$ : we calculate the value at time $\tau p$ of the remaining payments from time $\tau p$ until the end of the loan. That is, we evaluate the value of the remaining payments.

\section{C: principal}
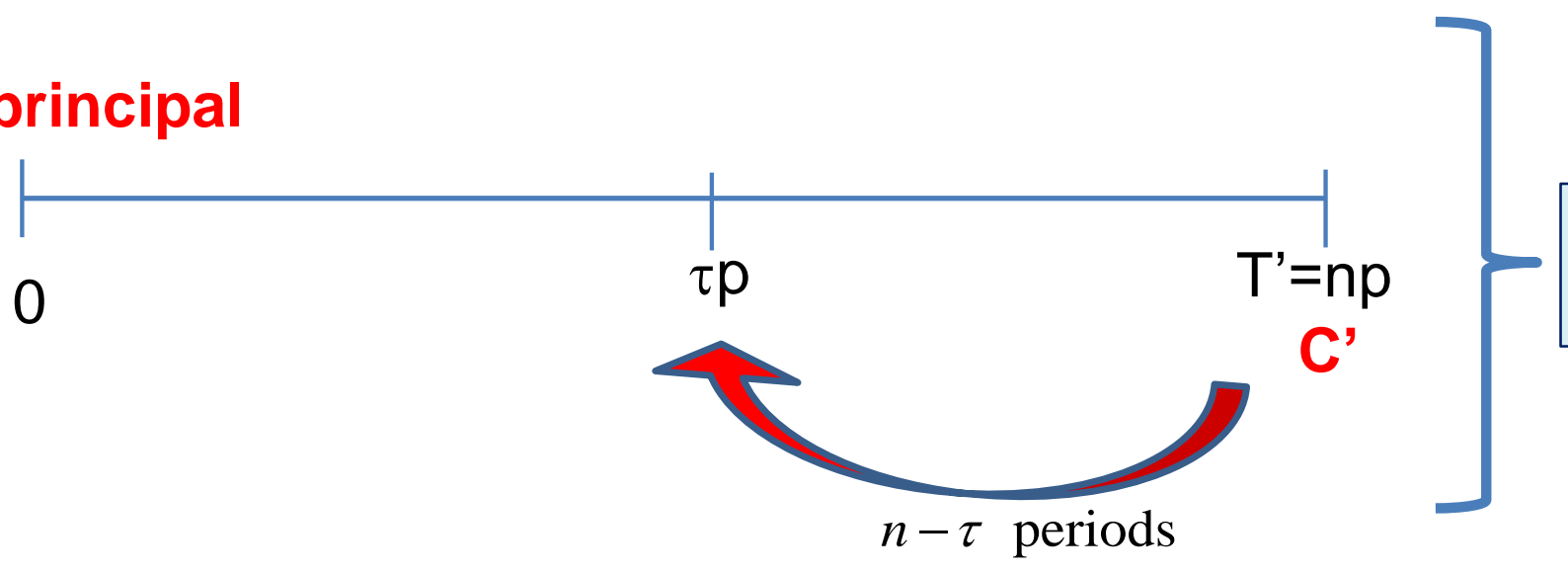

$$
O L B_{\tau}^{\text {prop }}=C^{\prime}\left(1+I_{m}\right)^{-(n-\tau)}
$$

Example 5: In example 1, find the outstanding loan balance using the prospective method at time 0 , at 18 months after the beginning of the loan and at the end of the loan, immediately after the payment C' has been made.

$C=2600$

0

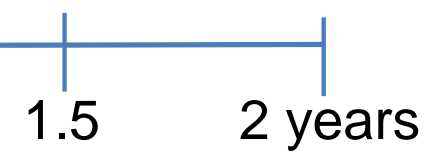

$C^{\prime}=3041.63$

$$
O L B_{\tau}=\left\{\begin{array}{cc}
2600 & t=0 \\
3041.63\left(1+I_{2}\right)^{-1}=2924.64 & t=1.5 \\
0 & t=2
\end{array}\right.
$$


$\square$ Retrospective method $\left(O L B_{\tau}^{\text {retro }}\right)$ : this calculates the loan balance as the accumulated value at time $\tau p$ of the principal minus the accumulated value of all repayments paid up to the time of evaluation, $\tau p$.

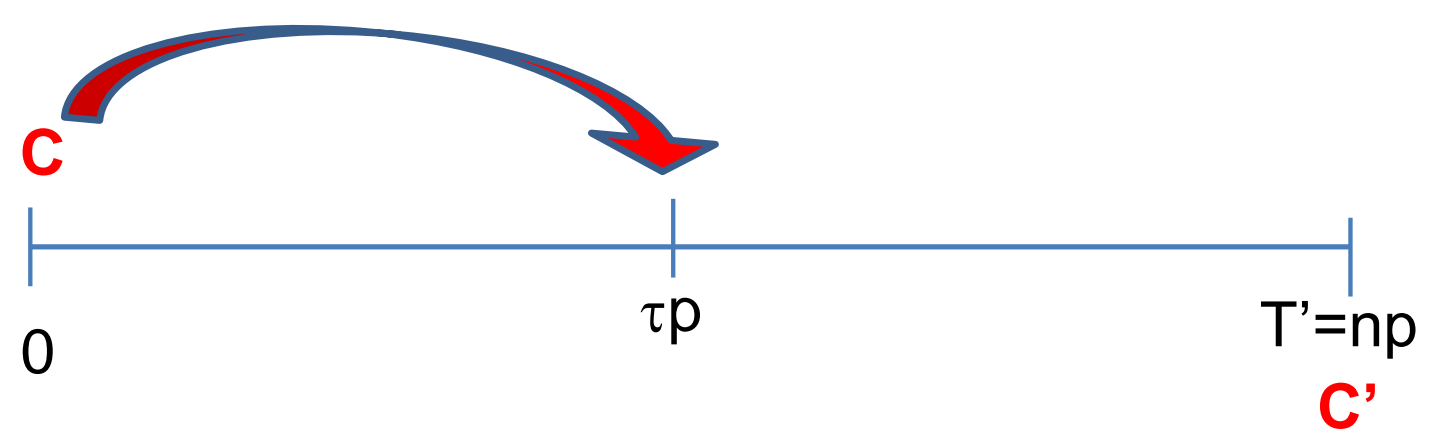

$$
O L B_{\tau}^{\text {retro }}=C\left(1+I_{m}\right)^{\tau}-0=C\left(1+I_{m}\right)^{\tau}
$$

In this loan there are no repayments until

the end of the loan

Example 6: In example 1, find the outstanding loan balance using the retrospective method at time 0, at 18 months after the beginning of the loan and at the end of the loan, immediately after the payment $C^{\prime}$ has been made.

$$
O L B_{\tau}=\left\{\begin{array}{cc}
2600 & t=0 \\
2600\left(1+I_{2}\right)^{3}=2924.64 & t=1.5 \\
0 & t=2
\end{array}\right.
$$


As the two methods are equivalent, the outstanding loan balance is

$$
O L B_{\tau}=\left\{\begin{array}{cc}
C & \tau=0 \\
C\left(1+I_{m}\right)^{\tau}=C^{\prime}\left(1+I_{m}\right)^{-(n-\tau)} & 0<\tau<n \\
0 & \tau=n
\end{array}\right.
$$

Example 7: A loan of amount/principal $€ 50,000$ is being repaid with a single amount in five years. If the nominal rate of interest convertible quarterly is $1 \%$, find:

- the amount, C', that must be repaid; and

- $C P_{\tau}, M_{\tau}$ and $O L B_{\tau}$ at $\mathrm{t}=0,3.5$ and 5 years. 


\section{Outstanding loan balance $\left(O L B_{\tau}\right)$ versus non-amortized capital $\left(C P_{\tau}\right)$}

Now we can compare the outstanding loan balance with the non-amortized capital.

$$
\begin{array}{ccc}
\text { If } \tau=0 & \Rightarrow & C P_{0}=O L B_{0}=C \\
\text { If } 0<\tau<n & \Rightarrow & C P_{\tau} \neq O L B_{\tau} \\
\text { If } \tau=n & \Rightarrow & C P_{\tau}=O L B_{\tau}=0
\end{array}
$$

Example 8: In example 1, compare the outstanding loan balance with the non-amortized capital at $\mathrm{t}=0,0.5$ and 2 years. 


\section{"Non-amortizing loan" or "interest only loan"}

One possible way to structure repayment of a loan is for the borrower to pay the interest on the loan periodically but to make no partial repayments of the loan principal. That is, the payments prior to the end of the loan contain no principal. Then a lump-sum payment of the principal is made at the end of the financial transaction.

So, you pay $\mathbf{Y}$ (interest) at the end of each period, and at the end of the loan term, you repay $\mathbf{C}$ (the principal of the loan).

C: principal

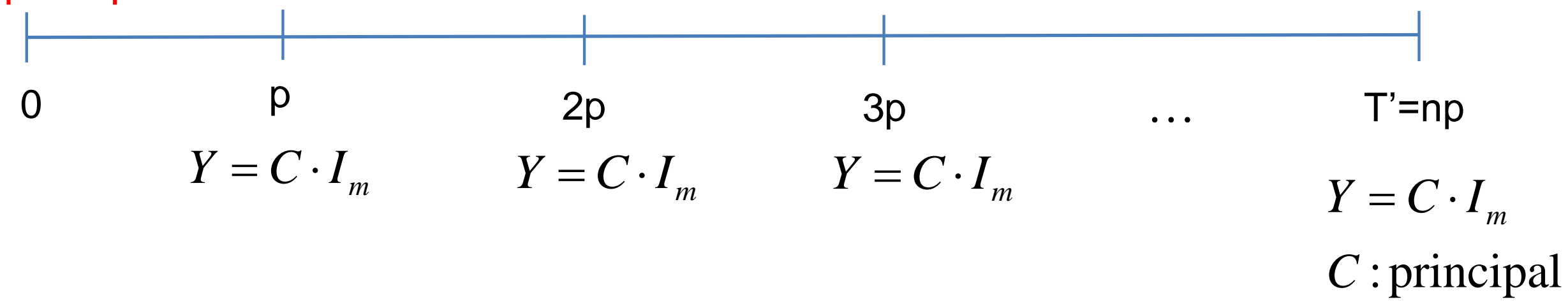




\section{Initial equilibrium equation}

C: principal

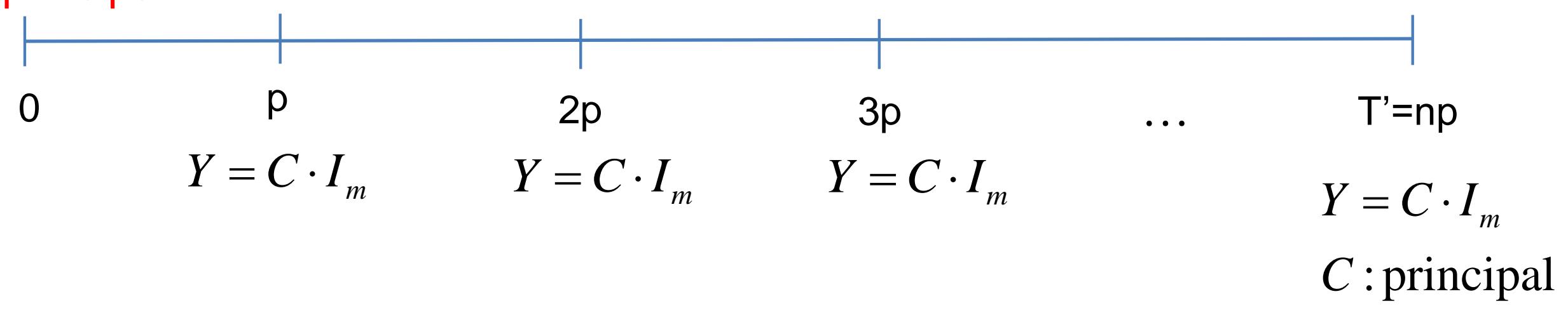

$(C, 0) \sim\left\{\left(C \cdot I_{m}, p\right),\left(C \cdot I_{m}, 2 p\right), \ldots,\left(C \cdot I_{m}+C^{\prime}, n p\right)\right\}$

$C=C I_{m} \frac{1-\left(1+I_{m}\right)^{-n}}{I_{m}}+C\left(1+I_{m}\right)^{-n}$

This is the present value of a level immediate annuity with $n$ payments $Y=\mathrm{Cl}_{m}$ 
Example 9: A loan amount/principal of $€ 100,000$ will be repaid with monthly interest payments and a lump-sum payment of the principal in three years. The nominal rate of interest payable monthly is $6 \%$. Find the monthly payments, and plot a graph of the loan.

$$
I_{12}=\frac{i_{12}}{12}=\frac{0.06}{12}=0.005
$$

100,000

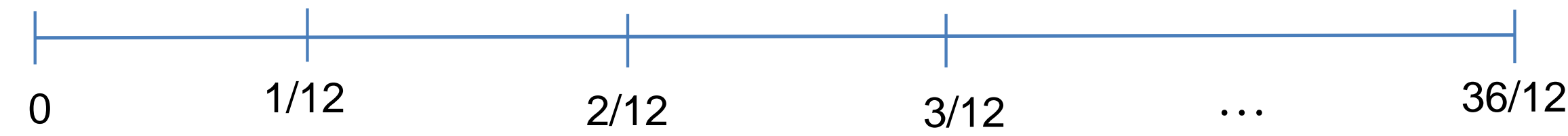

$$
Y=100,000 \cdot I_{12}=100,000 \cdot 0.005=500
$$$$
Y=C \cdot I_{m}
$$

$C:$ loan amount

Then

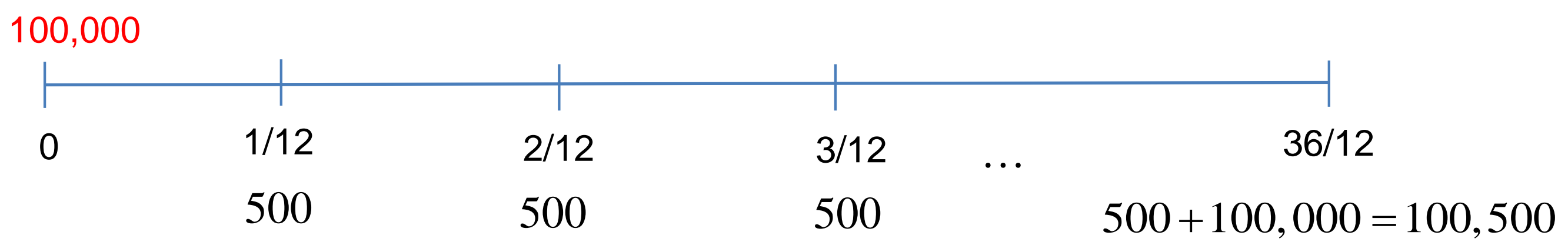


Example 10: A loan amount/principal of $€ 560,000$ will be repaid with quarterly interest payments and a lumpsum payment of the principal in five years. The nominal rate of interest convertible monthly is $6 \%$. Find the quarterly payments, and plot a graph of the loan.

\section{"Non-amortized capital of the loan" or "outstanding principal" $\Rightarrow C P_{\tau}$}

The part of the principal left to pay at time $\tau p$ is:

C: loan amount

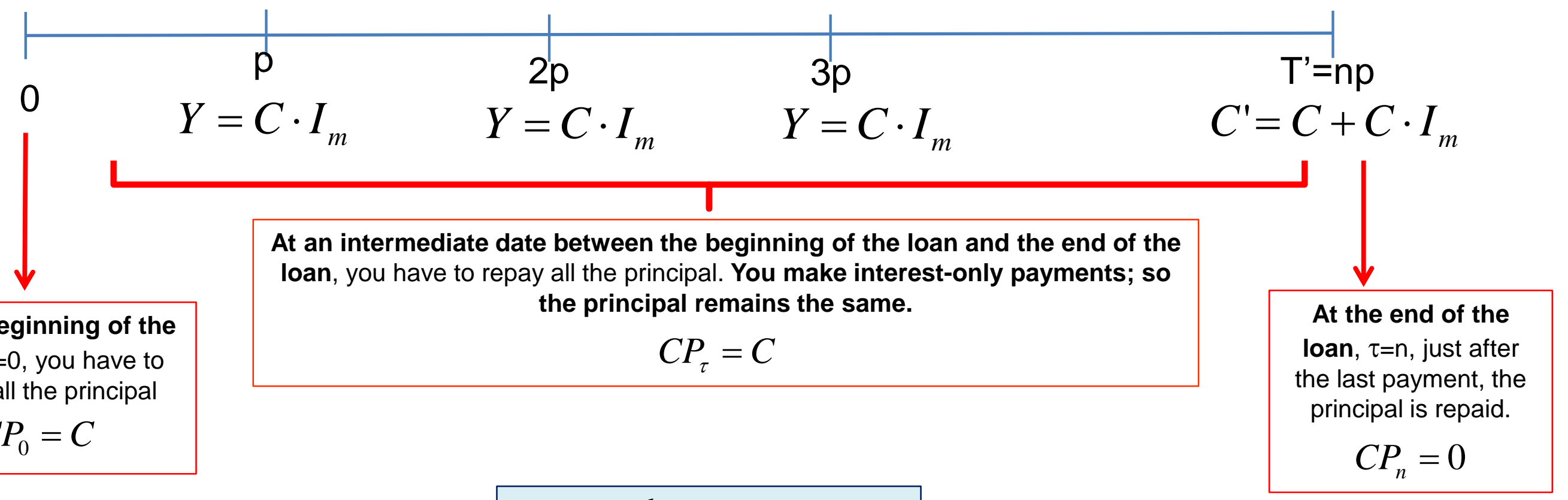

At the beginning of the loan, $\tau=0$, you have to repay all the principal

$C P_{\tau}=\left\{\begin{array}{cc}C & \tau=0 \\ C & 0<\tau<n \\ 0 & \tau=n\end{array}\right.$

At the end of the loan, $\tau=n$, just after the last payment, the $C P_{n}=0$ 
Example 11: In example 9, find the non-amortized capital at time 0, 2 months and 15 days after the beginning of the loan, in 3 months, and at the end of the loan.

100,000

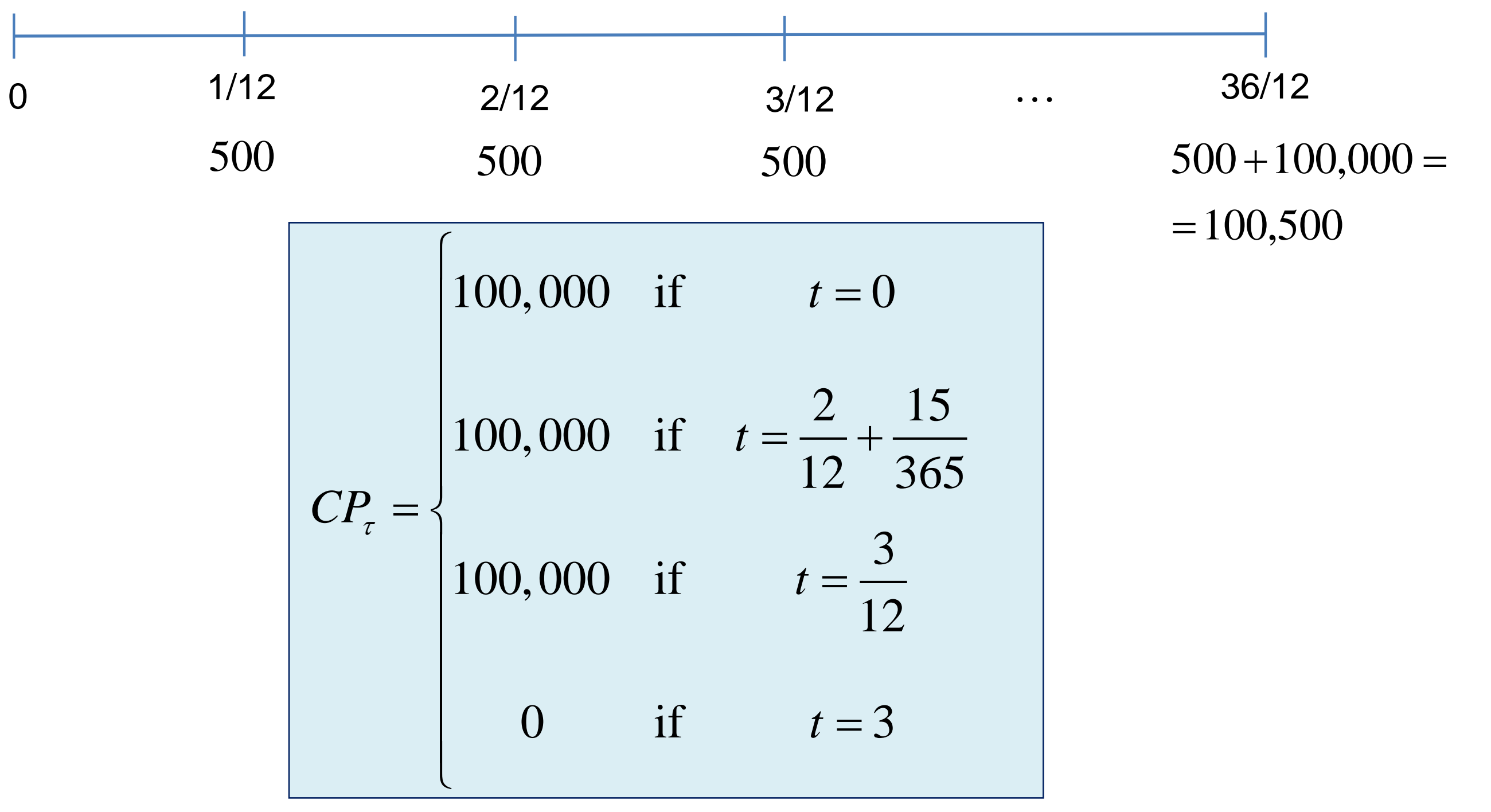

Example 12: In example 10, find the non-amortized capital at time 0 , in one year and at the end of the loan. 


\section{Amortized capital of the loan $\Rightarrow M_{\tau}$}

The part of the principal paid at time $\tau p$ is:

$$
M_{\tau}=C-C P_{\tau}=\left\{\begin{array}{cc}
0 & \tau=0 \\
0 & 0<\tau<n \\
C & \tau=n
\end{array}\right.
$$

Example 13: In example 9, find the amortized capital at time 0 , in one year and at the end of the loan.

$$
C P_{\tau}=\left\{\begin{array}{ccc}
0 & \text { if } & t=0 \\
0 & \text { if } & t=1 \\
100,000 & \text { if } & t=3
\end{array}\right.
$$

Example 14: In example 10, find the amortized capital at time 0 , in one year and at the end of the loan. 


\section{Outstanding loan balance $\Rightarrow O L B_{\tau}$}

We consider:

- $r$ : moment of payment of $Y$

- $\tau$ : a moment between two payments of $Y$

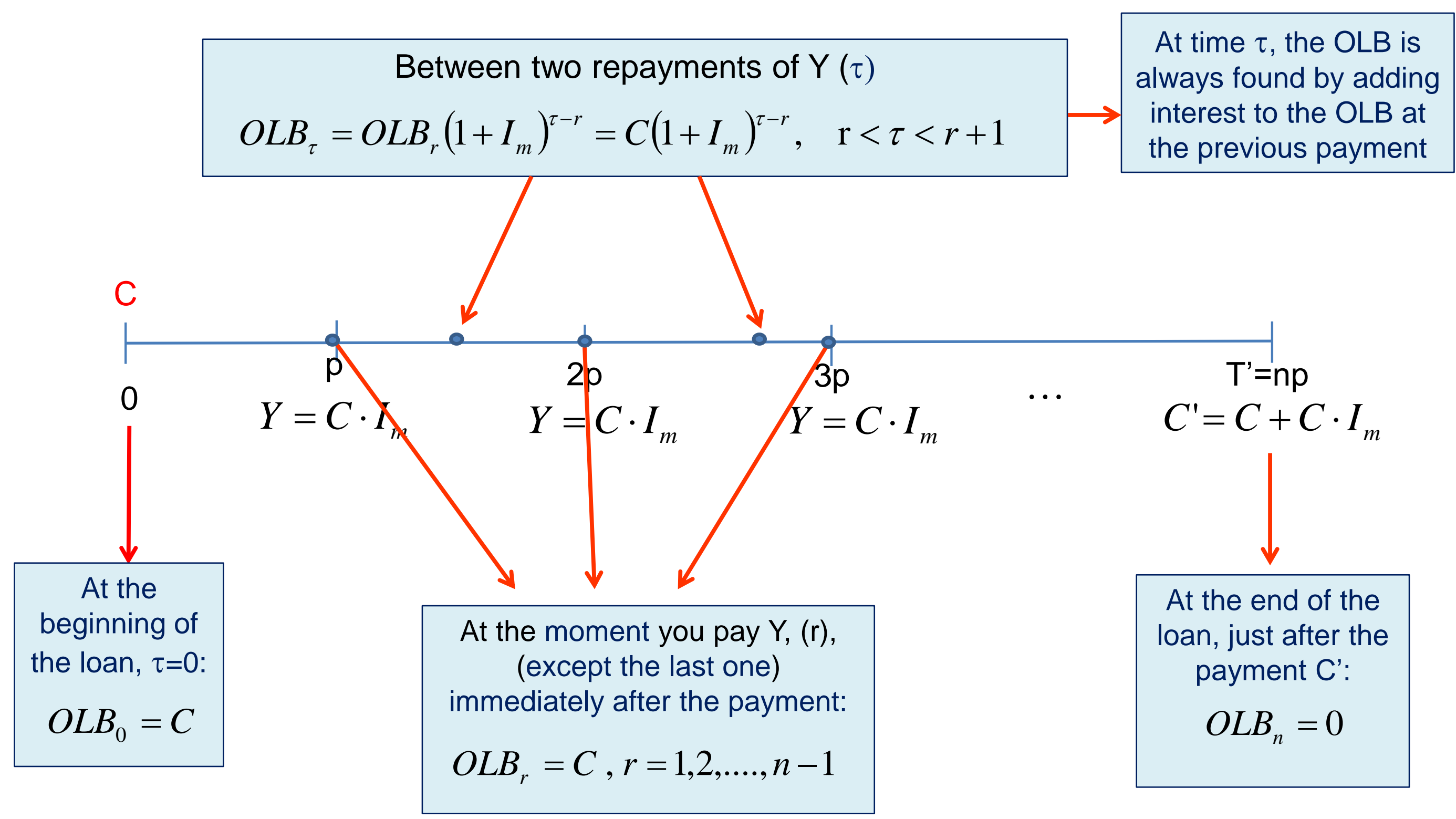


Summarizing the previous ideas, the OLB in an "interest only loan" can be calculated as:

E at the beginning of the loan term,

$$
O L B_{0}=C
$$

E at the moment of interest payments,

$$
O L B_{r}=C, r=1,2, \ldots, n-1
$$

E between two interest repayments, $\tau$

$$
O L B_{\tau}=O L B_{r}\left(1+I_{m}\right)^{\tau-r}=C\left(1+I_{m}\right)^{\tau-r}, \quad \mathrm{r}<\tau<r+1
$$

where $r$ is the moment of the previous payment.

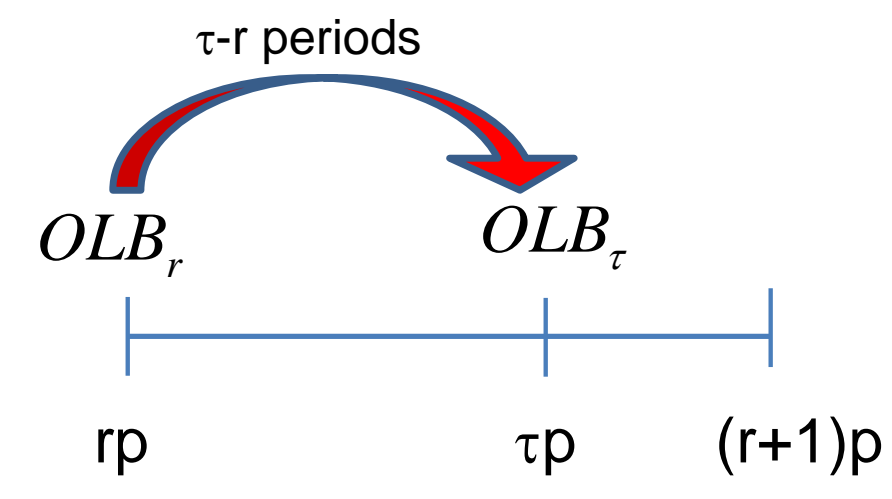

E at the end of the loan term,

$$
O L B_{n}=0
$$


Example 15 (recall example 9): A loan amount/principal of $€ 100,000$ will be repaid with monthly interest payments and a lump-sum payment of the principal in three years. The nominal rate of interest convertible monthly is $6 \%$. Find the OLB at $\mathrm{t}=0,3 / 12,3$ months and 15 days, and 3 .

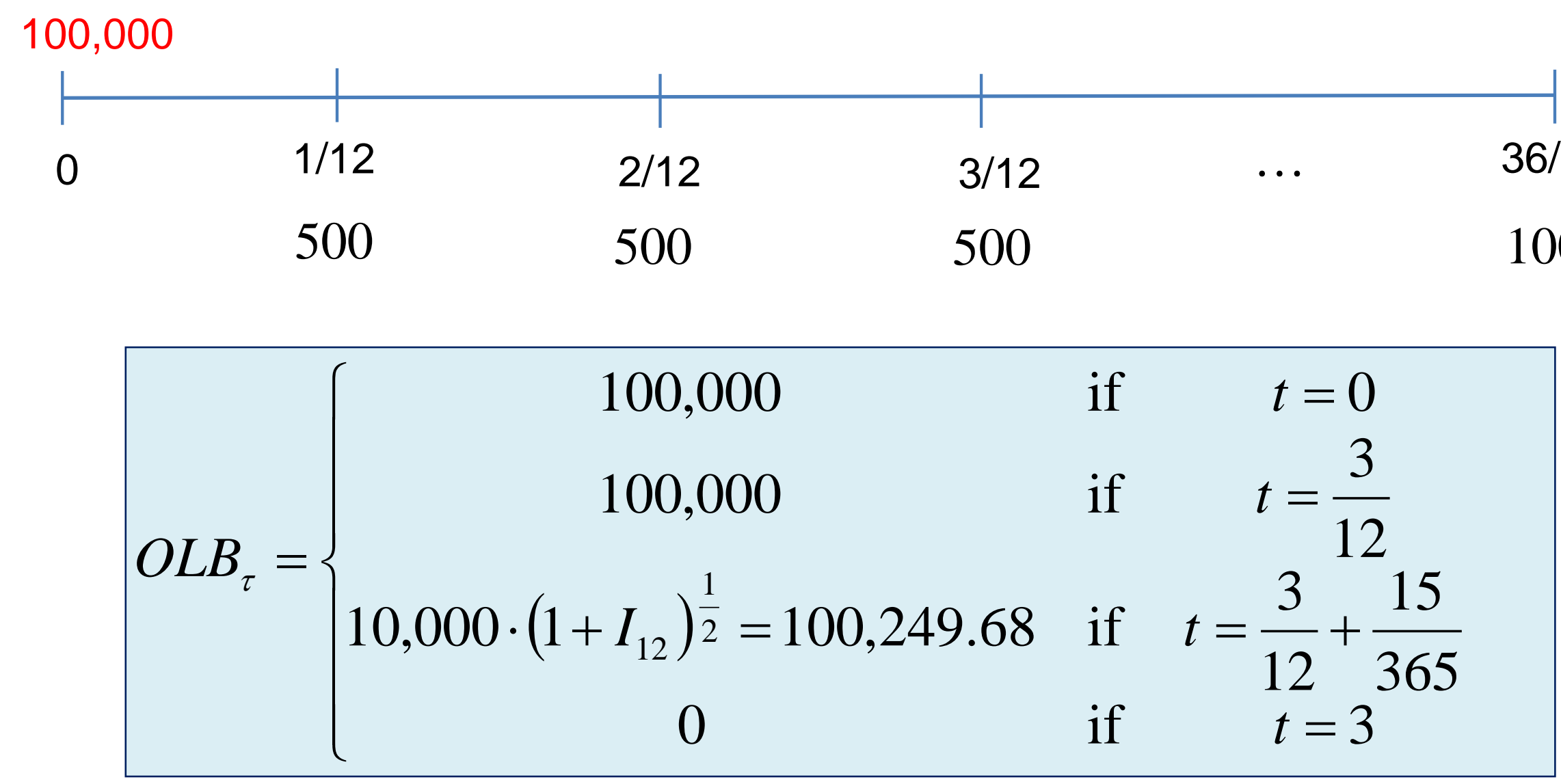

Example 16: In example 10, find the OLB at $\mathrm{t}=0,3 / 12,4$ months and 15 days, and 5. 
Example 17: A loan amount/principal of $€ 35,000$ is being repaid with annual interest payments and with a lump-sum payment of the principal in ten years. If the nominal rate of interest convertible monthly is $3 \%$ :

- find the annually interest payments;

- plot a graph of the loan; and

- find $C P_{\tau}, M_{\tau}$ and $O L B_{\tau}$ at t=0, 3.5, 5 and 10 years. 


\section{Outstanding loan balance $\left(O L B_{\tau}\right)$ versus non-amortized capital $\left(C P_{\tau}\right)$}

Now we can compare the outstanding loan balance with the non-amortized capital.

$$
\begin{array}{ccc}
\text { If } \tau=0 & \Rightarrow & C P_{0}=O L B_{0}=C \\
\text { If } \tau=r=1,2, \ldots, n-1 & \Rightarrow & C P_{r}=O L B_{r}=C \\
\text { If } r<\tau<r+1 & \Rightarrow & C=C P_{\tau} \neq O L B_{\tau}=C\left(1+I_{m}\right)^{\tau-r} \\
\text { If } \tau=n & \Rightarrow & C P_{n}=O L B_{n}=0
\end{array}
$$

Example 18: In example 9, compare the outstanding loan balance with the non-amortized capital at $\mathrm{t}=0,0.5$ and 3 years. 


\section{Amortizing loans: loans with level repayments}

This type of loan is repaid with level payments, $\alpha$, at the end of each period. The repayments include partial repayment of the principal of the loan and payments of interest: the level payments, $\alpha$, have two components:

$$
\alpha=Y_{r}+A_{r}, \quad r=1, \ldots, n \leftarrow \begin{gathered}
\text { Amortization payments } / \\
\text { payment amount }
\end{gathered}
$$

an interest component (payments of interest).

$$
Y_{r}, r=1, \ldots, n \leftarrow \text { Interest payment }
$$

a principal component (partial repayment of the principal).

$$
A_{r}, \quad r=1, \ldots, n \leftarrow \begin{gathered}
\text { Principal payment } / \\
\text { principal repayment }
\end{gathered} \Rightarrow C=\sum_{i=1}^{n} A_{i}
$$

\section{C: principal}

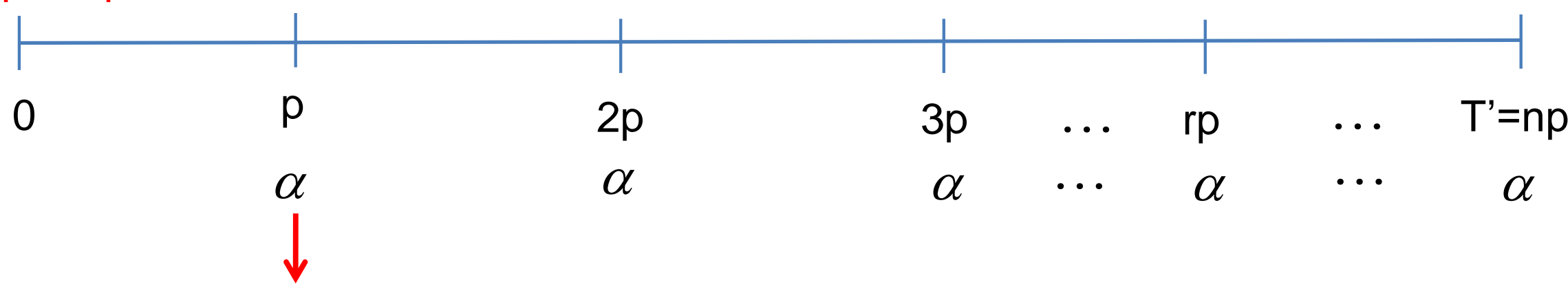




\section{Initial equilibrium equation}

C: principal

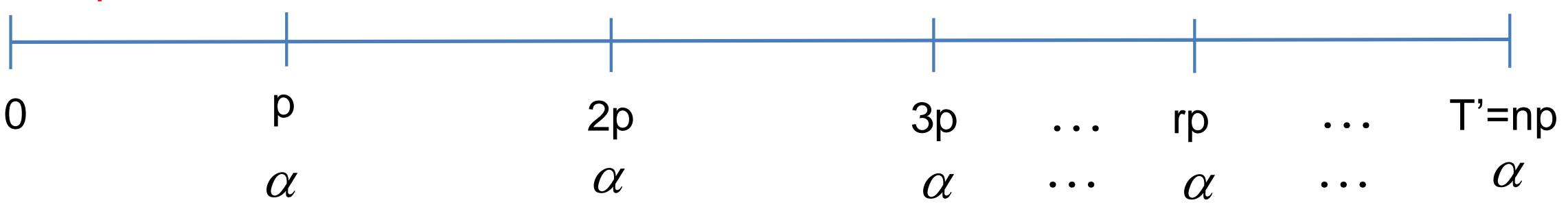

$(C, 0) \sim\{(\alpha, r p)\}_{r=1, \ldots, n}$

$$
C=\alpha \frac{1-\left(1+I_{m}\right)^{-n}}{I_{m}}=\alpha \cdot a_{\bar{n} \mid I_{m}}
$$

This is the present value of a level immediate annuity of amount $\alpha$ 
Example 19: Marc purchases a house for $€ 256,000$. He makes a down payment of $€ 40,000$ and finances the remainder of the purchase with a thirty-year mortgage with monthly payments at an annual effective interest rate of $6.5 \%$. Find the amortization payments.

$$
\begin{aligned}
& C=216,000 \\
& \mid \begin{array}{l|l|}
\mid & \mid \\
1 / 12 &
\end{array}
\end{aligned}
$$

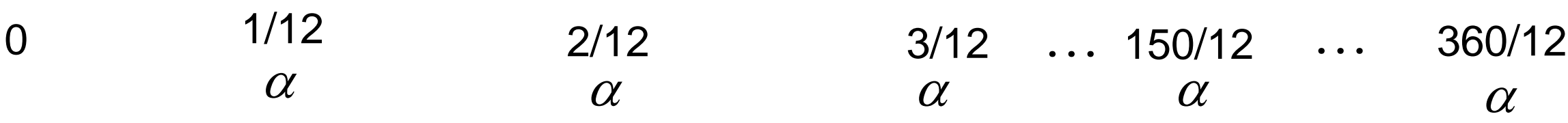

$$
\begin{aligned}
& I_{1}=0.065 \\
& I_{12}=\left(1+I_{1}\right)^{\frac{1}{12}}-1=0.005261 \\
& C=\alpha \frac{1-\left(1+I_{m}\right)^{-n}}{I_{m}} \Rightarrow 216,000=\alpha \frac{1-\left(1+I_{12}\right)^{-360}}{I_{12}} \\
& \Downarrow \\
& \underline{\alpha}=\frac{216,000}{\frac{1-\left(1+I_{12}\right)^{-360}}{I_{12}}}=\underline{1338.84}
\end{aligned}
$$


Example 20: Marc borrows $€ 20,000$ at an annual effective interest rate of $4.8 \%$. The loan is to be repaid by level end-of-quarter payments for five years. Find the amount that Marc has to repay quarterly.

Example 21: Alba took out a loan. The loan was governed by compound interest at an annually effective interest rate of $5 \%$. She made annually payments of $€ 256$ for ten years. Find the principal of the loan.

Example 22: Gala borrowed $€ 13,488.70$. The loan was governed by compound interest at a monthly effective rate of $0.5 \%$. At the end of each month, she made a repayment of $€ 1000$. How many repayments did Gala make?

Example 23: Suppose you want to borrow money to buy a house. You are considering a 15-year or a 20-year loan. The lender offers different interest rates, reflecting the difference in the risk of shorter-term and longer-term lending. For the 15-year loan, the interest rate is $1 \%$ (compounded monthly), with 180 equal monthly payments. For the 20 -year loan, the interest rate is $0.75 \%$ (compounded monthly), with 240 equal monthly payments. If you borrow $€ 150,000$, what would your monthly payments be for each loan? 


\section{"Non-amortized capital of the loan" or "outstanding principal" $\Rightarrow C P_{\tau}$}

In the following example, let $n=5$.

At the beginning, you have not repaid any of the principal

$$
C P_{0}=C
$$

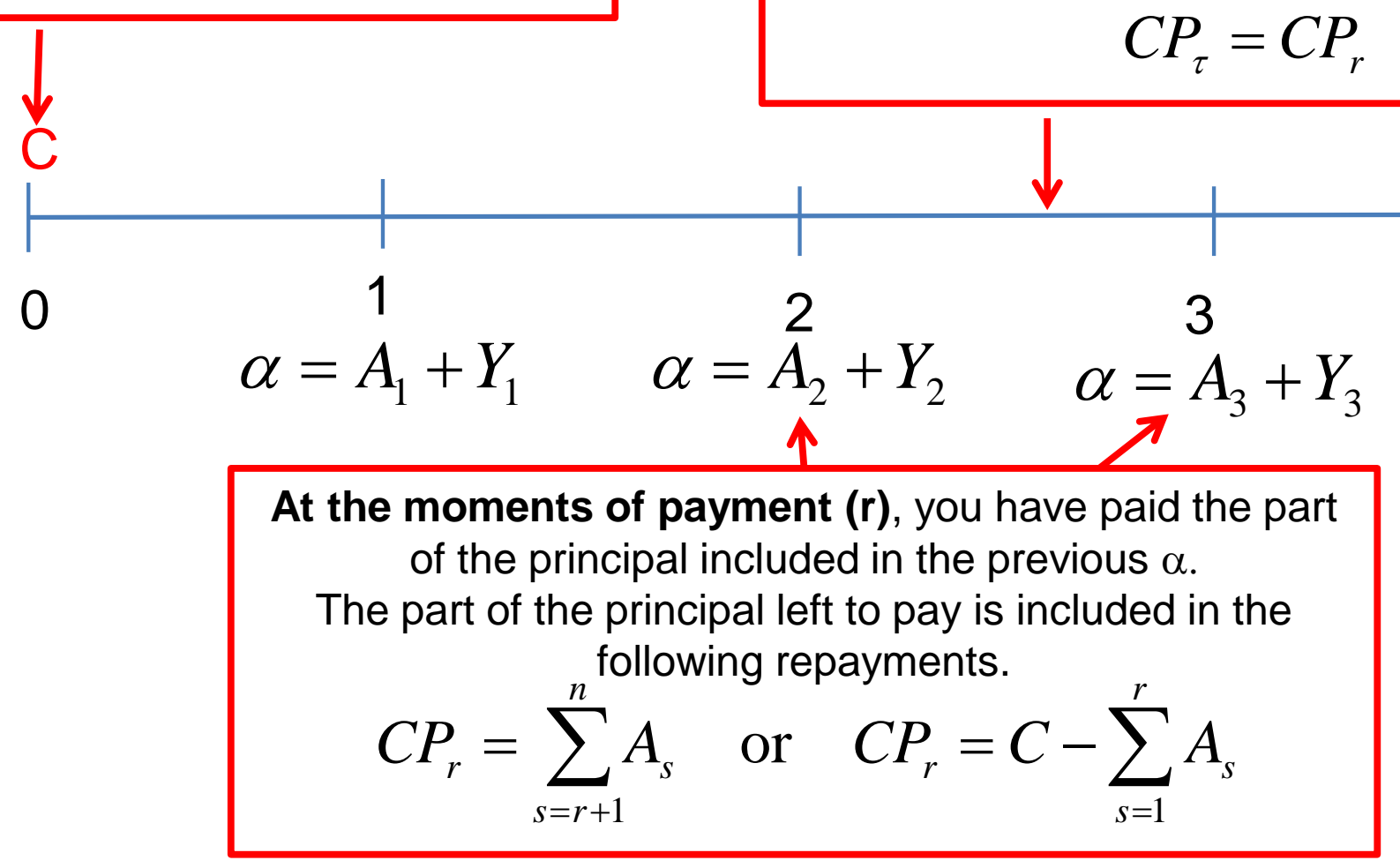

\section{Between two moments of payment $(\tau)$,} there is no repayment of principal since the last moment of payment, so the amortized capital is the same.

$$
C P_{\tau}=C P_{r}
$$

For example, for $\tau=2.5$

$$
C P_{2.5}=C P_{2}
$$

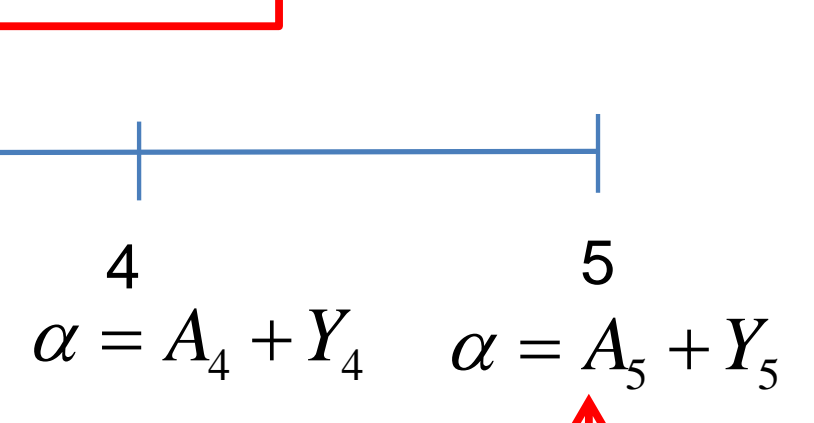

For example, for $\mathbf{r = 2}\left\{\begin{array}{l}C P_{2}=\sum_{s=2+1}^{5} A_{s}=A_{3}+A_{4}+A_{5} \\ C P_{2}=C-\sum_{s=1}^{2} A_{s}=C-\left(A_{1}+A_{2}\right)\end{array}\right.$

After the last payment, you have amortized all the principal

$$
C P_{5}=0
$$


Summarizing the previous results, the part of the loan amount left to pay is:

$\oplus$ for $\tau=0$

$$
C P_{0}=C
$$

$\oplus$ for $r=1,2, \ldots, \mathrm{n}-1$ (moments of payment of $\alpha$, except the last one)

$$
C P_{r}=\sum_{s=r+1}^{n} A_{s} \quad C P_{r}=C-\sum_{s=1}^{r} A_{s}
$$

$\oplus$ for $r<\tau<r+1$ (between two moments of payment)

$$
C P_{\tau}=C P_{r}
$$

$\oplus$ for $\tau=n$, after the last payment

$$
C P_{n}=0
$$




\section{Amortized capital of the loan $\Rightarrow M_{\tau}$}

Recall that: $M_{\tau}=C-C P_{\tau}$

So, the part of the loan amount paid at time $\tau$ is:

$\oplus$ for $\tau=0$

$$
M_{0}=0
$$

$\oplus$ for $\mathrm{r}=1,2, \ldots, \mathrm{n}-1$ (moments of payment of $\alpha$, except the last one)

$$
M_{r}=\sum_{s=1}^{r} A_{s} \quad M_{r}=C-\sum_{s=r+1}^{n} A_{s}
$$

$\oplus$ for $\mathrm{r}<\tau<r+1$ (between two moments of payment)

$$
M_{\tau}=M_{r}
$$

$\oplus$ for $\tau=n$, after the last payment

$$
M_{n}=C
$$




\section{Outstanding loan balance $\Rightarrow O L B_{\tau}$}

In the following example, let $n=5$.

At the beginning, your debt is the whole principal of the loan.

$$
O L B_{0}=C
$$

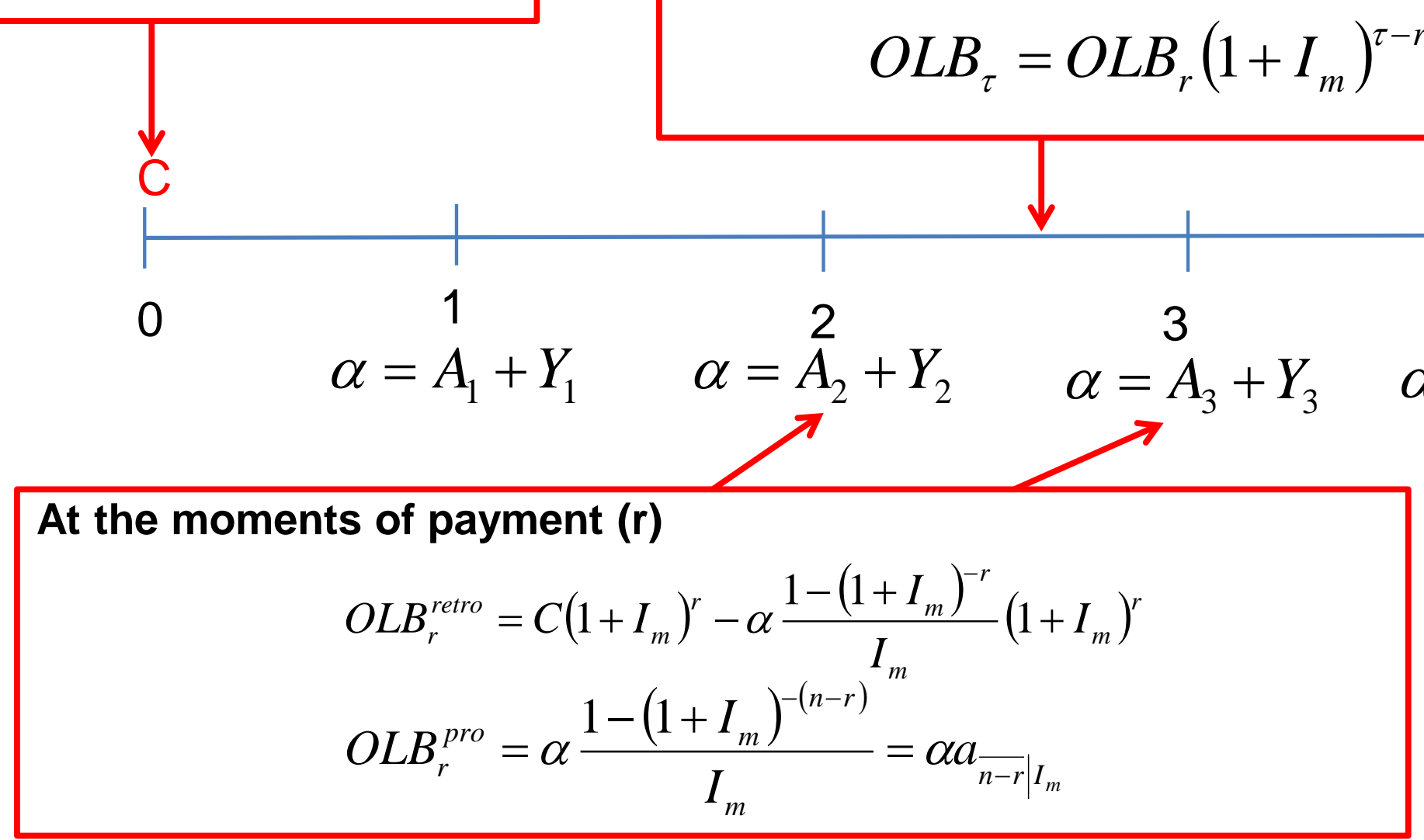

\section{Between two moments of payment $(\tau)$, there} is no repayment since the last moment of payment, so the OLB is the same as at the previous moment of payment, taking into account the interest charged in the period $(r, \tau)$.

$$
O L B_{\tau}=O L B_{r}\left(1+I_{m}\right)^{\tau-r}
$$

$\rightarrow$ For example, for $\mathrm{r}=2.5$ $O L B_{2.5}=O L B_{2}\left(1+I_{m}\right)^{2.5-2}$

For example, for $r=2$,

$$
O L B_{2}^{p r o}=\alpha \frac{1-\left(1+I_{m}\right)^{-(5-2)}}{I_{m}}=\alpha a_{\left.\overline{3}\right|_{m}}
$$

$$
\underset{O L B_{2}^{\text {retro }}}{\searrow}=C\left(1+I_{m}\right)^{2}-\alpha \frac{1-\left(1+I_{m}\right)^{-2}}{I_{m}}\left(1+I_{m}\right)^{2}
$$


$\oplus$ for $\tau=0$

$$
O L B_{0}=C
$$

$\oplus$ for $\mathrm{r}=1,2, \ldots, \mathrm{n}-1$ (moments of payment, except the last one)

$$
\begin{aligned}
& O L B_{r}^{\text {retro }}=C\left(1+I_{m}\right)^{r}-\alpha \frac{1-\left(1+I_{m}\right)^{-r}}{I_{m}}\left(1+I_{m}\right)^{r} \longrightarrow \begin{array}{l}
\text { This is calculating the OLB as the } \\
\text { accumulated value of the loan at the } \\
\text { time of evaluation } \tau \text { minus the } \\
\text { accumulated value of all repayments } \\
\text { paid up to the time of evaluation. }
\end{array} \\
& O L B_{r}^{\text {pro }}=\alpha \frac{1-\left(1+I_{m}\right)^{-(n-r)}}{I_{m}}=\alpha a_{\overline{n-r} \mid I_{m}} \longrightarrow \begin{array}{l}
\text { This is calculating the OLB as the present value } \\
\text { of the remaining payments }
\end{array}
\end{aligned}
$$

$\oplus$ for $\mathrm{r}<\tau<r+1$ (between two moments of payment)

$$
O L B_{\tau}=O L B_{r}\left(1+I_{m}\right)^{\tau-r}
$$

$\oplus$ for $\tau=n$, after the last payment

$$
O L B_{n}=0
$$


Example 24: A loan of $€ 45,000$ is being repaid with level payments at the end of each month for two years. Assume that the nominal rate of interest compounded monthly equals $10 \%$. Find:

$\checkmark$ the repayment that has to be made monthly

$$
\begin{gathered}
i_{12}=0.1 \Rightarrow I_{12}=\frac{i_{12}}{12}=0.008333 \\
€ 45,000=\alpha \frac{1-\left(1+I_{12}\right)^{-24}}{I_{12}} \Rightarrow \alpha=\frac{€ 45,000}{\frac{1-\left(1+I_{12}\right)^{-24}}{I_{12}}}=€ 2076.51
\end{gathered}
$$

$\checkmark$ the outstanding loan balance immediately after the fifth payment is made.

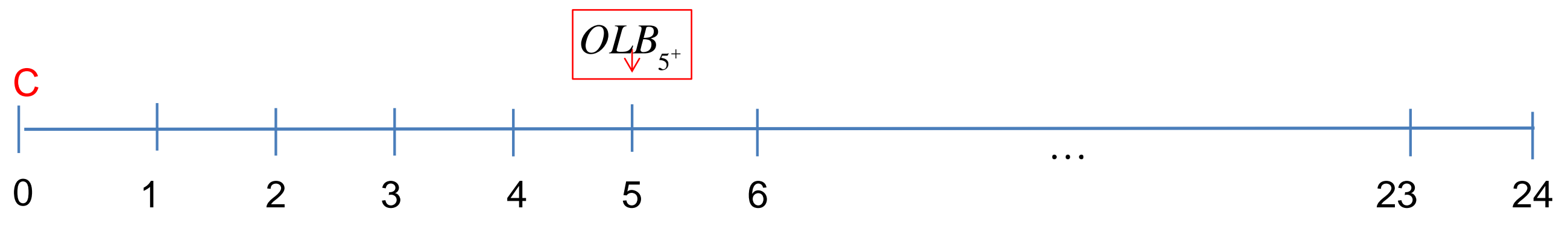

$$
\begin{aligned}
O L B_{r}^{\text {retro }}=C\left(1+I_{m}\right)^{r}-\alpha \frac{1-\left(1+I_{m}\right)^{-r}}{I_{m}}\left(1+I_{m}\right)^{r} \longrightarrow O L B_{5^{+}}^{\text {retro }} & =45,000\left(1+I_{12}\right)^{5}-2076.51 \frac{1-\left(1+I_{12}\right)^{-5}}{I_{12}}\left(1+I_{12}\right)^{5}= \\
& =€ 36,349.32
\end{aligned}
$$$$
O L B_{r}^{p r o}=\alpha \frac{1-\left(1+I_{m}\right)^{-(n-r)}}{I_{m}}=\alpha a_{\overline{n-r} \mid I_{m}} \quad \Longrightarrow O L B_{5^{+}}^{\text {pro }}=2076.51 \frac{1-\left(1+I_{12}\right)^{-(24-5)}}{I_{12}}=€ 36,349.32
$$ 
At 5 months and 15 days after the beginning of the loan:

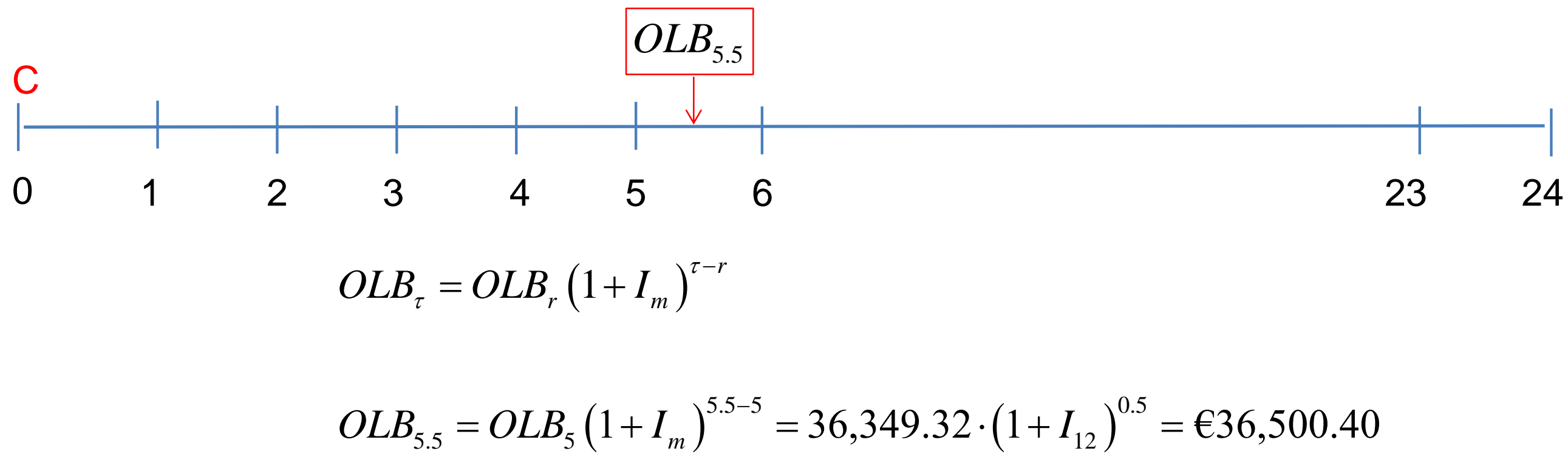

$>$ Just before the payment that has to be made at month five:

$$
\begin{aligned}
& O L B_{5^{-}}=O L B_{5}+\alpha \\
& O L B_{5^{-}}=36,349.32+2076.51=€ 38,425.83
\end{aligned}
$$

Find the OLB just after the beginning of the loan and just after the last payment:

$$
\begin{gathered}
O L B_{0}=€ 45,000 \\
O L B_{24}=0
\end{gathered}
$$




\section{Outstanding loan Balance $\left(O L B_{\tau}\right)$ versus Non-amortized capital $\left(C P_{\tau}\right)$}

Now we can compare the outstanding loan balance with the non-amortized capital:

$$
\begin{array}{clc}
\text { If } \tau=0 & \Rightarrow & C P_{0}=O L B_{0}=C \\
\text { If } \tau=r=1,2, \ldots, n-1 & \Rightarrow & C P_{r}=O L B_{r} \\
\text { If } r<\tau<r+1 & \Rightarrow & C P_{\tau}=C P_{r} \neq O L B_{\tau}=O L B_{r}\left(1+I_{m}\right)^{\tau-r}=C P_{r}\left(1+I_{m}\right)^{\tau-r} \\
\text { If } \tau=n & \Rightarrow & C P_{n}=O L B_{n}=0
\end{array}
$$


Example 25: Pau takes out a $€ 200,000$ loan for ten years at a level annual effective interest rate of $5 \%$ to be repaid with monthly repayments. Find:

$\checkmark$ the repayment that has to be made monthly;

$>$ the outstanding loan balance immediately after the first payment is made;

$>$ the outstanding loan balance just before the payment that has to be made at month ten;

$>$ the outstanding loan balance at 10 months and 15 days after the beginning of the loan; and

$>$ the outstanding loan balance after the beginning of the loan and just after the last payment.

Example 26: A loan of $€ 1000$ is being repaid with quarterly payments at the end of each quarter for 5 years, at $6 \%$ interest convertible quarterly. Find the outstanding loan balance at the end of the 2 nd year.

Example 27: Julie bought a house with a $€ 100,000$ mortgage for 30 years being repaid with payments at the end of each month at an interest rate of $8 \%$ compounded monthly. What is the outstanding balance at the end of 10 years, immediately after the 120th payment?

Example 28: A loan is being repaid with 16 quarterly payments, where the first 8 payments are $€ 200$ each and the last 8 payments are $€ 400$ each. If the nominal rate of interest convertible quarterly is $10 \%$, use both the prospective method and the retrospective method to find the outstanding loan balance immediately after the first six payments are made. 


\section{Interest payment}

$\checkmark$ Now, we are going to analyze the interest payment, $\mathrm{Y}_{\mathrm{r}}$

$\checkmark$ In each period, the interest is paid on the OLB in the previous period:

$$
Y_{r}=O L B_{r-1} \cdot I_{m}=C P_{r-1} \cdot I_{m}
$$

$\checkmark$ The expression that we will use is:

$$
Y_{r}=O L B_{r-1} \cdot I_{m}=C P_{r-1} \cdot I_{m} \Rightarrow \begin{gathered}
\text { and the first interest payment is } \\
Y_{1}=O L B_{0} \cdot I_{m}=C \cdot I_{m}
\end{gathered}
$$

The interest payments decrease each period 


\section{Principal payment}

$\checkmark$ This is the partial repayment of the principal:

$$
A_{r}=\alpha-Y_{r}
$$

$\checkmark$ In this kind of loan, the principal repayments increase in geometrical progression:

$$
A_{r}=A_{1}\left(1+I_{m}\right)^{r-1}
$$

$\checkmark$ In order to obtain the first principal repayment:

$$
A_{1}=\alpha-Y_{1}=\left\{Y_{1}=O L B_{0} \cdot I_{m}=C \cdot I_{m}\right\}=\alpha-C \cdot I_{m}
$$

So we can obtain $A_{r}$ using $A_{r}=A_{1}\left(1+I_{m}\right)^{r-1}$. 
Example 29: A loan is being repaid with level annual payments based on an annual effective interest rate of $8 \%$. If the amount of principal in the $10^{\text {th }}$ payment is 100 , calculate the amount of principal in the $5^{\text {th }}$ payment.

Example 30: A loan is being repaid with level annual payments based on an annual effective interest rate of $8 \%$. If the outstanding balance immediately after the $10^{\text {th }}$ payment is 1000 , calculate the amount of interest in the $11^{\text {th }}$ payment.

Example 31: A loan is being repaid with quarterly installments of $€ 1000$ at the end of each quarter for 5 years at $12 \%$ interest compounded quarterly. Find the amount of principal in the $6^{\text {th }}$ installment.

Example 32: A loan of $€ 25,000$ is being repaid with annual payments of $€ 2243$ at the end of each year. The interest rate on the loan is $7.5 \%$. Calculate the interest in the $5^{\text {th }}$ payment. 


\section{Amortization Table}

All the previous results can be grouped into an amortization table:

\begin{tabular}{|c|c|c|c|c|c|}
\hline$r$ & $\alpha_{r}$ & $Y_{r}$ & $A_{r}$ & $M_{r}$ & $C P_{r}=O L B_{r}$ \\
\hline 0 & & & & $M_{0}=0$ & $C P_{0}=C$ \\
\hline 1 & $\alpha$ & $Y_{1}=C \cdot I_{m}$ & $A_{1}=\alpha_{1}-Y_{1}$ & $M_{1}=M_{0}+A_{1}$ & $C P_{1}=C-M_{1}$ \\
\hline 2 & $\alpha$ & $Y_{2}=O L B_{1} \cdot I_{m}$ & $A_{2}=\alpha_{2}-Y_{2}$ & $M_{2}=M_{1}+A_{2}$ & $C P_{2}=C-M_{2}$ \\
\hline$\ldots$ & $\ldots$ & $\ldots$ & $\ldots$ & $\ldots$ & $\ldots$ \\
\hline$r$ & $\alpha$ & $Y_{r}=O L B_{r-1} \cdot I_{m}$ & $A_{r}=\alpha_{r}-Y_{r}$ & $M_{r}=M_{r-1}+A_{r}$ & $C P_{r}=C-M_{r}$ \\
\hline$\ldots$ & $\ldots$ & $\ldots$ & $\ldots$ & $\ldots$ & $\ldots$ \\
\hline & & & $\ldots$ & & \\
\hline$n$ & $\alpha$ & $Y_{n}=O L B_{n-1} \cdot I_{m}$ & $A_{n}=\alpha_{n}-Y_{n}$ & $M_{n}=M_{n-1}+A_{n}=C$ & $C P_{n}=C-M_{n}=0$ \\
\hline
\end{tabular}


Example 33: Create an amortization schedule for a loan of $€ 1000$ to be repaid over four years if the annual effective rate of interest is $8 \%$.

Example 34: Create an amortization schedule for a loan of $€ 8500$ to be repaid over three years if the annual effective rate of interest is $5 \%$.

Example 35: A loan of $€ 800$ is being repaid with monthly payments over half year at $8 \%$ interest compounded monthly. Draw up the amortization table for this loan. 


\section{Changes during the life of a loan}

$>$ What happens if you want to make extra payments during a loan?

$>$ What happens if interest rates decrease or increase?

$>$ What happens if the borrower is temporarily unable to make payments? (outstanding payments)

\section{What happens if you want to make extra payments during the loan?}

When an extra payment is made (lump-sum overpayments), your loan balance (OLB) will be reduced. So, because your balance is lower, you can either:

$\checkmark$ re-calculate the payment immediately, then the revised payment will be smaller $\left(\alpha^{3}\right)$; or

$\square$ keep paying your current payment $(\alpha)$ so that you repay your loan sooner. 
Example 36 (re-calculating payments): A loan is being repaid with 25 annual payments of $€ 300$ each. With the 10th payment, the borrower pays an extra $€ 1000$ and then repays the loan over 10 years with a revised annual payment. The effective rate of interest is $8 \%$. Calculate the amount of the revised annual payment.

Solution: First of all, we calculate the outstanding balance after the 10th payment,

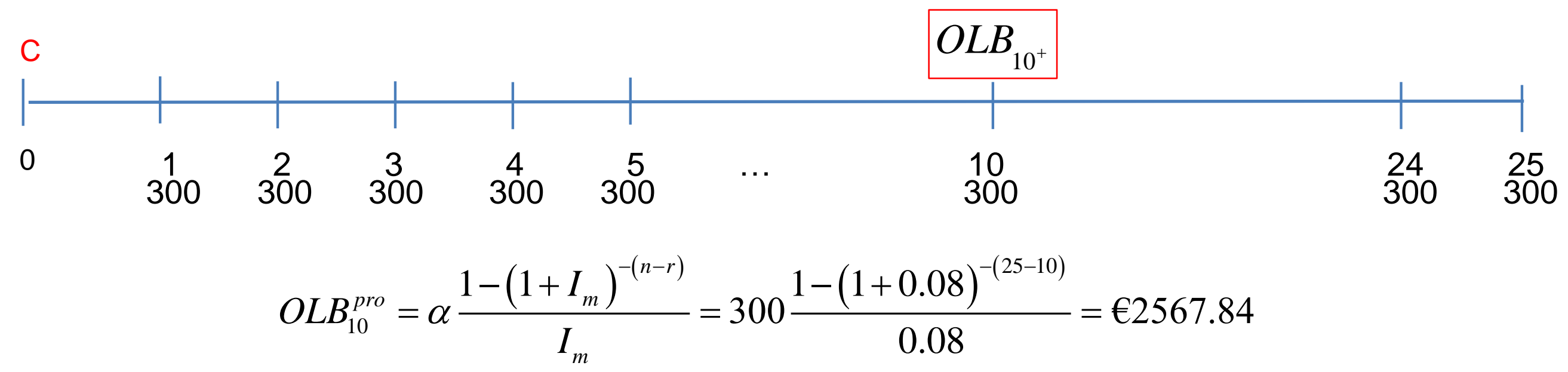

If the borrower pays an additional $€ 1000$, the balance becomes:

$$
€ 2567.84-€ 1000=€ 1567.84
$$

So, $€ 1567,84$ is the new principal of the loan. That is to say, $C^{\prime}=€ 1567,84$. So the revised payment, $\alpha^{\prime}$, can be obtained from the following equation:

$$
\begin{gathered}
C^{\prime}=\alpha^{\prime} \frac{1-\left(1+I_{m}\right)^{-n}}{I_{m}} \\
1567.84=\alpha^{\prime} \frac{1-(1+0.08)^{-10}}{0.08} \Rightarrow \alpha^{\prime}=€ 233.66
\end{gathered}
$$


Example 37: A loan is being repaid with 20 annual payments of $€ 400$ each. At the time of the fourth payment, the borrower wishes to pay an extra $€ 200$ and then repay the loan over 10 years with a revised annual payment. If the effective annual interest rate is $7 \%$, find the amount of the revised annual payment.

Example 38: $A € 100,000$ loan is to be repaid by 30 equal payments at the end of each year. The monthly effective rate is $0.5 \%$. After payment of the $5^{\text {th }}$ repayment, the borrower pays an extra $€ 4500$. Calculate the amount of the revised monthly payment.

Example 39: Mary borrows $€ 175,000$ from a bank. The loan is being repaid with 360 monthly payments. The effective rate of interest is $5 \%$. With the $120^{\text {th }}$ payment, Mary pays an extra $€ 6500$. Calculate the amount of the revised monthly payment.

Example 40: A loan is being amortized using an interest rate of $8 \%$ convertible quarterly with level payments at the end of each quarter for the next 10 years. After the $10^{\text {th }}$ payment, the borrower wants to reduce the quarterly payment. Obtain the expression that allows you to calculate the extra payment the borrower has to make in order to reduce the quarterly payment by $10 \%$. 


\section{Example 41 (Keep paying your current payment so that you repay your mortgage sooner): A loan is} being repaid with 25 annual payments of $€ 300$ each. With the 15th payment, the borrower pays an extra amount of $€ 815.20$. If the borrower wants to keep paying $€ 300$ and the annual effective rate of interest is $8 \%$, find how many repayments the borrower has to pay in order to cancel the loan.

Solution: First of all, we calculate the outstanding balance after the 15th payment,

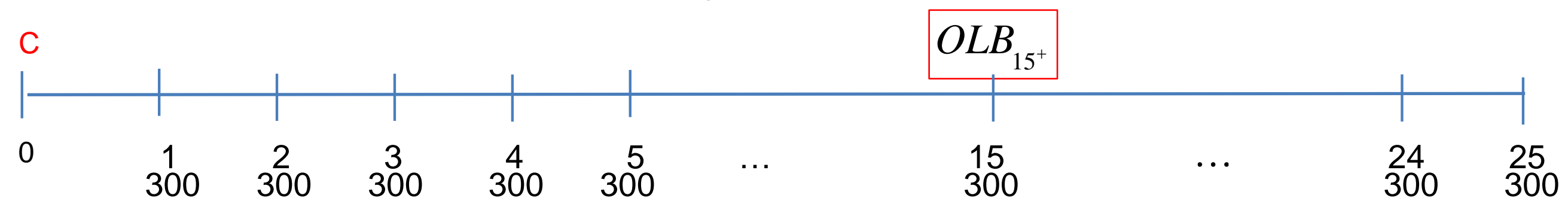

$$
O L B_{15}^{p r o}=\alpha \frac{1-\left(1+I_{m}\right)^{-(n-r)}}{I_{m}}=300 \frac{1-(1+0.08)^{-(25-15)}}{0.08}=€ 2013.02
$$

If the borrower pays an extra $€ 815 ' 20$, then $€ 2013.02$ - $€ 815.20=€ 1197.82$, which is the new principal. That is to say: C'= $€ 1197.82$. So:

$$
\begin{gathered}
1197.82=300 \frac{1-\left(1+I_{1}\right)^{-n}}{I_{1}} \Rightarrow \frac{1197.82 \cdot I_{1}}{€ 300}=1-(1+0.08)^{-n} \\
(1+0.08)^{-n}=1-\frac{1197.82 \cdot I_{1}}{300} \Rightarrow \ln (1+0.08)^{-n}=\ln \left(1-\frac{1197.82 \cdot I_{1}}{300}\right) \\
n=-\frac{\ln \left(1-\frac{1197.82 \cdot I_{1}}{300}\right)}{\ln (1+0.08)} \Rightarrow n=5
\end{gathered}
$$


Example 42: Mary borrows $€ 200,000$ from a bank. The loan is to be repaid with 240 monthly payments. The monthly effective rate of interest is $1.5 \%$. Calculate the extra payment Mary has to make in 10 years if she wants to cancel the loan in 15 years paying her current payment. 


\section{What happens if interest rates decrease or increase?}

\section{Related to the interest rate:}

$\square$ Fixed-rate loan: the interest rate for a fixed-rate loan is locked in and will not change for the full term of the loan. Principal and interest payment amounts are set in advance for the full term, so you will know precisely how much your payments will be throughout the entire term. You get the advantage of a predictable payment.

$\square$ Variable-rate roan: the loan rate will fluctuate.

If you choose a variable-rate loan, you will benefit from a lower rate; however, your rate will go up and down as the interest rate ${ }_{1}$ goes up and down. You may feel better paying a slightly higher rate knowing your rate will be set throughout the term; in this case, a fixed-rate mortgage may be a better choice for you. 
Example 43 (variable rate): An investor took out a loan of $€ 150,000$ at $8 \%$ interest compounded quarterly, to be repaid over 10 years with quarterly level payments at the end of each quarter. After 12 payments, the interest rate dropped to $6 \%$ compounded quarterly. Find the new term.

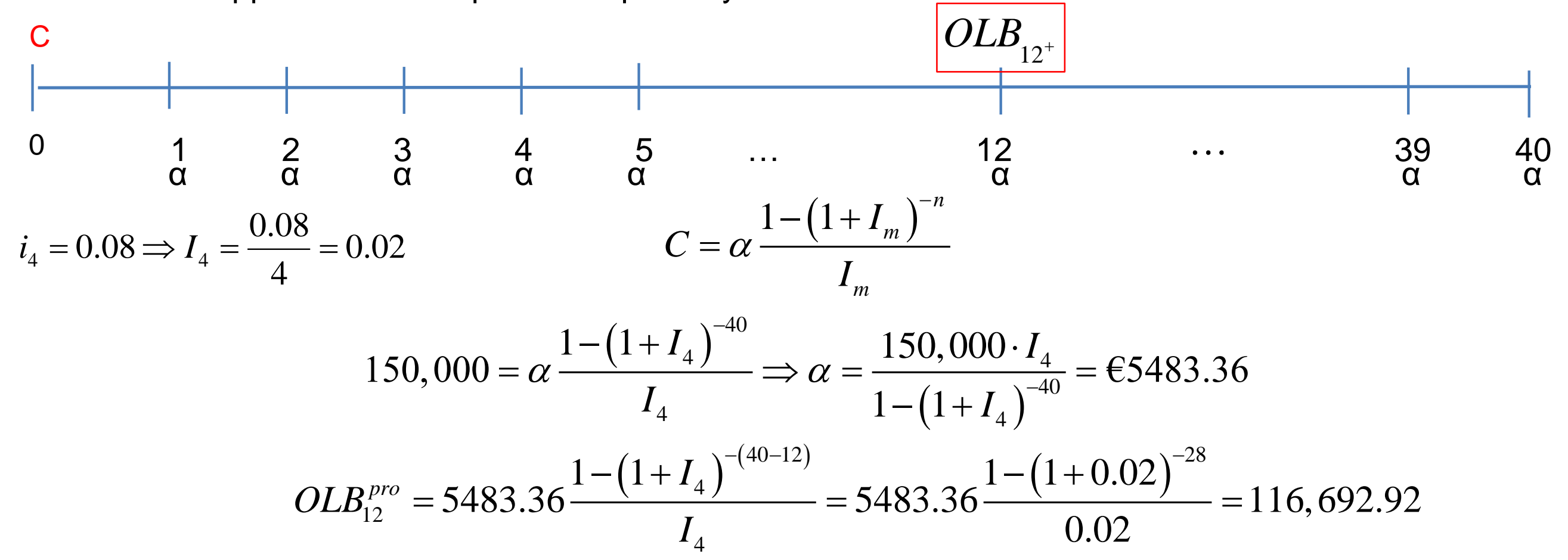

The interest rate dropped to $6 \%$ compounded quarterly:

$$
i_{4}^{\prime}=0.06 \Rightarrow I_{4}^{\prime}=\frac{0.06}{4}=0.015
$$

Then:

$$
\begin{gathered}
116,692.92=\alpha \frac{1-\left(1+I_{4}^{\prime}\right)^{-28}}{I_{4}^{\prime}} \\
\alpha=\frac{116,692.92 \cdot 0.015}{1-(1+0.015)^{-28}}=€ 5134.61
\end{gathered}
$$


Example 44: A housing loan of $€ 400,000$ was to be repaid over 20 years by monthly installments of an annuity-immediate at the nominal rate of $5 \%$ per year. After the 24 th payment was made, the bank increased the interest rate to $5.5 \%$.

- If the lender was required to repay the loan within the same period, how much would the increase in the monthly installments be?

- If the installment remained unchanged, how much longer would it take to pay back the loan? 
Example 45: A $€ 20,000$ mortgage is being repaid with 20 annual installments at the end of each year. The borrower makes 5 payments, and then is temporarily unable to make payments for the next 2 years. Find an expression for the revised payment to start at the end of the 8th year if the loan is still to be repaid at the end of the original 20 years and the annual effective interest rate is $3 \%$.

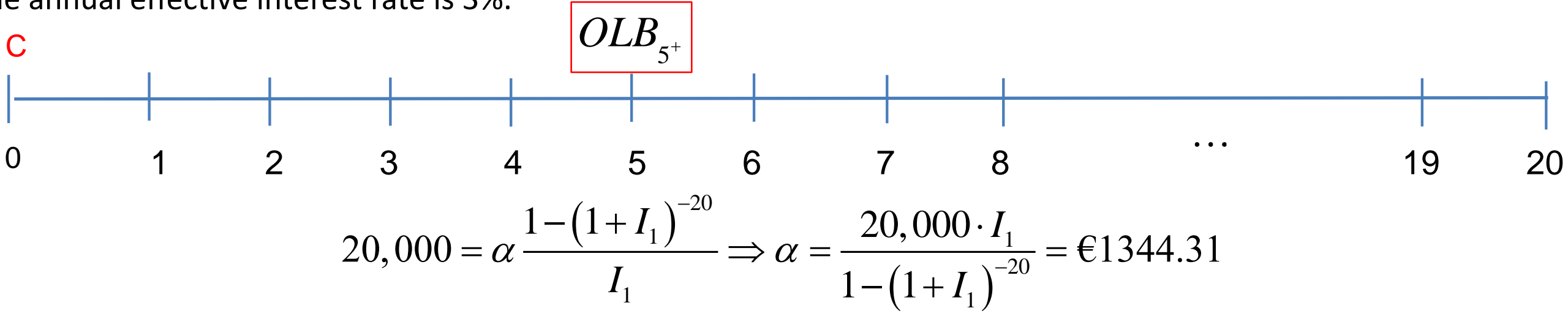

The borrower is temporarily unable to make payments for the next 2 years. We calculate The OLB at $\mathrm{t}=5$,

$$
O L B_{5}^{p r o}=1344.31 \frac{1-\left(1+I_{1}\right)^{-(20-5)}}{I_{1}}=€ 16,048.33
$$

And we charge interest until the next payment at $t=7$

$$
O L B_{5}^{\text {pro }} \cdot\left(1+I_{1}\right)^{2}=16,048.33 \cdot\left(1+I_{1}\right)^{2}=€ 17,025.67
$$

And this is the new principal,

$$
\begin{aligned}
& 17,025.67=\alpha^{\prime} \frac{1-\left(1+I_{1}\right)^{-13}}{I_{1}} \\
& \alpha^{\prime}=€ 1600.91
\end{aligned}
$$


Example 46: A housing loan is to be repaid with a 15-year monthly annuity-immediate of $€ 2000$ at a nominal rate of $6 \%$ per year. After 20 payments, the borrower requests for the installments to be stopped for 12 months. Calculate the revised installment when the borrower starts to pay the loan back again, so that the loan period remains unchanged. 


\section{Waiting period}

In an amortizing loan with waiting period $d$ (measured in periods $p$ ), the first principal payment is made at time $d+p$. That is to say, during an initial period the borrower does not make partial repayments of the loan amount. We can analyze two situations:

- The borrower does not pay anything during the waiting time. However, the interest accumulates on the principal of the loan during this period..

\section{$C_{d}$ is the new principal of the loan}

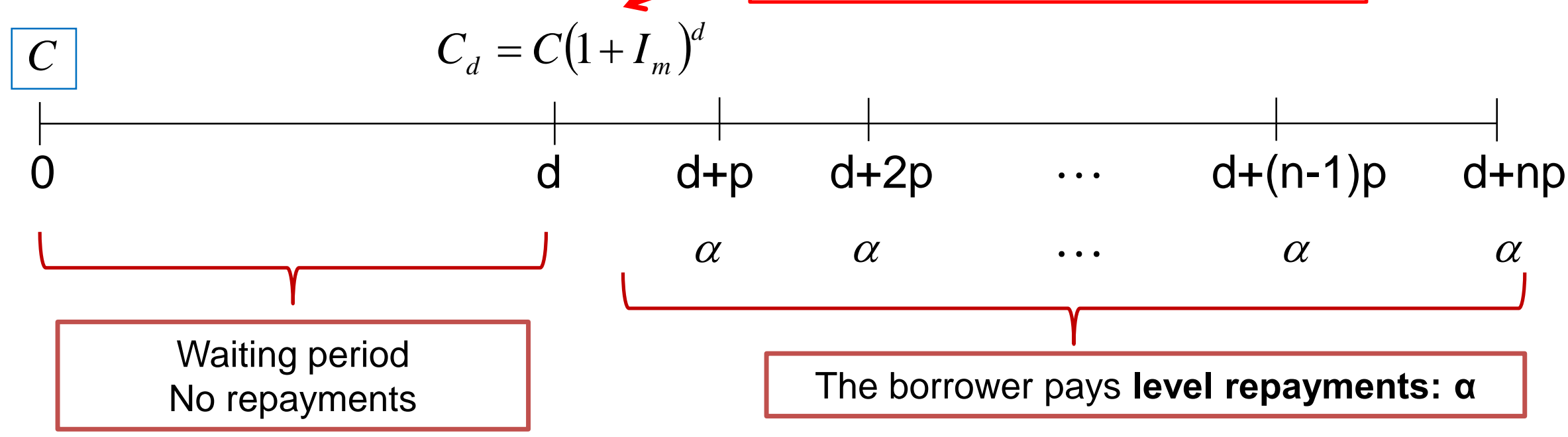

So, the Initial equilibrium equation is:

$$
\begin{gathered}
C\left(1+I_{m}\right)^{d}=C_{d}=\alpha \frac{1-\left(1+I_{m}\right)^{-n}}{I_{m}} \\
C=\alpha \frac{1-\left(1+I_{m}\right)^{-n}}{I_{m}}\left(1+I_{m}\right)^{-d}
\end{gathered}
$$


- During the first $d$ periods the borrower only pays the interest on the loan periodically

$$
Y=C \cdot I_{m}
$$

C

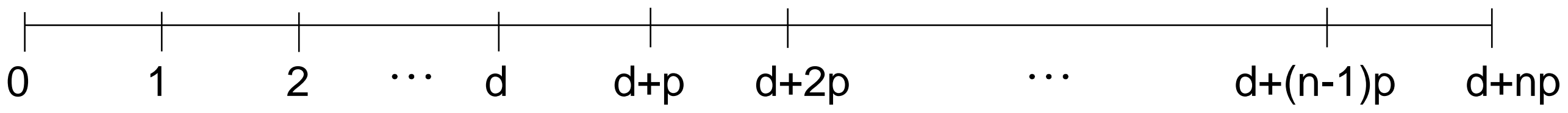
$C \cdot I_{m}$
$C \cdot I_{m} \quad \cdots \quad C \cdot I_{m}$
$\alpha \quad \alpha$
$\alpha$
$\alpha$

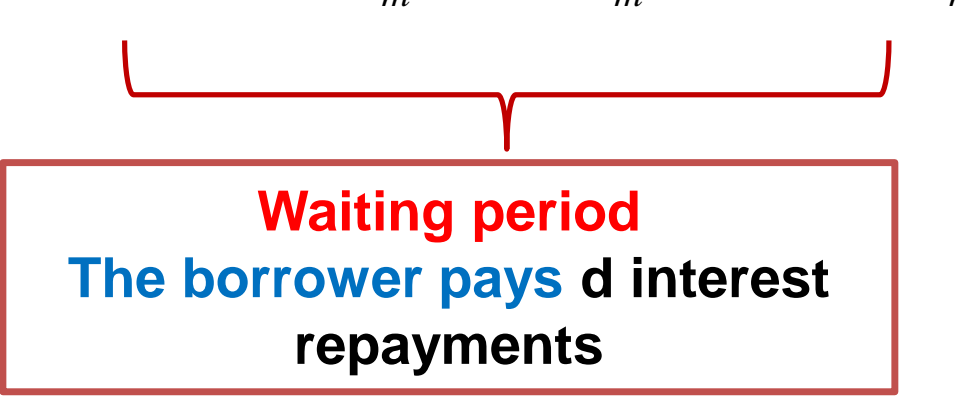

So, the Initial equilibrium equation is:

$$
C=Y \frac{1-\left(1+I_{m}\right)^{-d}}{I_{m}}+\alpha \frac{1-\left(1+I_{m}\right)^{-n}}{I_{m}}\left(1+I_{m}\right)^{-d}
$$

and to obtain $\alpha$ we use:

$$
C=\alpha \frac{1-\left(1+I_{m}\right)^{-n}}{I_{m}}
$$


Example 47: Pau is going to buy a car. He borrows $€ 13,000$. The loan is governed by compound interest at a monthly effective rate of $0.5 \%$. He will repay 20 level repayments at the end of each month. The first repayment is made at the end of the first year. Calculate the amount of the monthly repayment.

$C=13,000$

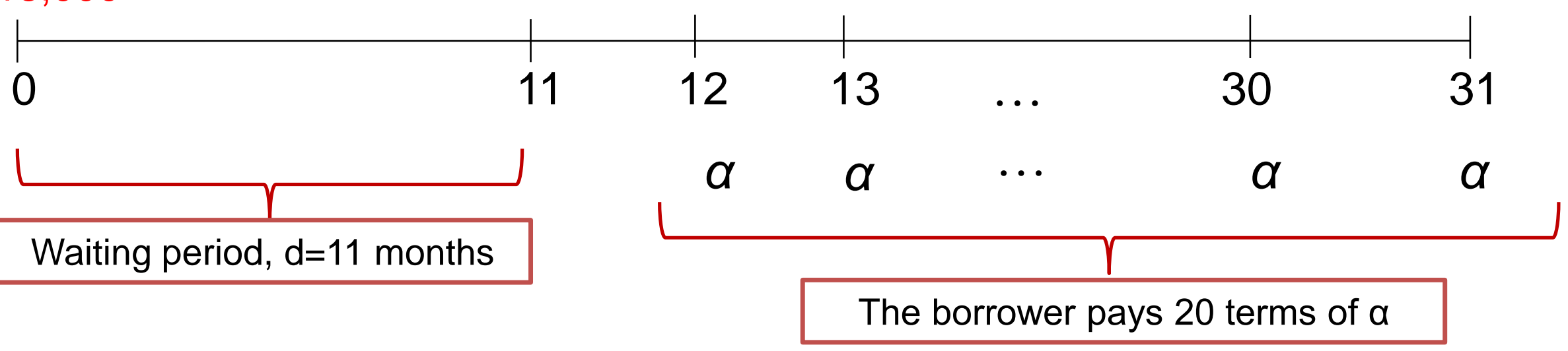

$$
\begin{aligned}
& C_{d}=C\left(1+I_{m}\right)^{d} \\
& \text { | } 1+1 \\
& \begin{array}{rrrrrr}
0^{\prime} & 1^{\prime} & 2^{\prime} & \ldots & 19^{\prime} & 20^{\prime} \\
& \alpha & \alpha & \ldots & \alpha & \alpha
\end{array} \\
& C_{d}=13,000\left(1+I_{12}\right)^{11}=€ 13,733.14 \\
& 13,733.14=\alpha \frac{1-\left(1+I_{12}\right)^{-20}}{I_{12}} \Rightarrow \alpha=\frac{13,733.14}{\frac{1-\left(1+I_{12}\right)^{-20}}{I_{12}}}=€ 723.27
\end{aligned}
$$


Example 49: A loan of principal $€ 50,000$ is being repaid with level repayments at the end of each year for 15 years. The payments begin exactly two years after the loan is made. If the annual effective interest rate is $3 \%$, find the level repayments

Example 50: A loan of principal $€ 50,000$ is being repaid with fifteen level repayments at the end of each year. During the first five years the borrower only pays interest. If the annual effective interest rate is $3 \%$, plot a graph of the loan, obtain the initial equilibrium equation and calculate the repayments. 


\section{Annual percentage rate (APR)}

\section{Definition}

The annual rate $\left(I_{1}^{*}\right)$ that is charged for borrowing is expressed as an annual effective interest rate that represents the actual cost of the loan over the term of the loan. This includes any fees or additional costs associated with the transaction.

That is to say, the APR is a way to calculate the real cost of loans, taking into consideration loan origination fees and the other costs associated with loans. For example:

- Arrangement fees; some arrangement fees are charged as a percentage of the loan.

- Notary fees.

- Valuation fee for a mortgage; this is a basic survey to check that the property is adequate security for the loan.

- Processing fees. 
In order to obtain the APR, it is necessary to obtain the initial equilibrium equation. Remember that in this equation the left-hand side is the present value of the payments and the right-hand side is the present value of the repayments made by the borrower. In both cases, the present value is defined given the APR as the interest rate. So the present value of the payments is equal to the present value of the repayments, given the APR as the interest rate:

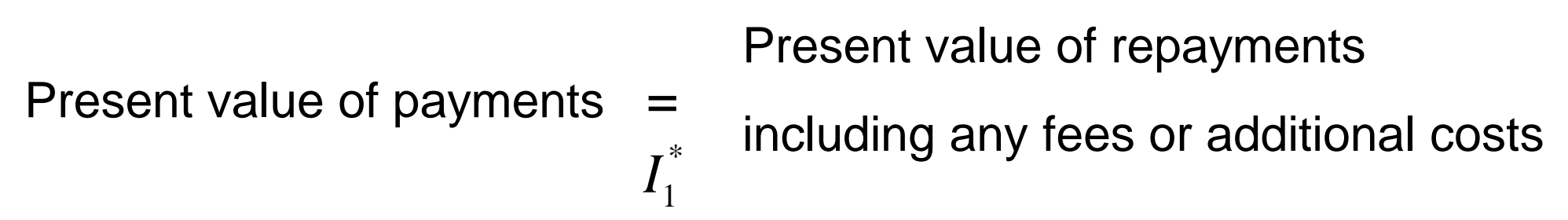

\section{The APR was developed to assist consumers when comparing loans.}

In the European Union (directives 2008/48/EC and 2011/90/EU, fully in force in all member states since 2013), the APR is defined as: "a comprehensible set of information to be given to consumers in good time before the contract is concluded and also as part of the credit agreement [...] every creditor has to use this form when marketing a consumer credit in any Member State". 
However, the exact legal definition of the APR can vary greatly from one country to another, depending on the type of fees included.

In Spain, the Bank of Spain webpage (http://www.bde.es) provides the definition of the TAE (Tasa anual equivalente):

"La T.A.E. es un indicador que, en forma de tanto por ciento anual (efectivo anual), revela el coste o rendimiento efectivo de un producto financiero, ya que incluye el interés y los gastos y comisiones bancarias. $O$ sea, que se diferencia del tipo de interés en que éste no recoge ni los gastos ni las comisiones; sólo la compensación que recibe el propietario del dinero por cederlo temporalmente."

Las entidades están obligadas a informar sobre la TAE de sus operaciones en la publicidad de sus productos que se haga referencia a coste o rentabilidad, en los contratos, en los documentos de liquidación y en las ofertas vinculantes

As you can see, the definition is the same as the definition of the APR. But there is a difference! 
"En el cálculo de la TAE no se incluyen los gastos que el cliente pueda evitar (como los gastos de transferencia de fondos), los que hay que abonar a terceros (corretajes, honorarios notariales e impuestos) o los gastos por seguros o garantías (aunque sí se incluyen aquellas primas destinadas a garantizar a la entidad el reembolso del crédito en caso de fallecimiento, invalidez o desempleo, siempre que la entidad imponga su suscripción para la concesión del crédito). Tampoco se tienen en cuenta las deducciones por impuestos."

So, if you want to obtain the TAE

“Según la normativa establecida por el Banco de España (Circular 5/2012), de todos los gastos de una operación, el único que puede formar parte de la TAE del préstamo es la comisión de apertura"

\section{So:}

- to calculate the APR, you have to include all fees and additional costs associated with the transaction;

- to calculate the TAE, you only have to consider the arrangement fees. 
Example 51: A loan of principal $€ 5000$ is being repaid with a single amount in eight months. The interest rate compounded monthly is $5 \%$. The arrangement fee is $2 \%$ of the principal of the loan, and the notary fee is $€ 330$ to pay at the beginning of the loan. Find the repayment the borrower will make in eight months, and both the APR and the TAE of the loan.

$$
\begin{gathered}
\text { C: } 5000 \\
i_{12}=0.05 \Rightarrow I_{12}=\frac{i_{12}}{12}=\frac{0.05}{12}=0.004166 \\
C^{\prime}=5169.11
\end{gathered}
$$

Remember that if you want to obtain the APR, you have to take into account all the fees and additional costs associated with the transaction; but if you want to obtain the TAE, you only have to take into account the arrangement fee.

$$
\begin{aligned}
\text { Present value of payments }= & \begin{array}{l}
\text { Present value of repayments } \\
\text { including fees }
\end{array}
\end{aligned}
$$


If we take into account all the fees and additional costs associated with the loan, we will obtain the actual cost of the loan (APR)

- Arrangement fee $=0.02 \cdot € 5000=€ 100$

- Notary fee $=€ 330$

C: 5000

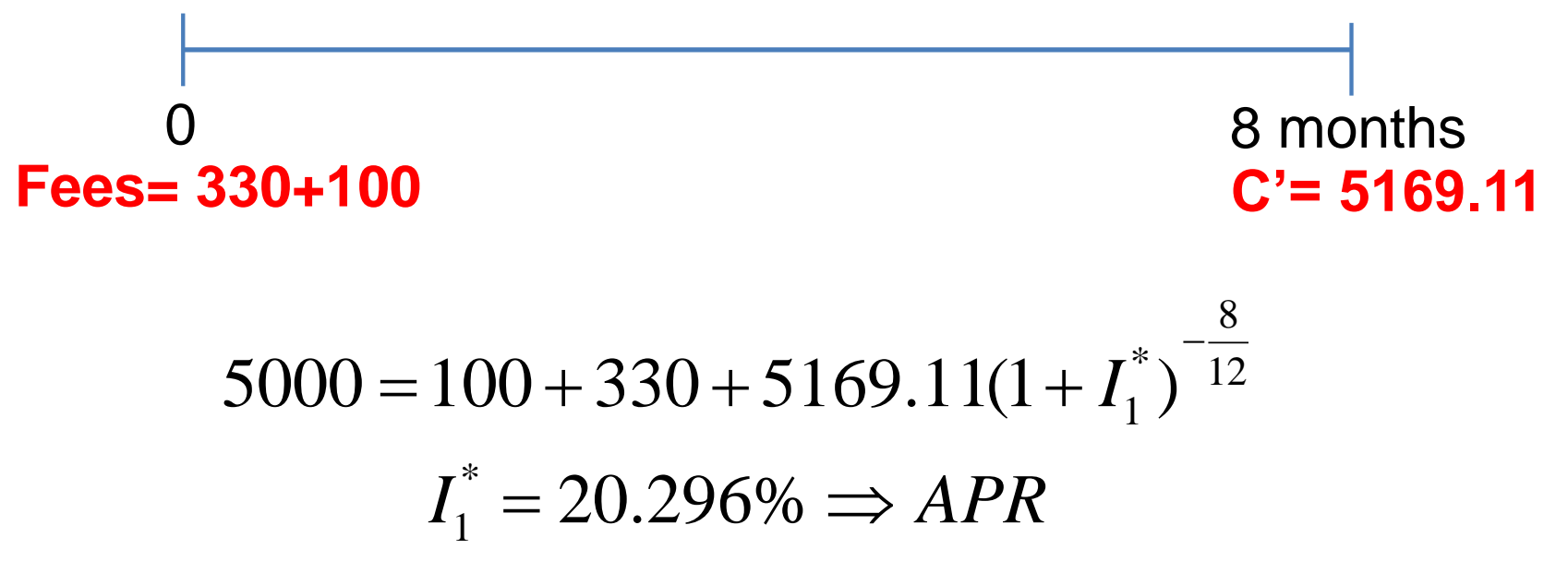

To obtain the TAE, we only take into account the arrangement fee:

C: 5000

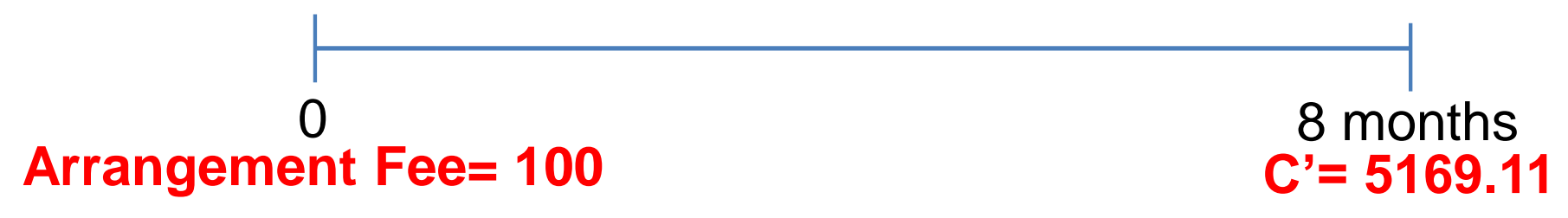

$$
\begin{gathered}
5000=100+5169.11(1+T A E)^{-\frac{8}{12}} \\
T A E=8.35 \%
\end{gathered}
$$


Example 52: A loan of principal $€ 125,000$ is being repaid with 180 monthly payments. The interest rate compounded monthly is $6 \%$. The arrangement fee is $2 \%$ of the principal of the loan, and the notary fee is $€ 550$ to pay at the beginning of the loan. Find the monthly level repayment, and both the APR and TAE of the loan.

$$
i_{12}=0.06 \Rightarrow I_{12}=\frac{i_{12}}{12}=0.005 \quad 125,000=\alpha \frac{1-\left(1+I_{12}\right)^{-180}}{I_{12}} \Rightarrow \alpha=\frac{125,000}{\frac{1-\left(1+I_{12}\right)^{-180}}{I_{12}}}=€ 1054.82
$$

$C=125,000$

\begin{tabular}{llllllllllc|}
\hline & $\mid$ & $\mid$ & $\mid$ & & & $\mid$ & & & \\
0 & 1 & 2 & 3 & 4 & 5 & 6 & $\ldots$ & 179 & 180 \\
$=2500$ & $\alpha$ & $\alpha$ & $\alpha$ & $\alpha$ & $\alpha$ & $\alpha$ & $\ldots$ & $\alpha$ & $\alpha$
\end{tabular}

\section{APR}

$125,000=2500+550+1054,82 \frac{1-\left(1+I_{12}^{*}\right)^{-180}}{I_{12}}$

You need to use some software to obtain $I_{12}^{*}$ (for example Excel)

$$
I_{1}^{*}=\left(1+I_{12}^{*}\right)^{12}-1
$$

\section{TAE}

$125,000=2500+1054.82 \frac{1-\left(1+I_{12}^{T A E}\right)^{-180}}{I_{12}}$

You need to use some software to obtain $I_{12}^{T A E}$

$$
T A E=\left(1+I_{12}^{T A E}\right)^{12}-1
$$


Example 53: A loan of $€ 100,000$ is being repaid with level payments at the end of each month for three years. The arrangement fee is $1 \%$ of the principal of the loan, and the notary fee is $€ 150$ to pay at the beginning of the loan. Assume that the quarterly effective interest rate is $2 \%$. Find:

a) the repayment that has to be made monthly;

b) the amount of interest and the amount of principal in the $11^{\text {th }}$ payment;

c) the amount of the revised annual payment if with the $12^{\text {th }}$ payment, the borrower pays an extra $€ 3000$, and then repays the loan over two years with a revised monthly payment;

d) A graph of the payments and repayments over the life of the loan considering the extra payment;

e) initial equilibrium equation that allows you to calculate the APR and TAE after paying the extra repayment.

Example 54: A loan of $€ 55,000$ is being amortized by means of level monthly payments at an annual effective interest rate of $7 \%$ over ten years. After 100 payments, the interest rate dropped to $6 \%$. If the lender was required to repay the loan within the same period, find the revised monthly payment 
Example 55: Sara is repaying a loan of $€ 60,000$ with level payments at the end of each month over five years. During the first year, Sara only pays the interest on the loan. The interest rate compounded monthly is $6 \%$.

a) Plot a graph of the loan, obtain the initial equilibrium equation and calculate the repayments.

b) If the arrangement fee is $0.6 \%$ of the principal of the loan, obtain the initial equilibrium equation that allows you to calculate the APR and TAE.

Example 56: A loan of principal $€ 75,000$ will be repaid with quarterly interest payments and a lump-sum payment of the principal in three years. The nominal rate of interest compounded quarterly is $2 \%$.

a) Plot a graph of the loan and find the quarterly payments.

b) Find the $C P_{\tau}, M_{\tau}$ and $O L B_{\tau}$ at $\mathrm{t}=0, \mathrm{t}=3^{+}$months, $\mathrm{t}=4$ months, and after the last repayment.

Example 57: A loan of principal $€ 1600$ is being repaid with a single amount in ten years. If the annual effective interest rate is $4 \%$, the arrangement fee is $1 \%$ of the principal, and the notary fee is $€ 225$ to pay at the beginning of the loan:

a) plot a graph of the loan and find the repayments; and

b) calculate the APR and TAE. 


\section{BONDS}

$\checkmark$ Introduction: definitions and notation

$\checkmark$ Coupon bonds

$\checkmark$ "Zero coupon bonds" or "discount bonds" 


\section{Definition}

A bond is a security issued by a government entity or corporation (issuer of the bond) that promises certain payments at future dates to the purchaser of the bond (issuer's creditors or holders of the bond).

- The issue date is the time that the investor lends the bond issuer money by purchasing the bond. The amount that the investor pays for the bond is the purchase price (P).

- The last of the payments occurs on the maturity date

- The term of the bond is the length of time from the date of issue to the date of the final payment.

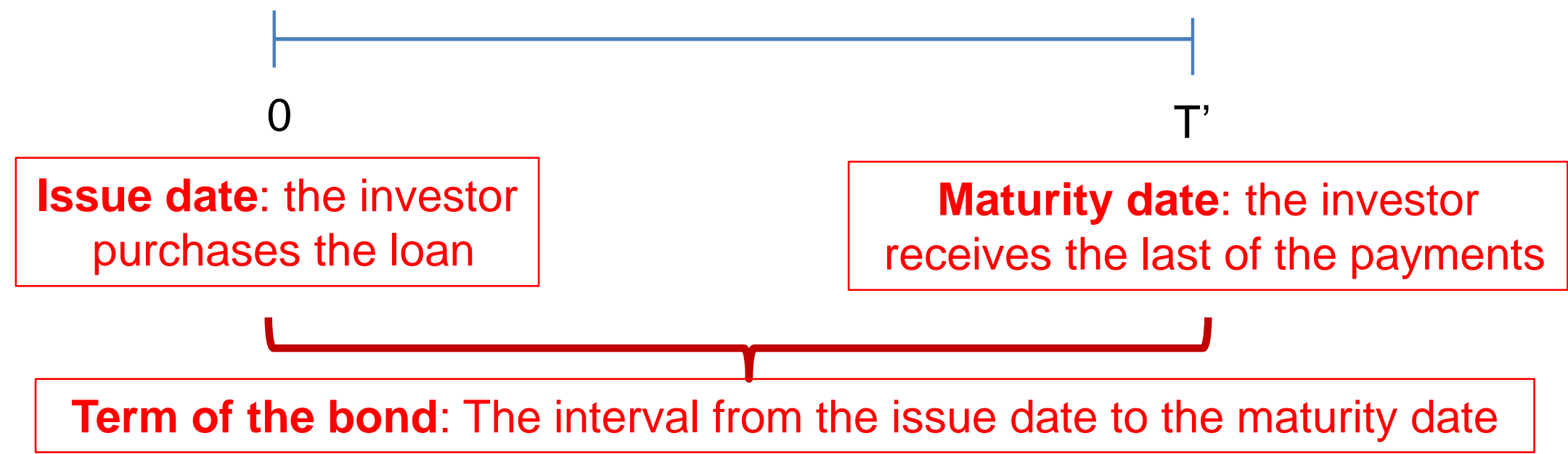

Bonds are nothing more than loans, but from a different perspective. When we purchase a bond, we are lending money to the issuer of the bond. The price of the bond is the amount we are lending. So we are taking the perspective of the lender rather than that of the borrower. 


\section{Depending on the maturity date}

- If the maturity date is fixed, the bond is said to be non-callable (we will consider non-callable bonds)

- If the maturity date is not fixed, the bonds are callable bonds.

- Bonds with an infinite term are called perpetuals.

\section{Depending on the payments}

- Zero-coupon bonds (or pure discount bonds) are bonds that promise only a simple payment at a fixed maturity date; that is to say, they pay no periodic interest payments: just a lump sum.

- Coupon bonds are bonds that promise a sequence of payments prior to and on the maturity date, as well as an additional redemption (amortización) payment, which is usually the largest payment. That is to say, periodic payments of interest are made by the issuer of the bond prior to redemption. 


\section{Coupon bonds}

$\checkmark$ Purchase price (P): This is the amount that the investor pays for the bond.

$\checkmark$ Face value or par value (F): Printed on a bond is its face value or par value. In general, this need not to be either the price the investor pays for the bond or the redemption value of the bond on the maturity date.

$\checkmark$ Coupon amount (Y): These are the periodic payments of interest made by the issuer of the bond that are paid $\mathbf{m}$ times each year; they depend on the coupon rate $\left(\mathrm{I}_{\mathrm{m}}\right)$.

$\checkmark$ Redemption amount (C): This is the amount that the bond holder receives on the maturity date of the bond, excluding the regular coupon amount.

\section{The investor}

purchases the bond and pays $\mathrm{P}$

p

0

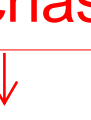



P




\section{Coupon amount (Y)}

$\checkmark$ The coupon depends on the coupon rate $\left(I_{m}\right)$, and it is calculated by considering the face value of the bond, not the price of the bond:

$$
Y=F \cdot I_{m}
$$

$\checkmark$ The length of the intervals between coupon payments is referred to as the coupon period.

$\checkmark$ Coupons are paid $\mathrm{m}$ times each year. If the bond is an $\mathrm{N}$-year bond, then the number of coupon payments over the term of the bond is denoted by $\mathrm{n}$,

$$
n=N \cdot m
$$

\section{Redemption amount (C)}

$\checkmark$ If $\mathbf{C}=\mathrm{F}$, the bond is said to be a par-value bond or to be redeemable at par. If no redemption is specified, either directly or indirectly, then you should assume that the bond is a par-value bond.

$\checkmark$ Some bonds are redeemable at premium: the redemption amount is greater than the face value of the bond, that is to say $C>F$. The redemption value is stated as a percentage of the face value. For example, a $€ 1000$ bond redeemable at 105 is redeemed at $105 \%$ of $€ 1000$; that is to say: $€ 1050$. 


\section{Purchase price (P)}

Bonds can be priced at a premium, discount, or at par.

$\checkmark$ SELL AT PAR: if the price, $P$, is equal to the face value:

$$
P=F
$$

$\checkmark$ SELL AT A PREMIUM: if the price, $\mathrm{P}$, is greater than the face value:

$$
P>F
$$

The difference $(P-F)$ is called the premium or amount of premium.

$\checkmark$ SELL AT A DISCOUNT: if the price, $P$, is less than the face value:

$$
P<F
$$

The difference $(F-P)$ is called the discount or amount of discount.

Note the difference between "bought at par" and "redeemable at par"! 


\section{Yield rate or yield to maturity: $I_{m}^{*}$}

$\checkmark$ In bond amortization, the relevant interest rate is the yield rate. The yield rate is the interest that the bond purchaser would achieve if they held the bond until the maturity date. That is to say, the interest rate actually earned by the investor, assuming the bond is held until maturity.

$\checkmark$ In order to calculate it, you have to take into account the purchase price, the coupon payments and the redemption amount.

$\checkmark$ Pay attention! Remember that the coupon rate $I_{m}$ is used to calculate the coupon payment, but it does not represent the actual profitability of the bond. 
An $\mathrm{N}$-year bond with face value $\mathrm{F}$ and $\mathrm{m}$ coupons per year, pays $\mathrm{n}$ coupon payments over the term of the bond.

$$
\longrightarrow\left\{\begin{array}{l}
P=F \Rightarrow \text { sell at par } \\
P>F \Rightarrow \text { sell at a premium } \\
P<F \Rightarrow \text { sell at a discount }
\end{array}\right.
$$

P: Purchase price

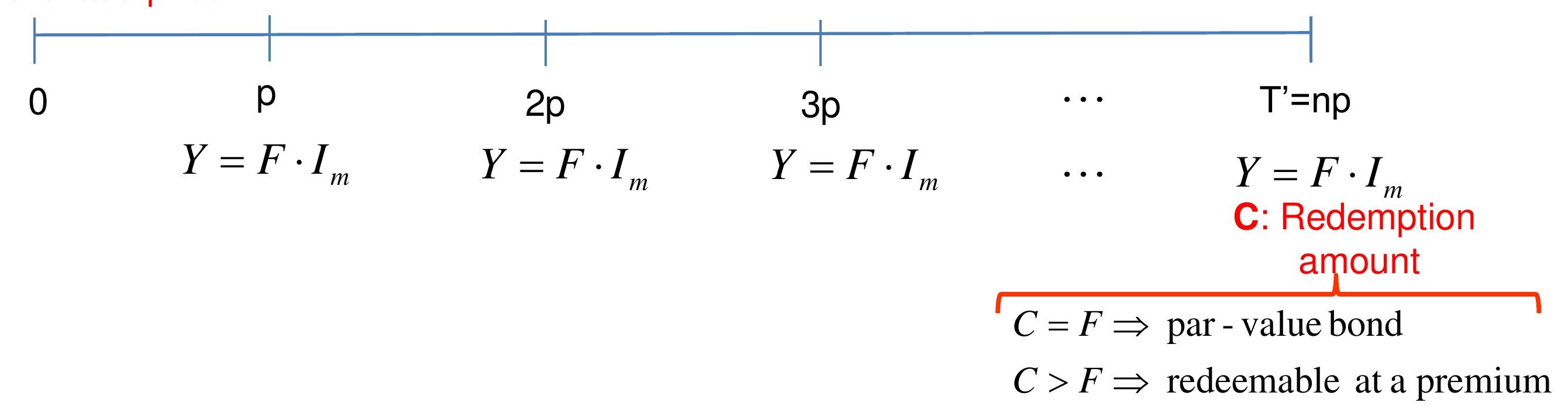

\section{Basic price formula for a bond (initial equilibrium equation):}

$$
P=F \cdot I_{m} \frac{1-\left(1+I_{m}^{*}\right)^{-n}}{I_{m}^{*}}+C\left(1+I_{m}^{*}\right)^{-n}
$$

If $P=C=F \Rightarrow$ "Sell at par" and "par - value bond" $\Rightarrow I_{m}^{*}=I_{m}$ 
Example 1 (Finding the price of a bond): A bond with a par value of $€ 1000$ and a $6 \%$ coupon rate compounded semi-annually will be redeemed at $105 \%$ at the end of 15 years. Find the price if the effective yield rate is $5 \%$.

$$
N=15 \quad m=2 \quad F=1000
$$

P: Purchase price

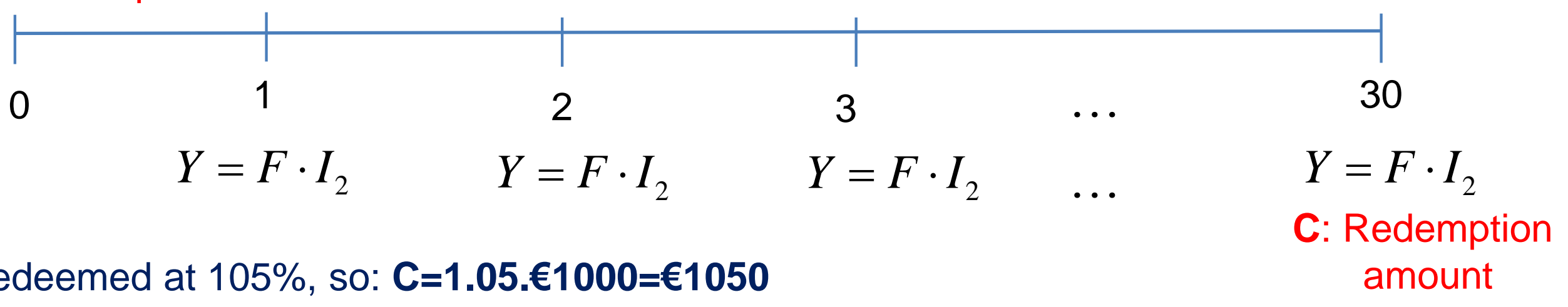

- It is redeemed at $105 \%$, so: $\mathbf{C}=1.05 . € 1000=€ 1050$ amount

- Coupon rate: $i_{2}=0.06$

$$
I_{2}=\frac{0.06}{2}=0.03
$$

- Coupon amount: $Y=€ 1000 \cdot I_{2}=€ 1000 \cdot 0.03=€ 30$

- Yield rate:

$$
I_{1}^{*}=0.05 \Rightarrow I_{2}^{*}=\left(1+I_{1}^{*}\right)^{\frac{1}{2}}-1=0.0246950
$$

- Basic price formula for a bond:

$$
P=F \cdot I_{m} \frac{1-\left(1+I_{m}^{*}\right)^{-n}}{I_{m}^{*}}+C\left(1+I_{m}^{*}\right)^{-n}=30 \frac{1-\left(1+I_{2}^{*}\right)^{-30}}{I_{2}^{*}}+1050\left(1+I_{2}^{*}\right)^{-30}=€ 1135.54
$$


Example 2: Imagine an eight-year bond with a face value of $€ 3000$, semi-annual coupon at a coupon rate of $10 \%$ compounded semi-annually and redemption value of $€ 2800$. The price of the bond, $P$, gives the investor an annual effective yield rate of $12 \%$. Find the price of the bond.

Example 3: A 20-year bond matures for its par value of $€ 10,000$. The coupon payable semiannually is $€ 400$. Calculate the price of the bond at a $6 \%$ annual effective yield rate and the coupon rate.

Example 4: A 10 -year $€ 100$ par-value bond bearing a $10 \%$ coupon rate payable semi-annually, and redeemable at 105 , is bought to yield $8 \%$ convertible semi-annually. Find the price.

Example 5: A $€ 1000$ par-value 20-year bond with annual coupons and redeemable at maturity at 1050 is purchased for $P$ to yield an annual effective rate of $8.25 \%$. The first coupon is $€ 75$. Each subsequent coupon is $3 \%$ greater than the preceding coupon. Find $\mathrm{P}$.

Example 6: An $\mathrm{N}$-year $€ 1000$ par-value bond bearing a $9 \%$ coupon rate payable semi-annually and redeemable at $€ 1125$ is bought to yield $10 \%$ compounded semi-annually. Find the purchase price of the bond if the present value of the redemption value is $€ 214.14$ at the given yield rate. 
Example 7 (Finding the yield rate of a bond): A 12-year bond with a face value of $€ 2000$ and quarterly coupons with a coupon rate of $8 \%$ compounded quarterly is bought for $€ 2200$. It is a parvalue bond. Find the effective yield rate.

$$
N=12 \quad m=4
$$

P: 2200

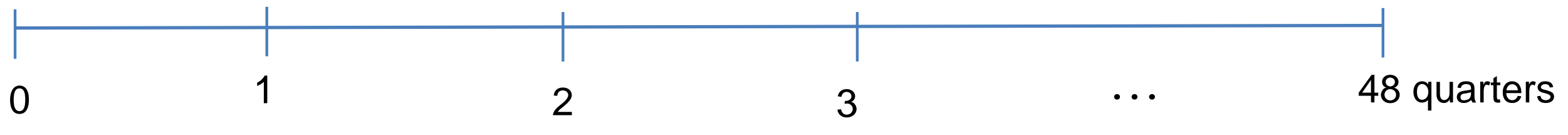

$$
Y=F \cdot I_{m} \quad Y=F \cdot I_{m} \quad Y=F \cdot I_{m} \quad \ldots \quad Y=F \cdot I_{m}
$$

- It is a par-value bond, therefore: $\mathbf{C}=\mathbf{F}=€ 2000$

C: Redemption amount

- Coupon rate: $i_{4}=0.08$

$$
I_{4}=\frac{0.08}{4}=0.02
$$

- Coupon amount: $Y=2000 \cdot I_{4}=2000 \cdot 0.02=€ 40$

- Basic price formula for a bond:

$$
\begin{gathered}
P=F \cdot I_{m} \frac{1-\left(1+I_{m}^{*}\right)^{-n}}{I_{m}^{*}}+C\left(1+I_{m}^{*}\right)^{-n} \\
2200=40 \frac{1-\left(1+I_{4}^{*}\right)^{-48}}{I_{4}^{*}}+2000\left(1+I_{4}^{*}\right)^{-48} \\
I_{1}^{*}=\left(1+I_{4}^{*}\right)^{4}-1
\end{gathered}
$$


Example 8 (Finding the redemption amount of a bond): A 9-year bond with a face value of $€ 5000$ and semi-annual coupons with a coupon rate of $7 \%$ compounded semi-annually is purchased for $€ 4986$. This price allows the purchaser an annual effective yield of $6 \%$. Calculate the redemption amount.

- $\mathrm{N}=9$ and $\mathrm{m}=2$

- $F=€ 5000$

- $P=€ 4986$

- Coupon rate: $i_{2}=0.07 \Rightarrow I_{2}=\frac{0.07}{2}=0.035$

- Yield rate:

$$
I_{1}^{*}=0.06 \Rightarrow I_{2}^{*}=\left(1+I_{1}^{*}\right)^{\frac{1}{2}}-1=0.0295630
$$

- Coupon amount: $Y=5000 \cdot I_{2}=5000 \cdot 0.035=€ 175$

- Basic price formula for a bond:

$$
\begin{gathered}
P=F \cdot I_{m} \frac{1-\left(1+I_{m}^{*}\right)^{-n}}{I_{m}^{*}}+C\left(1+I_{m}^{*}\right)^{-n} \\
4986=175 \frac{1-\left(1+I_{2}^{*}\right)^{-18}}{I_{2}^{*}}+C\left(1+I_{2}^{*}\right)^{-18} \\
C=€ 4342.33
\end{gathered}
$$


Example 9 (Determining the amount of the premium or discount of a bond): A bond with a face value of $€ 6000$ and an annual coupon rate of $12 \%$ compounded semi-annually will mature in 10 years for its face value (it is a par-value bond). If the bond is priced using a nominal interest rate of $6 \%$ compounded semi-annually, what is the amount of premium or discount on this bond?

- $\mathrm{N}=10$ and $\mathrm{m}=2$

- $\mathrm{C}=\mathrm{F}=€ 6000$

- Coupon rate: $i_{2}=0.12 \Rightarrow I_{2}=\frac{0.12}{2}=0.06$

- Yield rate: $i_{2}^{*}=0.06 \Rightarrow I_{2}^{*}=\frac{0.06}{2}=0.03$

- Coupon amount: $Y=6000 \cdot I_{2}=6000 \cdot 0.06=360$

- Basic price formula for a bond:

$$
\begin{gathered}
P=F \cdot I_{m} \frac{1-\left(1+I_{m}^{*}\right)^{-n}}{I_{m}^{*}}+C\left(1+I_{m}^{*}\right)^{-n} \\
P=360 \frac{1-\left(1+I_{2}^{*}\right)^{-20}}{I_{2}^{*}}+6000\left(1+I_{2}^{*}\right)^{-20}=€ 8677.94
\end{gathered}
$$

Remember that if the price, $\mathrm{P}$, is greater than the face value, $\mathbf{P}>\mathbf{F}$, the difference, $\mathbf{P}-\mathbf{F}$, is called the premium or amount of premium.

$$
P-F=8677^{\prime} 94-6000=€ 2677.94
$$


Example 10: A bond with a face value of $€ 4000$ and monthly coupons with a coupon rate of $6 \%$ compounded monthly is bought for $€ 3900$. It will be redeemed at $103 \%$ in ten years. Find the annual effective yield rate.

Example 11: A 5-year bond with a face value of $€ 1000$ and quarterly coupons with a coupon rate of $4 \%$ compounded quarterly is purchased for $€ 1075$. This price allows the purchaser an annual effective yield of $5 \%$. Calculate the redemption amount.

Example 12: A 7-year bond with a face value of $€ 3000$ and an annual coupon rate of $10 \%$ compounded semi-annually is priced using a nominal interest rate of $6 \%$ compounded semiannually. It is a par-value bond with semiannual coupons. Find the amount of premium or discount on this bond. 


\section{Book Value $B_{t}$}

In the same way that a loan has an outstanding balance at any time, we can talk of the book value of a bond at any time, t. We define the book value to be the present value of all future payments. If we let But be the book value after the t-th coupon has just been paid, then the value of the remaining payments is $(n-t)$ coupons and a payment of $C$ on the date of redemption (maturity date). So:

P: Purchase price

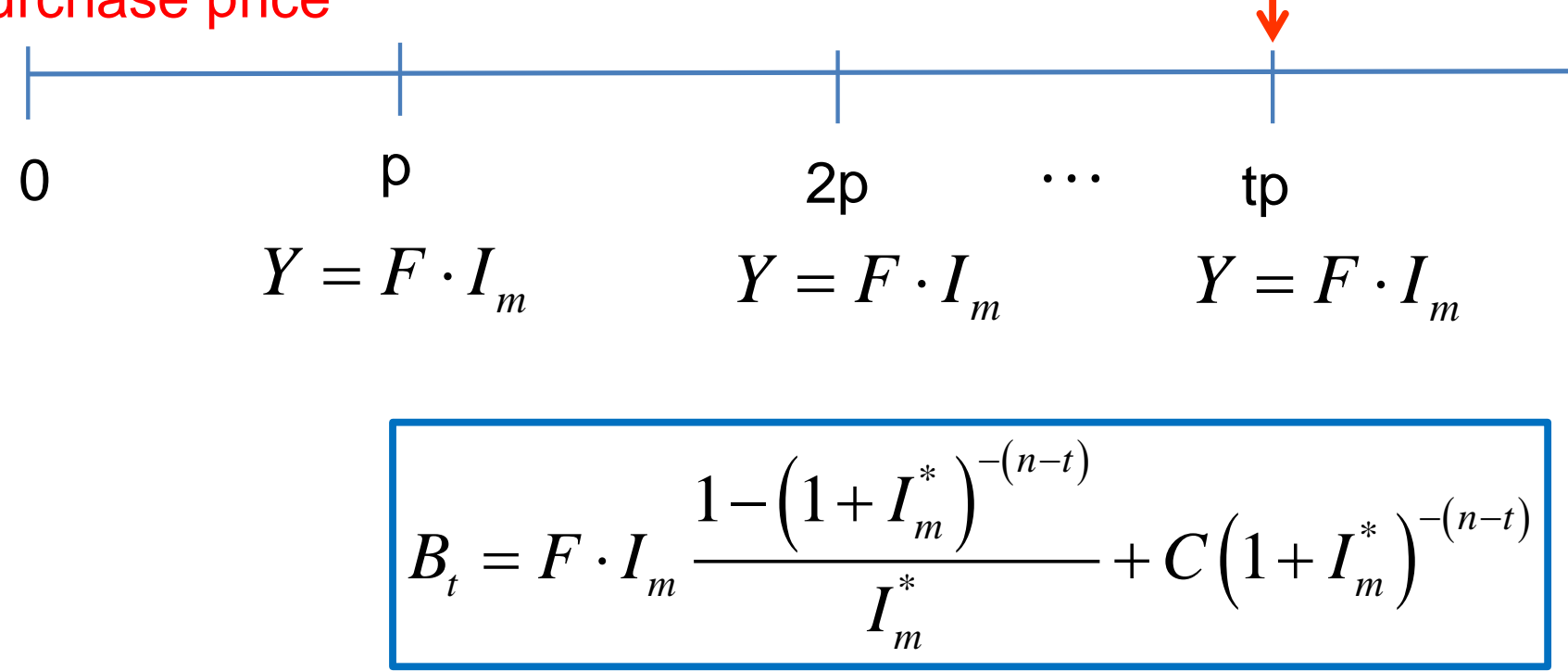

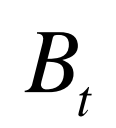

$, \quad, \quad B_{t}$

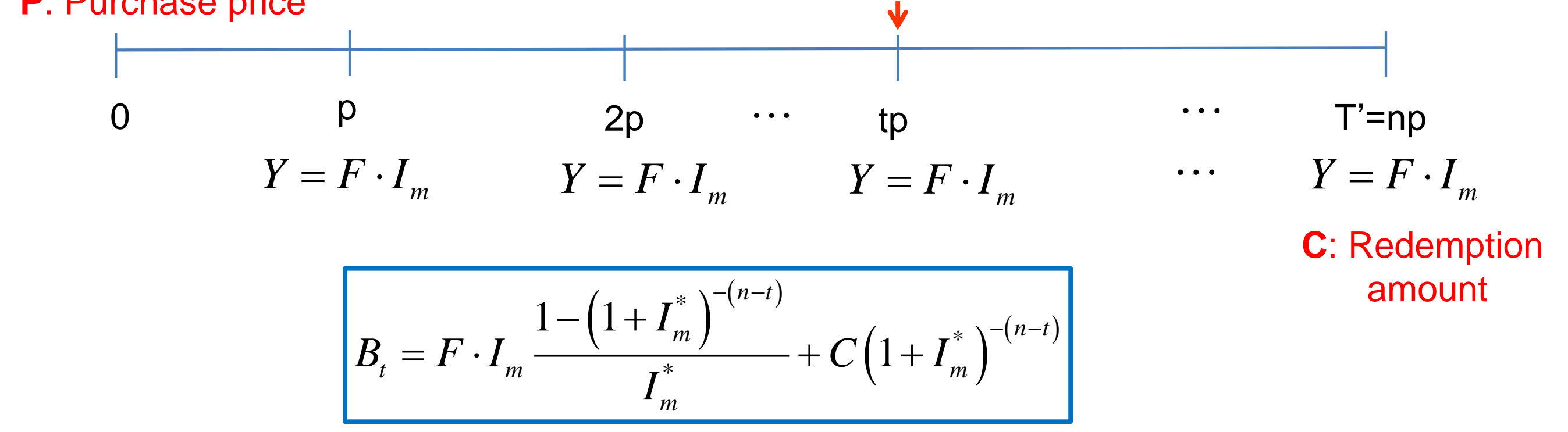

$\checkmark$ Letting $t=0$ in the expression, we find: $B_{0}=P$.

$\checkmark$ Similarly, letting $t=n, B_{n}=C$. That is to say, on the redemption date, the book value of a bond equals the redemption value of the bond. 
Example 13 : Find the book value immediately after payment of the 14th coupon of a 10-year $€ 1,000$ par-value bond with semi-annual coupons, if the coupon rate is 0.05 convertible semiannually and the yield rate is $12 \%$ convertible semi-annually.

Example 14 : A bond with a par value of $€ 2000$ and a 7\% coupon rate compounded semi-annually will be redeemed at $106 \%$ at the end of 5 years. If the effective yield rate is $5 \%$, find the book value immediately after payment of the $4^{\text {th }}$ coupon.

$B_{t}$ does not take into account market forces and is therefore usually not equal to the price for which you could sell the bond at time $t$. 
Remember that the yield rate or "yield to maturity" is the interest rate actually earned by the investor, assuming the bond is held until maturity. But a bond sale typically involves transaction costs, most notably a broker's mark-up. These costs, which commonly range from $1 \%$ to $5 \%$ of the bond's value, clearly must be taken into account when making investment decisions. However, we will usually disregard transaction costs, which can be denoted as: $G_{0}$.

But, if we do consider the transaction costs, then:

P: Purchase price

$\mathbf{G}_{\mathbf{0}}$ : Transaction costs

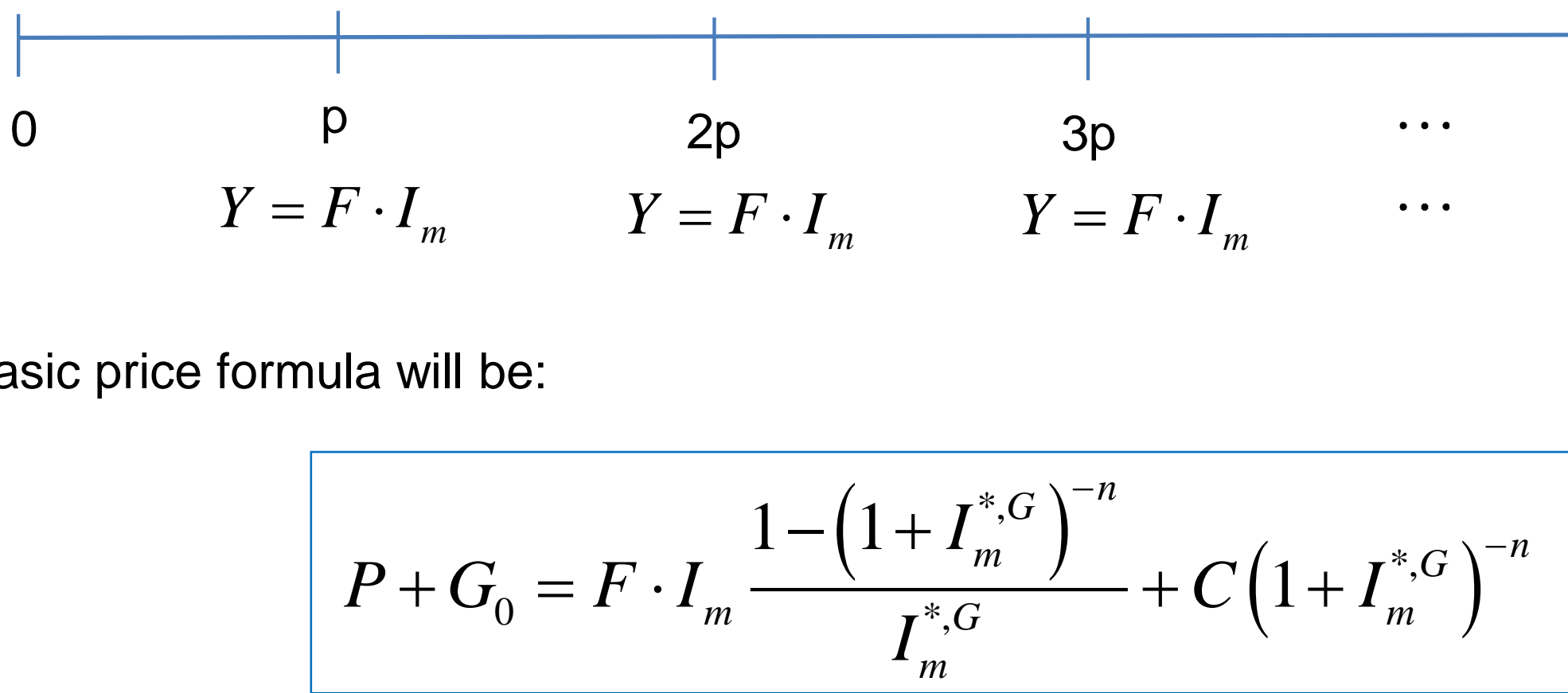

And the basic price formula will be:

C: Redemption amount 
Example 15: A bond with a face value of $€ 1000$ and monthly coupons with a coupon rate of $4 \%$ compounded monthly is bought for $€ 990$. It will be redeemed at $103 \%$ in ten years. Registration fees and bank charges are $1 \%$ of the face value. Find the yield to maturity including transaction costs. 


\section{Valuing a bond after its date of issue}

When an investor purchases a bond, the price paid for the bond might reasonably be referred to as its value. remember that the book value, $B_{t}$, was the present value, calculated with respect to the yield rate to maturity, of the remaining payments promised by the bond.

$\checkmark$ So if we wish to value the bond at an arbitrary time, $T$, given in coupon periods, $0<T<n$, we might consider again, using the yield rate, the present value of the remaining payments. Then the value is $B_{t}$

P: Purchase price

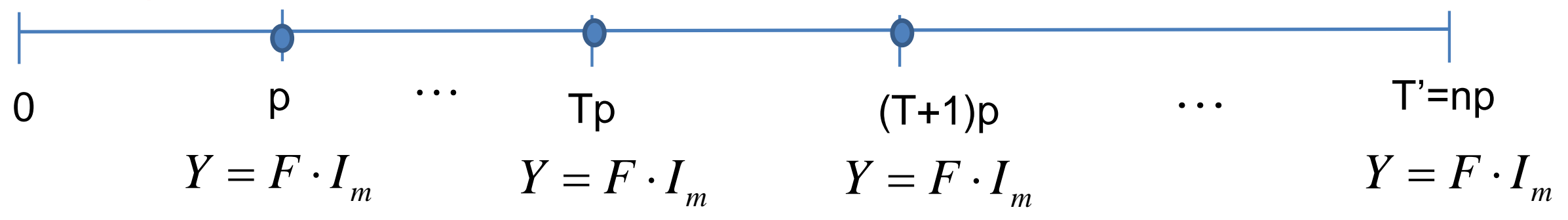


Example 16: Assume that the redemption value of a bond is the same as its face value, which is $€ 1000$. Find the purchase price of the bond immediately after its $10^{\text {th }}$ coupon payment on June $15^{\text {th }} 2010$.

\begin{tabular}{ll}
\hline Type of bond & Government bond \\
\hline Issue date & June 15,2005 \\
\hline Date of purchase & June 15,2009 \\
\hline Maturity date & June 15,2020 \\
\hline Coupon rate & $\mathrm{i}_{2}=0,042$ \\
\hline Yield rate & $\mathrm{i}_{2}=0,04$ \\
\hline
\end{tabular}


The pricing formulas discussed are applicable to a bond on its issue date or a date immediately after a coupon payment. But obviously bond transactions may occur any time before maturity. We now consider the pricing formula of a bond traded between coupon payment dates.

If the bond is a cum-dividend bond, this means that the buyer of the bond has the right to receive the current coupon payment on the bond (usual in the United States). The purchaser of a new cumdividend bond receives the coupon payment at the end of the coupon period during which the sale was made. That is, the buyer receives the whole coupon, even though they have held the bond for only a portion, $1-f$, of the coupon period.

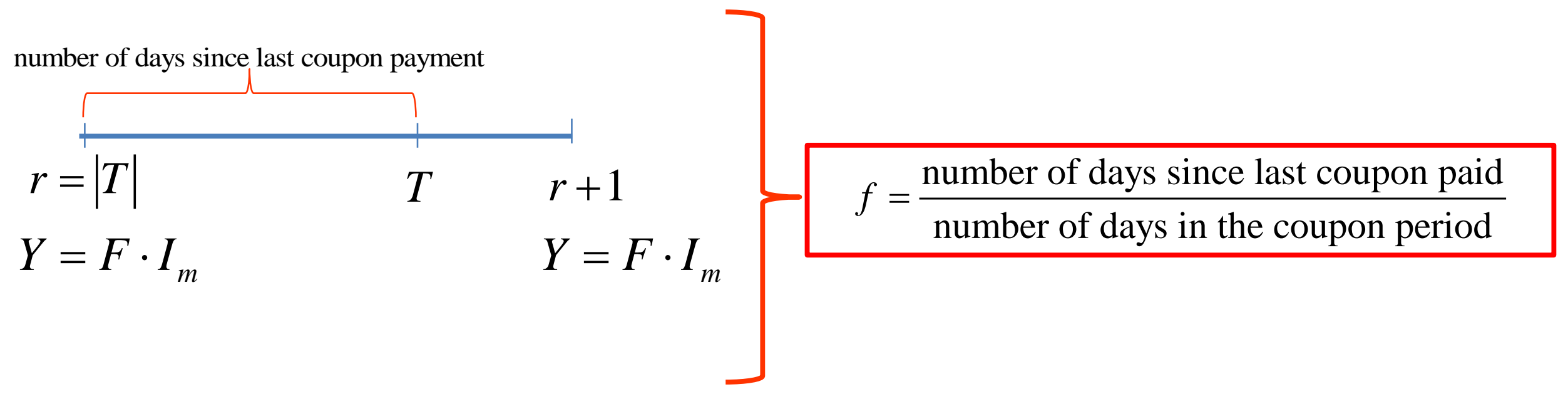

For example, in a bond with annual coupons, if $\mathrm{T}=2$ '25, then
- $r=2$ years
- $r+1=3$ years

$$
f=\frac{90}{360}=0^{\prime} 25
$$$$
\begin{gathered}
T=|T|+f \\
2^{\prime} 25=\left|2^{\prime} 25\right|+0^{\prime} 25=2+0^{\prime} 25
\end{gathered}
$$ 
So, the current holder would expect to receive part of this coupon as interest for the period which we call accrued interest. The purchaser of the bond has to pay the accrued interest to the seller.

- Let's obtain the accrued interest $\left(A_{T}\right)$ using the practical method:

$$
A_{T}=F \cdot I_{m} \cdot f=\frac{\text { number of days since last coupon paid }}{\text { number of days in the coupon period }}
$$

- We define the dirty price, $\mathbf{D}_{\mathbf{T}}$, as the price paid by the purchaser of the bond.

number of days since last coupon payment

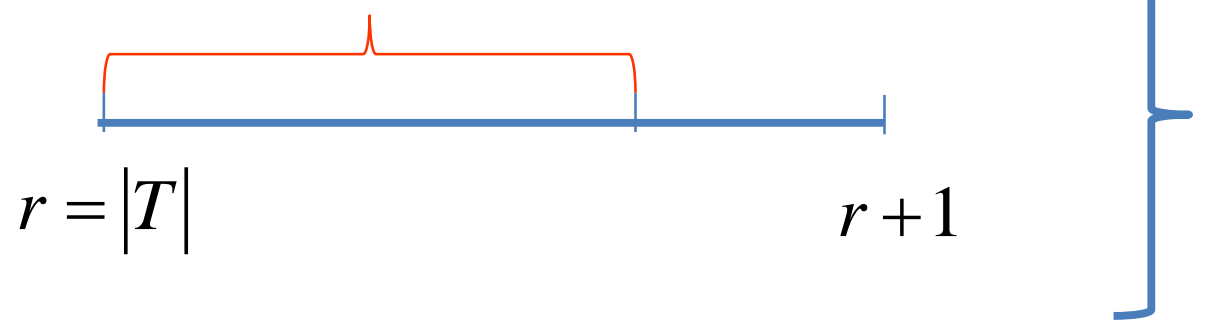

$$
\text { Theoretical method } \Rightarrow D_{T}=\left(1+I_{m}^{*}\right)^{f} B_{|T|}
$$$$
\underline{\text { Practical method }} \Rightarrow D_{T}=\left(1+f \cdot I_{m}^{*}\right) B_{|T|}
$$

From previous concepts we can define the clean price $\left(\mathrm{C}_{\mathrm{T}}\right)$ as:

Clean price $=$ Dirty price - Accrued Interest

$$
C_{T}=D_{T}-A_{T}
$$


Example 17 : A six year bond with par value $2500 €$ and annual coupons at $14 \%$ is purchased at issue date for 3432 '26, and the redemption amount is 2427 ' $36 €$. The yield rate is 0.06 . Find the dirty price using the practical method, the clean price and the accrued interest at $t=3,25$ years using the practical method

P: 3432 '26

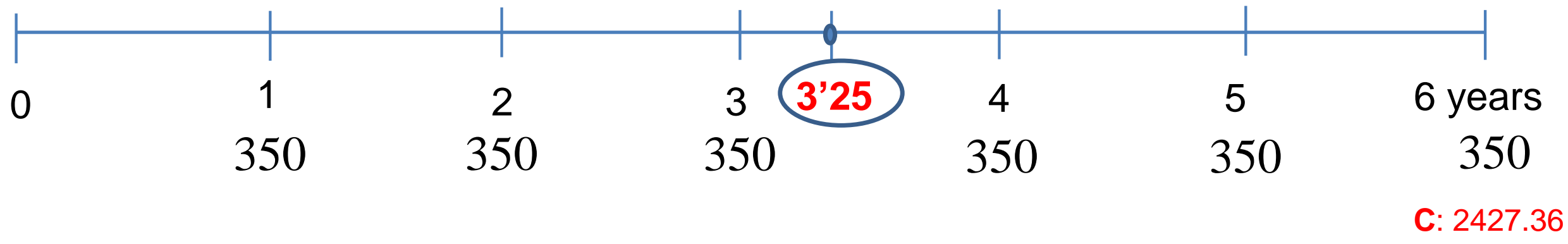

- $\mathrm{F}=2500 \mathrm{~N}=6 \quad \mathrm{~m}=1 \rightarrow Y=2500 \cdot I_{1}=2500 \cdot 0.14=350$

Book value at third coupon payment

$$
B_{3}=350 \frac{1-(1+0.06)^{-3}}{0.06}+2427.36(1+0.06)^{-3}=2973.61
$$

And the dirty price is

$$
D_{T}=\left(1+f \cdot I_{m}^{*}\right) B_{T \mid} \rightarrow D_{3.25}=\left(1+\frac{1}{4} 0.06\right) B_{3}=2973.61\left(1+\frac{1}{4} 0.06\right)=3018.22
$$

$\underline{\text { Accrued interest }}$

$$
A_{3.25}=F \cdot I_{m} \cdot f=350 \frac{1}{4}=87.5
$$

Clean price

$$
D_{T}=C_{T}+A_{T} \Rightarrow C_{T}=D_{T}-A_{T}=3018.22-87.5=2930.72
$$


Example 18: The bond in example 16. Assume that the coupon payments for the government bond are due on June 15th and December 15th of each year. On August 18th 2010, an investor purchased the bond to yield 3.8\% convertible semi-annually. Find the dirty price, accrued interest and clean price of the bond on the date of purchase, based on a face value of $€ 1000$ using practical method.

Example 19: A bond with a par value of $€ 2000$ with a $4 \%$ coupon rate compounded semiannually will be redeemed at $106 \%$ at the end of 5 years. Find the dirty price, the clean price and the accrued interest at $t=9$ months using the practical method if the yield rate is $5 \%$ compounded semi-annually.

Example 20 : A bond with a par value of $€ 1000$ and a $6 \%$ coupon rate compounded semiannually will be redeemable for $€ 1125$ at the end of 3 years. It was purchased on the issue date for its face value. Find its dirty value seven months after issue using the practical method.

The yield rate is $I_{2}^{*}=0.0484490$ 
Of course, when a bond is bought or sold on the secondary market, it is the dirty price that is paid; that is the market value of the bond.

So bonds are quoted at clean prices but transact at dirty prices.

For this reason, the dirty price is sometimes called the invoice price.

The rule in the bond market is

"buy clean, pay dirty." 


\section{Selling a bond after its date of issue}

Example 21 : Sara purchases for $€ 1212 €$ a $€ 2000$ 6\% eight-year par-value bond with annual coupons. Three years later, just after receiving the third coupon, she sells the bond to Marc for $€ 1600$.

- Find Sara's book value $B_{3}$

$$
\mathrm{F}=2000 \quad \mathrm{~N}=8 \quad \mathrm{~m}=1 \quad \mathrm{P}=1212 \quad \mathrm{C}=2000 \quad I_{1}=0.06 \quad \Rightarrow \quad Y=F \cdot I_{1}=2000 \cdot 0.06=120
$$

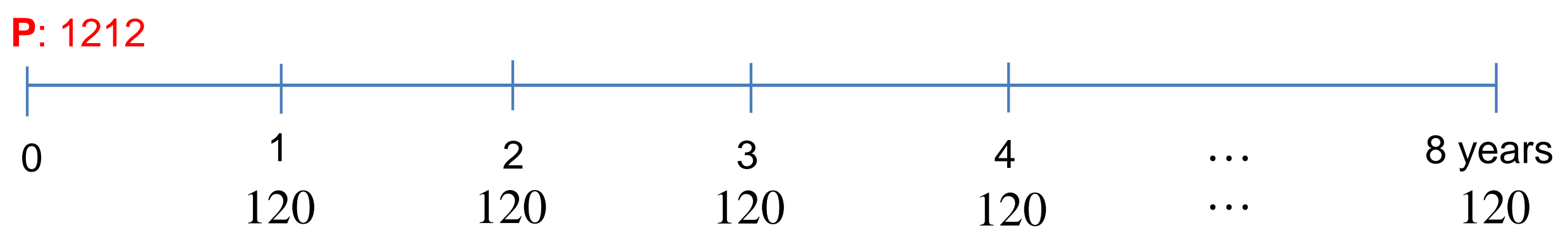

Basic price formula

$$
\begin{gathered}
P=F \cdot I_{m} \frac{1-\left(1+I_{m}^{*}\right)^{-n}}{I_{m}^{*}}+C\left(1+I_{m}^{*}\right)^{-n} \Rightarrow 1212=120 \frac{1-\left(1+I_{m}^{*}\right)^{-8}}{I_{m}^{*}}+2000\left(1+I_{m}^{*}\right)^{-8} \\
I_{1}^{*}=0.14691366
\end{gathered}
$$

Book value at third coupon payment

$$
B_{3}=120 \frac{1-(1+0.146913)^{-5}}{0.146913}+2000(1+0.146913)^{-5}=1413.02
$$


- Find Sara's actual yield for her 3- year investment

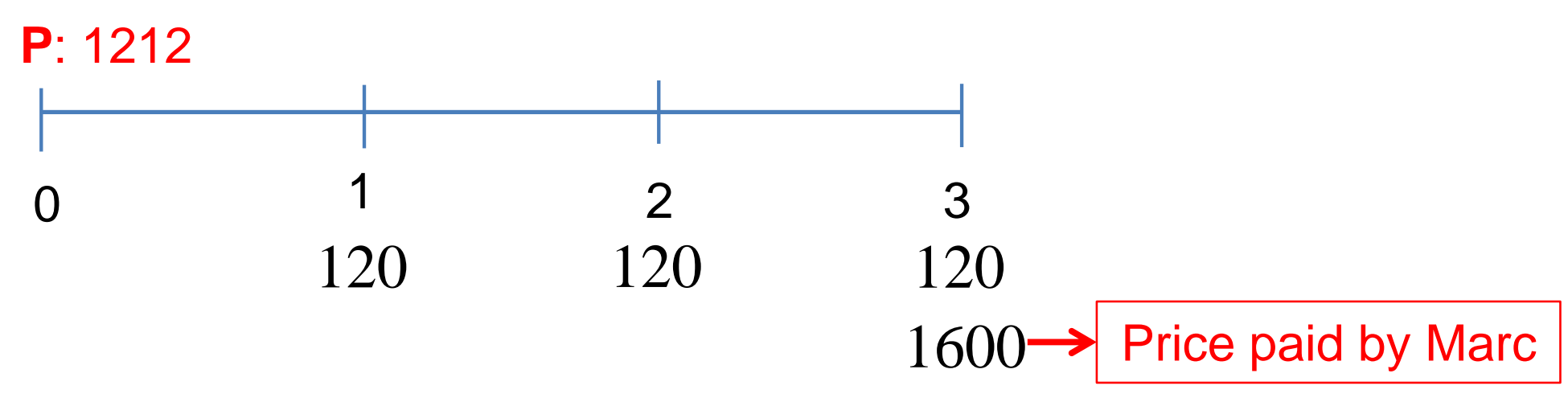

Then, the initial equilibrium equation

$$
1212=120 \frac{1-(1+y)^{-3}}{y}+1600(1+y)^{-3} \Rightarrow y=0.187955
$$

- Find Marc's yield on his 5-year investment Price paid by Marc $\leftarrow \mathbf{P}: 1600$

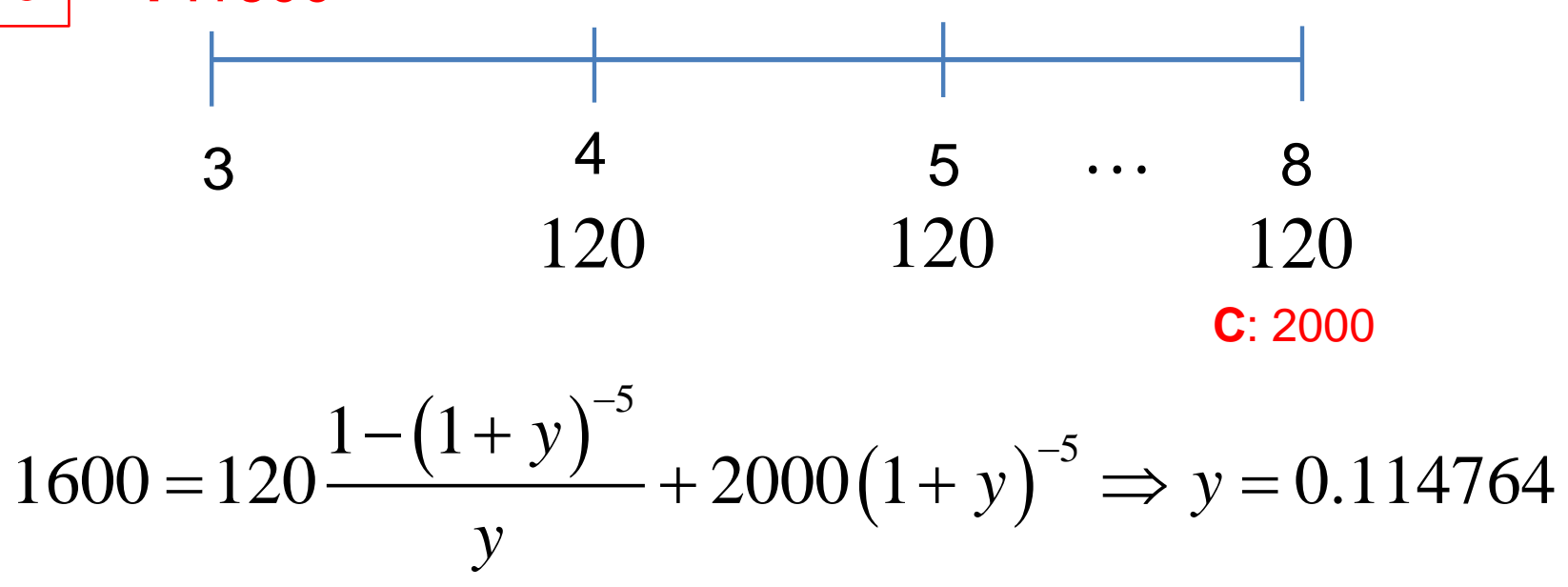


Example 22 : Alba purchases for $€ 1050$ a three-year $€ 10005 \%$ compounded semi-annually parvalue bond with semi-annual coupons. The redemption amount is $€ 1020$. One year later, just after receiving the second coupon, she sells the bond to Pau for $€ 1030$.

- Find Alba's book value, $B_{2}$.

- Find Alba's actual yield for her 1-year investment.

- Find Pau's yield on his 2-year investment. 


\section{Market value of a bond}

Very often, a bond is negotiable; i.e., the holder can transfer the bond in the secondary market. The factor that influences a bond more than any other is the level of prevailing interest rates in the economy.

- When market interest rates increase, the market value of an existing bond decreases.

- When market interest rates decrease, the market value of an existing bond increases.

\section{The market value of a bond will fluctuate as interest rates rise and fall.}

To explain the relationship between bond prices and bond yields, let's use an example. First, let's assume you just purchased a bond with a maturity of five years and a coupon of $5 \%$, and you bought it at par investing $€ 1000$. At this point, your bond is worth exactly what you paid for it, no more and no less. Also, just to be clear, you will receive annual interest of $€ 50$ plus a return of your principal at maturity. However, the market value of your bond will fluctuate after your purchase as interest rates rise or fall. 
- Let's assume that interest rates rise to 7\%. Because new bonds are now being issued with a $7 \%$ coupon, your bond, which has a $5 \%$ coupon, is not worth as much as it was when you bought it. Why? If investors can invest the same $€ 1000$ and purchase a bond that pays a higher interest rate, why would they pay $€ 1000$ for your lower-interest bond? In this case, the value of your bond would be less than $€ 1000$. Hence, your bond would be trading at a discount.

- If interest rates decrease after your purchase, the value of your bond will rise because - investors cannot buy a newly issued bond with a coupon as high as yours. In this case, your bond would be worth more than $€ 1000$. Hence, it would trade at a premium. 
Example 23 (market interest rates decrease): Consider a $€ 1000$ bond, redeemable at par on December $1^{\text {st }}$ 1998, with 9\% coupons paid semi-annually. The bond is bought on the secondary market on June $1^{\text {st }} 1996$. Find the price if the market interest rate is $8 \%$ compounded semi-annually.

$$
\begin{array}{lll}
F=1000 & \text { Coupon rate } & i_{2}=0.09 \Rightarrow I_{2}=\frac{0.09}{2}=0.045 \\
C=F=1000 & \text { Market rate } & i_{2}^{m}=0.08 \Rightarrow I_{2}^{m}=\frac{0.08}{2}=0.04 \\
Y=F \cdot I_{2}=1000 \cdot 0.045=45 &
\end{array}
$$

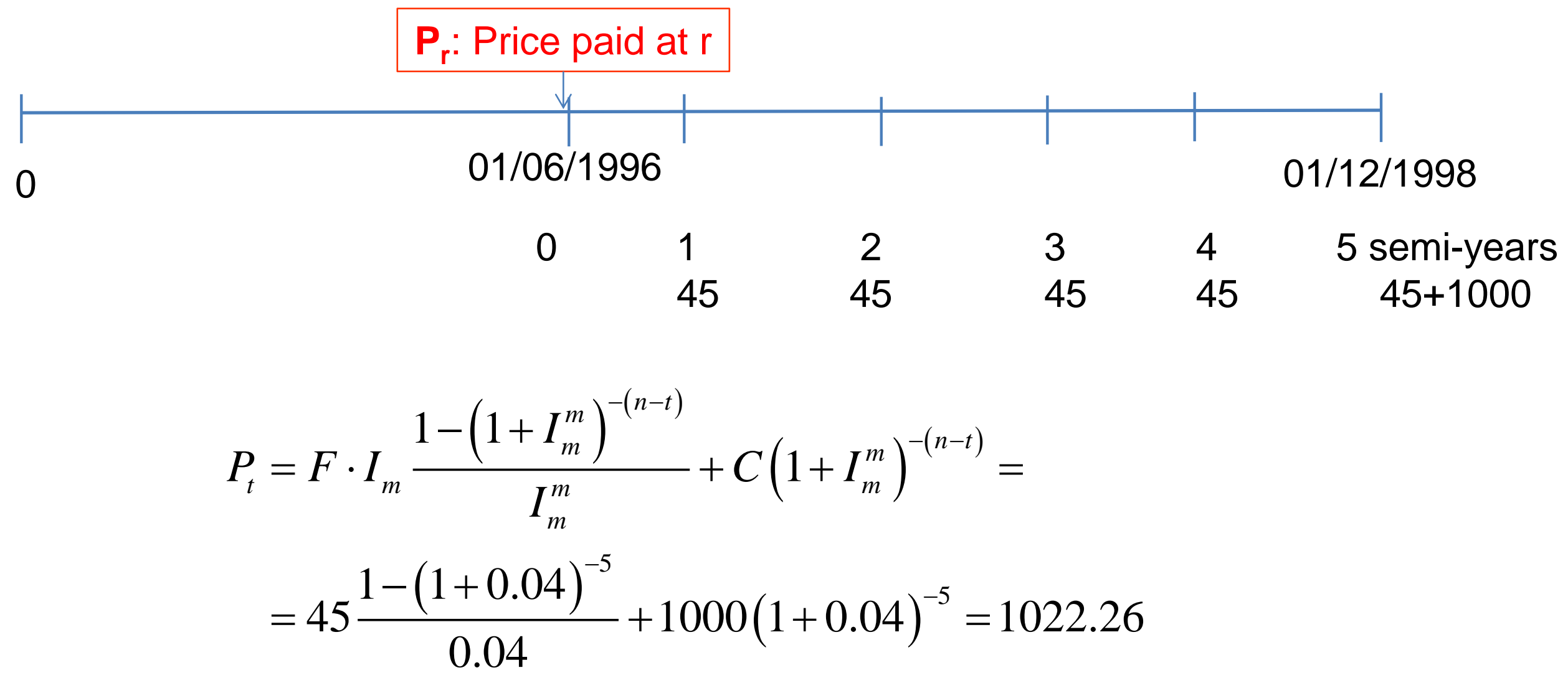


Example 24 (market interest rates increase): Consider a $\$ 1000$ bond, redeemable at par on December $1 \mathrm{st}$ 1998, with 9\% coupons paid semi-annually. The bond is bought on the secondary market on June 1st 1996. Find the price if the market interest rate is $10 \%$ compounded semi-annually.

- Coupon rate: $i_{2}=0.09 \Rightarrow I_{2}=\frac{0.09}{2}=0.045 \quad Y=F \cdot I_{m}=1000 \cdot 0.045=45$

- Market rate: $\quad i_{2}^{m}=0.1 \Rightarrow I_{2}^{m}=\frac{0.1}{2}=0.05$

$$
\begin{gathered}
\begin{array}{c}
\mathbf{P}_{\mathrm{r}} \text { : Price paid at } \mathrm{r} \\
0 \\
0
\end{array} P_{t}=F \cdot I_{m} \frac{1-\left(1+I_{m}^{m}\right)^{-(n-t)}}{I_{m}^{m}}+C\left(1+I_{m}^{m}\right)^{-(n-t)}= \\
\\
=45 \frac{1-(1+0.05)^{-5}}{0.05}+1000(1+0.05)^{-5}=978.35
\end{gathered}
$$




\section{Zero-coupon bonds}

Zero-coupon bonds are bonds that do not pay interest during the life of the bonds.

> When a zero-coupon bond matures, the investor receives a lump sum equal to the initial investment plus the imputed interest, which is discussed below.

$>$ We focus our attention on treasury bills (T-bills).

\section{Treasury bills (T-bills)}

A Treasury bill is a zero-coupon bond. That is to say, T-bills pay no coupons prior to maturity.

$>$ T-bills are short-term instruments.

- Investors buy T-bills at a discount, below the face value, and then receive the full amount of the face value when the bill matures. That is to say, T-bills are issued at a discount from their face value.

The holder of the T-bill pays a purchase price lower than the face value.

P: Purchase price $=$ Face value - Discount

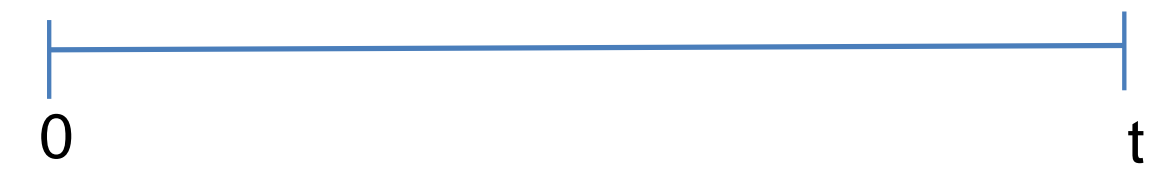

F: Face value

$>$ The basis for counting time periods for T-bills is actual $/ 360$. 
T-bills are sold at a discount from their face value and the Treasury pays back the face value of the T-bill at maturity. The discount amount is the interest deducted in advance from the face value.

\section{The Treasury receives the face value minus the discount, but pays back the full face value.}

Example 25: An investor bought a six-month $€ 5000$ treasury bill with a discount rate of $0.12 \%$. What is the amount of the discount? What is the price of the T-bill?

\section{Purchase price: $\mathbf{P}$}

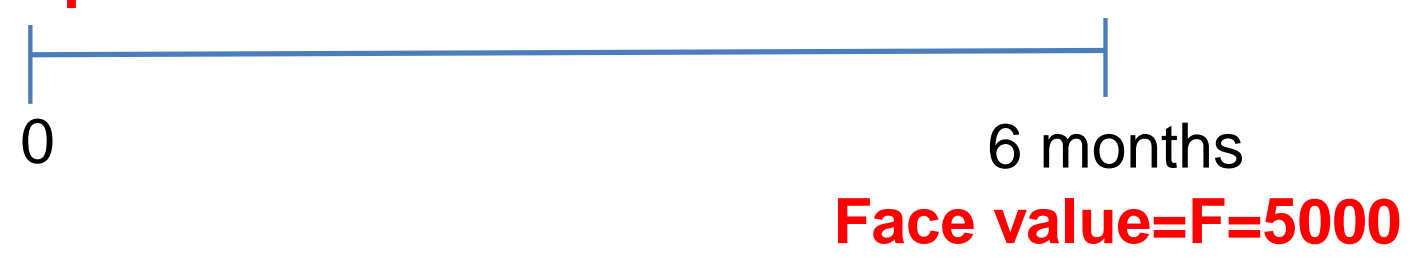

The discount rate on a T-bill is always a simple annual interest rate. Consequently, the discount (interest) is found by using the simple interest formula:

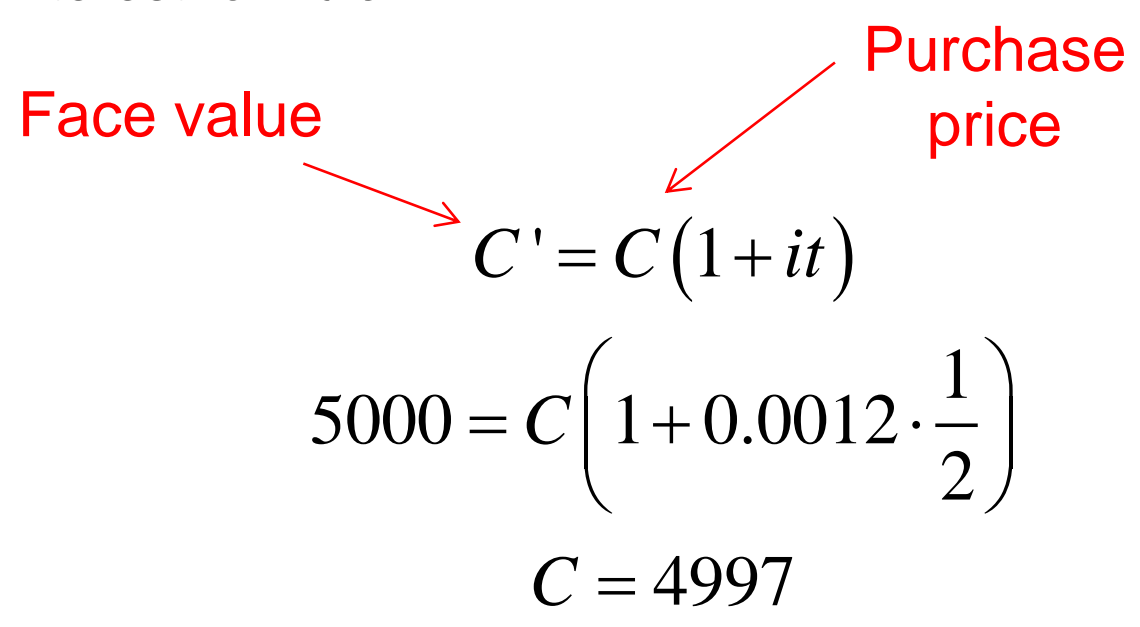

The value of the discount is $€ 5000-€ 4997=€ 3$. 
Example 26: Find the price on the secondary market of a $€ 1000$ one-year treasury bill that matures in 185 days, knowing that the published average interest rate is $0.18 \%$

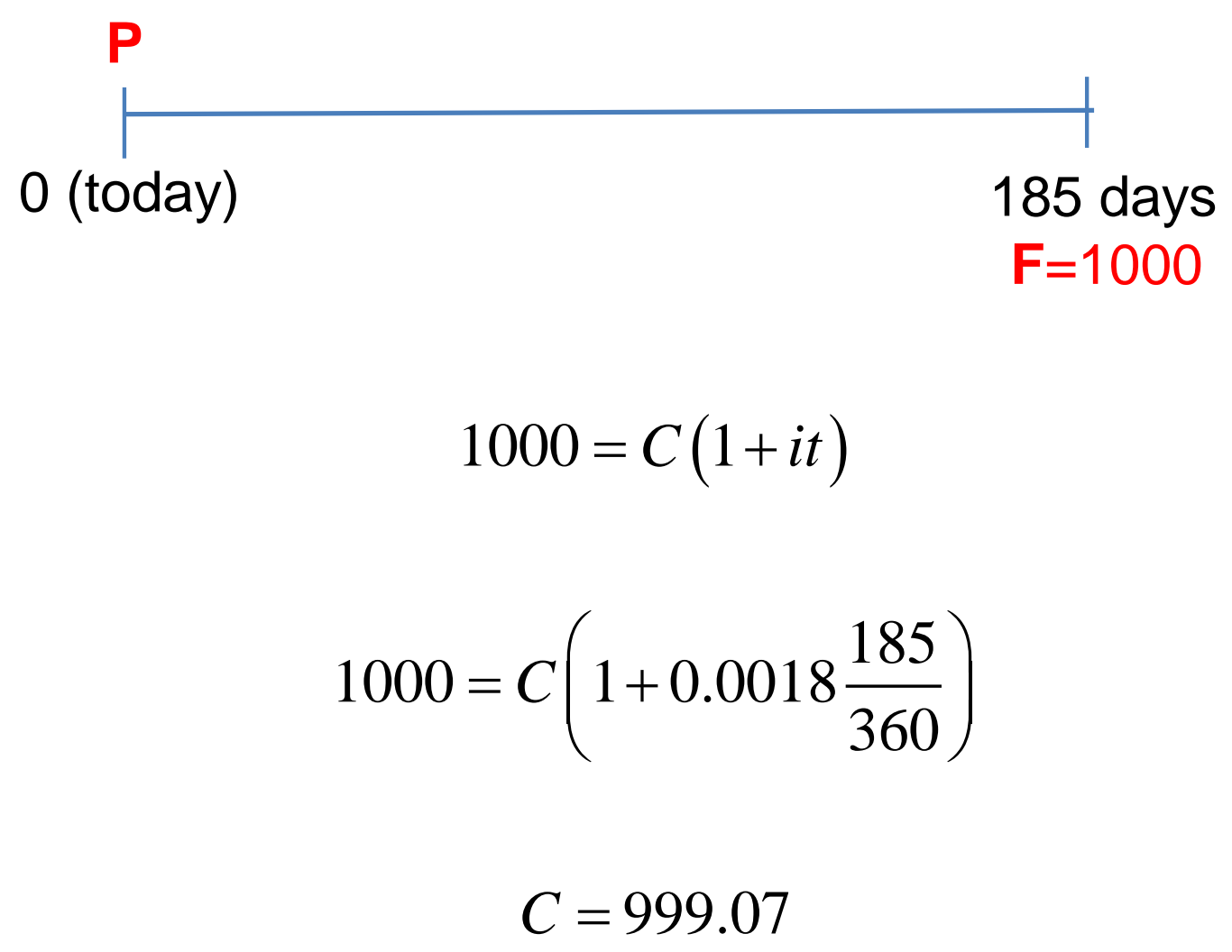

So the price of the treasury bill is $€ 999.07$ 
Example 27: You bought a $€ 1000$ treasury bill 95 days ago at $98.24 \%$. Today you sell it on the secondary market at $98.89 \%$. Find the interest rate you have obtained.

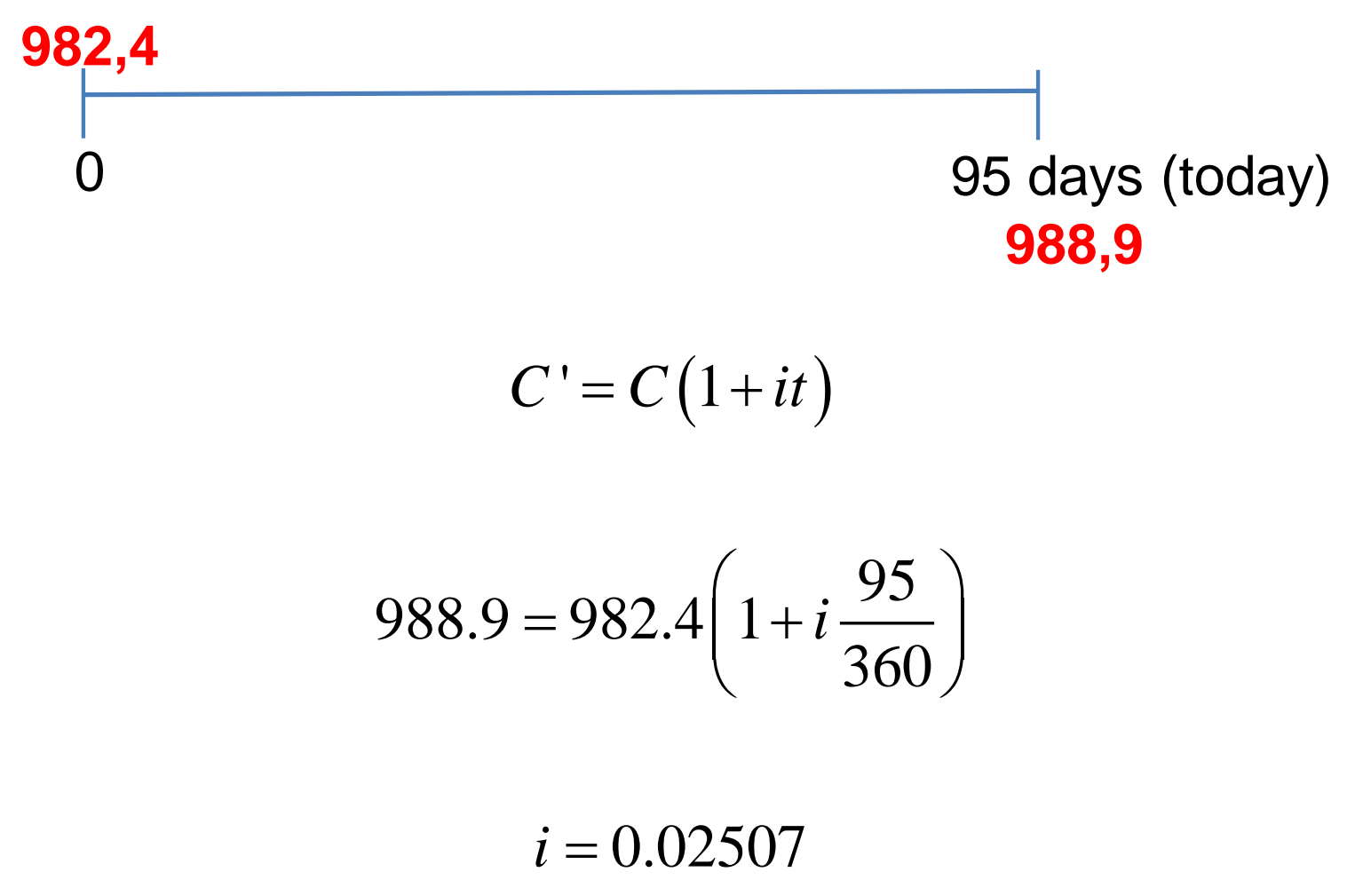


Example 28: An investor bought a $€ 1000$ treasury bill nine months ago at a discount rate of $0.15 \%$. What is the amount of the discount? What is the price of the T-bill?

Example 29: Find the price on the secondary market of a $€ 1000$ six-month treasury bill that matures in 100 days, knowing that the published average interest rate is $0.12 \%$.

Example 30: You bought a $€ 1000$ treasury bill 127 days ago at $98.17 \%$. Today you sell it on the secondary market at $99 \%$. Find the interest rate you have obtained. 
On the webpage Tesoro Público (www.tesoro.es) you can find information about treasury bills.
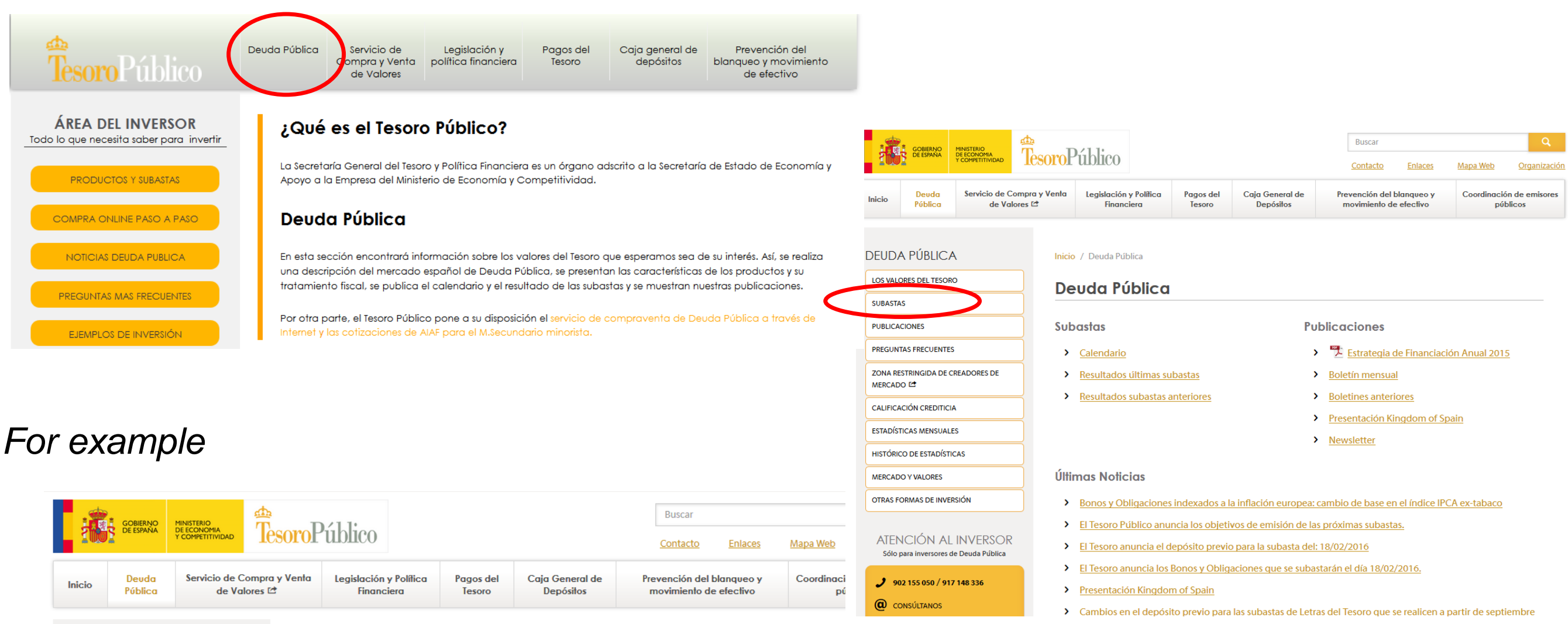

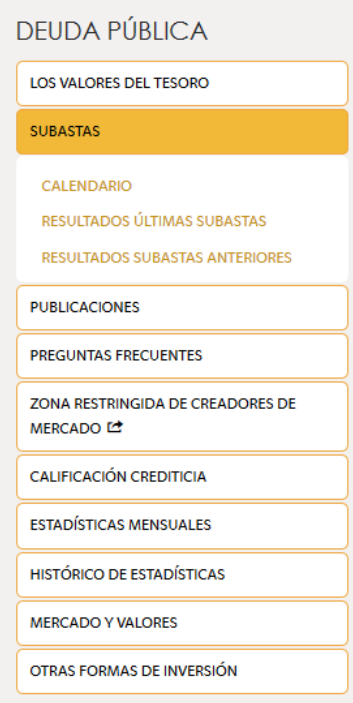

Subastas

\begin{tabular}{|l|l|l|l|l|l|}
\hline Calendario & Resultados últimas subastas \\
\hline
\end{tabular}

Resultados subastas anteriores 


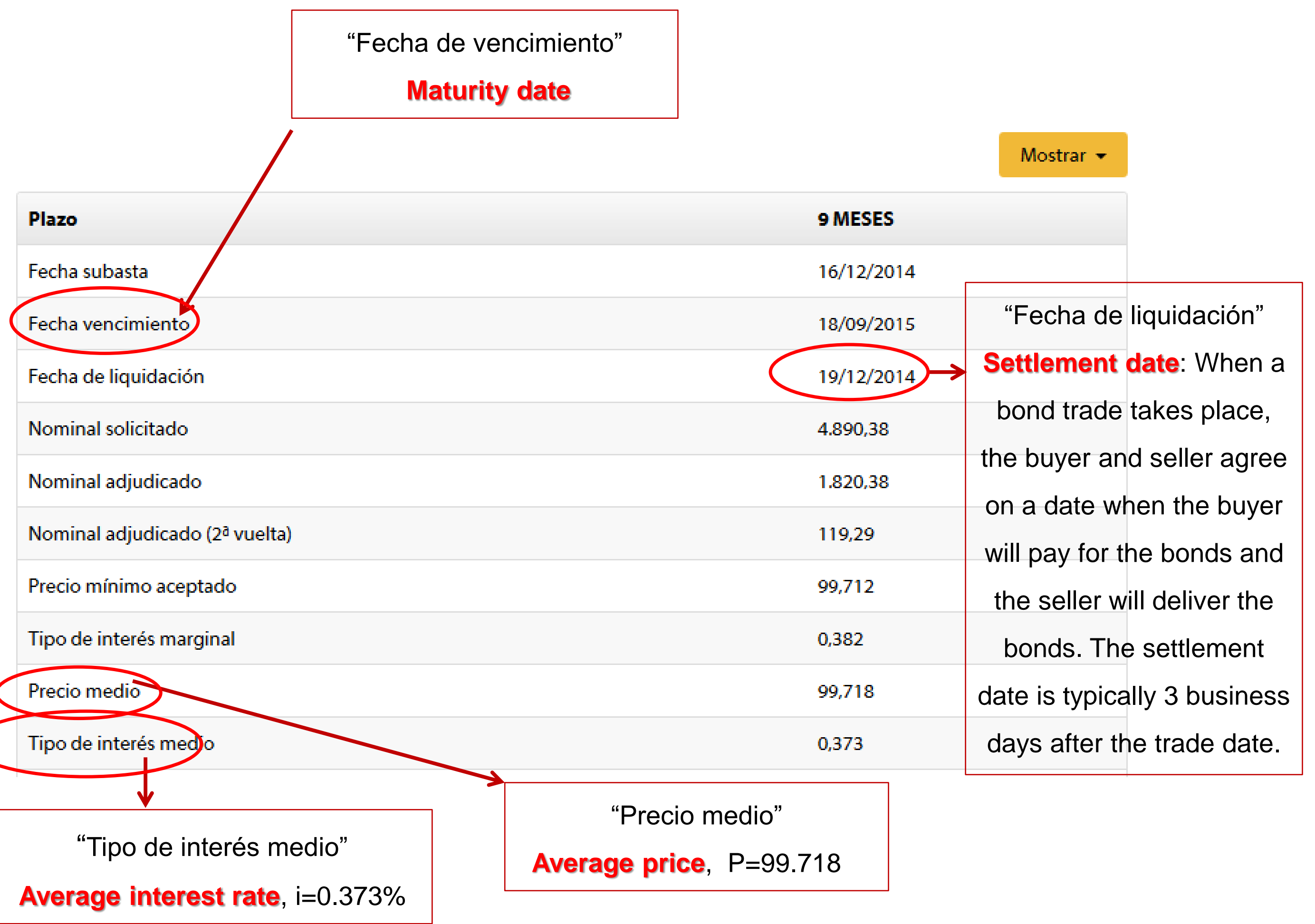


- Face value: $€ 1000$

- Average price: 99.718

- Settlement date: 19.12 .14

- Maturity date 18.09.15

- Days until maturity date: 273 ( from settlement date to maturity date using ACT/360)

Example 31: Prove that the average interest rate is correct.

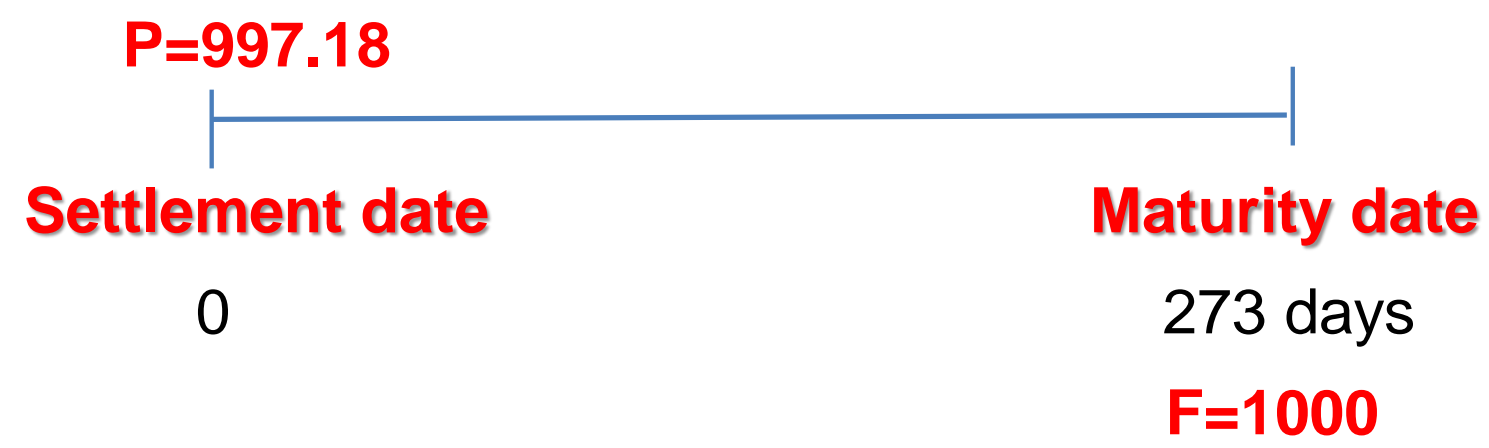

The number of days until maturity is less than 365 , so we should apply simple interest.

$$
\begin{gathered}
C^{\prime}=C(1+i t) \\
1000=997.18\left(1+i \frac{273}{360}\right) \\
i=0.00373
\end{gathered}
$$




\section{Example 32: Imagine the following T-bill}

- Face value: $€ 1000$

- Average price: 98.066

- Settlement date : 11.03 .2013

- Maturity date 20.06.14

- Days until maturity date: 466 (from settlement date to maturity date using ACT/360)

Obtain the average interest rate.

Sol: The number of days until maturity is greater than 365 , so we should apply compound interest.

$$
\begin{gathered}
C^{\prime}=C \cdot\left(1+I_{1}\right)^{n} \\
1000=980.66 \cdot\left(1+I_{1}\right)^{\frac{466}{360}} \\
I_{1}=0.015202 \simeq 0.01520 \Rightarrow 1.52 \%
\end{gathered}
$$




\section{Example 33: Find the average interest rate.}

\begin{tabular}{|c|c|}
\hline Plazo & 3 MESES \\
\hline Fecha subasta & $28 / 01 / 2014$ \\
\hline Fecha vencimiento & $16 / 04 / 2014$ \\
\hline Fecha de liquidación & $31 / 01 / 2014$ \\
\hline Nominal solicitado & $4.901,57$ \\
\hline Nominal adjudicado & 936,56 \\
\hline Nominal adjudicado ( $2^{\circ}$ vuelta) & 42,00 \\
\hline Precio mínimo aceptado & 99,928 \\
\hline Tipo de interés marginal & 0,350 \\
\hline Precio medio & 99,929 \\
\hline Tipo de interés medio & \\
\hline
\end{tabular}

Solution: $0.343 \%$ 


\section{Example 34: Find the average price.}

\begin{tabular}{|l|l|}
\hline Plazo & 12 MESES \\
\hline Fecha subasta & $20 / 01 / 2015$ \\
\hline Fecha vencimiento & $22 / 01 / 2016$ \\
\hline Fecha de liquidación & $23 / 01 / 2015$ \\
\hline Nominal solicitado & $9.041,79$ \\
\hline Nominal adjudicado & $4.264,79$ \\
\hline Nominal adjudicado $\left(2^{a}\right.$ vuelta) & 732,33 \\
\hline Precio mínimo aceptado & 99,779 \\
\hline Tipo de interés marginal & 0,219 \\
\hline Precio medio & 0,213 \\
\hline Tipo de interés medio & \\
\hline
\end{tabular}

Solution: 99.785 


\section{Example 35: Find the average interest rate.}

\begin{tabular}{|c|c|}
\hline Plazo & 3 MESES \\
\hline Fecha subasta & $18 / 03 / 2014$ \\
\hline Fecha vencimiento & $20 / 06 / 2014$ \\
\hline Fecha de liquidación & $21 / 03 / 2014$ \\
\hline Nominal solicitado & $3.606,28$ \\
\hline Nominal adjudicado & $1.131,28$ \\
\hline Nominal adjudicado ( $2^{\circ}$ vuelta) & 0,00 \\
\hline Precio mínimo aceptado & 99,949 \\
\hline Tipo de interés marginal & 0,204 \\
\hline Precio medio & 99,953 \\
\hline Tipo de interés medio & \\
\hline
\end{tabular}

Solution: $0.189 \%$ 


\section{Bibliography}

Mathematical interest theory. L.J. Federer Vaaler and J.W. Daniel. Second edition. Pearson Prentice Hall. 2009

$\square$ A basic course in the theory of interest and derivatives market. M.B. Finan. Arkansas Tech University. 2009 